\title{
El uso de las plantas silvestres \\ por la comunidad de Chos Malal \\ (Provincia de La Pampa).
}

Tesis para acceder al grado de Doctor en Ciencias Naturales

Universidad Nacional de La Plata

Facultad de Ciencias Naturales y Museo

2010

Autor: Lic. Walter Alejandro Muiño
Director: Lic. Pastor Arenas Rodríguez
Codirectora: Dra. María Lelia Pochettino 


\section{Agradecimientos:}

Al personal del Departamento de Postgrado de la Facultad de Ciencias Naturales y Museo de la Universidad Nacional de La Plata, por mantenerme comunicado y facilitarme a lo largo de estos años la realización de los trámites administrativos relacionados con la carrera.

A la Municipalidad de La Humada, por el apoyo brindado a este trabajo de investigación, hecho que demuestra el compromiso con la cultura de la región.

A Pastor Arenas, quien me inició en la disciplina etnobotánica y me brindó a través de su dirección el estímulo permanente, su apoyo intelectual y material y la calidez humana propias de un maestro.

A María Lelia Pochettino por toda su dedicación en la dirección de este trabajo, por su ayuda y sus buenos consejos que sirvieron para orientarme en las actividades de la carrera de postgrado, sus observaciones en la redacción de la tesis y por su articulación permanente con el Departamento de Postgrado.

A María del Valle y Marta Sánchez, directoras de la Escuela Hogar No 88 de La Humada, quienes al ofrecerme las instalaciones de la escuela no solamente se constituyeron en un gran apoyo para este proyecto sino que además me permitieron conocer la bella comunidad educativa de docentes, no docentes y estudiantes con la que trabajan cotidianamente.

A Nelio Romero por brindarme su hospitalidad y amistad en su casa de La Humada.

A Américo Corvalán y toda su familia, quienes me permitieron el uso de las instalaciones del salón comunitario de Chos Malal y me ayudaron en cada momento de dificultad durante las tareas de campo en la zona.

A Carla Suárez por su solidaridad y sus consejos que facilitaron el trabajo de edición de la tesis. 
A Graciela Alfonso y Anibal Prina por su constante apoyo, sus lecturas y observaciones sobre el texto de la tesis y por hacerme ver como prioritarios mis objetivos de postgrado por sobre otras actividades que con ellos comparto.

A Héctor Troiani por su colaboración en la determinación taxonómica de especies cultivadas con las que tuve dificultad.

A José Luis Hierro por su dedicación en las revisiones de la traducción al inglés del resumen de esta tesis y de otros trabajos que formaron parte de las actividades de postgrado.

A todas las familias de Chos Malal y La Humada que colaboraron en el trabajo de campo, por su hospitalidad $y$ buena predisposición que fueron indispensables para hacer posible esta tesis.

A Diana, mi esposa, porque su apoyo en momentos de desaliento fue la fuerza que me ayudó a seguir adelante y a mis hijos, por haberme tenido tanta paciencia.

A todos ellos, muchas gracias. 
... "Pero le diré, no todos van a los pueblos cuando están enfermos. Mucha gente de acá va a curanderos o curanderas de la región. Claro que los hay buenos y algunos que no saben nada. Los buenos tienen mucho conocimiento de las yerbas, de los efectos medicinales que tienen las hojas o raices de plantas que se encuentran en el campo, en fin...

Cochengo Miranda. Verseador y puestero del oeste pampeano Jorge Prelorán ...Si un criollo por esos campos pregunta por buena leña le digo así como seña tu don de milagrerías ¡Amalaya! Quién diría que hoy estuviera cantando el mismo que anduvo hachando tus raices con tinturas hoy te busco en la llanura y sos cenizas volando

Julio Domínguez de Piquillín (Milonga pampeana) 


\section{ÍNDICE}

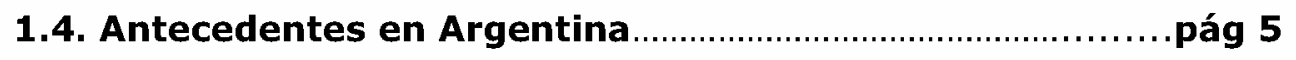

1.5. Importancia del tema de estudio pág 6

2. EL ESPACIO, LA GENTE Y SU VIDA. pág 8

2.1. Área de estudio pág 8

2.1.1. Geografía y clima pág 9

2.1.2. Biogeografía pág 10

2.1.3. Núcleos poblacionales. pág 10

2.1.4. Breve historia de la historia de la ocupación poblacional del área. pág 12

2.1.5. Caracteristicas de la población: origen, pertenencia étnica y rasgos culturales. pág 13

2.1.6. Cultos religiosos... pág 16

2.2. La actividad económica. .pág 18 pág 20 

pág 25

2.4.2. Los actores sociales, su rol en torno a la medicina tradicional. pág 26

2.5. Cultura material. pág 28

2.6. Recursos energéticos .pág 29

2.6.1. Maderas combustibles. pág 29

2.6.2. Los sistemas de iluminación en la actualidad. pág 29

3. MATERIALES Y METODOLOGÍA. pág 30

3.1. Búsqueda de fuentes de información pág 30

3.2. Trabajos de campo pág 31

3.2.1. Entrevistas pág 31

3.2.2. Colecta de material vegetal pág 33

3.3. Trabajos de gabinete. pág 33

3.4. Procesamiento y análisis de la información pág 34

4. RESULTADOS. pag 35 pág 35 
4.1.2. Plantas tóxicas o con efectos adversos en la actividad. .pág 36

4.1.3. Tratamientos veterinarios. pág 38

4.1.4. Construcciones rurales e instrumentos de uso ganadero. pág 40 ..pág 44

4.2.1. Recolección de plantas silvestres y cultivo de introducidas. .pág 44

4.2.2. La actividad cinegética. .pág 48

4.2.3. Las comidas pág 49

4.2.4. Las bebidas. pág 52

4.2.5. La conservación de los alimentos. pág 53

4.3. Salud y Medicina pág 54

4.3.1. Enfermedades. Descripción y etiología pág 54

4.3.1.1. Enfermedades naturales. .pág 55

4.3.1.2. Enfermedades impuestas o postizas. .pág 56

4.3.2. Terapéutica. .pág 57

4.3.3. Las curaciones de dolencias en contextos de la religiosidad... pág 61

4.3.4. Los remedios de origen animal....... .pág 65

4.3.5. Las plantas en la medicina. pág 65

4.3.6. La mujer, el embarazo y el parto .pág 67 
4.4.1. La construcción de los puestos pág 73

4.4.2. Jardines hogareños. pág 79

4.4.3. Arbolado. pág 81

4.5. Artesanías y Enseres Domésticos pág 83

4.5.1. Enseres domésticos pág 83

4.5.2. Tejeduría en lana pág 86

4.5.3. Las plantas tintóreas. pág 92 
6. CONCLUSIÓN pag 120

7. BIBLIOGRAFÍA. pag 125 ANEXO I. MODELOS DE ENTREVISTA ABIERTA Y ENCUESTA ETNOBOTÁNICA.. pag 145

ANEXO II. TABLAS. pág 154

ANEXO III. CATÁLOGO BOTÁNICO DE NOMBRES Y USOS. pag 177 ÍNDICE DE NOMBRES CIENTÍFICOS Y COMUNES. .pág 265 


\section{RESUMEN}

Esta investigación tiene por finalidad el estudio de los nexos existentes entre una comunidad campesina del noroeste de la provincia de la Pampa con su entorno vegetal. Se desarrolló, como referente de caso, en poblados situados en el oeste del departamento Chicalcó en la mencionada región. La zona representa el área seca con menos lluvia de la región pampeana y reúne todos los atributos paisajísticos de un monte xerófito. Distintas circunstancias históricas han configurado un tipo de habitante con rasgos culturales propios que los distinguen y definen como campesino "criancero", es decir, el hombre dedicado básicamente a la actividad ganadera. El enfoque elegido para abordar este tema ha sido el de la etnobotánica. De esta manera se fija como objetivo relevar el conocimiento, empleo y significados de los vegetales en este grupo humano. Al mismo tiempo, se analiza la dinámica de los nexos con este entorno vegetal a fin de reseñar su vigencia o pérdida a raíz de cambios acaecidos en años recientes. Se realizaron trabajos de campo y de gabinete, aplicándose diversas estrategias propias de las etnociencias. En base a ellas, la información fue registrada mediante entrevistas abiertas y observación participativa. Junto con éstas se llevaron a cabo encuestas en forma aleatoria a fin de lograr una aproximación cuantitativa sobre aspectos específicos de la relación humano-planta, como la pérdida de vigencia del empleo de algunas especies, los motivos de esta pérdida, y los eventuales vínculos entre desaparición de usos y cambios culturales vinculados a las formas de vida. Los ejemplares colectados fueron herborizados e identificados en su mayoría por el autor y fueron depositados en el Hebario de la Facultad de Agronomía de la Universidad Nacional de La Pampa (SRFA).

Los resultados logrados se presentan en varios cuerpos: a) Una exposición de los distintos ámbitos de la vida social y cultural donde tienen cabida las plantas, b) Un conjunto de datos sumarizados en forma de tablas que se reúnen en el anexo II y c) Un repertorio del papel y uso de las especies vegetales entre la gente reunidos en el anexo III. Los resultados se organizaron en función de categorías o ámbitos de uso, de esta manera los 
resultados se presentan en los tópicos: Actividad económica, Alimentación, Salud y medicina, Vivienda, Artesanías y enseres domésticos y Combustibles e iluminación.

En este estudio se presenta una documentación testimonial y fidedigna que versa sobre un total de 145 especies vegetales silvestres y 101 cultivadas o adquiridas comercialmente que juegan algún papel en la vida del hombre del oeste pampeano.

En esta investigación se destaca la importancia que tienen las plantas en la vida cotidiana de esta comunidad. La presencia de estas en la alimentación, la vivienda, el restablecimiento de la salud y en la satisfacción de otras necesidades de menor prioridad ponen de manifiesto el grado de dependencia sobre estos recursos que los pobladores mantuvieron y aún hoy lo hacen para desarrollar sus vidas en un medio natural que por sí mismo, y debido a múltiples condiciones, no ofrece alicientes para el establecimiento permanente de poblaciones humanas.

\section{ABSTRACT}

The aim of this work is to study the links between a rural community from the northwest of La Pampa province, Argentina, and its vegetal environment. It was made in settlements of the west of Chicalcó department. The area is placed in the driest region of the Pampa plain and holds all the landscape attributes of a xerophytic shrubland. Several historical circumstances formed a type of settler with distinguishable features, which define them as "criancero" farmers, that is people dedicated to stockbreeding.

Ethnobotany has been the approach selected to take up this topic. The goal of this study is to record the knowledge, uses and meanings of plants in this community. At the same time, the dynamics of the links of this community with the vegetal environment is examined to review their persistence or loss due to changes occurred in recent years.

Field and lab work were made using different methods concerning to the ethnosciences. The information was recorded through open interviews and 
personal observation. Semi-structured interviews were made in a random way to obtain a quantitative approach on specific subjects about human-plant relation, such as the loss of uses of some species, the reasons of these losses, and the eventual links between losses of uses and cultural changes related to ways of living. Collected specimens were stored and most of them were identified taxonomically by the author. Vouchers were kept in the Herbarium of Facultad de Agronomía, Universidad Nacional de La Pampa (SRFA).

Results are presented in several parts: a) an exposition of the different stages of the social and cultural life where plants are present, b) a set of summarized data in the way of tables showed in appendix II, and c) an index of the role and use of plant species showed in appendix III. Results were arranged according to categories of use. So, they are presented as: Economic activity, Food, Health and medicine, Dwelling, Crafts and household effects, and Fuel and lighting.

This research present information of a total of 145 wild and 101 cultivated or commercially acquired plant species, which play a role in the life of humans in the western pampas.

This research emphasizes the importance of plants in the life of this community. The presence of plants in the food, dwelling, health recovery and fulfillment of other minor priority requirements expresses the degree of dependence that settlers have kept and still do on these resources for developing their lives in a natural environment that does not encourage permanent human settlement. 


\section{INTRODUCCIÓN}

Esta investigación fue llevada a cabo con la finalidad de estudiar la relación de los habitantes del oeste pampeano con su entorno vegetal. A lo largo de estas páginas se pretende lograr una mejor comprensión acerca del modo en que esta población ha construido significados y valores vinculados con el ambiente haciendo especial énfasis en las plantas y su papel en la subsistencia de esos grupos humanos.

Este trabajo se desarrolló en el NO de la provincia de La Pampa, sitio que corresponde al límite occidental de la región pampeana en su interfase con la región de Cuyo. Esta zona representa el área seca con menos lluvia de la región y sus elementos paisajísticos conforman la fisonomía propia de un monte xerófito. La geografía, clima, vegetación, fauna y la propia historia regional han configurado un tipo de habitante con rasgos culturales que difieren de sus vecinos de las áreas más húmedas de la región pampeana, pero que simultáneamente presentan otros que son comunes. Es necesario aclarar que en este trabajo, todas las veces que se mencione al oeste pampeano, la expresión hace referencia a este sector occidental de la provincia de La Pampa. Esta aclaración es pertinente ya que la región pampeana -en su amplio sentido geográfico- comprende una gran variedad de paisajes, ecosistemas y distintas fisonomías culturales de la población, que incluye otras regiones no tratadas en este trabajo (por ejemplo las áreas más húmedas y fértiles del las provincias de La Pampa, Córdoba, Santa Fé y toda la provincia de Buenos Aires).

La mencionada aridez del oeste pampeano hizo que a lo largo del tiempo el sector más húmedo despertara mayor atención por su potencial productivo, en tanto la región occidental seca quedara relegada a la situación de zona marginal para la producción. Como resultado, la primera fue objeto de múltiples estudios desde diferentes enfoques científicos, mientras que la segunda corrió a la zaga, situación que se justificaba por razones políticas y económicas. 
Esta alusión sobre el conocimiento científico previo en el área tiene de alguna manera cierta relación con las incertidumbres que se presentaron al inicio de esta tesis. Para explicarlo mejor, la carencia de estudios preliminares en la zona no permitía vislumbrar cuáles tópicos de la etnobotánica serían los que prevalecerían, u otorgarían mayor importancia al rol de las plantas. Por tal razón esta tesis no desarrolla en particular un ámbito de la actividad humana en relación con las plantas sino que presenta un carácter general y de diagnóstico de la etnobotánica en esta comunidad. Esta situación de base permite abrir nuevos horizontes para las investigaciones futuras en la zona desde una perspectiva diferente a las que hasta el presente se venían desarrollando.

Si bien el plan inicial de esta tesis se refirió sólo a la comunidad de Chos Malal, un acercamiento prospectivo detallado, antes de comenzar el trabajo, puso en evidencia que este paraje -integrado por una reducida cantidad de predios rurales-, presentaba una alta dependencia institucional, así como un notable proceso migracional hacia la cabecera del ejido municipal, el centro urbano de La Humada. Algunos de los pobladores más ancianos oriundos de Chos Malal viven actualmente en La Humada y han actuado allí como transmisores de conocimientos y prácticas entre las actuales generaciones. Además, las entrevistas preliminares revelaron la presencia de rasgos culturales de la región que son compartidos por otros habitantes del área limítrofe con Mendoza, con quienes se mantiene fluidos intercambios.

Esta situación, hizo ver que circunscribir el área de estudio solamente a Chos Malal significaría una reducción que se traduciría en una pérdida de información valiosa para comprender muchos aspectos de la vida de esta gente. Asimismo justificó la necesidad de redelimitar el área de estudio ampliándola hacia todo el sector de influencia de la localidad de La Humada, dentro del cual se encuentra el poblado de Chos Malal, razón por la cual este trabajo hará referencia al uso de las plantas silvestres y cultivadas en todo el ejido municipal.

Los estudios florísticos y ecológicos llevados a cabo por el autor en la zona, previos a este plan de tesis, permitieron enunciar una serie de observaciones sobre las características de la población en su relación con las 
plantas. Estas observaciones son las que condujeron a formular las siguientes hipótesis de trabajo:

H1: Los pobladores del NO pampeano basan sus actividades en la ganadería extensiva y debido a esto poseen un conocimiento acumulado sobre los recursos del medio $y$ el modo de interaccionar con él para desarrollar su existencia.

H2: El espacio geográfico regional presenta condiciones rigurosas para el asentamiento humano. Sin embargo los primeros grupos de inmigrantes lograron asentarse y desarrollar su vida con un alto nivel de dependencia de los recursos naturales.

H3: Pese a la limitada diversidad florística de la región, los pobladores han podido desarrollar estrategias de vida basadas en el aprovechamiento de las plantas del medio para poder subsistir, lo que significa un importante conjunto de información etnobotánica para la región.

H4: Los conocimientos y prácticas tradicionales sobre el medio natural a partir de sus elementos todavía persisten como una cultura viva.

H5: La persistencia de conocimientos y prácticas tradicionales sobre el entorno vegetal están en relación directa con la distancia a los centros de abastecimiento y los servicios.

\subsection{Objetivos generales}

El presente estudio tiene por finalidad contribuir al conocimiento del significado y uso de las plantas entre los pobladores del Oeste de la provincia de La Pampa. En él se hará énfasis sobre el conjunto de conocimientos y prácticas tradicionales que mantiene este pueblo con el entorno vegetal, y sobre el rol que tienen las plantas dentro de su cultura.

\subsection{Objetivos específicos}

En función de las hipótesis propuestas se plantean los siguientes objetivos específicos: 
- Conocer las relaciones entre la gente y su entorno vegetal a través del uso y el significado que poseen las plantas silvestres y cultivadas.

- Realizar una documentación exhaustiva de las especies vegetales utilizadas por los pobladores del extremo oeste de la provincia de La Pampa.

- Analizar las causas que motivan la vigencia y pérdida de costumbres relacionadas con el aprovechamiento de las plantas.

- Analizar el efecto sobre los conocimientos y usos de las plantas producido por las transformaciones ocurridas en la sociedad hasta el presente.

Con el fin de delimitar y de comprender mejor el espacio natural y cultural de los actores sociales -en cuya vida intervienen las plantas- este trabajo se divide en tres partes principales: I) Una sección introductoria donde se presentará en forma de apartados especiales una serie de nociones preliminares en relación al espacio geográfico, al grupo humano y su proceso histórico y a su forma de vida bajo el título de "El espacio, la gente y su vida", II) Una serie de tablas donde se sintetiza la información concreta de carácter estadístico y diagnóstico, III) Un catálogo sumario donde se enumeran las plantas, que conforma la totalidad de datos estrictamente etnobotánicos, con énfasis en el aspecto utilitario. Las partes II y III se reúnen como Anexo. Junto a esta estructura organizativa se alternan los habituales capítulos de Materiales y metodología, Resultados, Discusión, Conclusiones y Bibliografía.

\subsection{Marco teórico}

Por su carácter interdisciplinario, diferentes ramas de la ciencia hacen su aporte a la etnobotánica, en particular la botánica, la antropología y la ecología dando lugar a distintos enfoques en los trabajos de esta temática. Esta diversidad de perspectivas es la razón por la cual aún no existe un consenso, particularmente en lo que hace a sus objetivos y alcances como se puede evidenciar en los diferentes trabajos que hacen referencia a esta materia (Jones 1941, Portères 1966, Ford 1978, Barrau 1981, Alcorn 1995, Cotton 1996, Martin 2000, Hanazaki 2004). 
En lo referente a las cuestiones metodológicas es importante establecer los criterios interpretativos del registro de la información. En este sentido, existe una distinción clara entre las categorías emic y etic de la misma. Dentro de la primera se encuadra la perspectiva de la población local, es decir la interpretación del universo y los fenómenos tal como es percibido por ella, en la categoría etic la información es registrada desde la visión y clasificación de ese universo por parte del investigador (Martin 2000).

Referido también a lo metodológico, en los estudios etnobotánicos se advierte a partir de las dos últimas décadas del siglo pasado un interés especial por los análisis cuantitativos (Prance \& al. 1987, Phillips \& Gentry 1993a, Phillips \& Gentry 1993b, Graham 1994, Albuquerque \& al. 2006, Hoffman \& Gallaher 2007).

Probablemente los diferentes criterios por establecer un marco epistemológico en cuanto a los objetivos y alcances de la etnobotánica no hagan más que fortalecer su carácter de interdisciplina. No obstante, lo "etno", es decir el componente que hace referencia al contexto cultural representa no solamente un perfil orientador de la temática sino que se constituye en condición indispensable que define su objetivo final. En consecuencia, "lo esencial es intentar conocer las motivaciones que llevan al hombre a una planta, y qué tiene ésta para haberlo atraído, sea por su valor utilitario, o por sus figuraciones simbólicas" (Arenas 1997).

El enfoque con el cual se desarrollará la presente investigación etnobotánica se encuadra dentro de un marco conceptual y un esquema de trabajo que pone énfasis sobre el contexto cultural de las sociedades humanas. Abarca los aspectos cognitivos, tecnológicos y mágico-religiosos desde la perspectiva de una población rural actual del oeste pampeano, es decir haciendo prevalecer el enfoque emic en el registro de la información.

\subsection{Antecedentes en Argentina}

Para las comunidades actuales de la región centro-oeste de la Argentina la producción de estudios etnobotánicos es relativamente escasa. En disciplinas afines, y concretamente para la provincia de Mendoza, merecen 
mencionarse los trabajos florísticos de Ruíz Leal (1972) y Roig (2001) y los de carácter antropológico de Agüero Blanch (1963, 1965, 1967, 1968 y 1970) y Balbuena (1993). En la provincia de Córdoba se destacan diversos trabajos vinculados con la flora medicinal (Bocco \& al. 1997; Núñez y Cantero, 2000) al igual que para las provincias de San Luis (Del Vitto \& al. 1997 y 1998) y la Pampa (Steibel \& al. 2008). Más específicamente en el campo de la etnobotánica merecen citarse para la región los estudios de Martínez (2002, 2003) y de Martínez y Planchuelo (2003).

En la provincia de La Pampa los escasos trabajos que hacen referencia a informaciones etnobotánicas se remiten a las actividades de los artesanos tradicionales (Ladaga de San Cristóbal 1980, Steibel 1982, Medus y Poduje 1997) y al conocimiento y uso de las plantas por los ranqueles (Steibel 1997, Valencia 2006), quienes constituyen el único grupo aborigen sobreviviente, que en la actualidad atraviesa por un fuerte proceso de erosión cultural (Fernández Garay 1988). Sin embargo, no existen estudios que aborden las comunidades rurales actuales de una manera integral que permitan comprender, además de los usos de las plantas, las construcciones simbólicas y las motivaciones de la gente que explican su relación con el entorno vegetal, situación por la cual este trabajo se presenta en La Pampa como un estudio pionero en la materia.

\subsection{Importancia del tema de estudio}

Entre los aspectos que suelen ponerse de manifiesto en los estudios etnobotánicos como el que aquí se presenta, emergen las percepciones que el poblador tiene sobre el medio natural con las que se construyen los significados que hacen a su propia identidad. Este conjunto de valores constituyen elementos de importancia que pueden servir de base y deberían considerarse cuando se llevan a cabo políticas de desarrollo social, particularmente cuando éstas se orientan a promover cambios en los modos de producción y de uso de los recursos naturales locales. Las transformaciones acaecidas en la sociedad desde fines del siglo pasado -encuadradas dentro del fenómeno de globalización mundial- han impactado con más fuerza en las comunidades pequeñas (Bonasewicz 2004; Mateus \& Brasset 2002). Sin embargo, este hecho a la vez pone a las investigaciones etnobotánicas en un 
rol protagónico como disciplina orientada a encontrar soluciones locales a las problemáticas sociales o ambientales (Alexiades 2003).

La disminución de la biodiversidad provocada por la sobreexplotación de recursos, la fragmentación de hábitat y otros fenómenos que atentan contra la salud del planeta ponen nuevamente a la etnobotánica en un punto de particular atención relacionada no solamente con las amenazas sobre la diversidad biológica sino también sobre los riesgos de la pérdida de la diversidad cultural. En este sentido esta disciplina puede hacer un aporte en cuanto a valores de los recursos naturales no considerados anteriormente en el debate científico y en los espacios de decisión política, razón por la cual las investigaciones etnobotánicas constituyen una información básica para quienes deben idear y ejecutar soluciones a los problemas locales y regionales relacionados con los recursos naturales (Alcorn 1995).

Por otra parte, las investigaciones etnobotánicas contribuyen al conocimiento de nuevas fuentes de recursos naturales y a una mayor diversidad de usos basados en los conocimientos tradicionales, información que puede servir de base para la preservación de especies autóctonas (León 1992). No obstante, la difusión de esas posibilidades de uso debe realizarse en un marco de respeto a las comunidades portadoras de los conocimientos tradicionales ante el cual los investigadores deben asumir un compromiso ético con responsabilidad sobre los eventuales usos posteriores de esos saberes (Pochettino 2007).

El oeste de la provincia de La Pampa es un espacio culturalmente enriquecido por los aportes diversos donde confluyen rasgos de herencia hispana, introducidas durante la etapa colonial asi como las propias de la cultura aborigen. Estas últimas se conformaron de elementos multiétnicos, producto de intercambios entre los pueblos indígenas (De la Cruz 1910, Durán 1993-94, Prieto 1997-98 a, Lagiglia 2002). Con relación a la influencia cultural aborigen, el fenómeno más trascendente por su significado para la región fue el que ocurrió a partir del siglo XVII, cuando los mapuches transandinos avanzaron hacia el este sobre un territorio ocupado por diferentes grupos de las planicies, etapa histórica que se conoce como "araucanización de las pampas" (Ibarra Grasso 1981; Martínez Sarasola 1992). Esta riqueza cultural 
dio forma a la fisonomía actual de los pueblos comprendidos en la zona de transición entre la región pampeana y cuyana con rasgos particulares que han sido poco documentados hasta el momento en trabajos etnográficos (Zamorano 1950, Prelorán 1975, Balbuena 1993) y antropológicos (Böhm de Saurina 1961; Agüero Blanch 1963, 1965, 1967, 1968, 1970, 1971).

La importancia del presente estudio, realizado en una población rural del oeste de la provincia de La Pampa, radica en el aporte de información inédita sobre la etnobotánica de zonas áridas de la región central de la Argentina. La documentación aquí registrada constituye un aporte en esta disciplina tanto a nivel nacional como regional. En nuestro país es llamativa la asimetría que existe actualmente en la documentación de las relaciones humano-planta; en la primera escala se destaca un mayor caudal de información referido a las zonas tropicales y subtropicales del NOA y el NEA, si se compara con las regiones del centro y sur de Argentina. En la escala regional, este desbalance también se observa ya en términos generales sobre las investigaciones científicas entre la región oriental, más húmeda y la oriental seca, razón por la cual este trabajo, contribuirá en una mejor comprensión del significado de las plantas y de los ecosistemas áridos del oeste pampeano.

\section{EL ESPACIO, LA GENTE Y SU VIDA}

\section{1. Área de estudio}

Este trabajo se desarrolló en la región central de la República Argentina en el sector occidental del departamento Chicalcó del NO de la provincia de La Pampa. El área de estudio se ubica en la región de las mesetas occidentales del oeste pampeano (Covas 1998), donde se sitúa el ejido municipal de La Humada. Sus límites son, al E el trazado de la Ruta Provincial 25, al W y al N el límite provincial con la provincia de Mendoza $y$ al $S$ el límite con el departamento Puelén. El sector considerado en este trabajo comprende aproximadamente $4.500 \mathrm{~km} 2$. 

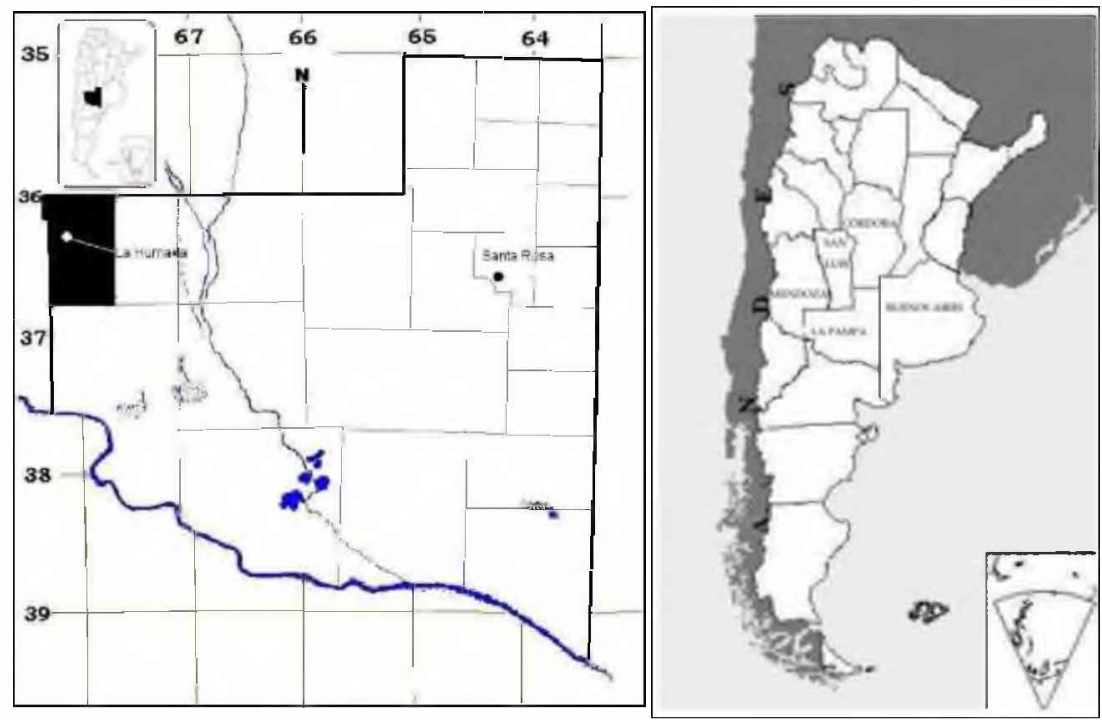

Fig. 1: Mapas indicando el área de estudio y provincias mencionadas en el texto.

\subsubsection{Geoarafía v clima}

La región se ubica entre los 800 y los 1000 m s m, presentando suelos arenosos con afloramientos ocasionales calcáreos de tosca y coladas basálticas de los antiguos mantos efusivos en el SO (Cuello 1968). El sector NW presenta las cotas más altas y se caracteriza por un paisaje serrano. En las áreas más bajas es frecuente la existencia de salitrales. El paisaje es una Ilanura con una pendiente de $W$ a $E$ del $0,5 \%$ a excepción del área serrana noroccidental, donde adquiere valores más altos. Los suelos son sueltos, presentando una textura arenosa fina con un $85 \%$ de la fracción arena (INTA, Gob. de La Pampa, UNLPam 1980).

La precipitación media anual es de $200 \mathrm{~mm}$ distribuidos principalmente entre los meses de octubre a marzo. Sin embargo, en las últimas décadas se observa un corrimiento de las isoyetas correspondiendo para la zona una precipitación algo superior a los $300 \mathrm{~mm}$ (Casagrande \& al. 2006). En invierno a veces se producen precipitaciones nivales. La temperatura media anual es de $14{ }^{\circ} \mathrm{C}$ con mínimas absolutas de $-15^{\circ} \mathrm{C}$ en el mes de junio y máximas de $42^{\circ} \mathrm{C}$ en el mes de enero (INTA, Gob. de La Pampa, UNLPam 1980).

Los vientos predominantes son principalmente del cuadrante Norte seguidos por los del Sur. Las velocidades promedio oscilan entre los 15 y 20 
$\mathrm{km} / \mathrm{h}$, pero en el mes de agosto, el más ventoso, suelen soplar ráfagas de hasta $96 \mathrm{~km} / \mathrm{h}$.

\subsubsection{Biogeografía}

Desde el punto de vista fitogeográfico corresponde a la provincia del Monte (Cabrera 1971) y en el sector austral incluye algunas porciones de la provincia de la Payunia (Martínez Carretero 2004). La vegetación está representada principalmente por un arbustal bajo, abierto, perennifolio micrófilo donde la jarilla (Larrea divaricata) es la epecie dominante junto con las verbenáceas Junellia seriphioides y Acantholippia seriphioides, y las gramíneas Poa lanuginosa, Aristida mendocina y Panicum urvilleanum. Además se presentan áreas de menor proporción cubiertas por matorrales abiertos subdesérticos y por vegetación halófila (INTA, Gob. de La Pampa, UNLPam 1980). La flora regional ha sido objeto de numerosos estudios (Prina 1995, Steibel 1995, 2000, Steibel \& Troiani 1999, Troiani \& Steibel 1999, Steibel \& al. 1997, Prina \& al. 2003, Prina \& al. 2008), y se registra una importante documentación de la misma en los herbarios SRFA y MERL.

En cuanto a la fauna, este ecosistema alberga una sorprendente riqueza de especies animales considerando el ambiente desértico del que se trata. Una idea aproximada de ello lo dan las estimaciones de vertebrados realizadas recientemente en los sistemas de áreas protegidas de La Pampa. En el caso particular de la Reserva Natural La Humada, ubicada $5 \mathrm{~km}$ al $\mathrm{S}$ de la localidad homónima y con solo una extensión de 4980 has, se estima la presencia del $20,29 \%$ de especies de vertebrados silvestres de toda la provincia dentro de los cuales, los reptiles y mamíferos constituyen los grupos más destacados (Salomone \& Gouts 2006).

\subsubsection{Núcleos poblacionales}

El departamento Chicalcó cuenta con una superficie aproximada de $9.117 \mathrm{~km}^{2}$, una población de 1595 habitantes y una densidad demográfica de $0,2 \mathrm{hab} / \mathrm{km}^{2}$. El núcleo poblacional más importante del área de estudio es la localidad de La Humada, en la que residen 419 habitantes y un total de 954 habitantes considerando la población urbana y rural (INDEC 2001). Otro 
núcleo poblacional cercano es Agua Escondida, en la aledaña provincia de Mendoza, la cual se encuentra a $36 \mathrm{~km}$ al NO, con aproximadamente 130 habitantes.

La localidad de La Humada está separada de Santa Rosa, capital de La Pampa, por $410 \mathrm{~km}$ a través de la Ruta Provincial 10, de los cuales $80 \mathrm{~km}$ no están asfaltados. El resto de la red vial que interconecta este núcleo urbano con otros está constituida por caminos de tierra, cuyas condiciones de transitabilidad se tornan difíciles en función de las condiciones climáticas. Dos empresas de transporte público de pasajeros comunican a La Humada, una de ellas con tres servicios semanales hacia Santa Rosa y otra con un servicio semanal hacia las localidades mendocinas de Agua Escondida, General Alvear y Malargüe.

Además de los servicios de transporte, La Humada cuenta con servicio de telefonía, televisión satelital y dos emisoras locales de radio FM, con aproximadamente diez y dos años de actividad al aire respectivamente. Desde agosto de 2009, la localidad dispone de conexión a Internet. No obstante estos adelantos tecnológicos, su ubicación en la provincia y la distancia respecto de otros centros urbanos la colocan, aún en nuestros días, en una situación de relativo aislamiento.

Distante a $20 \mathrm{~km}$ al NO se encuentra el paraje Agua de Torres, un sitio en el que confluyen varias vertientes que forman un pequeño arroyo, situación que otrora fuera aprovechada por los pobladores del lugar para realizar cultivos frutales, forestales, hortícolas y sembradíos. Estas condiciones son las que actualmente permite abastecer de agua potable a La Humada por medio de un acueducto de $20 \mathrm{~km}$ de longitud. Otros $15 \mathrm{~km}$ separan este paraje de la localidad mendocina de Agua Escondida situada en el límite de ambas provincias. Este pequeño pueblo de más de un centenar de habitantes posee un fluido contacto comercial con La Humada y sus habitantes se vinculan entre sí a través de lazos familiares y de amistad.

Ubicado a $70 \mathrm{~km}$ al $\mathrm{S}$ de La Humada se emplaza el paraje de Chos Malal, un conglomerado de 36 predios rurales, cuyos habitantes han desarrollado un importante sentido de pertenencia al lugar y sólidas relaciones 
de reciprocidad y mutua colaboración que les permitieron configurar una identidad cultural propia (Comerci 2005).

\subsubsection{Breve historia de la ocupación poblacional del área.}

Los registros que hacen referencia al poblamiento previo al arribo de los conquistadores europeos señalan que la región estaba ocupada por grupos étnicos denominados puelches de Cuyo, los cuales comprendían las parcialidades conocidas con los gentilicios morcollames, oscollames y chiquillames; éstos ocupaban el territorio que se extiende entre los ríos Diamante y Colorado (Prieto 1997-98 a).

A partir del siglo XVIII se registraron modificaciones en la composición étnica de la región ya que un importante avance desde Neuquén de poblaciones pehuenches ocupó el sur de Mendoza llegando hasta el río Diamante. Esta situación causó un retroceso de los puelches de Cuyo hacia el norte y hacia las planicies orientales. Posteriormente estos grupos humanos en la región sufrieron a su vez un importante proceso de aculturación mapuche con grupos araucanos transcordilleranos (Lagiglia 2002).

A partir del siglo XIX, los pehuenches ya controlaban en la zona el tráfico de ganado entre Argentina y Chile, pero finalmente ambas naciones fueron expulsadas mediante una política del Estado Argentino, de verdadero extermino, que es conocida como "Conquista del Desierto" (Durán 1993-94). En 1882, La Pampa deja de estar integrada a la Gobernación de Patagonia y se constituye en Territorio Nacional, momento en el cual se inician las tareas de mensura de tierras. El territorio quedó de esta manera dividido en las unidades que prevalecen actualmente, situación que garantizó el control político y económico del Estado Nacional. El proceso de colonización se realizó paulatinamente, facilitado por la "Ley Avellaneda" (1876), la "Ley de Remate Público" (1882) y la "Ley de Premios" (1885), no obstante las especulaciones financieras realizadas y las características productivas de la región, poco atractivas en comparación con otras más húmedas. De esta manera, el repoblamiento se desarrolló por dos vías: una natural a través de colonos de origen criollo, mestizos, extranjeros e indígenas sobrevivientes que ocuparon áreas disponibles y otra comercial vinculada a las empresas inmobiliarias 
(Comerci 2008). Si se considera el área a una escala regional en la que se incluye el sector austral de la provincia de Mendoza, el componente principal de los colonos extranjeros estuvo constituido por chilenos, españoles e italianos (Mateu 1989). Hacia 1930 se produjo una crisis económica que afectó fuertemente a la ganadería ovina y bovina regional que sumada a los efectos causados por un ciclo de sequía ocurrido entre 1928 y 1940 produjo una importante declinación en esta actividad económica (Prieto \& Abraham 199394).

No existe una fecha oficial de fundación de La Ahumada ${ }^{1}$, nombre con que se la designó al comienzo, pero se toma como fecha fundacional al año 1929 Sin embargo, el núcleo surgió a fines del siglo XIX como un asentamiento paulatino de pobladores en torno a un bajo con buenas condiciones para el pastaje de animales (Francisco Vázquez, com. pers.), y con disponibilidad de agua en cantidad suficiente para el ganado. A comienzos del siglo pasado prospera lentamente como conglomerado poblacional y en 1931, dos años después de la fecha convencional de fundación, se crea la escuela $N^{\circ}$ 418. No obstante, en concreto, el desarrollo urbano comenzó a partir de 1950, año que se instaló el primer comercio de ramos generales (Álvarez 1999).

\subsubsection{Características de la población: origen, pertenencia étnica $\vee$ rasgos culturales}

Las localidades del oeste del departamento Chicalcó fundados sobre la meseta basáltica sufrieron un proceso de colonización en el que predominó la afluencia de pobladores de origen cuyano. Estos pobladores son conocidos comunmente como "bardinos". Este proceso de colonización es diferente al que ocurrió en las localidades orientales de La Pampa (Álvarez 1999). En todos estos poblados predomina el habitante mestizo descendiente de europeos, criollos y aborígenes.

Desde el punto de vista socioeconómico se trata de campesinos ya que todas sus características y actividades los encuadra dentro de esta categoría

\footnotetext{
${ }^{1}$ Según obra en nota del Presidente de la Comisión Vecinal de La Humada enviada al Presidente del Consejo Provincial de Difusión, con fecha 14 de agosto de 1975. (Archivo Histórico Provincial)
} 
sociológica, es decir, poseen explotaciones de tipo familiar siendo sus integrantes quienes aportan el trabajo para la producción sin contratar mano de obra extrapredial salvo casos excepcionales (Bedotti \& al. 2005) y no poseen la capacidad de acumulación de excedentes que permita un crecimiento a escala comercial.

La situación de tenencia de la tierra es variable, en algunos casos se trata de propietarios de los predios, en otros de empleados permanentes. Merece también destacarse la existencia de familias poseedoras sin título de propiedad, condición que han mantenido durante varias generaciones. El destino de estas personas es actualmente incierto debido a las amenazas de desalojo que sufren por la llegada de inversores económicos atraídos por el aumento del precio de los inmuebles rurales y la falta de acciones de gobierno para dar solución definitiva a esos problemas. Este fenómeno, que comenzó hace algo más de una década, ha ocasionado un conflicto social creciente, ya que muchos "puesteros" cuya vida ha transcurrido en aquellos lugares en torno a esa actividad se ven obligados a migrar forzosamente hacia los pueblos cercanos donde no consiguen una adecuada inserción social y se multiplican las consecuencias negativas derivadas de esta situación. Este panorama socioeconómico es una consecuencia de la expansión de la frontera agrícola y la presión generada sobre el mercado de tierras (Gras y Barbetta 2004).

Las costumbres han sufrido cambios manifiestos con respecto a las existentes hasta hace sólo algunas décadas atrás. Muchos han sido los factores que operaron en estas modificaciones y el tema excede los objetivos de este trabajo. No obstante, en la comunidad de La Humada se presentan entremezcladas tradiciones propias y nuevos hábitos que se han incorporado a la cultura local.

Una de las tradiciones que suele reunir a los vecinos son las señaladas, que se realizan en marzo o en abril, al finalizar la producción de terneros. En este evento se marcan los animales nuevos con el fin de indicar su pertenencia y se castran los que no estarán destinados como reproductores. Quien hace de anfitrión invita a vecinos y familiares a lo que suele ser una o más jornadas de 
diversión y trabajo colectivo, acontecimiento que significa un fortalecimiento de los vínculos sociales de la población.

Durante la estadía, además de llevar a cabo las actividades laborales que dan sentido a la reunión, se hacen bailes, guitarreadas, se elaboran comidas típicas acompañadas con bebidas con o sin alcohol y se realizan juegos diversos. Las comidas más frecuentes son los asados y las empanadas de carne, localmente denominadas pasteles. Los juegos son variados pero los predominantes son aquellos en los que intervienen naipes y dados o "cachos" como se los denomina en la zona. Entre los juegos con naipes los más comunes son la "liga", el "truco" y con menos frecuencia el "chinchón". En ocasiones se suele jugar al fútbol y las carreras de caballos también se siguen desarrollando en estas reuniones. Un importante testimonio visual de estas costumbres ha quedado registrado en la película documental "Cochengo Miranda" del cineasta argentino Jorge Prelorán (1975).

La taba es un juego tradicional que aún tiene vigencia, aunque algunos entrevistados sostienen que ha declinado. Éstas pueden estar confeccionadas en madera de quebracho, a partir de las ruedas de los viejos carros o bien en hueso de acuerdo a la usanza clásica.

A diferencia de los eventos actuales, que salvo excepciones no suelen prolongarse más de un día y una noche completas, antes eran más frecuentes las reuniones de dos, tres y hasta más días, durante los cuales, los invitados permanecían en el predio del anfitrión. La mayoría de los entrevistados coincidieron en la opinión de que este cambio se debe a los gastos monetarios que ocasionan tales eventos y a otros aspectos relacionados con la vida moderna. En voces de ellos:

"Antes las fiestas no eran como ahora...La gente gustaba más de reunirse. Ahora no, hay mucho egoísmo. La gente antes colaboraba con lo que habia que consumir para ayudar" (Julia López, com. pers.)

"Ahora se ven menos las veladas. Ahora las veladas se hacen más para recaudar plata por la cantina" (Emeterio Vázquez, com. pers.) 
"Antes (en las fiestas) se jugaba mucho con el cuchillo a los planazos...peleas, pero nadie se enojaba, ahora eso no se puede hacer porque lo toman en serio" (Fermina Urrutia, com. pers.)

En el pasado las esquilas eran también un motivo para el encuentro entre vecinos y para el trabajo comunitario. Esta actividad ha desaparecido en la zona junto con la ganadería ovina en gran escala.

Otra de las tradiciones que no se han perdido y que actualmente suele reunir a los vecinos son las "boleadas" de avestruces ( $R$. americana). Esta actividad, que es netamente masculina, suele convocar a un centenar de jinetes de la zona y en ella se pone a prueba la destreza en el manejo de las boleadoras.

Otros eventos sociales que constituyen ocasiones apropiadas para la reunión son las fiestas de fin de año (navidades y años nuevos), los cumpleaños, bautismos y casamientos, los carnavales, y eventualmente algunos aniversarios patrios como el día de la independencia nacional o el día de la revolución de mayo. En estas circunstancias también se ponen en práctica los juegos y diversiones antes mencionados.

\subsubsection{Cultos religiosos}

La colonización de La Humada se llevó a cabo en su mayoría con familias practicantes del culto católico. En los años posteriores a este proceso, esta doctrina fue reforzada a través de la labor misionera de los sacerdotes salesianos.

Sin embargo, la presencia de referentes religiosos era por lo general escasa, y según relatos de pobladores, al no ser frecuente la presencia de sacerdotes, los bautismos se realizaban entre vecinos utilizando un poco de agua y un poco de sal (Nelio Romero com. pers.). Cuando algún vecino fallecía, inmediatamente alguien partía hacia Algarrobo del Águila para dar parte de la defunción y no se lo sepultaba hasta el regreso del emisario. En ese lapso la persona fallecida era velada por sus vecinos y familiares sin realizar oraciones ni ceremonia religiosa alguna. 
En la segunda mitad del siglo XX, la presencia de los misioneros salesianos en el oeste pampeano comienza a declinar a la vez que las iglesias protestantes comienzan a tomar mayor protagonismo en la actividad religiosa del lugar. Actualmente, la influencia de estas iglesias está más acentuada en los poblados, mientras que en el ámbito rural, la mayor parte de la población manifiesta su adhesión al catolicismo. En La Humada existen hoy, además de la Iglesia Católica, tres Iglesias Evangélicas activas. Estas son: Biblia Abierta, Pentecostal Unida, y La Luz del Desierto. Por otra parte, en el paraje rural de Chos Malal, la mayoría de la población adhiere a Biblia Abierta y Pentecostal Unida las cuales tienen templos en el lugar.

Las reuniones sociales de los protestantes están relacionadas principalmente con las ceremonias religiosas desarrolladas en el templo, dentro de las cuales se incluyen las veladas, que consiste en pasar una noche completa en forma grupal realizando cantos y plegarias.

Los católicos no realizan ceremonias religiosas con la misma frecuencia que el grupo anterior. No existen curas residentes en el pueblo, por lo que las misas se realizan aproximadamente en forma mensual, circunstancia que se aprovecha para efectuar bautismos, comuniones y otros sacramentos.

Los católicos del sector rural continúan realizando reuniones sociales denominadas "veladas" en conmemoración de algunos santos de la iglesia católica. Estas reuniones tienen un carácter más secular que el que probablemente tuvieron en el pasado, pero los más devotos continúan aprovechando estas fechas para cumplir con promesas y orar a sus santos para pedir por ayuda espiritual o material. Las celebraciones del santoral cristiano registradas en la zona son San Juan (24 de junio), Nuestra Señora del Cármen o los "carmeles" (16 de julio), San Vicente (22 de enero y 6 de abril), San Antonio (13 de junio), San Francisco de Asís (4 de octubre), San Cayetano ( 7 de agosto), San Roque (17 de agosto) y San Ceferino (26 de agosto). Otras fiestas, aunque perdieron algo de vigencia en el lugar, son la de Santa Rosa (30 de agosto) y la de los Fieles Difuntos (2 de noviembre).

Por otra parte también se llevan a cabo veladas a personajes legendarios a quienes se les atribuye propiedades milagrosas. Tal es el caso 
del Gaucho Gil (8 de enero), de origen correntino, que en los últimos años ha adquirido una popularidad creciente expresada en las numerosas ermitas situadas en los cruces de los caminos vecinales, y que han desplazado en número a otros santos de tradición local como la Difunta Correa. No obstante, los católicos de La Humada realizan anualmente una procesión en honor a esta proclamada santa por el pueblo.

Son frecuentes también los mitos y creencias, pero muchos de estos han ido desapareciendo merced a la acción de diversos procesos educativos, entre los que se pueden mencionar la influencia de la escolarización oficial y de los medios de comunicación. Ambrosetti (1893) da testimonio de lo comunes que eran las creencias y los mitos en el pasado: "...Las supersticiones en las gentes de la Pampa son abundantes y se explica dada su población heterogénea de distintas provincias como la de Buenos Aires, Córdoba, Santiago del Estero, Mendoza, San Luis y aún de la República de Chile, de modo que cada una trae el contingente de sus respectivas comarcas y todo forma un conjunto abigarrado de creencias variadas e interesantes para el observador".

Asimismo la instrucción religiosa impartida por las iglesias evangélicas ha contribuido con la desaparición de muchas creencias. Un testimonio ofrecido por una persona practicante de este culto ilustra claramente esta situación: "Antes las brujas salían a la entrada del sol. Eran sus espíritus que se desprendían del cuerpo y salían a hacer daño. Los gritos que daban eran como de pájaros. Ahora no se ve tanto porque la gente ora. Antes la gente ignoraba."

\subsection{La actividad económica}

La principal actividad económica de los pobladores rurales del oeste pampeano es la ganadería extensiva de cría en campo natural. La explotación ganadera se realiza con vacunos y caprinos, pero también es frecuente la existencia de tropillas de caballos.

En esta región con precipitaciones escasas el abastecimiento de agua para la explotación ganadera es un tema crucial. Durante las sequías más o 
menos prolongadas, la estrategia de los campesinos consiste en trasladar la hacienda a otros campos bajo contrato de alquiler, o en vender parte del rodeo para descomprimir la carga ganadera. Estos y otros condicionantes como el mal estado de los caminos y la gran distancia existente entre los puestos y las ferias ganaderas hacen que el aislamiento opere negativamente en la economía de la zona. Una caracterización más pormenorizada acerca de la ganadería en la zona no justificaría su inclusión en este estudio, ya que aquí se trata de concentrar la atención en la etnobotánica referida a los distintos ámbitos de la vida de la población. No obstante, una información más detallada relacionada con este tema en particular se expone en Muiño (2010).

El hogar rural tradicional es el "puesto", unidad productiva que alberga una o más familias. Localmente se denomina "puesto" a la unidad doméstica constituida por la vivienda rural y el espacio peridoméstico (Poduje 2000). Los puesteros, tal como se autodenominan los campesinos no realizan trashumancias. Ellos manejan el rodeo en forma sedentaria como lo hacían al momento de la colonización, esto significa que los animales pastorean libremente en campos abiertos en función de su disponibilidad y la del forraje. Tampoco llevan a cabo prácticas especiales de manejo sobre las pasturas como cultivos de pastos nativos o exóticos, cerramientos de protección de áreas forrajeras, o recolección y almacenamiento de forrajes tal como lo hacen en otras regiones ganaderas de Argentina (Scarpa 2007), pero se realizan otras como las quemas selectivas para favorecer el rebrote de ciertas especies con el fin de mejorar su calidad forrajera, una costumbre generalizada en muchos sistemas pastoriles del mundo (Scarpa 2007, Villagrán \& al. 2003, Kilongozi \& al. 2005).

Otras actividades vinculadas con la ganadería, que representan fuentes de ingresos adicionales son los trabajos artesanales en cuero y el tejido en lana (Medus y Poduje 1997), la elaboración de quesos de cabra artesanales y la venta de cueros de animales domésticos y silvestres.

Los riesgos más graves a los que están supeditados los puesteros en su actividad están relacionados con el clima. Dentro de este conjunto se destacan los incendios que suelen ocurrir en los veranos secos y la escasez de agua que condiciona inexorablemente la subsistencia de los animales. Los incendios más 
graves suceden cuando la sequía irrumpe luego de producirse ciclos de varios años húmedos, que conllevan a una gran acumulación de materia seca combustible.

En los últimos años se ha producido un aumento del número de predios con alambrado perimetral, pero en muy pocos casos existe la división de parcelas interiores. Los tamaños de las explotaciones son variados. Los latifundios son escasos siendo poco superados en número por las unidades prediales de tamaño medio. Estas unidades oscilan entre las 2500 has y las 5000 has. Las explotaciones menores a las 2500 has, en cambio son las predominantes.

\subsubsection{Los tipos de ganado.}

Los tipos de ganado que predominan en la región son el vacuno y el caprino. A estos le siguen en orden de importancia los equinos y ovinos. Junto con estas existencias ganaderas, en casi todos los hogares se complementan las necesidades alimentarias de la familia con la crianza de aves de corral.

La ganadería caprina se ve ampliamente favorecida por la existencia en el lugar de una vegetación arbustiva. Los animales son destinados a satisfacer las necesidades alimentarias del grupo familiar tanto como a la venta para consumo en los centros urbanos.

Los equinos también constituyen un tipo de ganado importante en la zona, pero el número de cabezas por predio rural registra una disminución en la segunda mitad del siglo XX (INTA, Gob. de La Pampa, UNLPam 1980).

\subsubsection{El ciclo anual de la ganadería.}

La ganadería vacuna de la zona tiene como objetivo la "cría" de animales, es decir, abarca el período que va desde el nacimiento del animal hasta su venta como ternero, aunque también según las posibilidades se realiza algo de engorde hasta lograr vaquillonas y novillos.

Con el inicio del otoño comienza un nuevo período productivo. En esta época, las gramíneas estivales finalizan su ciclo y si existen condiciones 
adecuadas de humedad, se favorece la germinación e implantación de sus frutos. Desde esta temporada hasta la primavera siguiente ocurre un período de escasez de precipitaciones. Durante otoño e invierno, los trabajos relacionados con la crianza de animales son notablemente menos intensos que en el verano.

No se observa una división de trabajo familiar marcada en torno a la producción ganadera. Dado que la época de las pariciones demanda una mayor mano de obra, es muy común que todo el grupo familiar, incluidos los niños, se dedique a estas labores. Sin embargo, las tareas que requieren más fuerza física, como el manejo de vacunos, la realizan los varones adultos. En la actualidad la migración periódica de integrantes del grupo familiar para generar ingresos adicionales a la economía hogareña no es tan frecuente como en el pasado, pero esta modalidad es muy variable de acuerdo al nivel socioeconómico de cada familia.

Con la primavera se inicia la parición del ganado. Los nacimientos de terneros se concentran entre los meses de septiembre y marzo. La producción de ganado caprino por otra parte comprende una sola parición al año. La producción de cabritos suele iniciarse en septiembre u octubre y continúa hasta el mes de diciembre.

Las ventas de la producción se realizan con mayor frecuencia en el puesto con todas las especies de ganado sin excepción. Con respecto a los vacunos, algunos campesinos venden la producción en ferias ganaderas de la zona. La producción de cabritos, en cambio, se vende a compradores ambulantes provenientes de diversas localidades.

En el mes de marzo o abril se realizan las señaladas y las castraciones de terneros y potrillos que no tienen destino de reproductores. Esta tarea se lleva a cabo en tiempo de luna menguante, ya que la tradición local considera que produce menos riesgos y daños en los animales.

En el pasado, las esquilas de ovejas eran también ocasiones de reunión de la gente. Este evento demandaba una importante cantidad de mano de obra local y de otras zonas y se efectuaban en dos momentos del año, un 
primer corte en el mes de marzo y otro posterior en octubre. Actualmente, debido a la reducción de los rebaños, esta tarea se lleva a cabo a escala familiar. La lana obtenida se vende o se emplea como materia prima en la tejeduría artesanal, una actividad que genera ingresos adicionales en la economía doméstica.

\subsubsection{Manejo del agua}

En el área que comprende este trabajo, el agua es en líneas generales de buena calidad pero su profundidad es muy variable. En algunos puestos de zonas bajas el agua se extrae a pocos metros de profundidad, pero en la mayoría de los establecimientos las perforaciones alcanzan aproximadamente los cien metros. El sector ubicado hacia el W presenta numerosas vertientes naturales de los cauces subterráneos que provienen de la cordillera. Cada campo se abastece con un pozo de agua y se agrega uno nuevo cuando la superficie excede las 5000 has.

Los períodos de sequía tienen una influencia directa sobre la disponibilidad del recurso; las vertientes disminuyen notablemente su caudal de salida y las napas descienden en su cota. Esta es la razón más señalada como causante del abandono de prácticas hortícolas y del mantenimiento de jardines hogareños en muchos puestos.

La elección del sitio para excavar un pozo de agua era y aún sigue siendo empírica. En líneas generales los puesteros construyen su vivienda en los sitios donde encuentran agua. Existen algunos indicios que se consideran al momento de iniciar un excavación, como la presencia de terrenos bajos y de ciertas plantas indicadoras como las "chirriadoras" (Chuquiraga erinacea), cuya abundancia señala la napa de agua a escasa profundidad.

La extracción de agua se realizaba mediante dos sistemas. El más tradicional era con pelota de cuero. En la actualidad todos los predios cuentan con sistema de extracción de agua por molino, por motor a explosión o ambos. Algunos establecimientos poseen excavaciones practicadas en el suelo hasta el nivel de la napa de agua denominadas "jagüeles". La extracción de agua se suelen realizar todavía mediante pelotas de cuero o baldes y 
constituyen sistemas exclusivos si se poseen rodeos pequeños o se mantienen disponibles para suplir a los molinos en casos de roturas.

\subsection{Alimentación.}

Desde la fecha en que se instalaron en estos territorios, los pobladores rurales debieron solucionar sus necesidades alimentarias a partir de lo que se podía obtener del entorno. Para ello debieron implementar las estrategias de producción que ya dominaban en sus lugares de origen así como otras nuevas adaptadas al ambiente que colonizaban. Si bien es una zona apta para la cría de diversos animales, las condiciones climáticas, la escasez de agua y el tipo de terreno actuaron muy frecuentemente como un freno para las experiencias agrícolas.

Si a estas características del medio se le añade el aislamiento de los centros de abastecimiento y el mal estado que con frecuencia presentaban los caminos, es comprensible que a lo largo de varias generaciones, estos pobladores hayan adquirido una dieta cuyo rasgo principal es el consumo de carnes.

En la actualidad, el centro urbano de La Humada fue cambiando parcialmente esta situación debido a que en los últimos años ha experimentado un paulatino desarrollo transformándose en un pequeño centro de actividad comercial del noroeste pampeano. Allí, la mayor parte de los puesteros de la zona pueden abastecerse de una variada gama de alimentos incluyendo frutas y verduras frescas, cuya procedencia son las ciudades mendocinas de General Alvear, San Rafael y Mendoza. Sin embargo el marcado protagonismo de las carnes en la dieta sigue siendo el carácter distintivo y responde a un hábito alimentario con fuerte arraigo entre la gente.

En el pasado, el abastecimiento de hortalizas se realizaba a partir de las pequeñas huertas hogareñas y de los vendedores ambulantes que pasaban por los puestos con sus carros y posteriormente, a partir de la década del 50, con camiones. Por lo general, las frutas y verduras que se adquirían eran aquellas que poseían la capacidad de conservarse largo tiempo sin corromperse, como papas, zapallos, cebollas, ajos, conservas desecadas y 
dulces, principalmente el de membrillo. Las frutas no eran tan frecuentes en estas operaciones, pero en la época de cosechas en Mendoza, los vendedores acostumbraban ingresar con uvas, duraznos y otras frutas de estación de aquella cuenca productora.

Además de la carne de los animales domésticos, la actividad cinegética era y es fuente de subsistencia y a la vez de entretenimiento. Los animales silvestres que integran en mayor medida la dieta son los piches (Zaedyus pichiy), el avestruz moro ( $R$. americana) y el overo o "choique" (Pterocnemia pennata). En menor proporción también son perseguidas las vizcachas (Lagostomus maximus).

A excepción del trabajo de Steibel (1997), poco se conoce sobre el papel de las plantas alimenticias nativas de la región. Este se puede deducir a partir de datos sobre propiedades de este tipo consignadas en otros estudios realizados en regiones próximas (Agüero Blanch 1967, Ruiz Leal 1972, Martinelli 2008, Rapoport \& al. 2001, Ladio \& Lozada 2004b).

\subsection{Salud y medicina}

Los trabajos etnográficos vinculados con la medicina y más en particular con las plantas medicinales en la región pampeana y cuyana constituyen una importante fuente de información de creencias y leyendas que ayudan a reconstruir los valores de las culturas que han desaparecido en el área como así también de los recursos naturales locales empleados en el tratamiento de las afecciones que padecían los grupos humanos establecidos en ella (Gusinde 1936, Martínez Crovetto 1963 y 1968, Ambrosetti 1976, Valencia 2006). Sin embargo, estos estudios suelen estar desactualizados en los nombres de los taxones o presentar errores en la identificación e incluso carecen de la correspondiente documentación de los registros botánicos.

Ya desde una perspectiva antropológica merecen destacarse los estudios referidos al complejo salud-enfermedad-atención, y al contexto social donde se encuadran los significados de salud y enfermedad, la etiología de las dolencias y las terapias tradicionales que conducen al proceso de curación (Agüero Blanch 1968, Newbery 1978, Grebe \& al. 1970). 
Más abundantes son en cambio los trabajos referidos a las floras medicinales de diferentes zonas de la región pampeana (Roig 2001, Bocco \& al. 1997, Del Vitto \& al. 1997 y 1998, Núñez y Cantero 2000). Estos trabajos presentan la particularidad, a diferencia de los anteriores, de brindar una información detallada de los usos de la flora local con rigurosidad taxonómica, pero no sitúan la farmacopea en el contexto del conocimiento y la praxis vernácula de los grupos sociales estudiados, por lo que reflejan limitadamente aspectos vinculados con la cultura de la población.

Entre los estudios etnobotánicos, como disciplina de síntesis de los enfoques mencionados anteriormente para las regiones pampeana y cuyana se pueden citar los estudios de Steibel (1997) y de Martínez \& Planchuelo (2003).

\subsubsection{El sistema de salud}

La farmacopea criolla se conformó a través de un proceso de mezcla de los conocimientos de las comunidades aborígenes y la medicina clásica vigente en la época de la conquista española. Los sacerdotes jesuitas fueron los primeros encargados de recopilar y traducir el saber de los pueblos originarios e identificar taxonómicamente los recursos naturales con el propósito de ser utilizado como fuentes de medicamentos nuevos para la corona española. No obstante el legado de esta orden religiosa es mucho más rico en el NE de Argentina y en Paraguay (Cantero \& Ariza Espinar 2006). Si bien existió un intercambio cultural entre nativos y europeos, las diferencias irreconciliables en lo referente tanto al marco etiológico como a las prácticas de curación entre la medicina aborigen y la medicina oficial del virreinato, entonces regida por el Real Protomedicato, condujeron a una situación de descrédito de la primera (Di Liscia \& Prina 2002), hecho que se extendió a la cultura aborigen en su conjunto a lo largo del tiempo a través del discurso científico de la sociedad occidental dominante durante el proceso de institucionalización del país en plena etapa del positivismo (Di Liscia 2002).

En el oeste pampeano la situación de los servicios de salud no escapa a la realidad de otras áreas rurales de nuestro país. Si bien a lo largo de los últimos años se manifiesta una mejoría en este aspecto por la instalación de postas sanitarias, sistemas de control y diagnóstico ambulatorio y servicios de 
traslado de pacientes, las grandes distancias a cubrir hasta los centros urbanos más cercanos siguen siendo un fuerte condicionante en esta materia. No obstante, la opinión de la gente en general es positiva con respecto a los servicios sanitarios, a excepción de los pobladores de algunos sectores más alejados donde la presencia de los médicos y enfermeros no es tan efectiva.

Actualmente, en el área que comprende este trabajo, el centro de atención médica más próximo es La Humada. Este pueblo posee una posta sanitaria con un médico, dos enfermeras y un servicio de ambulancia para los traslados de urgencia desde los predios rurales hasta la posta. Ésta cumple un rol destacado dentro de la comunidad y su presencia, a partir de marzo de 1975, es importante para la población local. Esto lo evidencian muchas opiniones a su favor por parte de los pobladores al comparar presente y pasado en relación con la salud. En líneas generales, la posta atiende situaciones de atención primaria de la salud y casos de menor gravedad. Los cuadros clínicos que revisten un riego mayor y que no son posibles de atender con los recursos locales son derivados hacia la localidad de Santa Isabel, distante a $110 \mathrm{~km}$ o a Santa Rosa a $400 \mathrm{~km}$. Conjuntamente con estas tareas se realizan visitas periódicas mensuales a la localidad de Chos Malal, ubicada $70 \mathrm{Km}$ al sur con el fin de controlar la salud de la población y realizar tareas de prevención.

\subsubsection{Los actores sociales y su rol en torno a la medicina tradicional}

La medicina tradicional es un conjunto de conocimientos que en más de una oportunidad ha tenido y tiene zonas de tensión con la medicina oficial. La formación profesional de los agentes de la salud en la Argentina está fundada en principios científicos que concuerdan con los postulados básicos de la medicina occidental. Dentro de este esquema no les resulta fácil consensuar con otros enfoques sobre las cuestiones de salud-enfermedad de modo tal que permita un ejercicio profesional con una mirada más ecléctica ante la diversidad cultural. En las zonas donde persisten estos conocimientos vernáculos, los agentes sanitarios deben tomar una posición al respecto y esta actitud influye a la hora de establecerse como referentes dentro de la comunidad. En este sentido y probablemente por las razones anteriormente expuestas, existe cierto rechazo por parte de los agentes hacia las prácticas 
tradicionales que no se ajustan a los paradigmas de la ciencia médica oficial. No obstante las terapias en las que se hace uso de plantas con principios activos de reconocida acción farmacológica son bien aceptadas por algunos profesionales.

Los pobladores por su parte, y principalmente aquellos que viven a cierta distancia del centro asistencial, mantienen vigentes muchas de estas prácticas tradicionales aún a sabiendas del descrédito que representan para los profesionales. La mayor parte de los casos de atención primaria de la salud se intentan resolver por medio de estas prácticas. No obstante, son muy frecuentes los casos de consultas en la posta sanitaria luego de probar con este tipo de terapias que no dieron los resultados esperados. Entre la población de La Humada, por el contrario, existe un alto número de consultas a la posta, aún en los casos de mínima gravedad.

La presencia de curanderos en la zona es escasa y existe en cambio una mayor cantidad de legos y especialistas en medicina tradicional. Todos ellos poseen una credibilidad relativa en el imaginario social. Su pérdida de prestigio a lo largo del tiempo se corresponde con el establecimiento de las instituciones médicas oficiales, con el paulatino aumento de su imagen positiva y con el discurso desautorizante que éstas emplean sobre la medicina tradicional. Durante las entrevistas se puso en evidencia la existencia en el pasado de un mayor número de curanderos. Sin embargo, en algunos sectores de la población, la figura del curandero y de los legos locales goza de crédito aún en nuestros días debido, en parte, a que suelen ser consultados cuando la medicina oficial no tiene respuesta o no satisface las expectativas del paciente. En La Humada se pudo registrar solamente la presencia de un agente sanitario con las características de los tradicionales curanderos, a quien los pobladores identifican como "yuyero".

No se puede dejar de mencionar aquí a otros de los personajes ligados a la salud en el oeste pampeano, al menos en el pasado. Ellos son los misioneros salesianos. En este sentido, fue mencionada varias veces en las entrevistas la presencia en la zona de los curas José Durando y Francisco Melo, quienes con sus conocimientos y su interés por las propiedades de las plantas nativas, sumado a la ausencia de médicos en la zona y el consuelo 
espiritual que proporcionaban a los pobladores, se convirtieron en referentes sanadores de la región. La presencia de los curas salesianos en el oeste provincial comenzó a disminuir a partir de la segunda mitad del siglo pasado, etapa que coincide con la aparición y aumento del número de iglesias protestantes (Radovich 1983). Merece mencionarse dentro del ámbito de acción de estos cultos, que un número considerable de afecciones de carácter psicosomático y dolencias que escapan al ámbito de acción de la medicina oficial son tratadas directamente en el templo durante las reuniones de sus fieles. En estas ocasiones la expulsión de los males se lleva a cabo por mediación del Espíritu Santo convocado para tal fin a través de plegarias, lo que constituye un ejemplo más de curación basada en los modelos terapéuticos sustractivo y exorcista (Laplantine 1997). La irrupción y dispersión de estos cultos también influyó en el descrédito y posterior pérdida de vigencia de muchas terapias tradicionales.

\subsection{Cultura material}

En todas las regiones del mundo donde persisten las economías tradicionales, los recursos vegetales cumplen un papel de máxima importancia en la cultura material. Estos constituyen la fuente de materia prima en la construcción de la infraestructura y los instrumentos necesarios para la actividad económica del grupo humano. Tal como está planteada aquí, la cultura material abarca múltiples aspectos como la construcción de la vivienda, las instalaciones rurales y los enseres domésticos. Dentro de estos últimos, a su vez pueden incluirse los utensilios para las labores cotidianas y los objetos realizados con maestría artesanal que se destinan tanto al uso diario como a la venta para generar ingresos adicionales en la economía hogareña.

Dada la amplitud del tema, y en pos de lograr su mejor comprensión, en este trabajo se presentarán dichos aspectos separados en unidades temáticas. La construcción de instalaciones rurales estará incluida en el capítulo referido a "Actividad Económica", mientras que "Vivienda" será tratado como capítulo aparte al igual que "Artesanías y Enseres Domésticos". Este último estará referido a la construcción de las herramientas de uso cotidiano y de los 
objetos de manufactura hogareña que incluye la tejeduría, la cestería y el trabajo en cuero.

\subsection{Recursos energéticos}

2.6.1. Maderas combustibles: La población rural hace un uso casi exclusivo de la leña para la calefacción de los hogares y la cocción de alimentos. En la localidad de La Humada, en cambio, la gente tiene otras opciones como el gas envasado, el cual se emplea principalmente en las cocinas, y el kerosén, que es muy utilizado en calefactores de ambientes. Estos recursos se suman a la venta de leña envasada o a granel en los comercios del pueblo. Sin embargo, y aunque cada vez más limitada por las restricciones que ponen los dueños de los campos, la recolección de leña en los alrededores del pueblo se sigue realizando como un complemento de los hidrocarburos mencionados.

Cuando la leña escasea, como ocurre en los alrededores de La Humada, en los puestos con muchos años de actividad continua o en aquellos otros ubicados en áreas de vegetación herbácea o arbustos bajos, los pobladores deben cubrir distancias variables en su búsqueda mediante vehículos automotores o a tiro de caballo con los montículos de leña recolectados.

2.6.2. Los sistemas de iluminación en la actualidad: Los sistemas de iluminación predominantes son en base a energía eléctrica. Hasta diciembre de 2007, la localidad de La Humada cubría esta demanda a través de un motor generador que proveía electricidad a la localidad de 6.30 a 1.00 hs cuyo funcionamiento y mantenimiento estaba a cargo de la Municipalidad. A partir de 2008 se hizo llegar el tendido de líneas del sistema eléctrico provincial contándose desde entonces con electricidad todo el día. Los predios rurales, en cambio, poseen motores generadores o sistemas de iluminación solar. En pocos casos se registraron hogares alumbrados exclusivamente con faroles de gas. 


\section{MATERIALES Y METODOLOGÍA}

La metodología estuvo sujeta a las distintas etapas que componen el trabajo de investigación requerido por este plan. A grandes rasgos, este se dividió en: búsqueda de fuentes de información, trabajos de campo, trabajos de gabinete y procesamiento y análisis de la información. En cada una de estas secuencias se emplearon estrategias diferentes que posibilitaron su ejecución.

\subsection{Búsqueda de fuentes de información}

Se realizó una búsqueda pormenorizada de la documentación gráfica relacionada con el tema en diferentes instituciones especializadas, así como una consulta permanente sobre trabajos de investigación de revistas científicas de libre acceso en la red de Internet. Además de otras entidades con menor documentación disponible, las instituciones en las que se realizaron mayor cantidad de consultas fueron las siguientes:

- Museo Etnográfico "Juan B. Ambrosetti". Moreno 350. Ciudad de Buenos. Aires.

- Instituto Nacional de Antropología.y Pensamiento Latinoamericano.3 de febrero 1378. Ciudad de Buenos Aires.

- Archivo Histórico Provincial "Fernando E. Aráoz". Mitre 85. Santa Rosa, La Pampa.

- Biblioteca del Museo de Ciencias Naturales, UNLP. Paseo del Bosque S/NO, La Plata. Buenos Aires

Conjuntamente con la documentación gráfica, también se realizaron consultas personales con especialistas de diferentes áreas con amplia experiencia en el trabajo de campo en el área geográfica que hace referencia este trabajo, quienes aportaron una información sumamente valiosa. 


\subsection{Trabajos de campo}

\subsubsection{Entrevistas}

Como tarea inicial se realizó un primer viaje en agosto de 2004 donde se tomó contacto con una familia de pobladores de la localidad de Chos Malal, experiencia que sirvió para informar directamente y por su intermedio a otros pobladores los propósitos de la investigación. La clara comunicación de los fines de este trabajo a los vecinos del lugar tuvo como objetivo evitar falsas expectativas y generar un clima de confianza entre el investigador $y$ los futuros entrevistados.

Se llevaron a cabo nueve campañas en total en los meses de febrero de 2005, enero, junio y julio de 2006, enero, junio y noviembre de 2007, noviembre de 2008 y febrero de 2009 que abarcaron un promedio de nueve días cada una. Estas campañas se realizaron en la población más importante del departamento, La Humada, como así también en el área rural de influencia de esta localidad. También se efectuaron trabajos de campo en los parajes de Agua de Torres y Chos Malal. En el segundo se concentra un nutrido grupo de familias con fisonomías culturales particulares donde se reproducen algunas de las formas de la vida indígena, como las relaciones intra e interfamiliares, la función de las explotaciones y las actividades artesanales (Comerci 2005).

Para el desarrollo de los trabajos de campo se implementó la metodología clásica utilizada para los estudios sociales, etnográficos y etnobotánicos (Barroso 2000, Martin 2000, Guber 2001). La información fue registrada mediante el método de entrevistas abiertas y encuestas. En menor proporción se realizó la documentación mediante observación participativa, estrategia que permitió también contextualizar las entrevistas. Todos los registros se realizaron en forma escrita a excepción de uno en el cual, debido a la escasa capacidad auditiva del anciano informante, se consideró más conveniente realizar la grabación en cinta magnetofónica. De esta manera, la captación directa de su voz por el micrófono en respuesta a las preguntas realizadas por el entrevistador, complementadas por el lenguaje gestual y gráfico resultó ser más eficiente en la toma de información. 
Durante las entrevistas abiertas se tomó un primer contacto con la población abordando temas vinculados con la historia de vida de los pobladores, lo cual permitió establecer las unidades temáticas para otras entrevistas así como otros elementos emergentes que pudieran enriquecer la información. Estos elementos pueden ser emocionales, estéticos, simbólicos y a veces no tienen vinculación directa con la cultura en estudio, no obstante pueden establecer contactos con otras anteriores o actuales. Esta estrategia también permitió identificar a los informantes mejor calificados sobre cada tema en particular.

Las historias de vida fueron de suma importancia como estrategia metodológica para la confección de los modelos de entrevistas, además de permitir una mejor comprensión de las limitaciones de la población en el pasado, las percepciones sobre el medio y las motivaciones que tuvieron para desarrollar prácticas de subsistencia.

Se tomaron como válidos todos los datos aportados por los entrevistados, aún aquellos que fueron mencionados solo una vez a lo largo de los encuentros. En algunos casos estos estuvieron referidos a nombres comunes diferentes aplicados a una misma especie. En cinco ocasiones no se pudo colectar la planta o no pudieron obtenerse otras referencias de la misma. En tales circunstancias la información fue considerada como no válida. Por el contrario, las repeticiones de datos indicaron el amplio consenso que tienen algunas especies y dieron cuenta de la vigencia del uso o la importancia que tuvieron en el pasado algunas plantas en la vida cotidiana de los pobladores.

La edad promedio de esta población alcanzó a los 56 años. Si bien se tuvo en cuenta la "Ley de rendimientos decrecientes" (Martin 2000) para establecer la cantidad de entrevistas suficientes, se llevaron a cabo una cantidad adicional de las mismas con el fin de cubrir en forma más homogénea el área de influencia de la localidad más importante y de detectar posibles elementos de culturas foráneas que revelasen procesos migracionales no registrados aún en la documentación disponible u otra clase de intercambio. El total de personas entrevistadas ascendió a 69, las cuales se dividieron en 27 mujeres y 42 varones. 
Por otra parte, se llevaron a cabo 47 encuestas en forma aleatoria a fin de lograr una aproximación cuantitativa sobre determinados aspectos de la relación humano-planta, como la pérdida de vigencia del empleo de algunas especies, los motivos de esta pérdida, y los eventuales vínculos entre desaparición de usos y cambios relacionados con las formas de vida. El propósito de las encuestas no fue hacer un análisis estadístico, para lo cual se hubiese debido diseñar un muestreo más intensivo y una selección de los informantes no aleatoria, sino detectar tendencias y entender mejor cuáles son las motivaciones de la gente que llevan a la continuidad o el abandono de las prácticas en torno a las plantas. Los modelos de entrevista abierta y encuesta utilizados se presentan como Anexo I.

\subsubsection{Colecta del material vegetal}

Una vez elegidos los referentes para la información de cada tema se llevaron a cabo salidas al campo en compañía de ellos para identificar las plantas con su nombre vernáculo y sus eventuales usos y simultáneamente herborizar los ejemplares para confeccionar pliegos de herbario. Las colectas botánicas fueron interrumpidas en las campañas desarrolladas en otoño e invierno, no solamente porque las plantas se encuentran en estado vegetativo sino porque gran parte de la vegetación de la zona es caducifolia. En los casos que la edad del informante o su estado de salud lo impedía, se realizó la colecta antes descripta y posteriormente se trabajó sobre la identificación e información de las especies en el domicilio del entrevistado, a la vista del material de referencia.

\subsection{Trabajos de gabinete}

Los ejemplares colectados fueron herborizados e identificados taxonómicamente por el autor, salvo en aquellos casos en los que se requirió la colaboración de especialistas de la Facultad de Agronomía de la Universidad Nacional de La Pampa, particularmente al momento de identificar especies cultivadas. Se utilizaron las claves disponibles en las floras regionales y de Argentina (Correa 1998, Rúgolo de Agrasar \& al. 2005). El material de referencia se depositó en el Herbario de la Facultad de Agronomía (UNLPam) cuya sigla responde a SRFA (Holmgren \& al. 1981). 


\subsection{Procesamiento y análisis de la información}

Al regreso de cada campaña, la información fue incorporada en una base de datos con el fin de facilitar el análisis posterior de los mismos. Se utilizó para ello el programa Microsoft Access XP. En ella se registró la información básica correspondiente a las entrevistas, es decir la fecha y lugar donde fue realizada, el nombre del colaborador, su edad y su lugar de origen. En cuanto a los datos relacionados con las especies vegetales mencionadas se dejó constancia del nombre común expresado por el entrevistado, el nombre de la especie y la familia botánica de pertenencia. La información vinculada a cada especie se agrupó de acuerdo a los ámbitos de subsistencia con un criterio similar al seguido por Scarpa (2000a). Estos ámbitos de subsistencia fueron establecidos como: "ganadería", "manejo del agua", "alimentación", "medicina e higiene", "vivienda", "artesanías y enseres domésticos", y "combustibles e iluminación". En el rubro "ganadería" se incluyó, además de las especies vegetales de destacado valor forrajero, aquellas que se consideraron pasibles de ocasionar efectos negativos para la actividad ganadera. Este ámbito también incluye las plantas utilizadas en la construcción de instalaciones ganaderas, y las que forman parte de los tratamientos veterinarios.

En el Catálogo Botánico de Nombres y Usos que se presenta como anexo se incluyen todas las especies que fueron citadas por los informantes en los trabajos de campo. Para una mejor comprensión, los taxa se ordenaron alfabéticamente dentro de cada nivel correspondiente. Los nombres científicos fueron actualizados a partir de la Flora del Cono Sur del Instituto de Botánica Darwinion.

(URL: http//www.darwin.edu.ar/Provectos/FloraArqentina/Especies.asp). Para los taxa adventicios que no se registran en esta base de datos se siguió la nomenclatura del United States Department of Agriculture, NRCS. 2010. The PLANTS Database (URL: http://usda.gov). 


\section{RESULTADOS}

\subsection{Actividad económica.}

\subsubsection{Recursos forrajeros}

Un total de 57 plantas fueron registradas como forrajeras de diferente preferencia animal en función del tipo de ganado. De las gramíneas invernales la más citada fue el unquillo (Poa lanuginosa). Junto con esta especie merecen mencionarse en el estrato herbáceo otras gramíneas y representantes de otras familias como el tupe (Panicum urvilleanum), flechilla fina (Nassella tenuis), cebadilla (Bromus catharticus var. rupestris), pasto de invierno (Schismus barbatus), pasto de hoja (Bothriochloa springfieldii), flechilla blanca (Jarava ichu), té pampa (Thelesperma megapotamica), alfilerillo (Erodium cicutarium) y gramilla (Eragrostis mexicana ssp. virescens), todas ellas preferidas por los vacunos y ovinos. Los caballares tienen preferencia por pastos duros como el coirón (Pappostipa vaginata), flechilla gruesa (Asistida mendocina) y otras matas y arbustos tales como el llaulin (Lycium chilense), tomillo (Acantholippia seriphioides), retamilla (Prosopidastrum striatum), yerba de oveja (Baccharis darwinii) y molle (Schinus johnstonii).

Para los campesinos de la zona, las características de las mejores especies forrajeras se relacionan con su capacidad de "engorde" del animal y con su palatabilidad, siendo el volumen de la planta un carácter poco considerado al momento de la evaluación. Esta apreciación puede observarse sobre plantas como el unquillo (Poa lanuginosa), que pese a ser una gramínea con macollas muy delgadas y volumen escaso, es considerado uno de los pastos más valiosos por la gente del lugar.

Además de las especies mencionadas, se señaló una particular preferencia en los ovinos por algunas herbáceas como la yerba del pollo (Gomphrena mendocina), la peludilla (Plantago patagonica), la yerba de la perdiz (Margyricarpus pinnatus), y la yerba de oveja (Baccharis gilliesii). Entre las de consumo ocasional se registró la blanquilla (Hyalis argentea), el tomillo 
macho (Junellia seriphioides) y solo las inflorescencias de la melosa (Grindellia chiloensis).

Las plantas que se mencionan como relevantes en la dieta de los caprinos son principalmente arbustos como la jarilla (Larrea divaricata), molle (Schinus johnstonii), alpataco (Prosopis flexuosa var. depressa), piquillín (Condalia microphylla), Ilaulín (Lycium chilense), ala (Monttea aphylla), jarillilla (Gochnatia glutinosa), solupe frutero (Ephedra ochreata), zampa (Atriplex lampa) y otras especies en menor proporción. La Tabla 1 (Ver Anexo) indica las especies forrajeras para todas las categorías de ganado. La importancia forrajera se expresa en base a la percepción de los informantes como:

$$
\mathrm{IF}=\mathrm{I} / \mathrm{N}
$$

en la que I es el número de veces que fue citada la especie $s$, y $\mathrm{N}$ es número total de eventos o entrevistas. Las familias más importantes en cuanto al número de especies forrajeras son las Poaceae y las Asteraceae. Las Verbenaceae, Solanaceae, Fabaceae y otras le siguen con una menor representación en el total (Tabla 2 ).

La percepción de los lugareños sobre los recursos forrajeros abarca no solamente aquellas especies que poseen buenas características nutritivas y de palatabilidad sino también aquellas cuya abundancia en el campo actúa en detrimento de la presencia de otras de buena calidad forrajera. El aumento significativo de aquellas es considerado como una señal de que "el campo estuvo muy cargado" de ganado. Dentro de esta categoría son conocidas por los lugareños la "melosa" (Grindelia chiloensis) y el "tomillo macho" (Junellia seriphioides), especies que se comportan como invasoras debido a su éxito reproductivo coadyuvado por el rechazo de los animales.

\subsubsection{Plantas tóxicas o con efectos adversos en la actividad}

Entre las plantas tóxicas de la región la más citada fue el tabaco cimarrón (Nicotiana noctiflora), consumida solo por aquellos animales que padecen hambre en períodos de escasez de forraje o aquellos provenientes de otra región. La hierba loca, nombre con que se designa a varias especies del 
género Astragalus, también se mencionó dentro de esta categoría, pero los casos de toxicidad estuvieron referidos a ganado que pace en áreas serranas de la provincia de Mendoza. En La Humada esta planta es muy poco frecuente y los informantes no han registrado intoxicaciones en sus rodeos.

También fue mencionada la sandilleja (Cucumis anguria) como causante de intoxicaciones en las cabras, que en casos de consumo intensivo pueden ser fatales. Cuando por su menor ingesta no alcanza a generar un cuadro de toxicidad, esta planta confiere mal sabor a la carne y a la leche de estos animales. Otra de las plantas reputadas como nociva para el ganado caprino fue el mastuerzo (Prosopis strombulifera).

Otras especies causan pérdidas en el ganado lanar, principalmente en los corderos, pero no por toxicidad. Tal es el caso de algunas flechillas que presentan antecios duros, como Jarava neaei y Nassella tenuis. En estas circunstancias los antecios se clavan en la lana primero y luego en el cuero del animal, produciendo heridas que pueden ocasionarles la muerte.

Algunos efectos de toxicidad están relacionados con el estado fenológico de la planta y con variaciones climáticas. Como ejemplo se puede mencionar el unco (Sporobolus rigens), una de las plantas capaces de producir intoxicaciones cuando es consumida tras el rebrote intenso. En otros casos, los períodos de precipitaciones abundantes generan condiciones adecuadas para el establecimiento masivo de ciertas especies tóxicas, que en otras condiciones pasan inadvertidas para la hacienda. Una de ellas es la pechuguilla (Euphorbia collina), hierba que causa diarreas intensas en los animales. En ambas especies la intoxicación puede tener desenlaces fatales de acuerdo al nivel de consumo.

Durante las primaveras muy lluviosas el rebrote intenso y las condiciones adecuadas para los ataques fúngicos de las plantas pueden ocasionar otros cuadros de intoxicación. En esta época del año suele ocurrir un síntoma particular de constipación equina denominado localmente "torozón", que sucede cuando estos animales consumen intensamente el forraje tierno de algunas plantas, como el llaulín (Lycium chilense). Las especies venenosas o con efectos adversos se indican en la Tabla 3 


\subsubsection{Tratamientos veterinarios}

Las afecciones que requieren tratamientos locales se relacionan mayormente con inflamaciones de etiología múltiple. Estas pueden incluir las infecciones cutáneas, quemaduras, irritaciones locales, etc, que en conjunto se denominan "pasmos" de acuerdo a la terminología local. La plantas utilizadas como desinflamatorios y desinfectantes son la jarilla (Larrea divaricata), el bejuco (Eupatorium patens) y la pichana (Baccharis spartioides). La aplicación puede ser directa en forma de emplastos preparados con las partes aéreas de las plantas machacadas o bien en lavajes con su decocción acuosa. Estas decocciones, y en particular las que se aplican a temperatura ambiente, reciben el nombre local de "agua", de allí la denominación de agua de jarilla o de bejuco. El tomillo (Acantholippia seriphioides) también se emplea para evitar irritaciones colocando dos ramas de la planta en forma de cruz entre la cincha de la montura y el cuero de los caballos, un tratamiento terapéutico con evidente sentido metafórico.

La retención de placenta en los partos de los animales constituye un problema común. Como oxitócicos por vía oral se utiliza mayormente la decocción concentrada de los tallos y hojas de jarilla (Larrea divaricata) y con menor frecuencia de uso la de jarillilla (Gochnatia glutinosa).

Las parasitosis que más requieren la atención primaria son las miasis; dentro de estas se mencionaron las "bicheras", el gusano del cuajo de los equinos y el gusano del cuerno entre los caprinos. Las "bicheras", producidas por larvas de moscas del género Cochliomya, se tratan con la jarilla (Larrea divaricata) y el bejuco (Eupatorium patens). Este tratamiento consiste en aplicar las hojas machacadas, como también su decocción acuosa en forma directa o mezclada con otros líquidos como por ejemplo aceite mineral de automotor $u$ otros productos de base oleosa. Estas preparaciones se aplican directamente sobre la herida y finalmente se recubren con estiércol vacuno. Como una variante terapéutica contra esta parasitosis se registró el empleo de collares confeccionados con ramas de bejuco (Eupatorium patens) que se cuelgan en el cuello de los animales afectados hasta la total desaparición de las larvas. Es probable que en estos casos el medicamento ejerza alguna acción repelente de los insectos. 
Para el tratamiento del gusano de cuajo (Gasterophilus spp.) y del gusano del cuerno (Hematobia irritans) también se administra la decocción mencionada de bejuco (Eupatorium patens) pero en forma oral. Este preparado también es usado en la atención de los caballos con diversas afecciones gastrointestinales. El tratamiento del gusano del cuajo incluye, además del mencionado, la administración por vía oral de leche con ajo (Allium sativum) o lavandina diluida en el agua del abrevadero.

El mal seco es también frecuente entre los equinos de la zona. Clínicamente identificada como adenitis estreptocócica equina, se trata de una enfermedad bacteriana que puede evolucionar favorablemente (URL:http//equine-stranqles.co.uk), pero que con frecuencia tiene desenlace fatal. Los lugareños aplican masajes con grasa animal sobre la región pectoral de los cabalgares para madurar el proceso infeccioso hasta lograr una profusa supuración. A veces esta se provoca realizando un corte sobre la región afectada. Posteriormente se efectúa la desinfección de la herida con una decocción de jarilla (Larrea divaricata).

Para el control de las diarreas de los terneros se suministra harina de trigo mezclada en agua fría y también fue citado el tratamiento con agua de ajenjo (Artemisia absinthium). Para las diarreas de los cabritos fue registrado el empleo de un cocimiento concentrado de ramas de tamarindo (Tamarix ramosissima). Todos estos tratamientos se efectúan por vía oral.

Entre los accidentes eventuales de la hacienda merecen destacarse las mordeduras de víboras. Cuando esto ocurre se realizan lavajes con agua de tabaco (Nicotiana tabacum) y ajo (Allium sativum) o simplemente emplastos de tabaco con aceite sobre las heridas.

Se registró un total de 10 especies de uso en veterinaria y su importancia se expresa en función del número de citas para cada una (Tabla 4). Esta importancia también queda expresada en función de la diversificación de los usos por cada especie (Tabla 5). 


\subsubsection{Construcciones rurales e instrumentos de uso ganadero}

Las plantas empleadas en las instalaciones ganaderas se relacionan mayormente con la construcción de cercos. Los postes que se emplean para construir los corrales del ganado mayor y en el perímetro del campo son de caldén (Prosopis caldenia) o de algarrobo (Prosopis flexuosa f. flexuosa). Entre ambas especies, la última, casi sin excepción, posee la madera preferida por su durabilidad. Las varillas intermedias de los alambrados y a veces también los postes suelen ser de eucalipto (Eucalyptus spp.) debido a su disponibilidad en el mercado, o de acacia (Robinia pseudoacacia); pero es común encontrar alambrados cuyas varillas han sido realizadas con maderas del lugar, como la de jarilla (Larrea divaricata).

Los sistemas de aberturas de los alambrados consisten en tranqueras y en tranquerones. Estos últimos consisten en una adaptación de una porción del alambrado para lograr la apertura y cierre de las parcelas. Las tranqueras y otras instalaciones como mangas, cargadores, cepos y otras se adquieren en el mercado y están fabricadas con maderas resistentes provenientes del norte de Argentina. Las más usadas son curupay (Anadenanthera colubrina var. cebil) y anchico colorado (Parapiptadenia rigida). Asimismo las varillas y postes adquiridos en el comercio pueden ser de maderas ajenas a la zona como el urundel (Astronium urundeuva), grapia (Apuleia leiocarpa), itín (Prosopis kuntzei), quebracho colorado (Schinopsis lorentzii) y eucalipto (Eucalyptus spp.).

a.

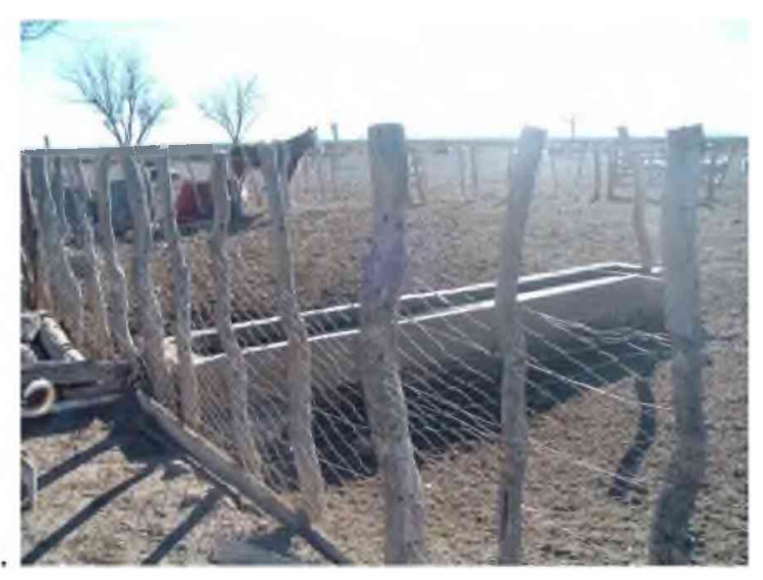



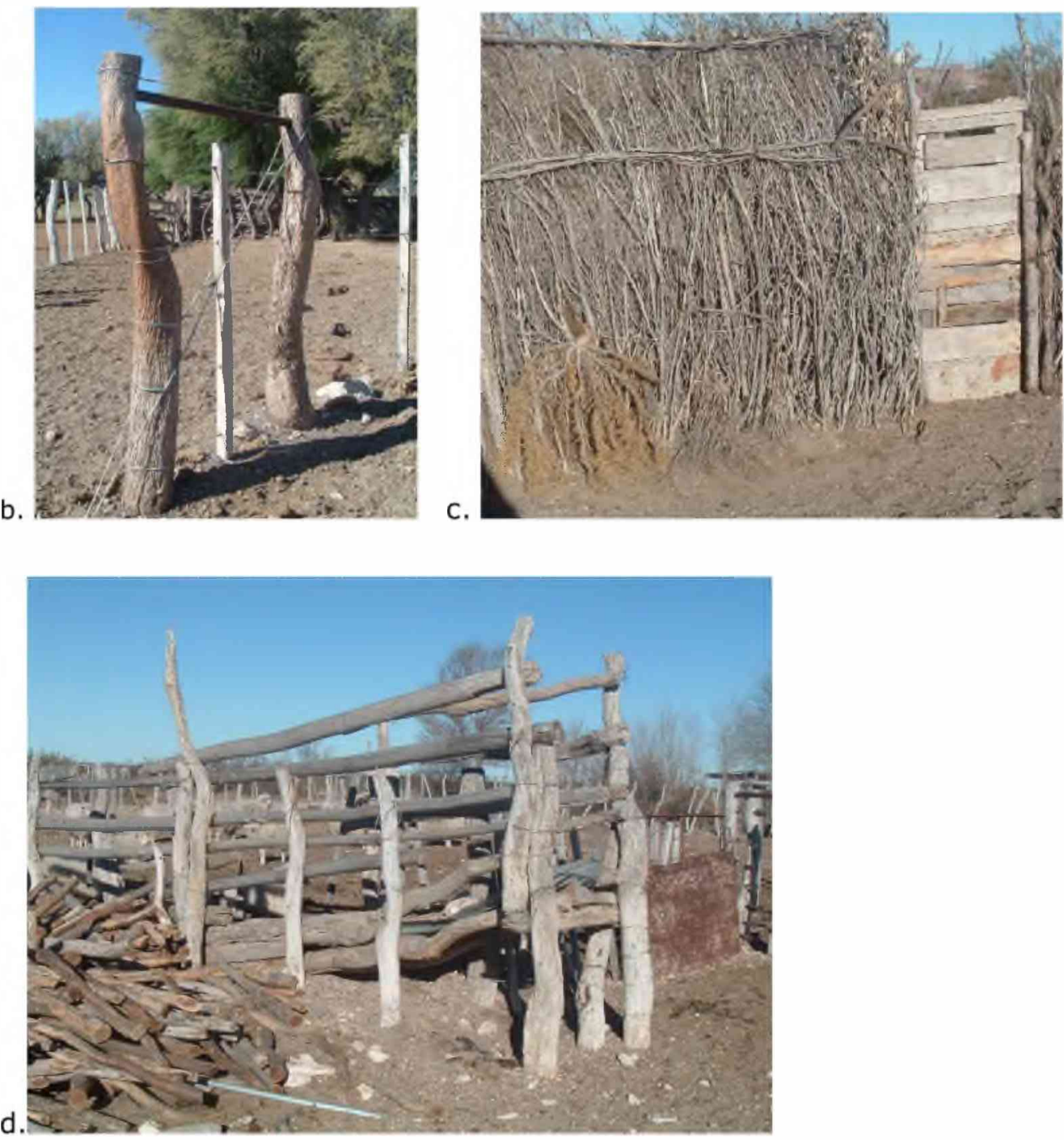

Fig. 2: Construcciones rurales. a: alambrados hechos con postes de $P$. flexuosa $f$. flexuosa. b: Esquineros hechos con postes de $P$. caldenia. c: cercos de los corrales de cabra hechos con ramas de $L$. divaricata. $d$ : cargador de hacienda hecho con postes de $P$. flexuosa f. flexuosa y $P$. caldenia.

Los sistemas tradicionales de aprovisionamiento de agua, como son las pelotas de cuero y los baldes, requieren maderas resistentes en su estructura de sostén. Para este fin se obtienen postes de árboles nativos como el algarrobo (Prosopis flexuosa f. flexuosa) o cultivados en los puestos como el olmo (Ulmus spp.) o la acacia (Robinia pseudoacacia). Estas maderas también se emplean para realizar los armazones internos de los jagüeles para evitar eventuales derrumbes. 

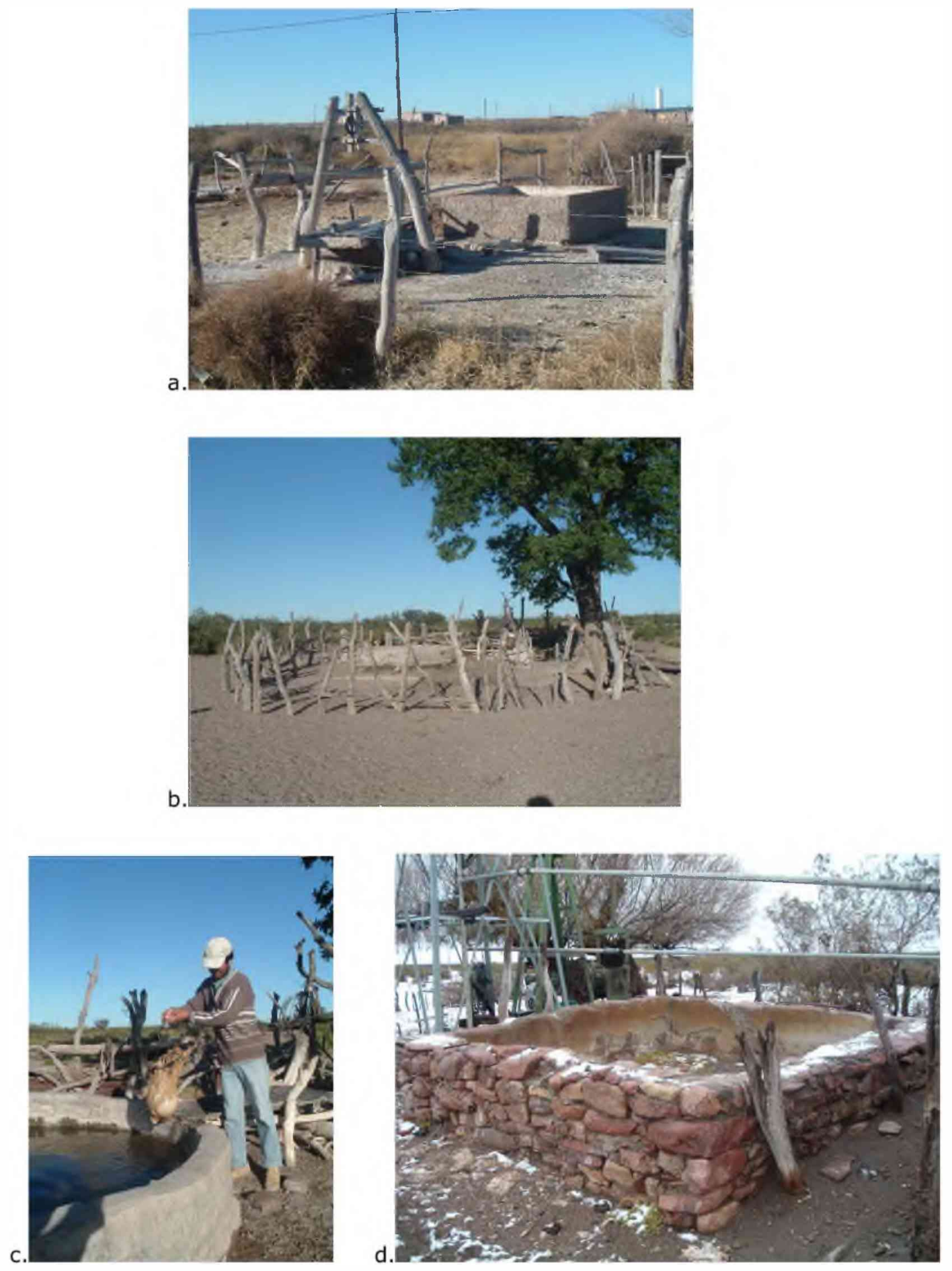

Fig. 3: Sistemas de aprovisionamiento de agua. a: jagüel con tripode hecho con postes de Prosopis sp. y tanque de agua metálico, b: pozo y aguada cercado con postes de Prosopis sp., c: joven puestero sacando agua con una bota de cuero, d: antiguo tanque de agua construido con piedra. 
Los corrales empleados para el encierro de las cabras se construyen de diversos materiales, pero los tradicionales son cercos de jarilla (Larrea divaricata) y solupe (Neosparton aphyllum) trabados y reforzados con postes de acacia (Robinia pseudoacacia), algarrobo (Prosopis flexuosa f. flexuosa), o piquillín (Condalia microphylla). Dentro de estas construcciones suele haber otra interna de menores dimensiones y construida con materiales muy diversos, destinada al encierro de los cabritos en la época de producción. Los corrales más modernos se arman con tablas obtenidas de los cortes exteriores de rollizos de álamo (Populus nigra), provenientes de las áreas bajo riego de La Pampa y Mendoza.

a.
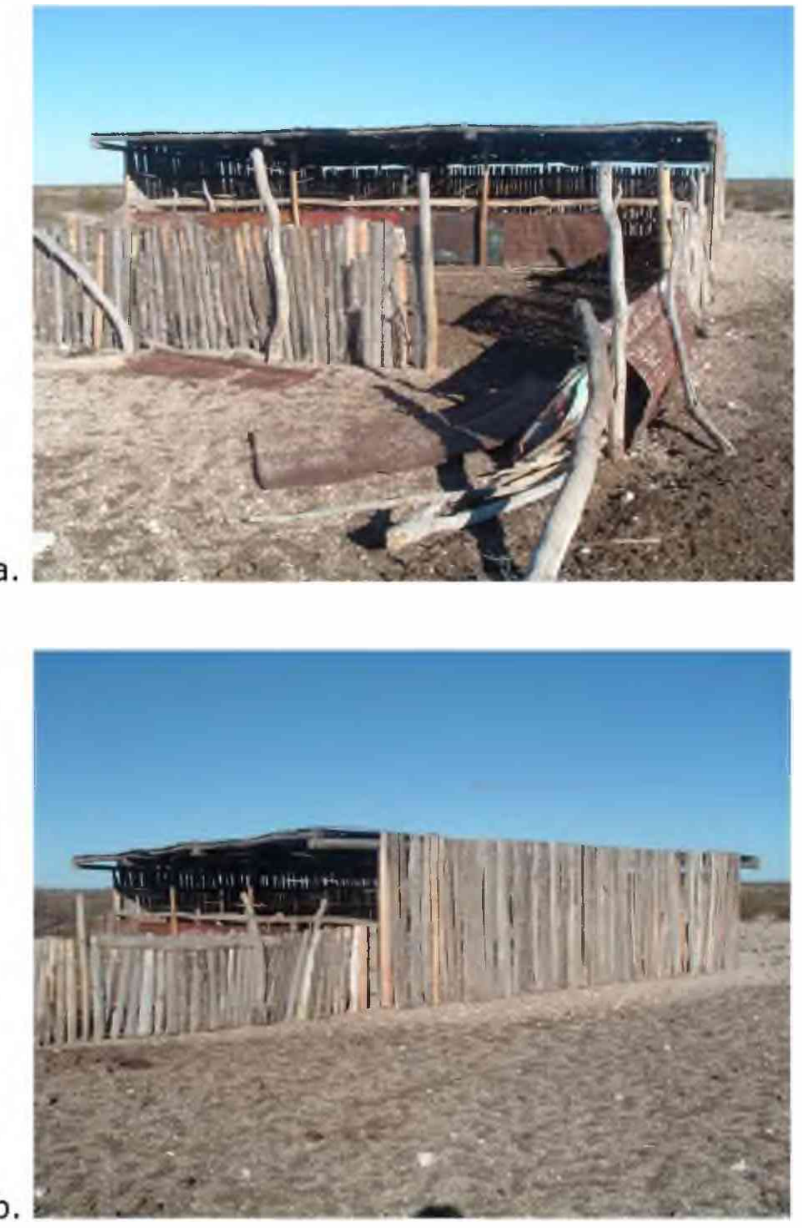

Fig. 4: Corrales modernos para caprinos hechos con postes de Prosopis sp. y paredes revestidas con tablas exteriores de rollizos de álamo o "cantonera" (Populus nigra). a: vista frontal. b: vista lateral. 


\subsection{ALIMENTACIÓN}

\subsubsection{Recolección de plantas silvestres y cultivo de introducidas}

La recolección de recursos vegetales para la alimentación es una costumbre poco desarrollada entre los criollos del oeste pampeano. La oferta de alimentos de origen vegetal es pobre debido a las condiciones de aridez imperante, a la uniformidad de la cubierta vegetal y a la diversidad específica relativamente baja. La limitada disponibilidad de agua superficial y subterránea además condiciona las prácticas de cultivo a experiencias esporádicas en los años lluviosos, época en la que se producen recargas adecuadas de los acuíferos.

La actividad de recolección más importante se realiza con los frutos de piquillín (Condalia microphylla). Las pequeñas drupas se suelen consumir como fruta fresca pero también es frecuente elaborar con ellas arrope. Las técnicas empleadas en la zona son la recolección manual directa o la que consiste en colocar un cuero o lona debajo del árbol y golpear sus ramas con un palo para provocar la caída de sus frutos, técnica muy difundida en otras partes del país para la recolección de diferentes frutos silvestres (Scarpa 1999). Éstos se retiran junto con el cuero y posteriormente se aventan, lanzando varias veces hacia arriba para lograr que el viento arrastre los fragmentos de tallos y hojas. De esta manera el remanente es un producto constituido principalmente por frutos.

Si bien la técnica de extracción directa es más complicada, muchos pobladores prefieren esta modalidad porque sostienen que provoca menos daño a la planta, de modo tal que pueden obtener buenas producciones todos los años. Ellos aseguran que con el otro método la planta disminuye drásticamente su producción de fruta en los años siguientes.

Los tubérculos del chaquil o macachín (Arjona tuberosa) también son recolectados para el consumo, aunque esta actividad era más frecuente en el pasado y actualmente se está abandonando. Los testimonios indican que estas "papillas" son más abundantes en lugares arenosos, principalmente entre las matas de tomillo macho (Junellia seriphioides). Los tubérculos, de sabor dulce, 
se pueden consumir directamente pero también pueden molerse y agregar al agua del mate para endulzarla o bien prepararlos en forma de arrope, aunque en la actualidad no se registró la elaboración de esta receta y solo se recolecta en forma ocasional.

Los árboles y arbustos del género Prosopis proveen frutos que aún se siguen recolectando. Tanto el algarrobo (Prosopis flexuosa f. flexuosa) como el alpataco (Prosopis flexuosa var. depressa) proveen legumbres con mesocarpo dulce que la gente consume directamente más como tentempié que como alimento principal. Su consumo en preparaciones como el patay, la aloja, o el arrope es una práctica que se está perdiendo, pero que los ancianos recuerdan como muy común en su infancia. Para realizar estas preparaciones eran más buscados los frutos del algarrobo que los de alpataco debido a que aquellos son más dulces.

Los frutos del albaricoque (Ximenia americana), chañar (Geoffraea decorticans), penca (Opuntia sulphurea) y solupe frutero (Ephedra ochreata) son consumidos en forma directa, pero están menos representados en la actividad recolectora. Con el último antes también se elaboraba arrope y se conservaba en botellas enterradas en el suelo.

De la papilla indiana (Prosopanche bonacine), planta holoparásita de varias especies, se extraía el fruto de debajo de la tierra y se consumía asado. Sin embargo, no se obtuvieron registros del consumo actual de esta especie.

Además de las mencionadas existen otras especies que si bien no constituyen alimentos en el sentido estricto, intervienen en el uso culinario como especias y saborizantes. Tal es el caso del tomillo (Acantholippia seriphioides), del que algunos utilizan la parte aérea para condimentar la carne asada de piches (Zaedyus pichiy) y otros animales silvestres. El mismo uso le dan a la yerba del lagarto (Acantholippia seriphioides), una variedad de tomillo que presenta una fragancia más delicada que la anterior con la cual se saboriza el mate. Aunque desde el punto de vista sistemático se trata del mismo taxón específico, esta diferenciación por parte de la comunidad la coloca en la categoría de etnoespecie. También son empleadas con este fin el chilchil (Tagetes mendocina) y el té pampa (Thelesperma megapotamica), 
pero es costumbre agregar al mate una amplia diversidad de plantas, que además de modificarle el sabor, actúan como digestivos y contribuyen con la salud. Por tal razón serán incluidas dentro de la categoría de los usos medicinales (Ver Catálogo Botánico de Nombres y Usos).

Los resultados expresan que la totalidad de la población entrevistada conoce plantas comestibles del monte y aunque varían las especies mencionadas, el piquillín (Condalia microphylla) estuvo presente en todas las respuestas. Sin embargo, no ocurre lo mismo con la recolección, ya que un 23 $\%$ de los entrevistados no recolecta plantas comestibles. Dentro de este grupo las razones expresadas que justifican tal comportamiento estuvieron relacionadas con una falta de motivación hacia esta actividad, con el desabrimiento de las frutas del monte, y con la escasez de frutos en algunos lugares. En general, cualquier integrante del grupo familiar se encarga de las tareas de recolección, aunque es muy frecuente que esta función la lleven a cabo los niños, en tanto de la elaboración de productos como el arrope o el patay se encargan mayoritariamente las mujeres adultas del hogar.

Se registraron en total 50 taxones específicos e infraespecíficos de uso alimentario, dentro de las cuales la mayoría son cultivadas (23 especies), seguidas por las adquiridas en los comercios (16 especies) y 10 especies obtenidas por recolección. La Tabla 6 expresa todas las especies registradas para la zona en relación con la alimentación humana.

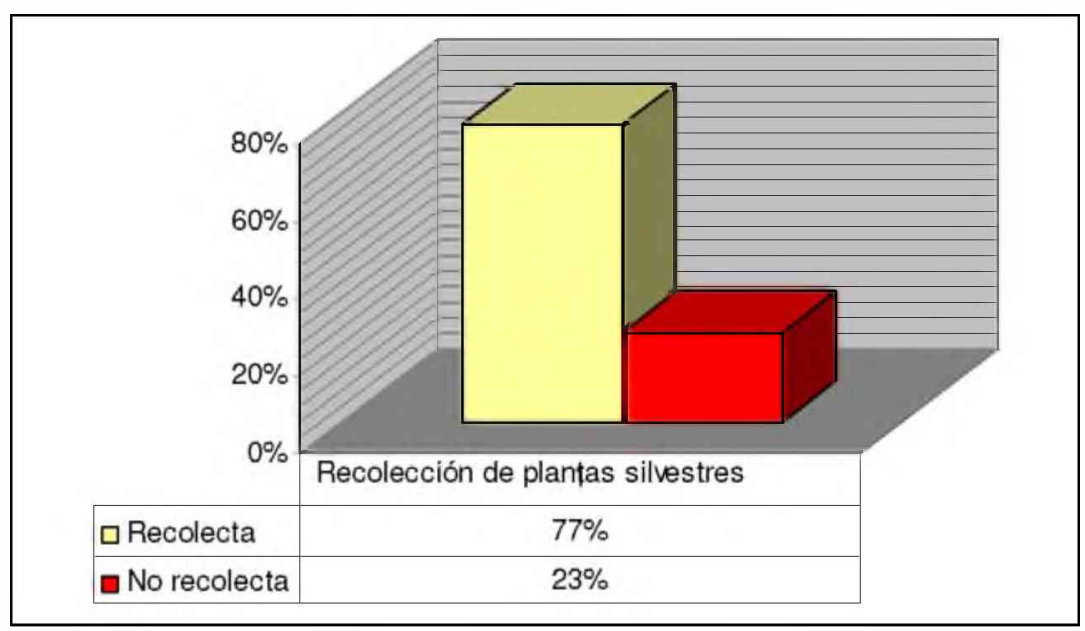

Gráfico 1: Actividad de recolección de plantas silvestres con fines alimentarios. 
Las experiencias de cultivos prediales de hortalizas y árboles frutales son limitadas. Las actividades agrícolas que desarrollaban los colonos del oeste pampeano en sus lugares de origen (generalmente Cuyo y San Luis) persistieron al llegar a esta tierra, pero condicionadas por las dificultades propias del medio circundante. En la región, la horticultura no ha logrado el impulso que se consiguió en la provincia limitrofe de Mendoza. Aún hoy, en las huertas hogareñas no existen adecuados sistemas de irrigación. Actualmente las mejores condiciones para el comercio de las materias primas permiten el acceso a frutas y verduras frescas en la localidad de La Humada, además de las compras que se realizan directamente en los puestos a través de vendedores ambulantes. Asimismo, los centros urbanos más cercanos de la provincia de Mendoza proveen plantas que se cultivan en las huertas y patios de los predios rurales y de los poblados. Entre los frutales, las especies más cultivadas son perales (Pyrus communis), durazneros (Prunus persica), damascos (Prunus armeniaca), vides (Vitis vinifera) y membrilleros (Cydonia oblonga). Los cultivos más frecuentes en las huertas son zapallos (Cucurbita maxima), maíz (Zea mays), lechuga (Lactuca sativa), remolacha (Beta vulgaris ssp. macrocarpa), acelga (Beta vulgaris ssp. vulgaris), sandía (Citrullus lanatus ssp. vulgaris), rabanito (Raphanus sativum), zanahoria (Daucus carota), tomates (Solanum lycopersicum), y caña de castilla (Arundo donax). No obstante, algunos de estos han disminuido pese a la promoción de la horticultura a través de programas nacionales como Prohuerta. En las huertas también se aprovecha el espacio para cultivar especias aromáticas y medicinales, siendo las especies más cultivadas en este sentido el orégano (Origanum vulgare), menta (Mentha spp.), ajo (Allium sativum), perejil (Petroselinum crispum), albahaca (Ocimum basilicum), ajenjo (Artemisia absinthium), aloe (Aloe saponaria) y té de burro (Aloysia polistachya).

Lo anteriormente expresado se manifiesta claramente en el resultado de las entrevistas. Del total de individuos entrevistados, solo una escasa minoría practica el cultivo de huertas. 


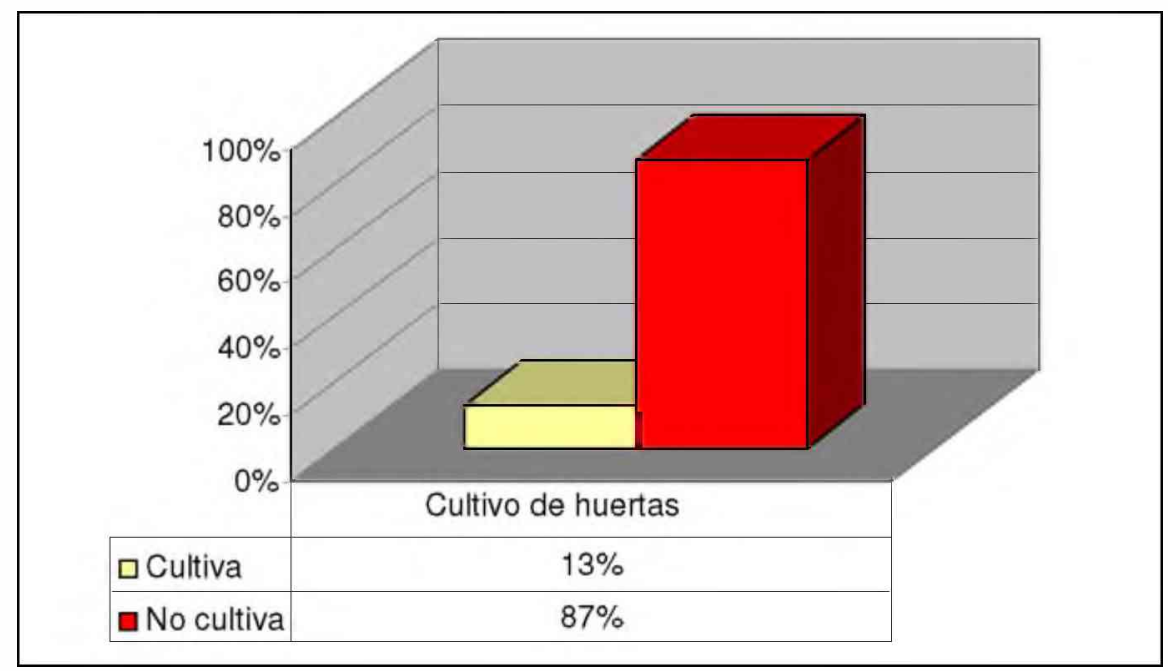

Gráfico 2: Actividad hortícola.

La escasa actividad hortícola, además de relacionarse con la poca disponibilidad de agua y al igual que ocurre en otras áreas circundantes (Böhm de Saurina 1961), probablemente se acentúe por constituir un esfuerzo poco rentable, ya que los precios son accesibles y hay fácil disponibilidad de las hortalizas en el comercio. Al momento de explicar la falta de huertas en sus predios los informantes expresaron en su mayoría que se debe a la escasez de agua para el cultivo, pero también manifestaron otras razones como falta de motivación, mala calidad de la tierra para el cultivo, carencia de un predio aislado de los animales y falta de tiempo para la actividad. Todos ellos adquieren las frutas y verduras en los comercios de La Humada y de los vendedores ambulantes.

\subsubsection{La actividad cinegética}

Pese a la limitada disponibilidad de alimentos vegetales silvestres, el ambiente ofrece refugio y sustento suficiente a una rica fauna que ha servido desde tiempos remotos como fuente principal de alimento de las poblaciones humanas que habitaron la región (Lagiglia 2002).

Los animales que se cazan con más frecuencia son piches (Zaedyus pichiy), avestruces moros (Rhea americana) y overos (Pterocnemia pennata) y vizcachas (Lagostomus maximus). Los primeros se cazan con ayuda de perros 
entrenados al igual que los avestruces $y$ en estos casos se emplean boleadoras. Las vizcachas, en cambio se cazan con trampas y con armas de fuego.

\subsubsection{Las comidas}

La alimentación de los pobladores rurales del oeste pampeano se basa fundamentalmente en la ingesta de carne y lejos está de poder considerarse como una alimentación balanceada.

En los puestos la alimentación tradicional comprende tres comidas al día. La primera transcurre temprano por la mañana al levantarse, a ella le sigue otra al mediodía y finalmente se toma otra por la noche. Sin embargo, este esquema varía en función del nivel socioeconómico y las costumbres propias de cada hogar.

Si bien los platos suelen ser variados, las comidas más frecuentes son las carnes asadas. Éstas proceden del ganado doméstico pero también de los animales silvestres obtenidos durante las cacerías. Generalmente esta preparación se realiza en los fogones del interior de la vivienda, que simultáneamente se emplean para la calefacción del hogar, o en hornos de barro instalados en el exterior. Cuando las jornadas de trabajo en el campo duran varios días, los jinetes acostumbran llevar "ensartadores" entre sus aperos. Éstos se hacen con una planchuela de hierro o con una rama de jarilla (Larrea divaricata) suficientemente resistente a la que se le quita la corteza. De este modo, el ensartador se clava en el suelo y puede sostener el peso de la carne.

Además de la forma asada, la carne interviene en muchos otros platos como son los locros, pucheros, guisos y carbonadas. El locro consiste en una preparación cuyo componente principal es el grano de maíz (Zea mays). En su cocción también intervienen legumbres, trozos de carne y otros ingredientes y la textura final es consistente y con poco líquido. El guiso, por el contrario, es un plato que se elabora con arroz (Oryza sativa), tomate (Solanum lycopersicum), carne y otros componentes que pueden variar de acuerdo a las preferencias. Con una consistencia similar se presenta el estofado, pero en su 
elaboración solo intervienen hortalizas como zapallo (Cucurbita maxima, C. pepo), camote (Ipomoea batatas), papa (Solanum tuberosum), zanahoria (Daucus carota) y cebolla (Allium cepa). A diferencia de estas tres, la carbonada se inicia rehogando cebolla y carne a lo que se añade agua y trozos de hortalizas como zapallo, papa, zanahoria y otras. Tras su cocción se obtiene un plato menos consistente y con más contenido liquido. El puchero posee una receta similar a la carbonada, pero con más caldo y sometido a un hervor más prolongado. Entre sus ingredientes infaltables intervienen el choclo (Zea mays) y trozos de carne. Una variante de estofado local es el denominado printincao, que se prepara con papa y otras hortalizas, porotos (Phaseolus vulgaris), abundante choclo y sin carne.

Dentro los platos típicos cotidianos y comunes en las reuniones sociales se cuentan las empanadas y los pasteles. Ambas comidas se elaboran con carne vacuna o de animales silvestres como los avestruces (Rhea americana), a la que se agregan otros ingredientes variables según los gustos y esta mezcla se envuelve en la masa circular de harina. La diferencia de los nombres radica en la forma de cocción de esta preparación, denominándose empanadas a las cocinadas en horno y pasteles a las fritas en grasa.

La población es muy afecta al uso de condimentos. Los más utilizados son el ajo (Allium sativum) y el ají (Capsicum. annuum), pero también se emplean con frecuencia otros como el pimentón (Capsicum annuum), el laurel (Laurus nobilis) y la pimienta (Piper nigrum). Casi todos ellos se compran en el comercio a excepción del ajo, que en ocasiones es cultivado en las huertas.

Entre las comidas típicas que han perdido vigencia se puede mencionar al mote, un plato que puede elaborarse con granos de trigo o de maiz. Estos se colocan en una olla con agua y cenizas de pichana (Baccharis spartioides) que actúan como acelerador de la cocción. Luego se cocina hasta lograr un ablandamiento de los granos, posteriormente se lava y, si se hace con maíz, se vuelve a cocinar para separar el tegumento del grano. Finalmente se añade leche hasta la cocción total.

El ñaco se elabora tostando granos de maíz o trigo sobre arena colocada en el fondo de una olla hasta que estos estallan. Los granos se retiran, los que 
estallaron pueden consumirse solos o mezclados con leche o agua y los que quedan enteros se muelen $y$ se cocinan también con leche o agua hasta adquirir el aspecto de una pasta suave. Con los granos de maíz partido se cocinan platos tradicionales como la mazamorra, que consiste en su cocción en leche hasta lograr una pasta en la que los granos quedan enteros pero blandos.

La elaboración tradicional del pan se realiza con grasa y el leudante empleado en la masa estaba constituido por una mezcla fermentada de harina con agua. Actualmente este leudante se reemplaza por levadura comercial. Los bollos de masa se cocinan en un hornillo hecho en un pozo de algunos centímetros en el suelo, que puede o no estar revestido con piedras. En él se hace un fogón con ramas de jarilla y cuando está suficientemente caliente, se separan las brasas, se deposita la masa y se cubre con una chapa de hierro hasta la cocción completa. Antes, cuando no se disponía de harina apropiada para hacer pan se usaba la "fariña" que es una suerte de harina de trigo más gruesa. Esta se preparaba mezclándola con cebolla picada y grasa de piche (Zaedyus pichiy) y luego se asaba. La grasa de piche para estos fines se guardaba enterrada en frascos o botellas.

Otro alimento tradicional que en la actualidad está perdiendo vigencia es el patay. Este se prepara moliendo y tamizando las legumbres de algarrobo (Prosopis flexuosa f. flexuosa) o alpataco (Prosopis flexuosa var. depressa). El proceso se realizaba en morteros de troncos ahuecados o con piedras redondeadas seleccionadas en la zona. La fracción más fina se coloca en recipientes de lata, se prensa y se coloca entre las brasas candentes de una hoguera. El producto que se obtiene es una suerte de bizcocho de sabor dulce agradable y particular. Con la fracción gruesa que queda remanente luego del tamizado se puede preparar aloja y arrope. La primera consiste simplemente en disolver el producto en agua fresca y se puede beber directamente. En este punto merece destacarse la diferencia que existe con la aloja preparada en otras partes de Argentina, donde esta bebida constituye un producto fermentado de las algarrobas molidas y disueltas en agua. El arrope se elabora de manera análoga a la que se describirá al tratar el preparado con el fruto del piquillín. 
A diferencia del anterior, está muy difundida la elaboración de tortas fritas y buñuelos o torrejas. Los buñuelos se pueden hacer dulces con harina, azúcar y huevo, pero también está la variante salada que además lleva pimiento y cebolla. La cocción se hace frita en grasa y en la variante dulce se condimentan con especias tales como clavo de olor, canela, esencia de vainilla, anís en grano y como sustituto de este último se emplean frutos de hinojo (Foeniculum vulgare).

\subsubsection{Las bebidas}

La bebida popular con mayor arraigo es el mate. Esta se consume a toda hora del día y suele servirse matizada con el agregado de diferentes plantas que además de modificar su sabor, actúan saludablemente sobre el organismo. Los niños también beben mate, pero con más frecuencia consumen mate cocido, infusión más diluida, también conocida como "yerbeado". Sin embargo, la bebida más nutritiva que preferentemente ingieren los niños, siempre que esté disponible, es la leche vacuna.

El vino era en el pasado -y sigue siendo- una bebida de consumo frecuente, en especial durante las fiestas y reuniones de vecinos. La cercanía relativa con el centro productor mendocino facilitaba la comercialización de este producto en barricas bordelesas que traían a los puestos los vendedores ambulantes. En las fiestas se preparaban sangrías y "cócteles" a partir del vino. La primera consiste en diluir vino con agua y añadirle azúcar a gusto. El "cóctel", bebida que en las fiestas consumían con preferencia las mujeres, se elaboraba mezclando dos yemas de huevo en un litro de vino y agregando azúcar. Se agitaba en una botella y cuando se homogeneizaba se le añadía más vino y azúcar hasta el gusto deseado. La "curillena", por otra parte, era una bebida espesa que se lograba mezclando ñaco con vino y azúcar y que adopta este nombre porque se trata de una bebida que sacia el apetito pero que a la vez embriaga.

Entre los licores de elaboración casera se registró el preparado en base a una infusión de té pampa (Thelesperma megapotamica) que se mezcla con alcohol y azúcar quemada, y la "chupilca", que en el área se logra mezclando coñac con huevo. 


\subsubsection{La conservación de los alimentos}

En la actualidad, los refrigeradores son artefactos corrientes en casi todos los hogares rurales. Las primeras heladeras funcionaban con kerosén y posteriormente fueron adaptadas paulatinamente para funcionar con gas. Hasta hace un par de décadas era un artículo considerado de lujo y en la mayoría de las viviendas era necesario emplear otras técnicas de conservación de los alimentos para su consumo a corto plazo.

Una de las estrategias de conservación empleadas es la elaboración de arropes y dulces. Tanto en los arropes como en los dulces o mermeladas, la elaboración se basa en el principio de evaporación del agua. En el caso de los arropes se concentran los azúcares propios de los ingredientes vegetales y en los dulces y mermeladas, además se agrega azúcar.

La preparación del arrope de piquillín (Condalia microphylla) consiste en hervir los frutos hasta su cocción. Luego se tamiza presionando intensamente a través de un trapo, separando así las semillas y la cáscara del fruto. El filtrado se continúa cocinando hasta el punto en el cual la masa forma un hilo delgado y continuo desde una cuchara suspendida a varios centímetros sobre el preparado. La preparación del arrope de piquillín no incluye el agregado de azúcar, al igual que lo registrado en las recetas tradicionales del norte de Argentina (Scarpa 1999), pero en muchos hogares del oeste pampeano se prefiere lograr un producto más dulce añadiendo este insumo. Algunas de estas preparaciones se conservan en botellas de un año para el otro colocándose en surcos practicados en el suelo y cubriéndolas con tierra.

Aunque se registró la elaboración de arrope a partir de otros recursos vegetales silvestres en el pasado, en la actualidad casi todos estos platos se encuentran en vías de desaparición, persistiendo solo el de piquillín (Condalia microphylla). Entre los recursos que han perdido vigencia de uso se destacan los frutos de solupe frutero (Ephedra ochreata), chañar (Geoffroea decorticans) y los tubérculos de chaquil (Arjona tuberosa). 


\subsection{Salud y medicina}

\subsubsection{Enfermedades. Descripción y etiología}

Los pobladores del oeste pampeano entienden la organización corporal y la identificación de sus partes en forma similar a como las interpreta el lego en otras partes del mundo. De esta manera las referencias hacen alusión a la espalda, las paletas, el pecho, el corazón, las costillas, el hígado, el estómago, y los intestinos o "achuras".

En cuanto al significado de "enfermedad" los testimonios la definen como la sensación de un malestar permanente o un dolor muy intenso si este no disminuye con el transcurso de los días. Esto se pone en evidencia en las descripciones, donde se manifiestan consonancias entre los conceptos de enfermedad y síntoma. La opinión general sobre las dolencias es que antes la gente aguantaba más el dolor, porque no existían las posibilidades de la medicina actual. También se registraron observaciones que señalan una correlación entre las épocas de sequía y el aumento de las enfermedades. La explicación a este fenómeno está dada porque cuando llueve, el agua caída que se evapora purifica el aire.

La situación sanitaria de la población en el oeste pampeano experimentó un cambio a lo largo del tiempo desde el establecimiento de los primeros colonos hasta nuestros días. Los pobladores más ancianos informaron que entre las enfermedades graves y comunes que recuerdan ya sea por vivencias propias o a través de narraciones de sus mayores eran el sobreparto, la difteria, la viruela y el tétanos neonatal, denominada localmente "mal de los siete días". En la actualidad no se registran casos de esas enfermedades debido a los alcances del sistema médico oficial por intermedio de las postas sanitarias y las campañas sanitarias que se promueven a través de los medios masivos de comunicación. No obstante, los entrevistados informaron que los desequilibrios de la salud más frecuentes en la actualidad son el cáncer, los accidentes cardiovasculares causados por hipertensión arterial e infartos, las gastritis y los problemas asociados al aumento del colesterol y el ácido úrico. 
Distintos autores que se refieren a la medicina tradicional han intentado sistematizar los conceptos e ideas que tienen los pueblos sobre el origen de las dolencias, dando como resultado diferentes sistemas clasificatorios (Grebe \& al. 1971, Jiménez de Pupareli 1984, García y Jiménez 1986, Idoyaga Molina 2001). Sin embargo, en el afán de encuadrar a cada una de ellas dentro de estos sistemas, no es raro que algunas dolencias escapen del marco propuesto, precisamente por incluir connotaciones compartidas por más de una clase. Todas estas clasificaciones son artificiales y simplemente sirven como materia operativa para delimitar el material recopilado. En este trabajo se adopta parcialmente el sistema propuesto por García y Jiménez (1986), en lo que respecta a las enfermedades naturales y las postizas o impuestas.

\section{a) Enfermedades naturales}

Dentro del criterio adoptado las enfermedades naturales son aquellas en las cuales no interviene la acción o pensamiento de otras personas como agente causal de la enfermedad. Algunos de estos nombres son muy frecuentes en el ámbito rural de toda la Argentina y se han documentado oportunamente (Sosa Verón y Vivante 1951, Newbery 1978).

Seguidamente se describen brevemente las dolencias naturales más frecuentes y su descripción según los lugareños:

Empacho: Conjunto diverso de síntomas causados por el consumo intensivo de alimentos o por cualquier alimento de difícil digestión.

Pasmo: Esta denominación hace referencia a las inflamaciones internas o externas de cualquier tejido u órgano, que a veces pueden evidenciarse por un aumento de volumen del área afectada. Se producen por un desequilibrio térmico ante la exposición brusca del cuerpo al frío o al calor. Sobre su etiología se explica: "Cuando uno llega con la piel mojada y se acerca al fuego se da el pasmo. A mí me daba el pasmo cuando salía por las chivas en un temporal y después entraba al calor de la casa". (M. E. Moyano com. pers.).

Aire: El nombre de esta dolencia hace referencia a los dolores musculares, provocados por la exposición del cuerpo a los cambios bruscos de temperatura del ambiente. En el área que compete a este trabajo no hay referencias con 
esta denominación a otras dolencias o agentes de carácter sobrenatural tal como se manifiesta en otras regiones del país con el nombre de mal aire (Arenas \& Galafassi 1994, Bianchetti 1995, Estrella 1996).

Orines atajados: Denominación local que hace referencia a los estados de anuria.

Puntadas: Se trata de cualquier dolor agudo, punzante y bien localizable en el interior del abdomen o el tórax.

Machucones: Nombre que recibe cualquier hematoma producido por una contusión o una compresión intensa de los tejidos musculares

Carnes abiertas: Denominación popular que reciben los desgarros musculares.

En las disfunciones del aparato digestivo, los órganos a los cuales se hizo mayor referencia fueron el estómago y el hígado. Cuando se trata del estómago los informantes hablan de empacho, diarreas, asientos de comida mientras que si se trata de una molestia hepática la expresión más frecuente es dolor de o mal del hígado. Es muy frecuente que se haga referencia a ellas como dolencias diferentes, aún cuando se trate de síntomas distintos dentro del mismo cuadro clínico. Es así como los malestares producidos luego de la ingestión de una comida copiosa que produce una alteración en el funcionamiento integral de todo el sistema reciben estos nombres particulares en función del síntoma y de la región donde se percibe el dolor.

\section{b) Enfermedades impuestas o postizas}

Estas enfermedades no son producidas naturalmente sino que son provocadas por la acción de otras personas. Dentro de esa categoría se incluirán aquellas cuyo agente causal actúa intencionalmente o en forma involuntaria. Esta última condición se adopta para incluir aquí a la ojeadura.

Ojeadura: Dolencia que proviene de la acción de una persona con mirada fuerte sobre otra. La mirada fuerte puede estar relacionada con sentimientos de rencor o envidia, pero en la mayoría de los casos la ojeadura no requiere intencionalidad y simplemente se produciría por un desequilibrio entre la 
energía de quien emite la mirada sobre quien la recibe, que generalmente son las personas débiles y los niños. Por lo común se considera que la mirada fuerte está favorecida por el uso de anteojos de aumento. En los registros de campo hubo frecuentes informaciones que estaban referidas al poder de la mirada, sin que particularmente estas acciones significaran una verdadera ojeadura. Sin embargo, el mecanismo a través del cual se ejerce la acción fue el mismo. Para el caso se puede dar como ejemplo las precauciones de mantenerse alejado de las miradas de otras personas al momento de realizar ciertas recetas culinarias como los almíbares o durante el proceso de tinción de lanas.

Daño o Mal impuesto: Afección representada por cualquier mal infligido de una persona a otra y que tiene su origen, en sentimientos de envidia o resentimientos personales.

Histericia: Esta dolencia ocurre en los niños cuando son abandonados temporal o definitivamente por sus padres. En estas circunstancias el niño puede presentar irritabilidad, decaimiento, y llanto frecuente. Si bien no se puede considerar en sentido estricto como una dolencia impuesta, aquí se la considera como tal ya que es efecto de la acción de un adulto, en este caso el abandono. Se trata del mismo trastorno que en el NOA se conoce como tirisia (Idoyaga Molina 2001)

\subsubsection{Terapéutica}

Se observa una pérdida paulatina del empleo de prácticas de la medicina tradicional en la atención de las dolencias debido en parte a la influencia que ejerce el discurso médico oficial a través de la posta sanitaria. No obstante existe todavía un importante número de hogares donde continúan vigentes tales prácticas, como se observa en el siguiente gráfico. 


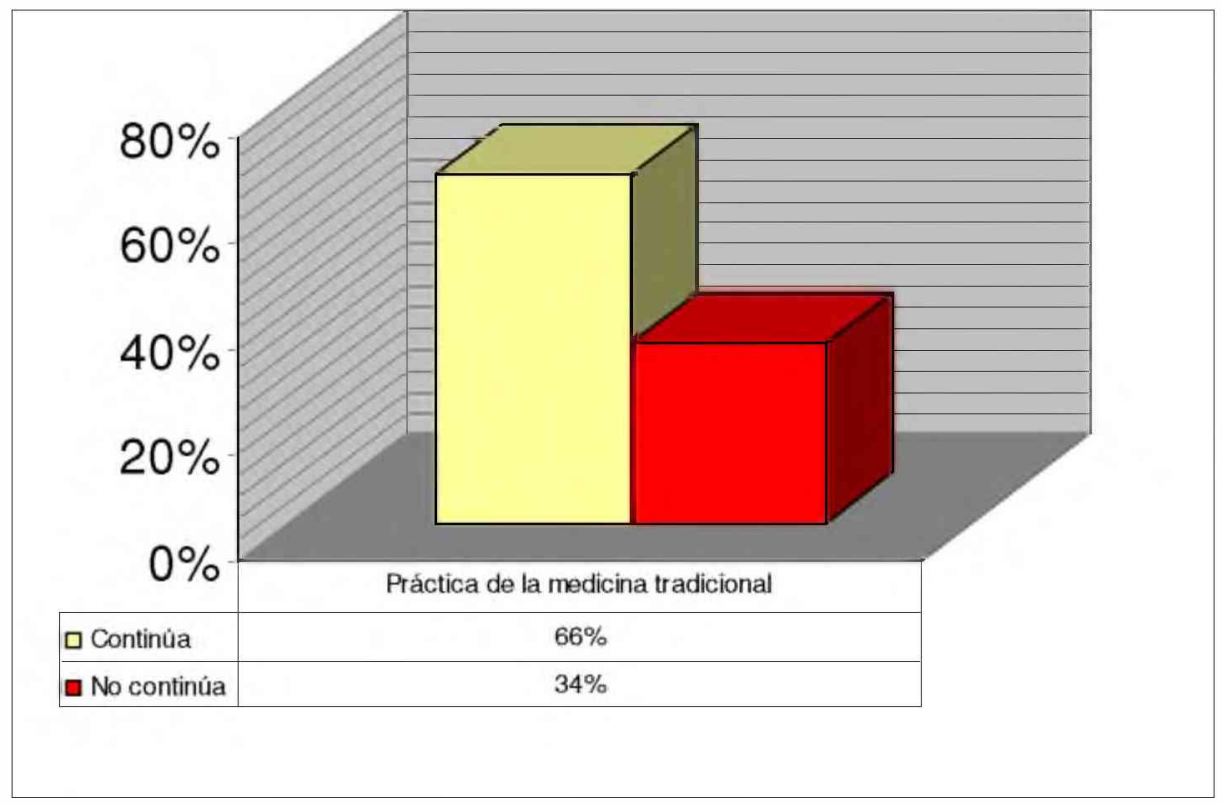

Gráfico 3: Persistencia de la medicina tradicional.

Los valores antes observados se remiten a todos los hogares visitados. Sin embargo, esta situación varía si se analiza en forma discriminada entre los hogares de la zona urbana y la zona rural.

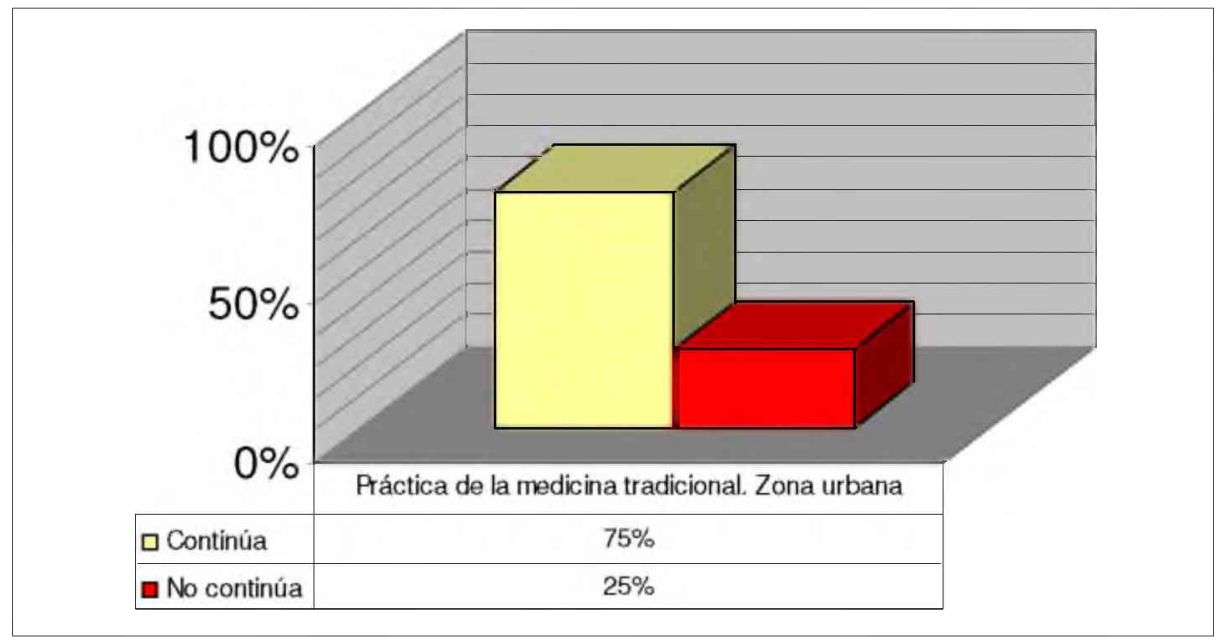

Gráfico 4: Persistencia de la medicina tradicional en la zona urbana. 


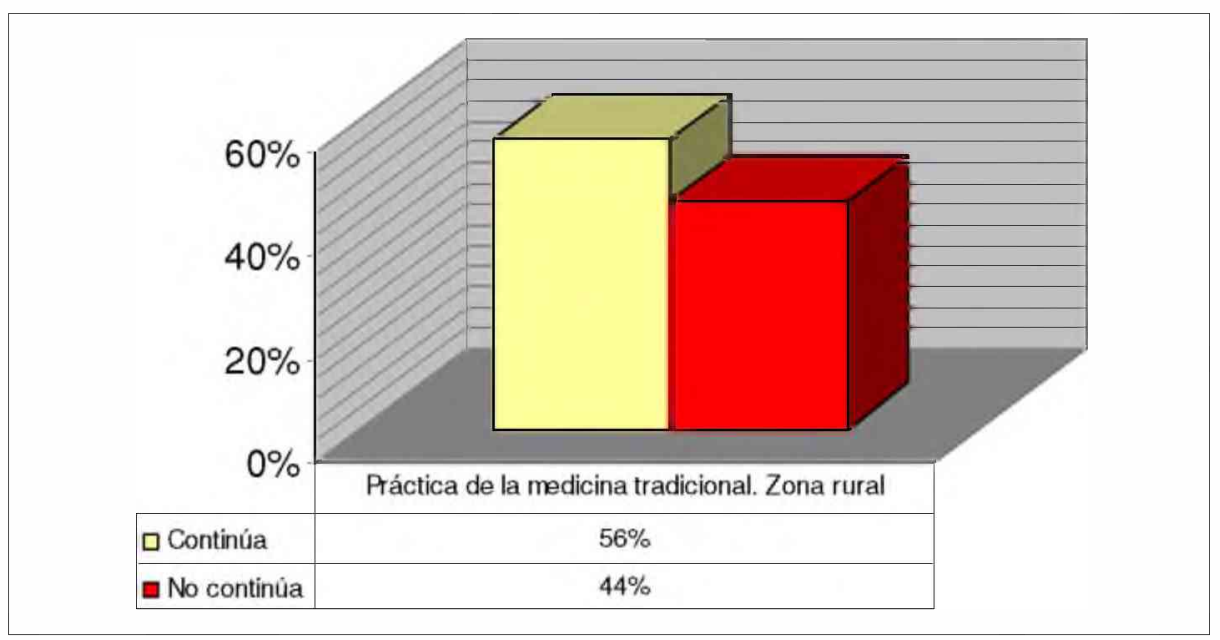

Gráfico 5: Persistencia de la medicina tradicional en la zona rural.

A continuación se describen los tratamientos más frecuentes que se usan en la atención de las enfermedades.

Las "aguas" constituyen uno de los tratamientos de la medicina tradicional más comunes que se aplican tanto interna como externamente. Estos remedios se elaboran por maceración o decocción de plantas. Su administración se realiza a temperatura ambiente y pueden ser más o menos concentrados según la planta utilizada y el propósito buscado. Si el "agua" se administra ad libitum y en cualquier momento del día, este preparado recibe el nombre de "aguapasto". Las partes empleadas varían en función de la dolencia a atender, pero en general se utilizan las partes aéreas (ramas y hojas) o raíces. Cuando se emplean partes leñosas como tallos y raíces, la técnica empleada para elaborar estas preparaciones consiste en rallar la "entrecáscara", término local que hace referencia a la región vascular luego de descortezar la planta. La recolección se realiza preferentemente en primavera y verano, época de mayor actividad metabólica en las plantas, pero en casos de necesidad se efectúa en cualquier estación.

Las infusiones reciben la denominación de "té" y son bebidas que se preparan de manera similar a lo que en otras partes del país se conoce como "quemadillos" (García y Jimenez 1986, Scarpa 2002). Éstas consisten en colocar una brasa incandescente en un recipiente donde se agrega una pequeña cantidad de azúcar hasta que comience a formarse un caramelo. Se 
añade luego la porción de la planta elegida y agua hirviendo, dejándola luego reposar un rato. Este tipo de preparados son administrados en enfermedades como el sarampión, cuyo tratamiento consiste en proporcionar calor al cuerpo del paciente a través de la ingesta de aspirina con una infusión de molle y provocar posteriormente una sudoración profusa. En las infusiones se suele usar una sola especie o esta puede mezclarse con otras de propiedades similares. Además del modo de administración descrito, muchas de ellas se suelen agregar al mate cotidiano, configurando así no solo un propósito curativo sino también de tipo preventivo.

Entre los tratamientos externos de uso popular también se destacan las "friegas", "paños" y las "cataplasmas". En las friegas, el principio activo se encuentra disuelto en otros líquidos o en una grasa animal que ayuda a transportar el preparado a través de la piel del paciente. Este principio activo puede obtenerse a partir de una planta pero también puede ser de origen animal o mineral. Los "paños" en cambio, son fomentos por lo general de base acuosa caliente que llevan el principio activo disuelto. Se emplean para desinflamar zonas localizadas del cuerpo y son efectivos en la atención de contusiones. Para ello se aplica calor a la región afectada, por medio de trapos embebidos en salmuera o en una infusión vegetal. De acuerdo a las necesidades los paños pueden aplicarse a temperatura ambiente. Como ejemplo se menciona el uso difundido de paños de alcohol y vinagre en las inflamaciones intestinales. En el caso de las cataplasmas se trata de aplicaciones directas de las plantas maceradas o picadas sobre la región del cuerpo afectada.

Las terapias que basan su efectividad en la acción mecánica mediante masajes o por transferencia de calor se utilizan para aliviar múltiples dolencias. Para el "aire", por ejemplo, se aplican fomentos con el fin de generar calor en la región afectada. En el pasado era común la aplicación de parches calientes confeccionados con las bolsas de yerba mate ya que éstas se fabricaban con cartón doble y estaban revestidas interiormente de una capa alquitranada. En las parotiditis, denominadas usualmente "paperas" o "agallones", el tratamiento más frecuente era la aplicación de masajes en la región afectada de los ganglios con pomada de belladona, pero también se 
practican masajes en la región de la mano y el antebrazo donde se presentan inflamaciones ganglionares para disminuir este proceso. Esta práctica es reputada como muy efectiva para acelerar la curación de la enfermedad.

En cuanto a los métodos basados en la transferencia de temperatura de un cuerpo a otro, se pueden mencionar varios ejemplos de aplicaciones. En los resfríos, la terapia tradicional consiste en beber por la noche un vaso de vino caliente del que se ha eliminado el alcohol por combustión, así como en el sarampión se recomienda la ingesta de té caliente. En ambas enfermedades, que son de origen frío, el objetivo buscado es generar calor en el cuerpo del paciente, efecto que se manifiesta por su sudoración profusa. Según los datos reunidos, es menester que el enfermo se mantenga abrigado y su cuerpo no se enfríe ya que de lo contrario, la enfermedad "vuelve adentro".

El aporte de calor al cuerpo también se evidencia en el tratamiento de las contusiones a través de paños de agua caliente con sal, como se indicó anteriormente. La región debe mantenerse libre de todo movimiento por medio de un fuerte vendaje. En el pasado un buen vendaje para estas dolencias se lograba a partir de las botas de vino en desuso. Éstas se cortaban y con sus lonjas se envolvía la parte golpeada con la superficie interior de la bota en contacto con la piel. El mismo principio, pero aplicado en forma inversa, se manifiesta en el método de alivio de los dolores de cabeza por insolación. Este consiste en colocar la hoja de un cuchillo en la nuca del paciente y apretar firmemente la frente de su cabeza. La hoja de metal estaría facilitando la transferencia del calor desde el cuerpo del paciente.

Dentro de los tratamientos mecánicos son muy frecuentes las terapias extractivas ya sea de cuerpos extraños como de humores nocivos con el fin de lograr alivio o curación de las dolencias. En este contexto se incluyen todos los procesos de extracción de espinas, verrugas, ojos de gallo, y otros elementos, así como los drenajes de procesos infecciosos.

\subsubsection{Las curaciones de dolencias en contextos de la religiosidad}

La religión, y en menor frecuencia la magia, también están presentes en torno a la curación de algunas enfermedades naturales y en la mayoría de las 
impuestas. Se debe aclarar que el término "magia" es un concepto etic (Arenas 2000), considerando aquí el criterio de García (1984) según el cual la magia es aquella acción "que se ejecuta con el fin de manipular las fuerzas de la naturaleza o las espirituales (almas, espíritus, dioses) y lograr de ellas la satisfacción de los deseos de quien efectúa la acción o de quien la solicita. En este sentido separamos estas acciones de las ligadas al culto religioso, que no se proponen forzar a la divinidad para lograr algo". En ninguna oportunidad los lugareños se refirieron a las curaciones usando la denominación "curas mágicas" sino bajo una más general de "curas" que se contextualizan principalmente en un acto religioso.

En la región, este tipo de curaciones son llevadas a cabo casi siempre por especialistas y curanderos, de la misma manera que fue documentado en otras regiones (García 1984, Jiménez de Pupareli 1984, Martínez \& al. 2004, Idoyaga Molina \& Sacristán Romero 2008). Con frecuencia la eficacia de las curas depende de un ritual que se define por el tipo y número determinado de oraciones, de respetar los pasos y elementos requeridos para el tratamiento y en todos los casos de la fe religiosa tanto del paciente como del sanador. En este caso la eficacia se sustenta en el correcto cumplimiento del ceremonial, lo cual hace que sólo ciertas personas tengan el conocimiento o el don de curar con estos métodos. A continuación se describen algunos ejemplos donde símbolos, fórmulas y rituales forman parte de la terapia, acompañando la administración de medicamentos como también la acción ritual por sí misma:

El número tres: Representa la Trinidad cristiana. Son frecuentes las referencias que indican tomar un medicamento tres mañanas seguidas o curaciones por la palabra que deben realizarse tres veces consecutivas.

El símbolo de la Cruz: Junto con el número tres constituye un elemento común en la medicina tradicional del oeste pampeano al igual que en otras partes de Hispanoamérica. Uno de los métodos de curación de las paperas consiste en calentar un mate en las cenizas del rescoldo después de la primera cebada y masajear con él la región inflamada de las parótidas haciendo pasadas en forma de cruz. 
Cura de palabra: En este método la curación se realiza mediante la invocación divina a través de rezos. Las oraciones intervienen en la curación de enfermedades de etiología múltiple como las paperas, dolores de muelas, empachos, esguinces, ojeaduras o males impuestos. A veces la oración forma parte de la terapia conjuntamente con otros rituales. Por ejemplo, en uno de los métodos de cura de las paperas, el enfermo debe estar en ayunas y colocar la mano correspondiente con el lado de las glándulas más inflamadas sobre las cenizas apagadas del fogón del hogar mientras el curandero o el lego pronuncia las oraciones necesarias. En la ojeadura, el diagnóstico se realiza arrojando gotas de aceite en un recipiente con agua mientras se efectúan rezos. En estos casos, el tamaño que adoptan las gotas al fusionarse entre sí está en relación directa con la magnitud de la afección. Las oraciones intervienen también en el tratamiento de esta dolencia que, cuando se trata de niños, se acompaña con suaves golpes en la espalda o en el pecho con una rama de palqui (Cestrum parqui). La cura de palabra no siempre requiere de la presencia del paciente junto al sanador. A veces, este es visitado por un allegado al paciente quien le comunica el nombre y la edad del afectado. Este método fue mencionado para la cura de torceduras y esguinces.

Curas por el rastro: Se trata de metodologías variadas con el fin de curar diferentes dolencias cuyo rasgo común se basa en la huella que debe dejar el paciente sobre una superficie. En el tratamiento de las paperas este paso consiste en hacer caminar al paciente sobre cenizas, realizando luego la señal de la cruz sobre la huella marcada. En los casos de niños herniados al nacer, la cura se realiza apoyando su pie derecho sobre el tronco de un árbol, que puede ser de cualquier especie. Se traza el contorno del pie sobre la corteza y ésta se extrae con la ayuda de un cuchillo. La cura del niño ocurre cuando la corteza se cierra debido al crecimiento de la planta. Este ritual debe realizarse al salir el sol y al igual que el anterior se acompaña con el rezo de oraciones, que recita mentalmente el lego.

Cura con la cinta: Método muy frecuente para la curación de los empachos. Aquí el especialista mide la distancia que lo separa del paciente por medio de una cinta, generalmente de color rojo, procedimiento que realiza tres veces en forma consecutiva rezando una oración. 
Medición de los nervios: Se utiliza para diagnosticar y curar contracturas y desgarros musculares. En el diagnóstico, el lego mide la longitud que existe entre los distintos músculos de la región afectada. Esto se acompaña de un ritual en el que se arrojan siete granos de trigo en un vaso con agua. La tendencia mayor o menor de juntarse los granos en el líquido indica la gravedad del "anudamiento de los nervios". Este tratamiento se realiza durante tres días consecutivos y la cura estaría mediada por las oraciones que pronuncia el lego durante el ritual.

Histericia: Los niños afectados con esta dolencia se llevan a un estanque o arroyo y se los salpica con agua utilizando para ello una rama de cualquier especie vegetal. Durante el procedimiento, que debe realizarse durante tres mañanas consecutivas, el especialista debe realizar las oraciones apropiadas.

Sobre la persistencia de estos tratamientos, los resultados de las entrevistas demuestran que estos saberes y prácticas antes gozaban de mayor popularidad y en la actualidad han disminuido. Del total de los entrevistados sólo el $36 \%$ dijo conocer enfermedades que reciban tratamientos de tipo mágico o religioso. Dentro de esta minoría, el $71 \%$ acude a especialistas o al curandero local.

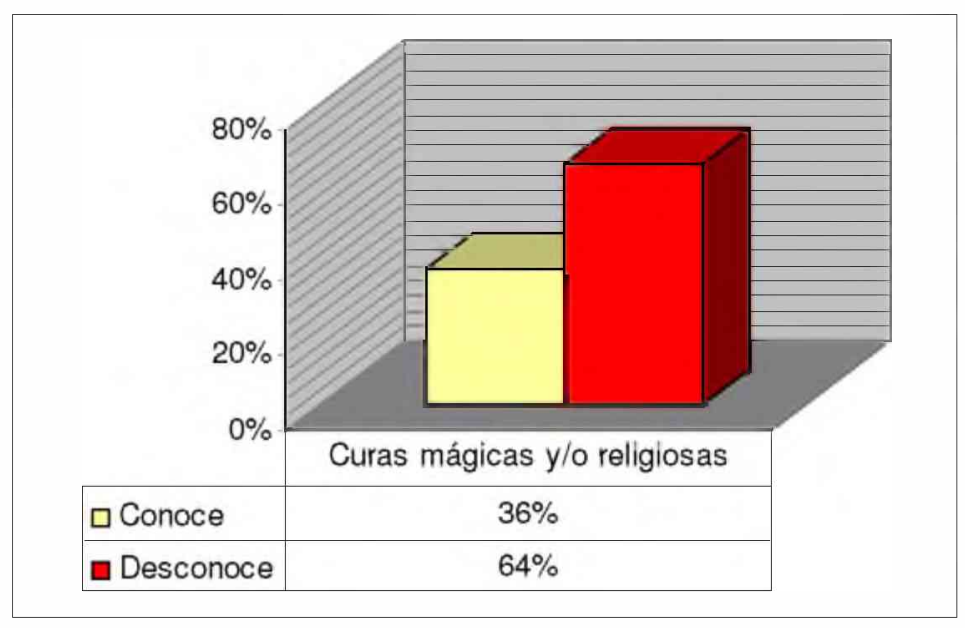

Gráfico 6: Conocimiento de los métodos de curas mágicas y religiosas. 


\subsubsection{Los remedios de origen animal}

Aunque en la farmacopea se registró una mayor representación de los vegetales, los animales y los elementos de origen mineral juegan un rol que merecen un espacio aparte en la terapéutica local. Dentro de este conjunto se ha documentado el empleo de animales como sapos y tortugas, partes corporales de los mismos, productos metabólicos y otros como por ejemplo túmulos de hormigueros o nidos de aves. Sin embargo la amplitud del tema excede los objetivos de este trabajo por lo que solo se enumerarán los usos de las grasas ya que muchas de ellas se emplean en fricciones como vehículo de sustancias de origen vegetal.

Grasas: Para dar alivio a las quemaduras se aplica grasa de potro (Equus caballus), de jote (Cathartes aura), de choique (Pterocnemia pennata), o en las paspaduras en general la grasa vacuna. Para las heridas se suele usar grasa de gato de pajonal (Lynchailurus pajeros) o también grasa de potro haciendo fricciones suaves. La "infundia" o grasa de gallina (Gallus gallus) derretida se aplica en friegas sobre el pecho para madurar procesos de bronquitis. Para curar los sabañones, en cambio, se indicaron los masajes con grasa de zorrino (Conepatus chinga) y sal. La grasa de piche (Zaedyus pichiy) se emplea junto con tabaco (Nicotiana tabacum) en el tratamiento de picaduras de insectos o de víboras masajeando el área afectada. En la atención de diversos dolores corporales se realizan masajes con grasa de león (Puma concolor) y atamisque (Capparis atamisquea) o de gallina (Gallus gallus) con tabaco (Nicotiana tabacum) y mostaza (Brassica nigra). La grasa de gallina también se emplea en fricciones mezclada con perlilla (Thymophylla pentachaeta) y manzanilla (Matricaria recutita) para dar calor al cuerpo. Para hacer efectiva la expulsión de las espinas se recomendó la aplicación de la "segunda cáscara" (catáfilas) de la cebolla (Allium cepa) calentada en grasa de caballo en forma de cataplasma sobre la parte afectada. La grasa de puma (Puma concolor) también se utiliza para este fin.

\subsubsection{Las plantas en la medicina}

El uso de los recursos naturales comprende una serie de condiciones en función de las creencias y de las prácticas empíricas del lugar. En el caso de 
las plantas la costumbre es hacer uso de las mismas cuando están verdes independientemente de la época del año, a excepción de las caducifolias, y en general se atribuye mayor efecto curativo si la planta está recién cortada que si está seca. "Si la planta se usa seca no hace el mismo efecto porque se les seca el corazón" (D. Pereyra com. pers.). No obstante también se hace acopio de hierbas en los hogares para disponer de ellas en otros momentos del año, especialmente cuando la fenofase de las plantas no permite su recolección, situación que ocurre con las especies anuales y las caducifolias.

Las plantas cultivadas, por otra parte, también están sujetas a ciertas creencias en lo que respecta a las pautas de recolección. Para que ellas no pierdan el efecto curativo deben ser cosechadas para su uso por quien las cultiva y en el caso de que la persona sea de sexo femenino no debe realizarlo durante el período menstrual. En caso contrario, además de no ejercer el efecto buscado la planta se seca. Esta creencia también fue documentada en el norte del país por Arenas y Galafassi (1994).

La ruda (Ruta chalepensis) es probablemente la más relevante de las plantas cultivadas en función de las connotaciones mágico-religiosas y de la frecuencia con la que está presente en los jardines domésticos. En casi todas las ocasiones el motivo de su cultivo radica en la creencia de sus cualidades para ahuyentar los males. Otra de las propiedades asignadas es la de contrarrestar los efectos de la envidia de otras persona. Con este fin, si la afectada es una mujer debe emplear ruda macho, y si la víctima es varón debe usar ruda hembra. Se trata en ambos casos de formas hortícolas de Ruta chalepensis. Por otra parte, el alcanfor (Artemisia abrotanum) suele cultivarse en el patio de las casas para evitar el ingreso de víboras y arañas.

Se registró un total de 85 especies de uso medicinal dentro de las cuales 52 son silvestres, 15 cultivadas y 18 adquiridas comercialmente o traídas por vecinos y familiares de otras áreas. Debido a la amplitud de los datos y a fin de facilitar el ordenamiento y la lectura de la información referida a este punto, las plantas empleadas en la medicina tradicional se consignan en la Tabla 7 y sus usos terapéuticos en el Catálogo Botánico de Nombres y Usos que figura como Anexo. 


\subsubsection{La mujer, el embarazo y el parto}

Los aspectos relacionados con la salud de la mujer constituyen un conjunto de saberes que aunque en general son compartidos por personas de ambos sexos, la mayor diversidad de recursos terapéuticos y las descripciones más claras de las técnicas empleadas en los partos son de dominio de las mujeres, tal como lo expresan los siguientes gráficos.
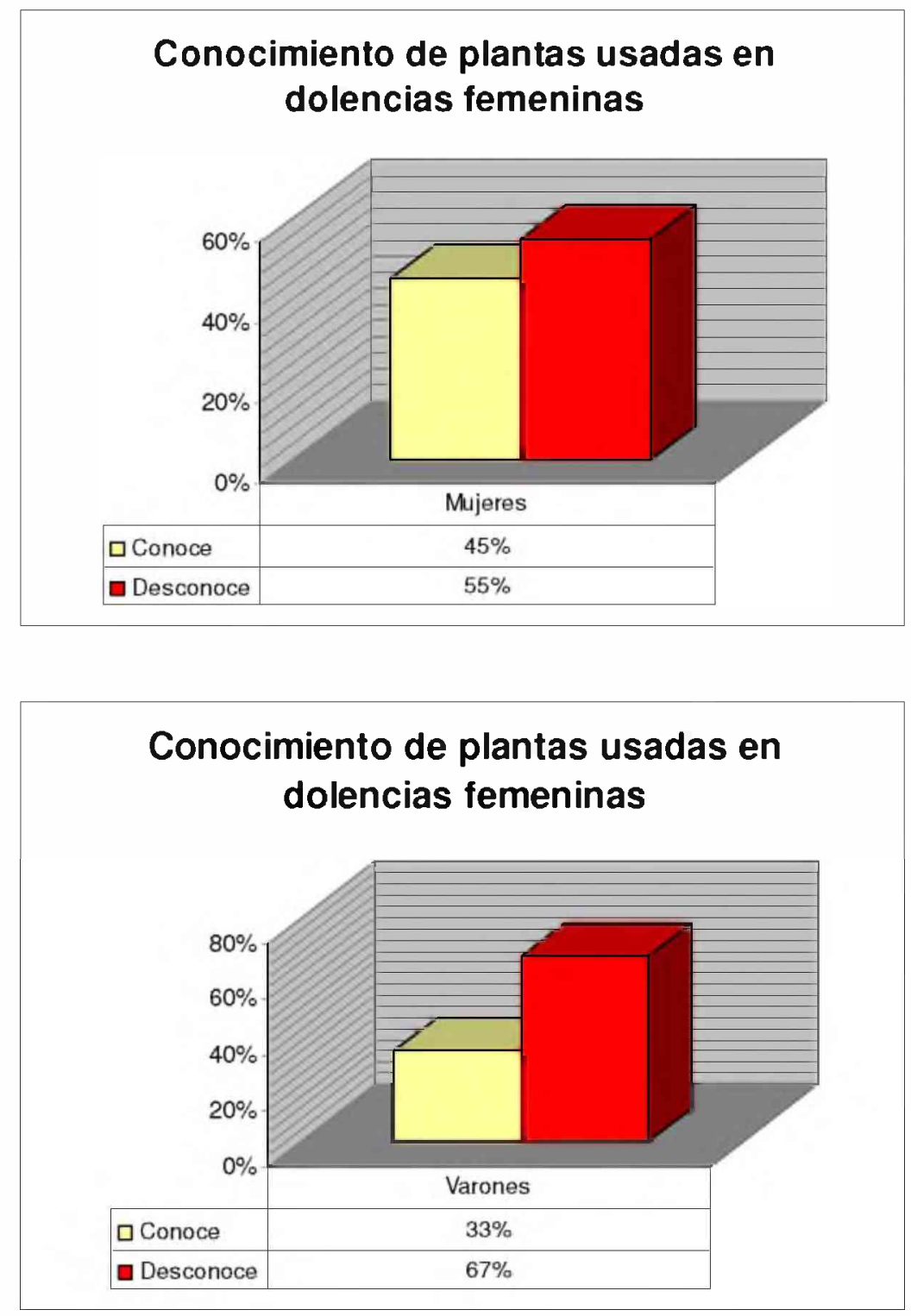

Gráficos 7 y 8: Conocimiento de plantas empleadas en la atención de la salud femenina en función del sexo de los informantes. 
La percepción del embarazo como parte del ciclo vital es muy variable. Algunos se refieren a él como un desequilibrio colocándolo en la categoría de enfermedad y restringido a veces solo a la etapa preliminar del parto, hecho que se manifiesta en expresiones como "se enfermó para tener familia". En otros testimonios se hace alusión a un proceso natural adoptando expresiones de la medicina oficial. Esta percepción es más frecuente dentro de la población más joven.

Como en otras culturas existen creencias en torno a lo que debe o no debe hacer la mujer que se encuentra en estado de gravidez. Al respecto se indicó que las mujeres embarazadas deben evitar la elaboración de ciertas especialidades culinarias en las que el proceso requiere un mezclado homogéneo de los ingredientes. Algunos ejemplos de la creencia de este precepto se registró para la elaboración de pasteles o algunos chacinados como las morcilllas, en los cuales se cree que si la mujer que atraviesa por este período no respeta esta pauta, se producirá el "corte", es decir, la mezcla quedará en mal estado y no apta para el consumo.

La información relacionada con los métodos abortivos fue escasa. Para este fin se registró el uso de cocimientos de las partes aéreas de jarilla (Larrea divaricata) y del tallo de perejil (Petroselinum crispus). Para las menstruaciones profusas, y con el fin de mitigar o interrumpir la hemorragia, se registró el empleo por vía oral de infusiones de yerba mate (Ilex paraguariensis) tostada.

Actualmente han caído en desuso casi todas las prácticas tradicionales de asistencia en los partos $y$ en el período puerperal. Los testimonios relacionados con la atención del parto y postparto fueron tomados a partir de los relatos de puesteras que en su juventud actuaron de parteras ayudando a otras vecinas de la zona. Las mujeres que actuaban en calidad de tal solían hacerlo por solidaridad, pero con frecuencia eran recompensadas con lo que podian ofrecer las familias asistidas. Algunas llegaban a adquirir tanta popularidad por su eficiencia que en el momento oportuno eran solicitadas desde muy lejos para llevar a cabo su tarea. La actividad de las parteras actualmente ya no se lleva a cabo y casi todos los partos son asistidos por profesionales en La Humada o en otros centros asistenciales de la zona. 
En el pasado los partos eran asistidos con la madre acostada o en cuclillas y con las manos sujetas a una soga o una sábana atada al techo de la vivienda. Una de las técnicas tradicionales en los partos difíciles era el "manteo". Este consistía en colocar a la parturienta sobre una frazada $y_{\text {, }}$ tomando a ésta de sus extremos, sacudir enérgicamente para inducir así a un mejor posicionamiento del bebé en el canal uterino. Luego de dar a luz, se hacía un nudo con un hilo en el cordón umbilical a pocos centímetros del cuerpo de niño, y ocasionalmente también se ataba la porción media del cordón a la pierna de la madre. Posteriormente se efectuaba el corte del mismo. Se explicó que mantener el cordón atado a la pierna materna impedía las consecuencias negativas de una eventual retracción por contracciones involuntarias. Luego de esto sobrevenía el alumbramiento. Cuando existían dificultades para lograr las contracciones necesarias para dar a luz o para la expulsión de la placenta, se proporcionaba calor al vientre de la madre y se suministraba de beber un té de manzanilla (Matricaria recutita) con canela (Cinnamomum zeylanicum) o de pimienta (Piper nigrum). Otros métodos consistían en darle de ingerir el tizne molido de ollas y sartenes mezclado con aceite.

Durante los días posteriores al parto se acostumbraba administrar agua de borraja (Borago officinalis) o de chañar (Geoffraea decorticans) para facilitar la expulsión de los coágulos de sangre y a mantener una dieta donde la sopa de gallina y el mate dulce eran los principales alimentos. Esta dieta tiene la fama de devolver la fuerza perdida en el trabajo de parto. Asimismo era conveniente que la madre no se bañara y se cuidara durante cuarenta días de exponerse a fríos o calores extremos.

El recién nacido también tenía sus cuidados. Entre los primeros alimentos que tomaba el niño, además de la leche materna estaba el agua de rosas, que se preparaba a partir de rosales cultivados en el puesto. El cordón umbilical se secaba durante los primeros días aplicando una tela embebida en alcohol. Posteriormente el bebé era firmemente fajado para evitar pasmos, hernias y malformaciones y sobre la cabeza se le colocaba un gorro que podía hacerse con la malla elástica de las medias femeninas. En general, existía 
antes el concepto de que un niño recién nacido debía estar firmemente fajado para lograr una conformación recta en el crecimiento del cuerpo.

\subsubsection{La limpieza y la cosmética}

No se puede dejar de hacer mención a estos dos aspectos de las actividades humanas al hablar de la salud. La limpieza del hogar, de las prendas de uso personal, la higiene del cuerpo y los afeites han tenido en todas las culturas una mayor o menor relación, según los casos con la idea de mayor bienestar. Se consideró conveniente incluir el tema en este capítulo considerando que existe un vínculo estrecho entre la higiene y el mejoramiento de la imagen personal con el sentimiento que generan de bienestar y buena salud.

Actualmente en el oeste pampeano, la mayor parte de los productos de limpieza personal y del hogar se obtienen por compra en los comercios de los poblados. Sin embargo, hace algunas décadas atrás la población, y en especial la más alejada de los centros urbanos, debía obtenerlos a partir de los recursos que ofrecía el medio. Los habitantes de La Humada y del sector rural de mayor edad recuerdan aún hoy las plantas y los productos de origen animal que utilizaban para afrontar esas necesidades cotidianas.

La limpieza de la ropa constituía una actividad que demandaba un tiempo considerable en la adquisición de ciertos insumos para elaborar el jabón y otros agentes tensioactivos. Estas tareas eran, y aún lo son en general, ámbitos de acción femeninos y la mayoría de las personas que aportaron la información más completa y detallada sobre la elaboración de lejías y los elementos usados principalmente en el lavado de prendas de tela, fueron mujeres. No ocurre lo mismo con el jabón de tupe (Panicum urvilleanum), ya que este se empleaba tanto para el lavado de ropa fina como para la higiene personal, en particular del cabello, por lo que hombres y mujeres de edad adulta tienen un completo conocimiento de su preparación.

El uso de jabón de tupe (Panicum urvilleanum) estaba tan generalizado que en varias ocasiones durante las entrevistas las referencias al jabón se referían al elaborado con esta planta y no con el obtenido a partir de grasa 
animal. La parte empleada eran los rizomas de esta planta machacados a los que se vertía agua hirviente, con lo cual se lograba una espuma abundante. Según las necesidades, este jabón líquido era empleado para el lavado de la lana destinada al tejido, de las prendas de vestir más delicadas y también para el lavado del cabello. El mismo proceso, es decir tras el machacado y posterior hervido en agua era realizado con la raíz de paico (Dysphania ambrosioides), pero su empleo no era tan generalizado como la especie anterior. Para eliminar las manchas rebeldes de la ropa se indicó la aplicación directa del jugo de los frutos maduros de quillo (Solanum elaeagnifolium) aunque el empleo de esta planta no era tan generalizado como las anteriores.

A veces, el jabón en pan era un insumo que se compraba a los vendedores ambulantes, pero en otros casos se elaboraba en el puesto con grasa vacuna ("chicharrón") y solución de soda cáustica. Otro método consistía en calentar la grasa con cenizas de plantas ricas en carbonatos, como la vidriera (Suaeda divaricata), pichana (Baccharis spartioides) o solupe (Neosparton aphyllum) agitando la mezcla hasta lograr el endurecimiento de la masa. Luego se procedía al moldeado y corte de las porciones a utilizar.

Otros agentes utilizados para ablandar el agua eran las cenizas de plantas que se mezclaban en agua caliente y posteriormente se filtraban, o bien se sumergían envueltas en un trapo durante un tiempo variable que podía durar hasta una semana. Las plantas empleadas eran aquellas ricas en carbonatos, ya indicadas en la elaboración de jabón y aún otras como el cardo ruso (Salsola kali), zampa (Atriplex lampa), jume (Allenrolfea vaginata) o yerba de vizcacha (Xanthium ambrosioides). Esta preparación era denominada lejía y también se empleaba para el lavado de ropa, en particular para aquellas confecciones que requerian un lavado más frecuente. Como batea se empleaban noques de cuero.

La totalidad de las especies empleadas como agentes tensioactivos se indican en la Tabla 8. (Ver Anexo)

El conocimiento de los métodos tradicionales de elaboración de productos para la limpieza forma parte de aquellos saberes que por falta de continuidad en el uso, se van perdiendo poco a poco en la cultura de la región. 
Los resultados indican que más de un $35 \%$ de los entrevistados desconoce los métodos de elaboración de jabón a partir de tupe y de lejías, y dentro de la población que dijo conocer estos métodos, más del $80 \%$ corresponde a informantes mayores de 40 años.

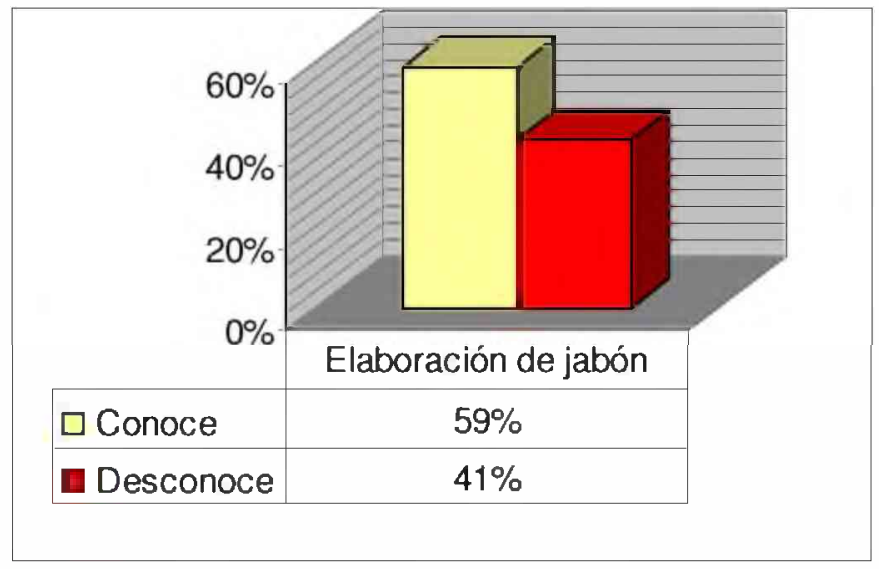

Gráfico 9: Conocimiento del método de elaboración de jabón.

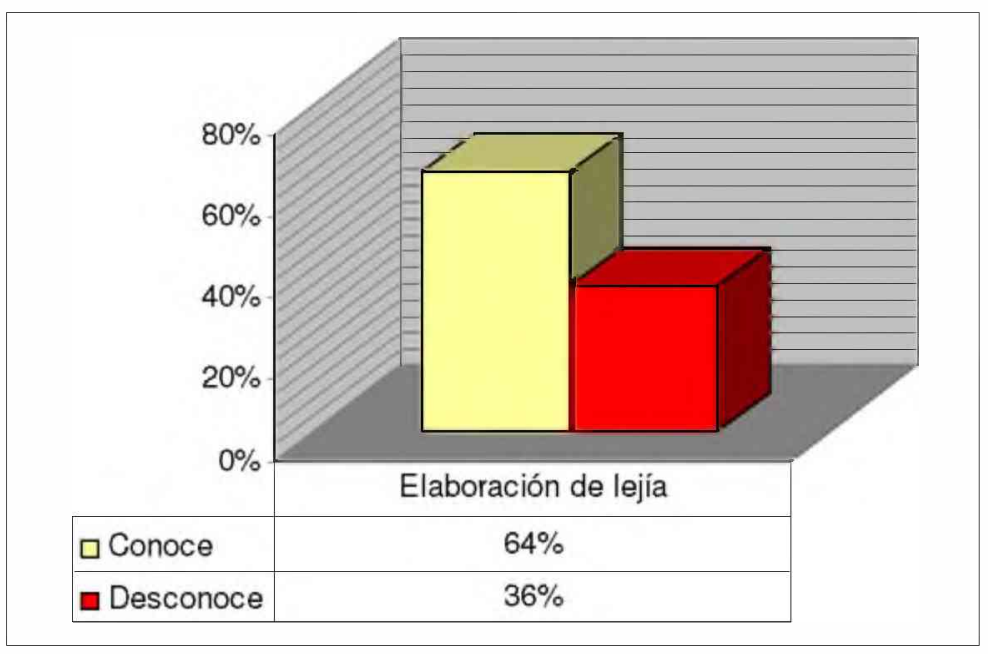

Gráfico 10: Conocimiento del método de elaboración de lejías.

Solo se registró como elemento aditivo y con fines desinfectantes para el lavado de ropa interior el uso del vinagre, especialmente como preventivo de las infecciones urinarias.

En cuanto a la cosmética, la información consignada no es abundante, pero se registraron algunos usos en el pasado de recursos locales particularmente 
vinculados a la elaboración de colonias y al empleo de productos capilares. En general, las lociones corporales se compraban a los ambulantes o en los poblados cercanos pero también se registraron testimonios de preparación de colonias a partir de las inflorescencias del solupe (Neosparton aphyllum), el tomillo macho (Junellia seriphioides) y la yerba del lagarto. Esta última es una variedad del tomillo de olor (Acantholippia seriphioides) morfológicamente idéntica, pudiendo distinguírselas a ambas por la fragancia de sus tallos y hojas. Estas plantas se sumergían en alcohol durante un tiempo determinado, para luego filtrarse y poder ser usadas como perfume de uso personal.

El cuidado del cabello requería también una atención esmerada, sobre todo en aquellos lugares donde el agua disponible para el aseo personal tiene alto contenido en sales. Además del ablandamiento del agua por medio de rizoma de tupe (Panicum urvilleanum) para usarse en la limpieza del cabello, existían otros aditivos que mejoraban su aspecto y cumplían la función de una crema de enjuague. Con este fin se utilizaban yemas de huevos o la bilis de los animales faenados para el consumo.

\subsection{Vivienda}

\subsubsection{La construcción de los puestos}

La heterogeneidad paisajística de la región occidental del departamento Chicalcó permite la utilización de diversos elementos del medio en la construcción tradicional de viviendas. Actualmente, debido a los planes de mejoramiento habitacional del gobierno provincial, la mayoría de ellas están hechas totalmente de ladrillo o anexadas a la vivienda anterior de adobe y con techos de chapa galvanizada, pero todavía se pueden observar en el área rural las viviendas del pasado que coexisten con las nuevas. Las viviendas actuales consisten en un ambiente principal que se comunica con los dormitorios y la cocina. En las viviendas rurales tradicionales, en cambio, las construcciones se independizaban en unidades funcionales separadas o contiguas. De este modo existía una construcción que hacía las funciones de cocina, y otra de dormitorios, además de existir otras dependencias subsidiarias como la despensa y las ramadas donde se colocan aperos, y otras herramientas. Las aberturas de las viviendas tradicionales son de pequeñas dimensiones, con 
marcos de palos de algarrobo o alpataco (Prosopis flexuosa) y ventanas construidas frecuentemente con las tablas de madera disponibles y sujetas con tientos de cuero o alambres.

En áreas rocosas es común encontrar todavía casas de paredes hechas con piedras del lugar pegadas con mezclas de barro, estiércol de vaca y cenizas o simplemente con manojos de plantas como la melosa (Grindelia chiloensis), que por su carácter resinoso se empleaba como adherente de las piedras. En los lugares donde no es fácil el acceso a la piedra, predominan las construcciones con barro, un material de mayor disponibilidad en el entorno. Las paredes de las casas de barro se realizaban de acuerdo a varias modalidades. Una de ellas consiste en colocar cuatro postes esquineros de maderas resistentes como algarrobo (Prosopis flexuosa f. flexuosa), alpataco (Prosopis flexuosa var. depressa), piquillín (Condalia microphylla) o chañar (Geoffraea decorticans). A partir de los esquineros se tendían varias hileras de alambre separados entre sí a unos $40 \mathrm{~cm}$. Si no se disponía de alambre podía reemplazarse por tiras de cuero y ramas finas de jarilla (Larrea divaricata) entrelazadas. Entre cada poste se colocaba una fila de ramas de jarilla dispuestas en forma vertical que podían sujetarse con alambres o con otras ramas entrelazadas. Sobre este cerco se realizaba un revestimiento externo e interno con estiércol vacuno mezclado con ceniza y agua hasta formar una pasta. Finalizada la construcción de una pared se continuaba con otra hasta completar el perímetro y luego, cuando estaba seca, se repetía este trabajo agregando paños arriba de los ya hechos hasta lograr la altura de la pared deseada. Por último, y a modo de enlucido se colocaba sobre las paredes una capa externa más fina con la mezcla de estiércol, ceniza y agua.

Otras variantes de la construcción de estas paredes consistía en tender alambres desde los postes y colocar sobre aquellos plantas enteras de coirones (Jarava ichu, J. hypsophylla, Pappostipa vaginata) que se colgaban invertidas sobre los alambres quedando cada hilera tapada por la superior en forma de quincha. Los coirones podían reemplazarse por "chorizos", masas de barro mezcladas con plantas fibrosas picadas, que se disponían sobre los alambres una junto a otra hasta completar los paños. Las especies usadas en los chorizos abarcaban, además de las arriba mencionadas, otras gramíneas 
fibrosas (Jarava neaei, Elionurus muticus) y otras plantas abundantes en el lugar como pichana (Baccharis spartioides). El revoque se efectuaba en forma análoga al método anterior. Un sistema similar consistía en colocar los chorizos en el suelo sobre la línea de pared o bien sucesivas hileras de pichanas picadas cubiertas por masas de barro hasta lograr la altura de la pared deseada. En cada esquina se practicaba una traba que hacía de enganche con la pared siguiente. Estas paredes también se revocaban como se describió anteriormente.

El adobe se utiliza aún en la actualidad y se elabora con tierra arcillosa que se obtiene en los lugares más bajos de la zona. Ésta se mezcla con pichana (Baccharis spartioides), pajas y coirones (Elionurus muticus, Jarava ichu, Jarava neaei, Pappostipa vaginata). Es común añadirle estiércol de vaca o de cabra que funciona como aglutinante del conjunto. Esta mezcla, convenientemente humedecida, se mezcla durante varios días mediante el pisoteo de un caballo hasta que adopta la textura adecuada. Finalmente se coloca en moldes y se deja secar unos veinte días, luego de los cuales, las piezas de adobe ya están aptas para ser usadas en la construcción.

a.

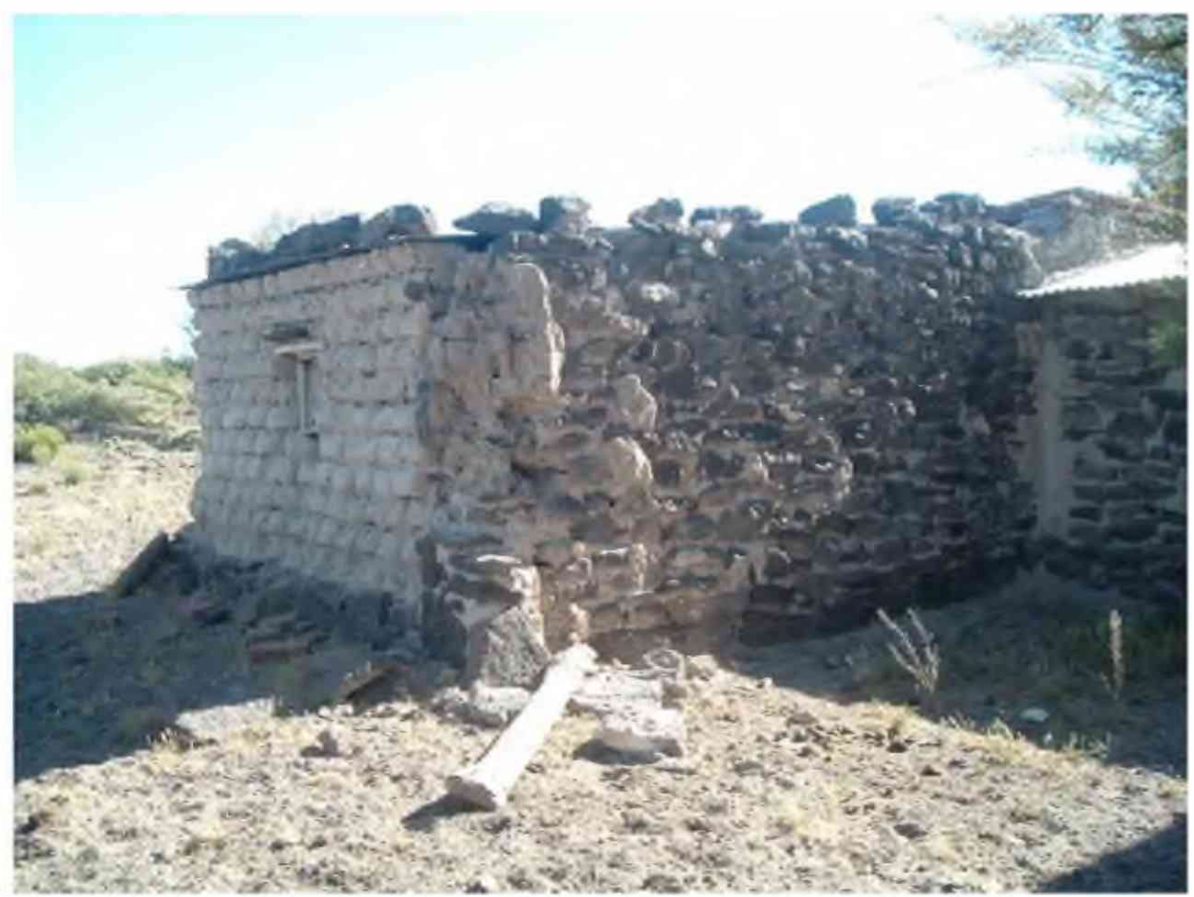


b.
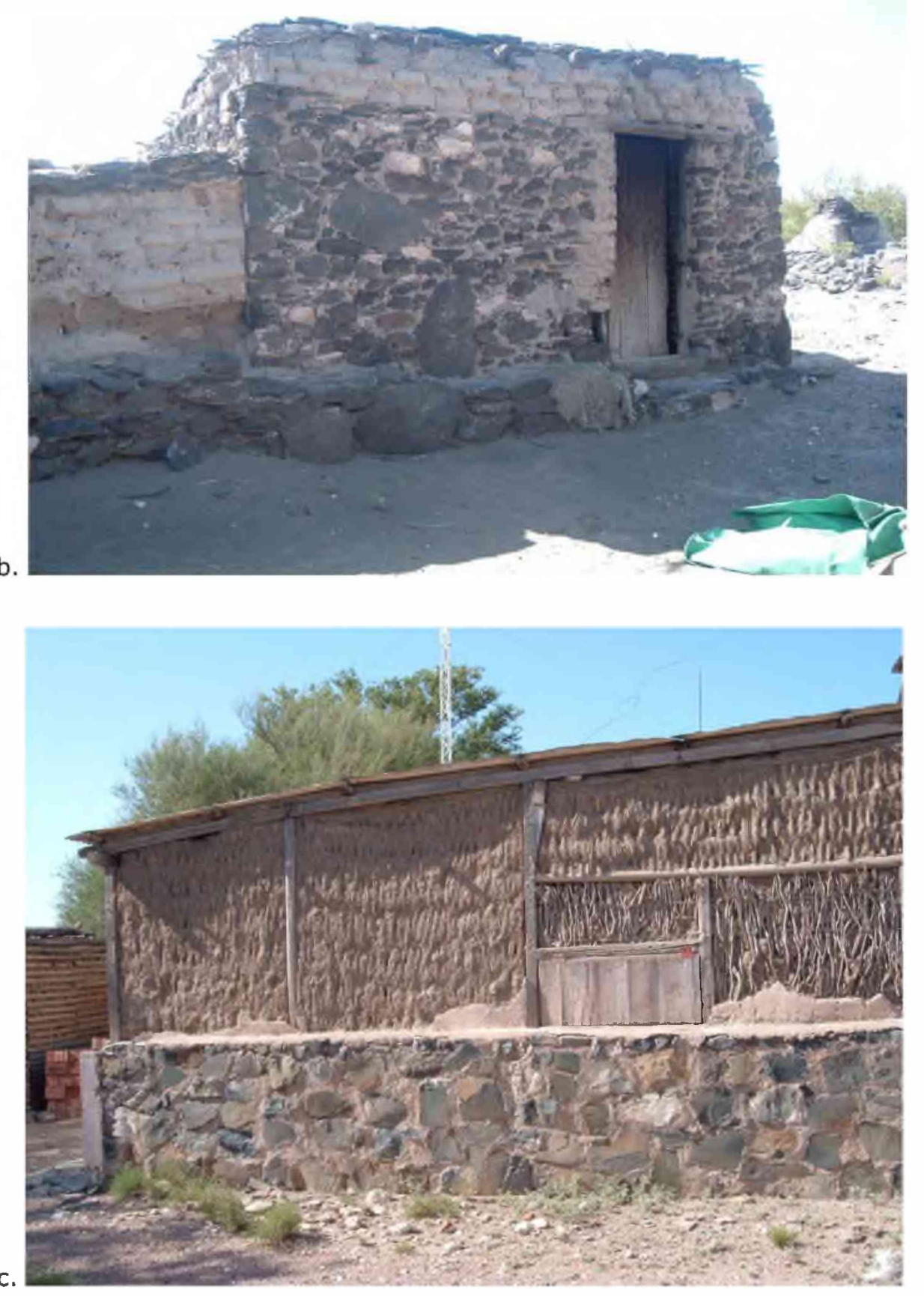
d.

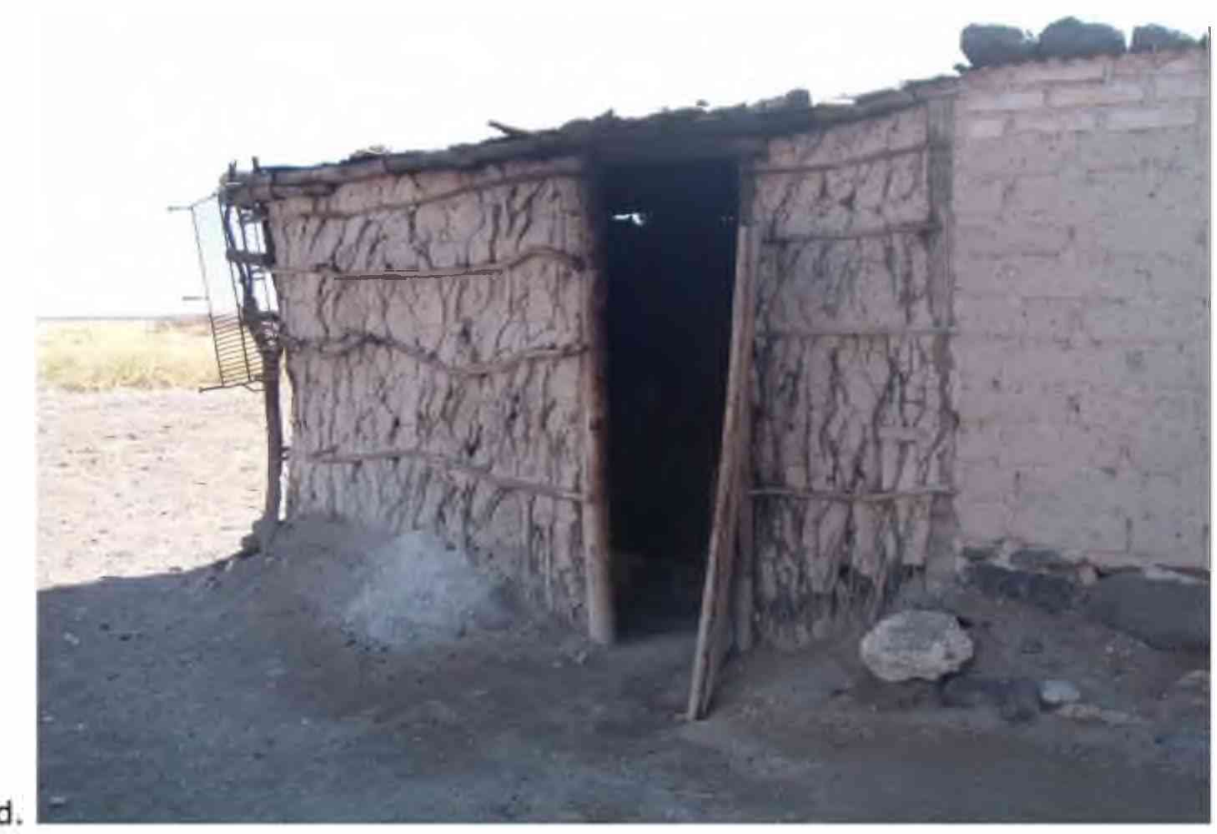

Fig. 5: Distintos tipos de construcciones de viviendas. a: Dormitorio con paredes mixtas hechas de piedra basáltica $y$ adobe, b: Cocina hecha con piedra basáltica, desnivel de caída del techo con adobe, $c$ : Pared de una barraca con tres técnicas distintas, base de piedra unidas con cemento, cerco de jarilla embarrado (al centro a la derecha), resto de la pared con técnica de chorizo de adobe, d: Cocina hecha de cerco de jarilla embarrado.

En el sector urbano de La Humada se registró un caso diferente a las demás construcciones de la zona en la elaboración de ladrillos para mampostería. A estos ladrillos se los denomina localmente con el nombre de "adobe champa". Para obtenerlos se buscan sitios bajos donde el pasto salado (Distichlis spicata) sea abundante y allí se efectúan con una pala sendas zanjas paralelas dejando en el medio un espacio de aproximadamente 0,5 m. El largo de las zanjas varía en función de las necesidades de material y la cobertura de la gramínea. Terminada la excavación de las mismas se procede a cortar transversalmente panes de unos 25 o $30 \mathrm{~cm}$ que luego se secan al sol. Por el carácter densamente rizomatoso de Distichlis spicata, estas unidades constituyen bloques prismáticos sumamente livianos empleados como ladrillos que se pueden pegar entre sí con adobe. Posteriormente la pared recibe un revestimiento variable en función de la disponibilidad de 
materiales, pudiendo cubrirse con la mezcla de barro ya descripta o con la argamasa convencional de arena, cal y cemento.

La construcción tradicional de los techos se realiza con una o dos caídas. Los de dos caídas se disponen a partir de una cumbrera frecuentemente de álamo (Populus nigra). En cualquiera de las variantes de techo, los tirantes, que también son postes de álamo de menor sección, se recubren transversalmente con ramas de jarilla. Por encima de esta cobertura se coloca una capa gruesa de barro y sobre ella, como cubierta final, un entramado de ramas de plantas diversas como melosa (Grindellia chiloensis), blanquilla (Hyalis argentea), solupe (Neosparton aphyllum) o vástagos de unco (Sporobolus rigens), que superpuestas en forma de quincha impiden el ingreso de agua.

Hasta antes de generalizarse las estructuras y el empleo de materiales de construcción modernos, existía en la zona una variante del diseño de las viviendas que consistía en la colocación de postes, generalmente de álamo (Populus nigra), olmo (Ulmus spp.) o acacia (Robinia pseudoacacia), clavados en el suelo y trazando un círculo. En la parte superior los postes convergían en un punto, dándole a la construcción una forma cónica. Los espacios entre los postes se rellenaban con hileras verticales de ramas de jarilla (Larrea divaricata) recubiertas con adobe, dejando los espacios libres necesarios para la puerta y las ventanas. Este tipo de vivienda recibe el nombre de "torito". Para conferirle más resistencia a los "toritos" era frecuente colocar un poste en el centro de la vivienda a modo de pivote. Este poste era de madera más resistente por lo que preferentemente se elegía el piquillín (Condalia microphylla). Esta estructura cónica podía también descansar sobre paredes verticales levantadas como se describió anteriormente.

El sector peridoméstico de las viviendas suele estar separado del campo por un alambrado perimetral o bien por un cerco realizado del mismo modo y con los mismos materiales a los utilizados en los corrales de las cabras (Ver 3.1.4. Construcciones rurales e instrumentos de uso ganadero) y a la vez puede tener otras divisiones internas para separar el jardín o la huerta hogareña. Las especies vegetales que intervienen en la construcción de la 
vivienda así como de los cercos y los corrales peridomésticos se consignan en la Tabla 10 referida a las especies empleadas en la cultura material.

\subsubsection{Jardines hogareños}

La gran diversidad de especies que se cultivan con fines ornamentales, y que son principalmente exóticas, exceden los objetivos específicos de este trabajo, ya que en este estudio se pretende poner énfasis en las especies nativas. Así como en otras categorías de uso se incluyen las especies introducidas para comprender mejor el tema en cuestión, aquí también es necesario destacar la importancia de las especies ornamentales en la vida cotidiana de la gente aún cuando estas sean adventicias. Las plantas ornamentales constituyen un tema que en comparación con otros ha sido muy poco estudiado en etnobotánica, y que en este caso merecería ser tratado aparte dada su amplitud, en la que se incluirían criterios estéticos y rutas de introducción, entre otros. Por tal motivo no se desarrollará aquí un listado pormenorizado de las especies ornamentales de los jardines hogareños limitándose a incluir solo las de cultivo más frecuente. Todas ellas están incluidas en el Catálogo de nombres y usos de las plantas (Ver Anexo III).

Aunque el cultivo de jardines suele realizarse simultáneamente y en el mismo espacio de la huerta, es común que en el sector de entrada a la vivienda de los puestos exista un espacio destinado al cultivo de plantas con un fin principalmente estético, pero donde también suelen coexistir otras cultivadas como aromáticas, medicinales y mágicas (Ver por ejemplo ruda en Anexo III).

La causa de las dificultades e impedimentos para el cultivo de jardines son las mismas a las que ya han sido expresadas en el punto que hace referencia a las huertas (Ver 3.2.1. Alimentación). Sin embargo, los procesos inmigratorios desde la región de Cuyo, donde la horticultura y la jardinería están ampliamente difundidas, han influido para que esta práctica, aunque poco desarrollada, continúe llevándose a cabo. Gran parte de los hogares visitados en los cuales el cultivo de un jardín o una huerta doméstica se realizan con esmero, están constituidos por familias oriundas de Mendoza, por 
descendientes de inmigrantes de esta provincia, o vinculadas a ella por motivos familiares o laborales.

La mayor cantidad de jardines se observó en la zona urbana de La Humada, donde se registraron en un $58 \%$ de los hogares visitados. En la zona rural en cambio se cultivan jardines en un $39 \%$ de los puestos visitados. Las razones por las cuales la gente no realiza este tipo de actividad son muy variadas. En el sector rural el motivo más referido durante las entrevistas fue la escasez de agua, mientras que en el pueblo, la falta de cercos perimetrales de los predios para impedir el ingreso de animales y las situaciones de estadías temporales en el domicilio fueron las razones más expresadas. En ambas zonas, quienes mayoritariamente se encargan del cuidado $y$ mantenimiento del jardín son las mujeres.

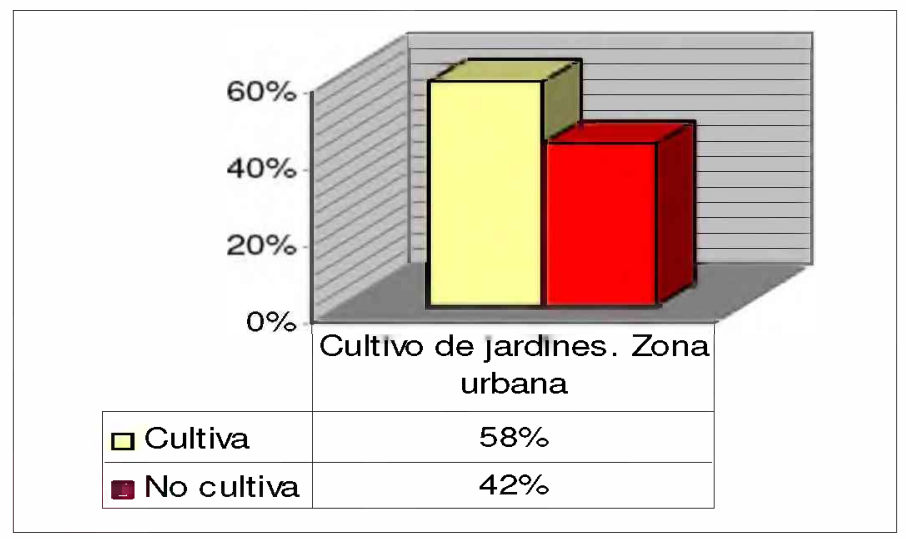

Gráfico 11: Cultivo de jardines en el área urbana de La Humada.

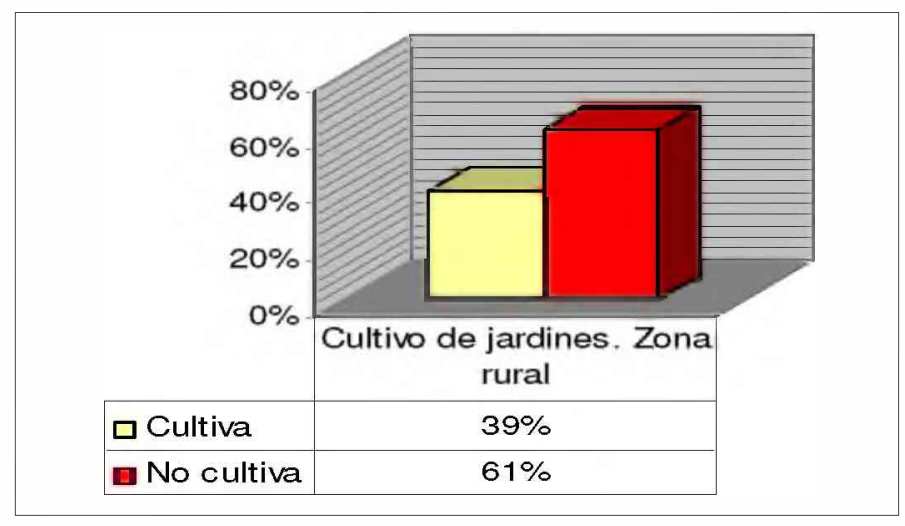

Gráfico 12: Cultivo de jardines en el área rural de La Humada. 


\subsubsection{Arbolado}

Dadas las exigencias ambientales de la región, las especies arbóreas que cumplen funciones ornamentales o para proveer sombra están condicionadas a la tolerancia de inviernos con heladas frecuentes, veranos con temperaturas altas, escasez de agua en las épocas de mayor demanda y en ocasiones otras limitantes como salinidad excesiva o escasa profundidad de suelo debido a la existencia de mantos rocosos. En consecuencia, el arbolado urbano $\mathrm{y}$ el de los predios rurales está representado por una modesta diversidad de especies.

En sector urbano de La Humada los árboles de la vía pública son olmos (Ulmus procera), álamos (Populus spp.), arabias (Eleagnus angustifolia), fresnos (Fraxinus spp.), acacias (Robinia pseudoacacia), cipreses (Cupressus spp.), pinos (Pinus spp.), y tamariscos o "tamarindos" (Tamarix ramosissima). Estos últimos constituyeron junto a los olmos la primera forestación de la localidad.

a.

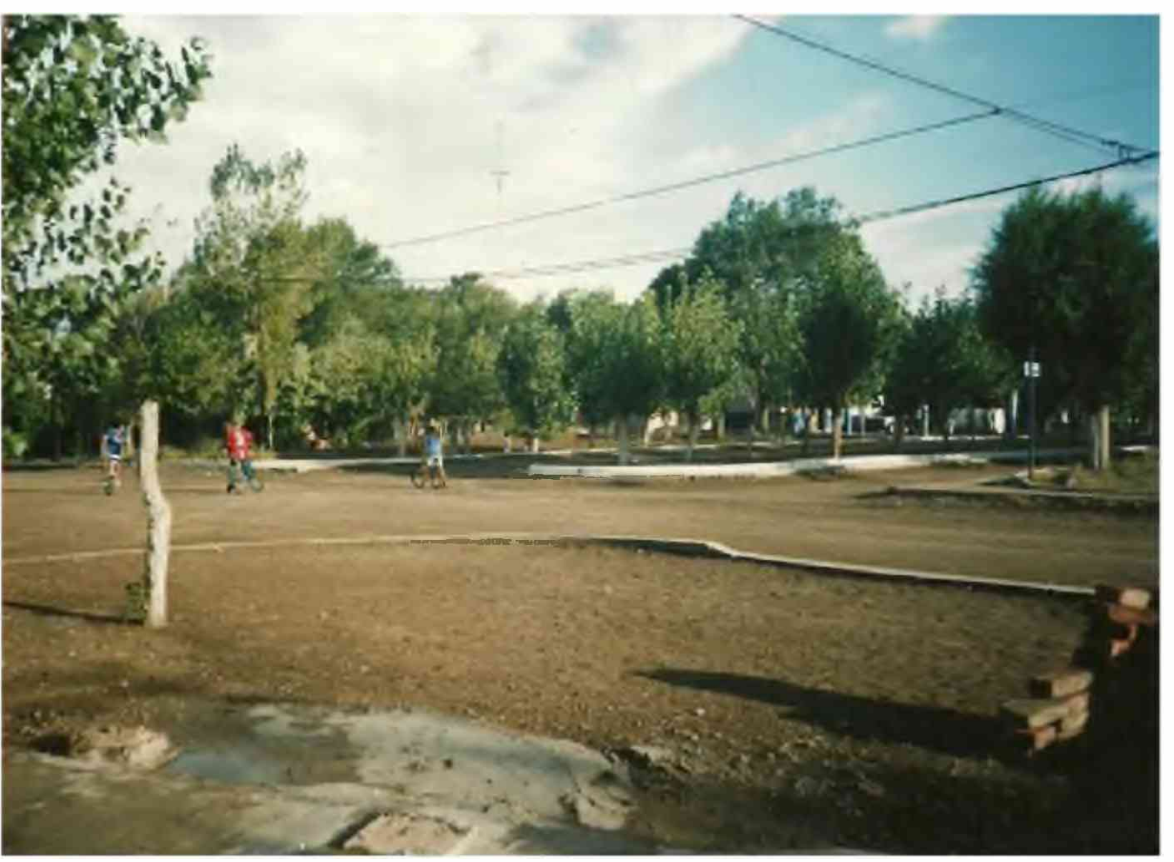




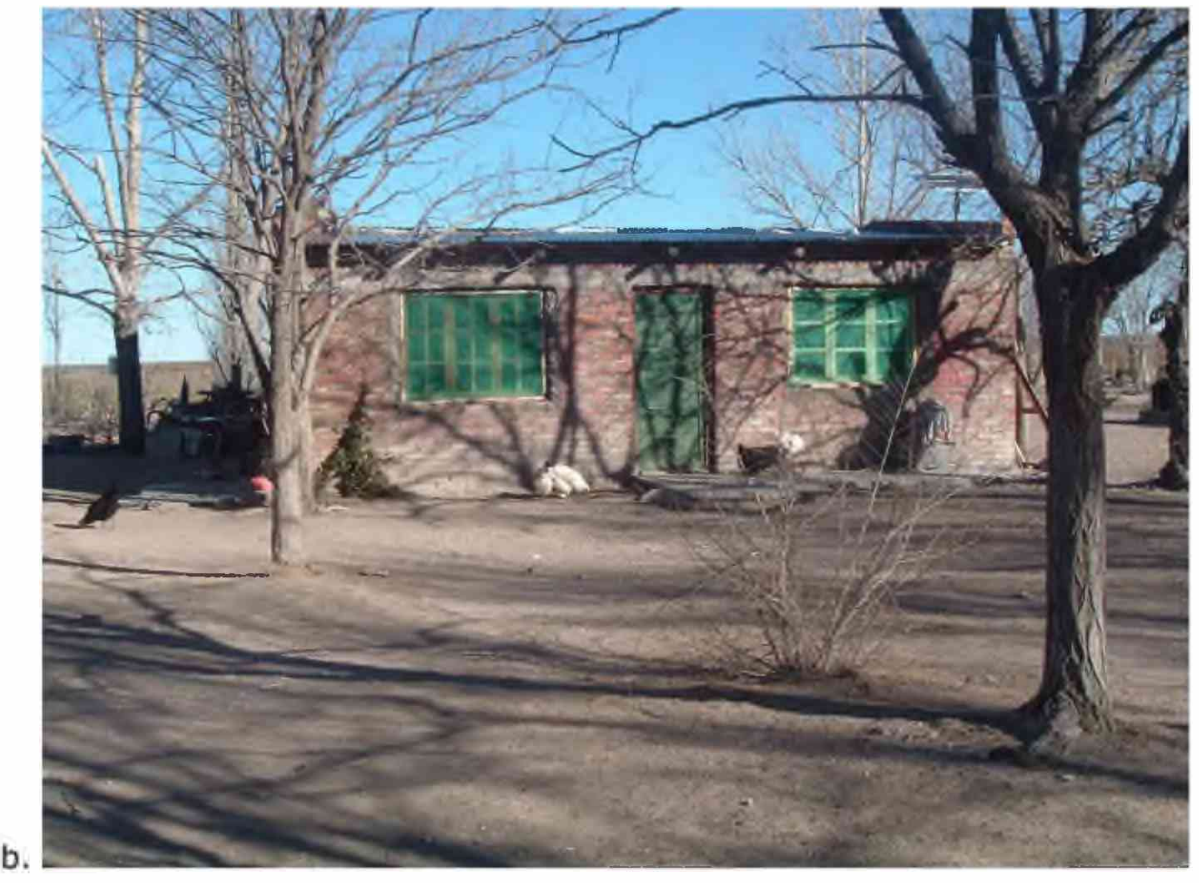

Fig. 6: Arbolado. a: calle de La Humada. Se observa la forestación urbana constituida principalmente por Populus sp., y Ulmus sp., b: Puesto con árboles de Robinia pseudoacacia para proveer sombra.

El acueducto que une Agua de Torres con La Humada hace posible el riego en las casas del pueblo y esto permite el establecimiento de algunas especies frutales como membrilleros (Cydonia oblonga), vides (Vitis vinifera), perales (Pyrus communis), damascos (Prunus armeniaca) y durazneros (Prunus persica) que cumplen funciones ornamentales además de proveer sombra y frutas.

En los predios rurales la situación es similar pero con menor diversidad respecto del pueblo debido a las limitadas posibilidades de riego. Las especies más cultivadas con fines de sombra u ornamentales y en orden decreciente son: olmos (Ulmus spp.), "tamarindos" (Tamarix ramosissima), arabias (Eleagnus angustifolia), álamos (Populus nigra), acacias (Robinia pseudoacacia) y cipreses (Cupressus spp.). Con menor frecuencia se cultivan eucalipto (Eucalyptus spp.), árbol del cielo (Ailanthus altissima), mora (Morus alba), parra loca (Parthenocissus quinquefolia), pino (Pinus spp.) y pimiento (Schinus areira). Cuando en los patios de los puestos hay algarrobos (Prosopis flexuosa $f$. flexuosa), en ocasiones estos son objeto de cuidados especiales ya 
que es la especie nativa de mayor porte y apta para estos fines. También presentes pero con carácter ocasional se pueden citar al paraíso (Melia azedarach), tuya (Platycladus orientalis) y vid (Vitis vinifera). Las especies arbóreas aquí mencionadas se indican en la Tabla 11.

\subsection{ARTESANÍAS Y ENSERES DOMÉSTICOS}

\subsubsection{Enseres domésticos.}

Entre las herramientas hogareñas realizadas con plantas, la escoba es la que tiene mayor representatividad siendo casi infaltable en todos los hogares rurales. El cabo es un palo de madera o una rama más o menos recta de cualquier planta del lugar en la que se ata en uno de sus extremos un haz de ramas delgadas de pichana (Baccharis spartioides). En los lugares donde no abunda esta especie, la escoba se confecciona con ramas de jarilla (Larrea divaricata).

La abundancia en el lugar de la jarilla (Larrea divaricata) permite que esta planta sea empleada para múltiples propósitos materiales. Además de intervenir en la construcción de escobas también se emplea en la confección de punzones, ensartadores para asar carne, zarzos para secar quesos y ejes de roldana usadas en los pozos de agua. Para ello se emplean ramas del espesor más conveniente de acuerdo a su uso. En el caso de los zarzos se eligen ramas finas que se entretejen para formar una superficie rectangular plana que asegura una buena ventilación de las hormas de queso que se depositan en ellos. Por lo común, estas bases se suspenden del techo de la vivienda.

No obstante el difundido uso de la jarilla (Larrea sp.) en la construcción de cabos de herramientas, varias especies del entorno son aprovechadas para tal fin pero la más apreciada es la de chañar (Geoffraea decorticans). La resistencia y elasticidad que presenta su madera la hace apta para los cabos de hachas, picos y otras herramientas que soporten golpes intensos. Otras plantas nativas registradas con esta finalidad fueron alpataco (Prosopis flexuosa var. depressa), algarrobo (Prosopis flexuosa f. flexuosa), y entre las adventicias la acacia (Robinia pseudoacacia) y el olmo (Ulmus spp.). Para 
lograr buena resistencia de estas maderas, las ramas a emplearse se cortan en invierno y se carbonizan en los extremos y en toda la superficie para evitar resquebrajamientos posteriores.

Las piezas de herramientas y artefactos antiguos que han caído en desuso, se suelen reutilizar cuando su calidad lo justifica. Uno de estos viejos elementos que se prestan para el reciclado de instrumentos de uso doméstico son los rayos de las ruedas de los viejos carros. Éstos se construían con maderas resistentes provenientes de otras regiones del país y por lo común se empleaba el quebracho colorado (Schinopsis $s p$.), árbol característico del Gran Chaco.
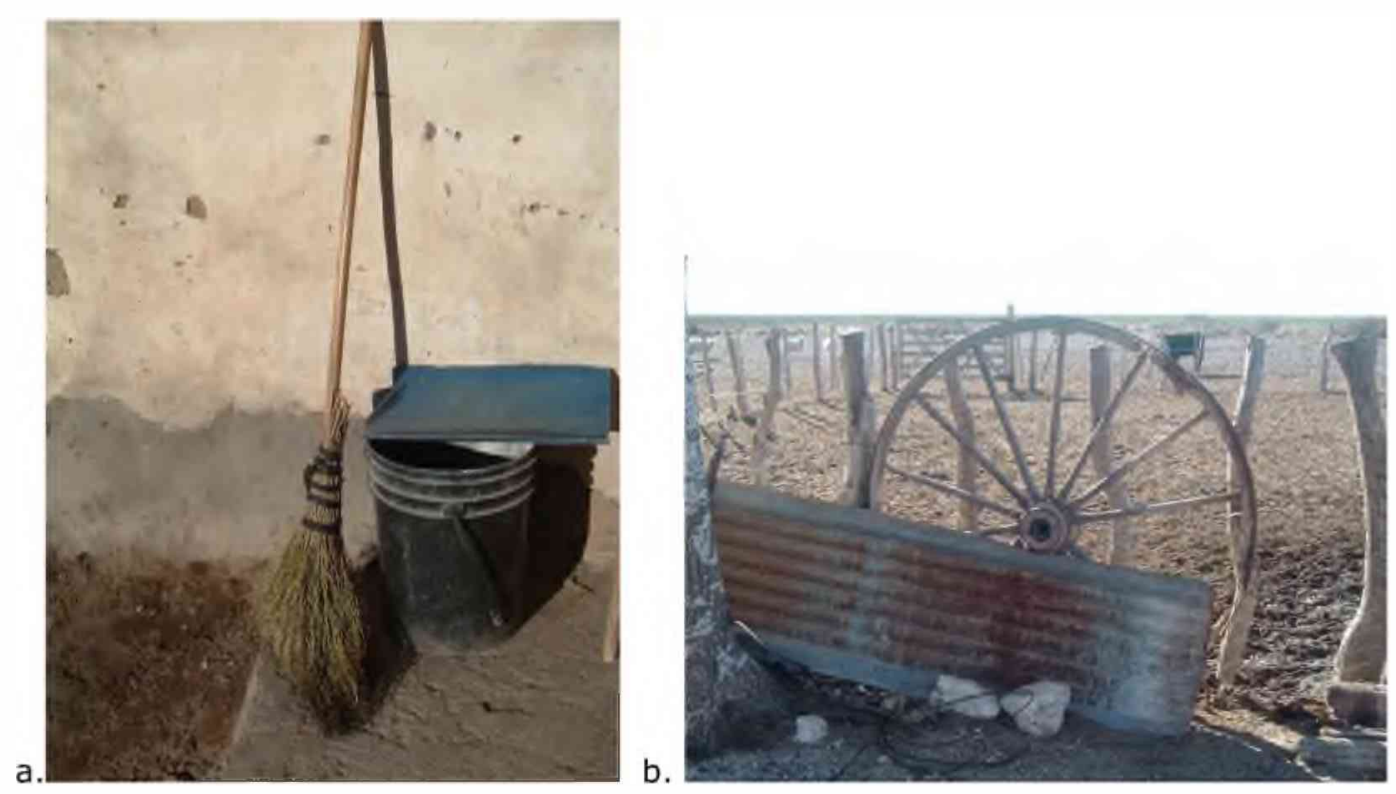

Fig. 7: a. escoba confeccionada con Baccharis spartioides, b: rueda de carro antiguo. Con sus ejes se confeccionan útiles que requieren maderas resistentes.

El álamo (Populus spp.) es una de las especies más cultivada y por lo tanto provee una cantidad de madera abundante, pero su fragilidad hace que su uso esté limitado a la construcción de elementos domésticos que no requieran grandes esfuerzos mecánicos, por lo que en general se obtienen postes para maderamen de los techos y tablas para construir diferentes muebles. 
En el pasado, algunos elementos del mobiliario como los canastillos para bebés se construían a partir de raíces o ramas flexibles de sauce (Salix spp.) o bien con alambre. Con estos materiales se confeccionaba un bastidor redondeado, dentro del cual se realizaba un tejido de "guasquilla" que formaba la base del canasto para que descanse el niño.

Más allá de lo reseñado en los párrafos precedentes, la confección de herramientas a partir de las plantas del entorno es una actividad que se está perdiendo, hecho que ocurre en forma más acentuada en el área urbana. Así, el $75 \%$ de los informantes entrevistados en el pueblo manifestaron no confeccionar instrumentos de uso cotidiano con las plantas. En el sector rural la cifra también es alta ya que alcanza a un $52 \%$. En todos los casos cuya respuesta fue negativa, la razón se debe a que se prefiere comprar tales instrumentos en los negocios del pueblo.

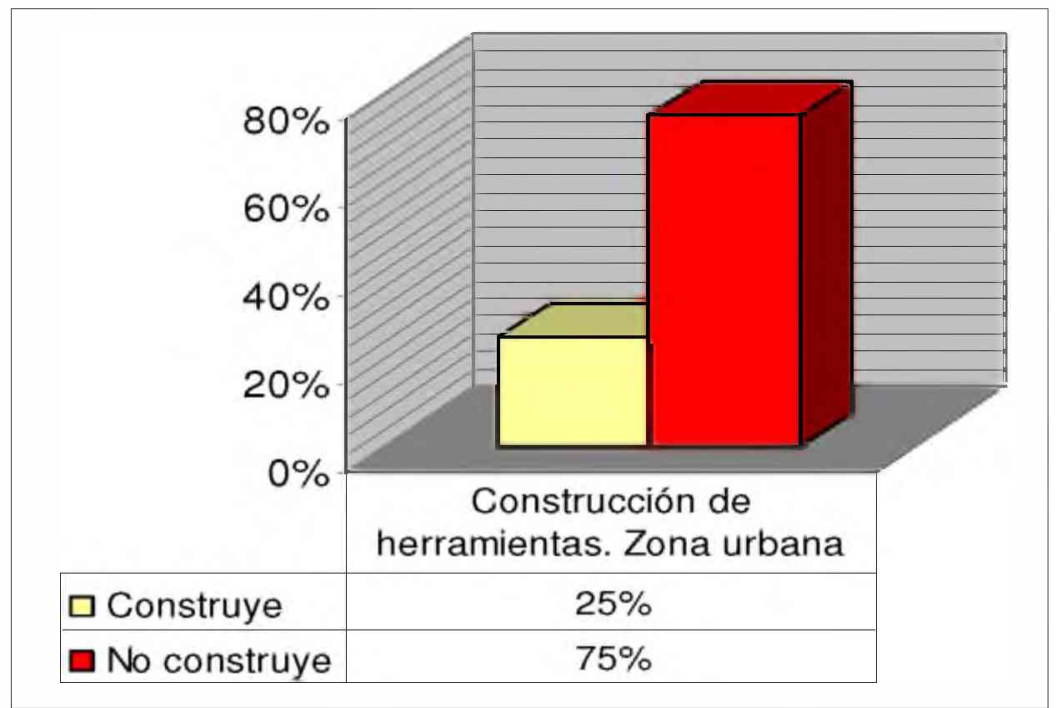

Gráfico 13: Confección de herramientas con plantas en el área urbana. 


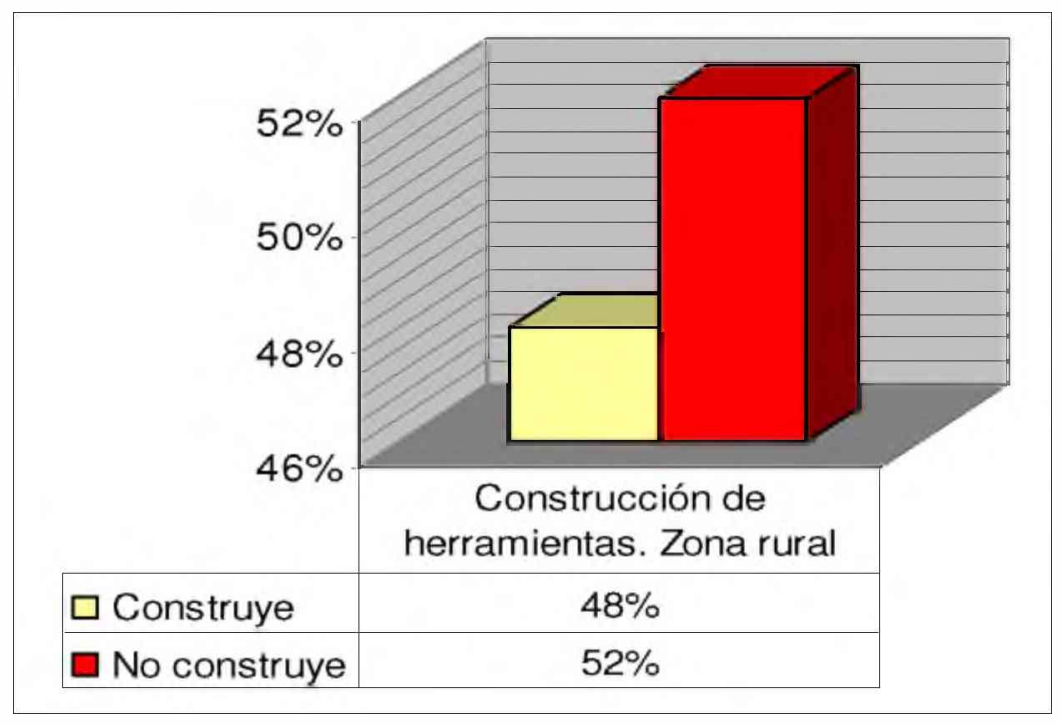

Gráfico 14: Confección de herramientas con plantas en el área rural.

Todas las especies que intervienen en la confección de artesanías y enseres domésticos se consignan en la tabla 10 relacionada con la cultura material.

\subsubsection{Tejeduría en lana}

En la región la tejeduría en lana de oveja se encuentra ampliamente desarrollada formando parte del acervo cultural aborigen que persiste hasta nuestros días. En este punto se describen los distintos pasos de la actividad textil poniendo énfasis en las plantas utilizadas para la confección de los utensilios empleados en la tejeduría y para la obtención de los tintes. Los detalles del proceso textil así como la descripción de los diseños escapan a los fines de este trabajo por lo cual solo serán mencionados sucintamente.

El primer paso del tejido en lana, aún antes de ser lavada, es el hilado, realizado en forma manual por medio del huso. Esta herramienta se constituye de un trozo de madera recta de sección circular en cuyo extremo lleva atravesado un disco, la "torcedera", que hace de contrapeso y que se obtiene frecuentemente a partir de fragmentos de piedras de afilar. Para hacer los husos se prefieren -por su rectitud- las ramas subterráneas del alpataco (Prosopis flexuosa var. depressa) o las de álamo (Populus spp.). El tamaño del huso está en relación con la sección del hilado que se busca. Instrumentos 
pequeños se emplean para obtener hilados más delgados y viceversa. El paso siguiente al hilado es el torcido que también se realiza con el huso y tras el cual se obtiene el hilo de lana del grosor deseado.

a.
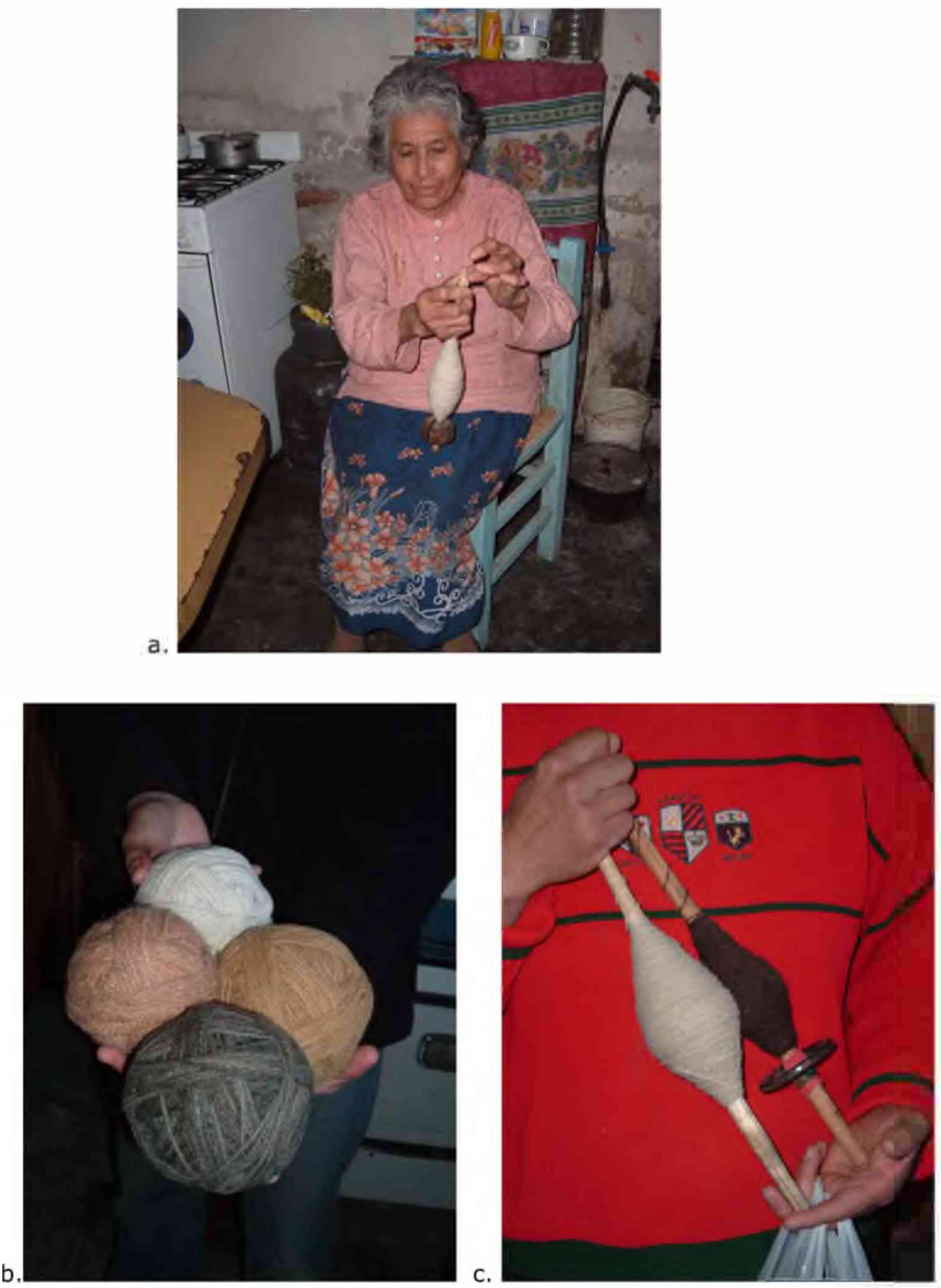

Fig. 8: a: Rut Moyano nos explica el manejo del huso, b: ovillos de lana ovina sin teñir y teñidos con infusiones concentradas de Thelesperma megapotamica, Schinus johnstonii y con hollín, c: Detalles de husos y torcedera. 
Posteriormente se arman las madejas y se lava la lana con agua caliente y jabón. Luego se la hierve en agua donde previamente se ha disuelto alumbre o sal que actúan como mordientes, se retiran las madejas y se procede al teñido. Este se efectúa con anilinas o colorantes obtenidos a partir de plantas del lugar o de otros elementos naturales. En el último caso las partes de las plantas colectadas deben someterse a una cocción de intensidad variable en función del color deseado, proceso que suele hacerse con agua de Iluvia. El hollín depositado en las paredes de las chimeneas es un recurso que también se suelen emplear para el teñido. Finalizado este proceso, se filtra la decocción, se agregan las madejas, se continúa el calentamiento hasta lograr la tonalidad buscada, que abarca aproximadamente media hora de hervor, y luego se dejan enfriar las madejas en el agua. Un testimonio que aporta un detalle adicional al conjunto de creencias ya enunciadas da cuenta de que el teñido debe hacerlo la persona sola, ya que si alguien está presente, el proceso "se corta", es decir, la tinción no queda uniforme.

El paso siguiente consiste en realizar una secuencia de hilos paralelos formando así la urdimbre en los travesaños del telar. Sobre ella se realiza la trama atravesándola con otros hilos y sirviéndose de ayuda con una pala de madera para afirmar el tejido. Estas palas se realizan con cualquier madera liviana, por lo general de pino (Pinus spp.) o de álamo (Populus spp.).

Para la operación de tejido se usan telares de maderas diversas como álamo, pino o cualquier madera recta disponible. El tipo de telar utilizado es el vertical, constituido por un bastidor de dos tirantes largos a los costados en cuyos extremos se ubican dos travesaños, los envolvedores. Este tipo de telar era el empleado por los pueblos originarios de la región (Millán de Palavecino 1964). Los trabajos realizados incluyen matras, fajas, ponchos, maletas, ataderas, peleros, y otros artículos que son destinados al uso propio o al mercado artesanal provincial cuyo funcionamiento depende del gobierno. Los diseños predominantes son la labor, la lista y el peinecillo (Balbuena 1993, Ladaga de San Cristobal 1980). El tejido en lana también incluye los trabajos realizados con aguja de tejer. Entre estos, cabe mencionarse bufandas, jerseys, boinas y los tradicionales y coloridos adornos realizados con huevos de avestruz (Rhea americana) forrados con lana. 

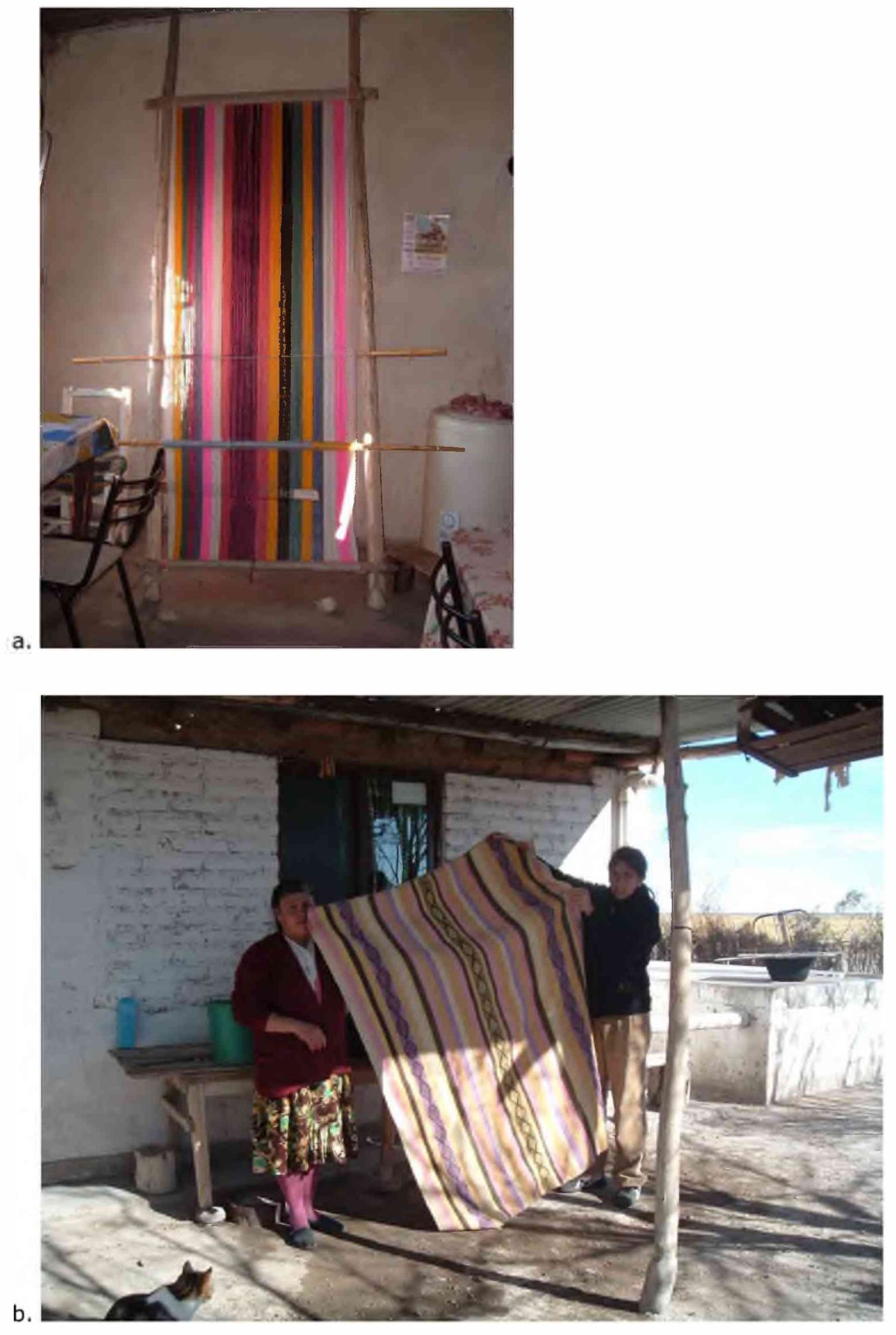

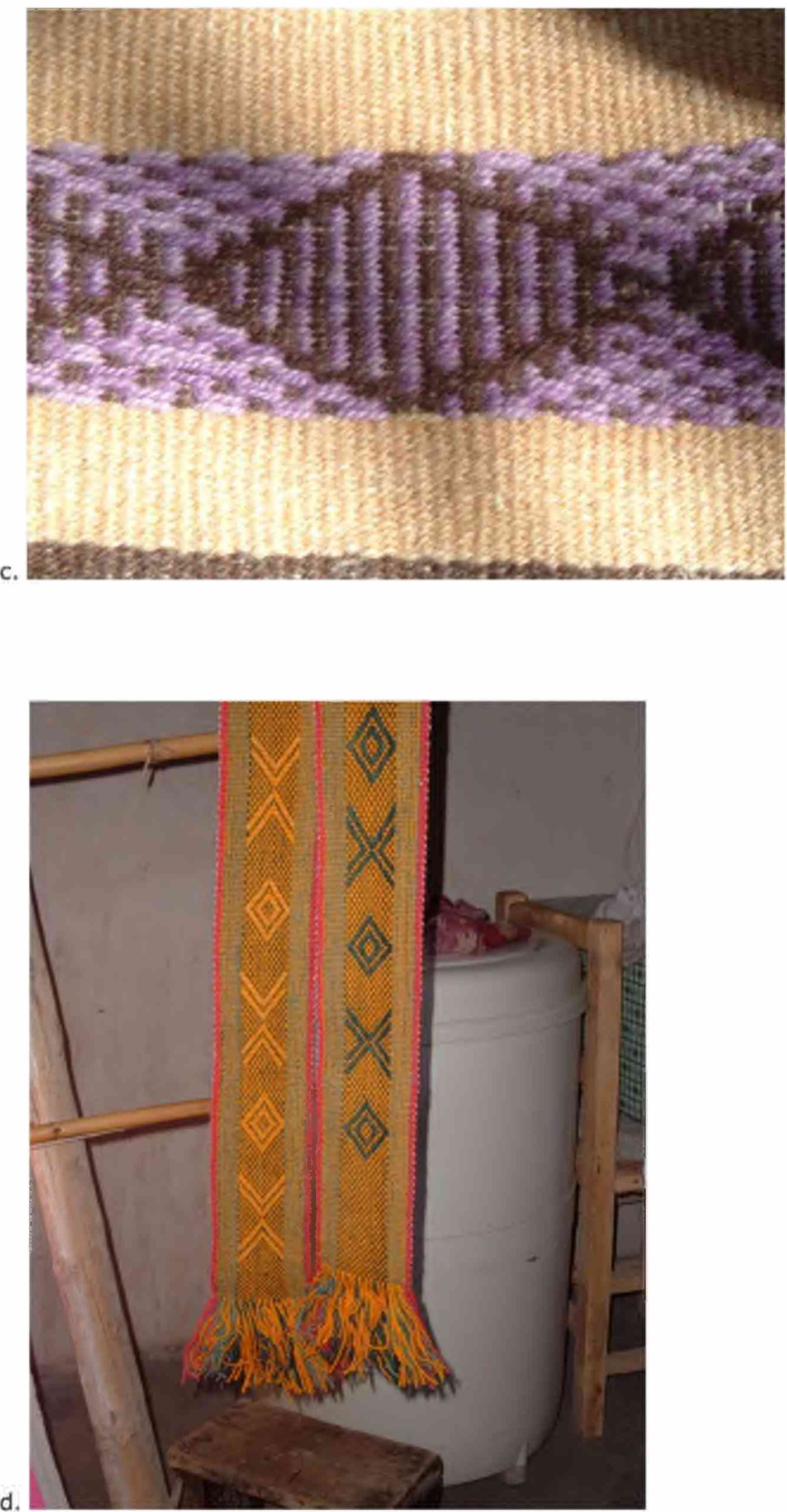


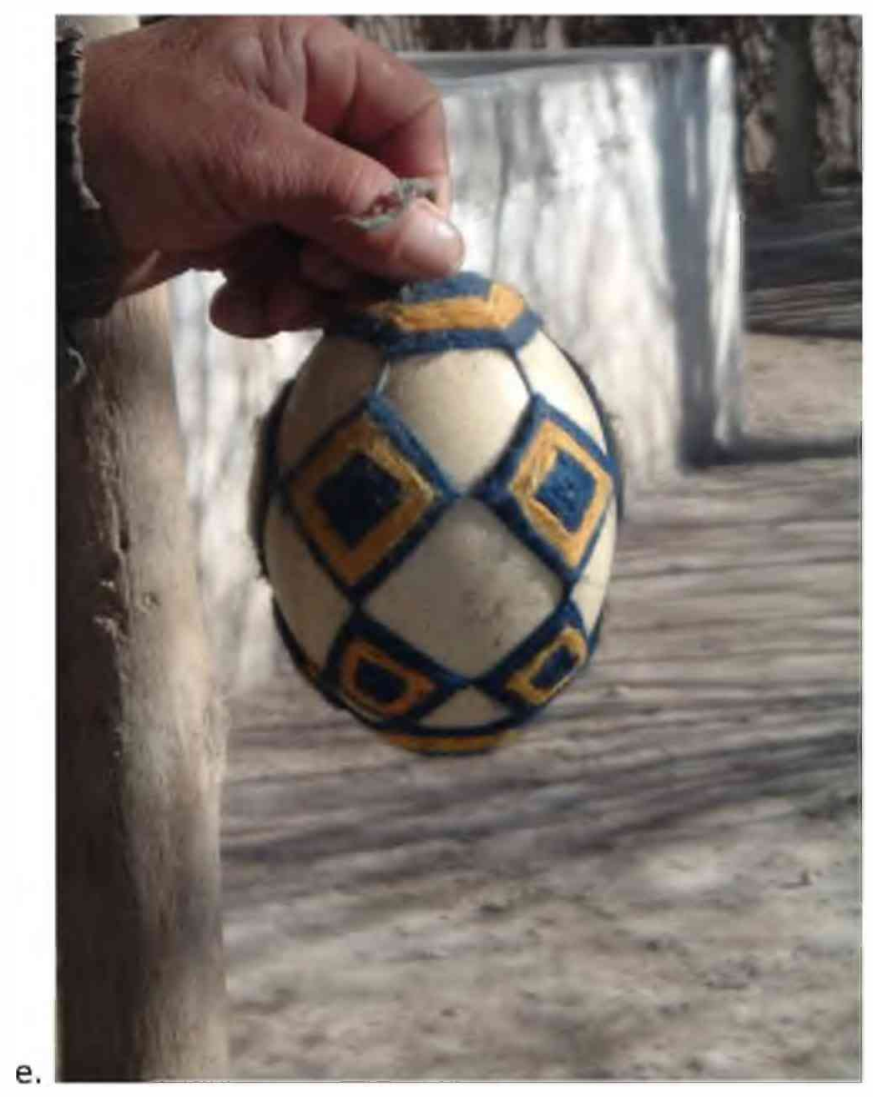

Fig. 10: a. Telar vertical con matra en elaboración, b: Matra realizada en telar vertical teñida con tintes naturales y artificiales, c: Detalle del tejido de la foto anterior, $d$ : Faja teñida con tintes naturales y artificiales. e: Adorno realizado con huevo de avestruz (Rhea americana) forrado con tejido en lana,

El tejido en lana, principalmente de oveja, todavía se sigue practicando en algunos sectores de La Humada. Donde más se concentra esta actividad es al Sur, en el paraje de Chos Malal así como en otros sectores del oeste pampeano y de la provincia de Mendoza. Los residentes de La Humada que mantienen esta práctica son inmigrantes de aquellas localidades o sus descendientes, ya que este saber se sigue transmitiendo de una generación a otra. La práctica del tejido es llevada a cabo principalmente por las mujeres y la transmisión del conocimiento se efectúa casi siempre a través de algún integrante de la familia de sexo femenino. No obstante también se observaron pocos casos de varones practicantes de este arte. Los resultados expresan que en un $32 \%$ de los hogares visitados continúa habiendo al menos algún miembro de la familia que realiza esta actividad. 


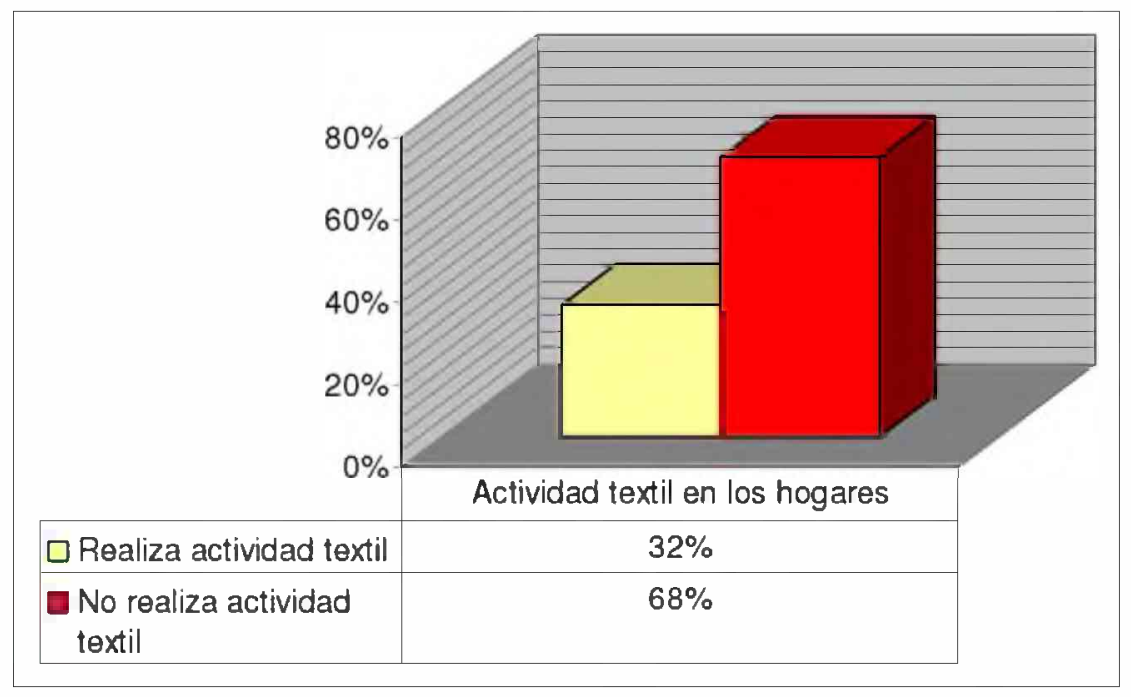

Gráfico 15: Persistencia de la tejeduría en lana.

\subsubsection{Las plantas tintóreas}

Las coloraciones naturales de los tejidos se obtienen a partir de elementos del entorno, muchos de los cuales son plantas. Las más usadas con este fin son la jarillilla (Gochnatia glutinosa), jarilla (Larrea divaricata, L. cuneifolia, L. nitida), té pampa (Thelesperma megapotamica), de las cuales se emplea las partes aéreas. Asimismo, también se sirven de molle (Schinus johnstonii), piquillín (Condalia microphylla), matorro (Cyclolepis genistoides) y algarrobillo o cacho de cabra (Senna aphylla), empleándose en estos casos las raíces.

Las tonalidades que se obtienen con ellas son: una mezcla de verde y amarillo (Gochnatia glutinosa, Larrea divaricata y Baccharis spartioides), amarillo (Baccharis crispa), castaño claro (Thelesperma megapotamica), marrón claro (Schinus johnstonii y Senna aphylla), marrón oscuro (Condalia microphylla) y azul oscuro (Cyclolepis genistoides). En algunas de las especies mencionadas, como por ejemplo la jarillilla (Gochnatia glutinosa), fue registrado que la época más adecuada para la recolección es el invierno. También se emplean plantas adquiridas en el comercio, como la cebolla (Allium cepa), con cuyas catáfilas exteriores se obtienen tonalidades castañas o la yerba mate (Ilex paraguariensis) para lograr otras tonalidades de verde. 
Es de destacar que algunas artesanas no recolectan ciertas plantas porque son conscientes de que en el teñido se requieren grandes volúmenes de algunas especies de alto valor forrajero y optan por dejar estas plantas para la hacienda. Esta situación se registró con Thelesperma megapotamica. La totalidad de las especies tintóreas aquí mencionadas se consignan en la Tabla 9.

Si bien la tejeduría no presenta un desarrollo masivo sino más bien localizado en algunos sectores del área, algo distinto ocurre con el conocimiento de las plantas tintóreas. Este, en cambio está más difundido y en él no se verifican diferencias por edades ni sexo de los entrevistados. Del total, el $87 \%$ conoce plantas tintóreas, al menos las más frecuentemente utilizadas.

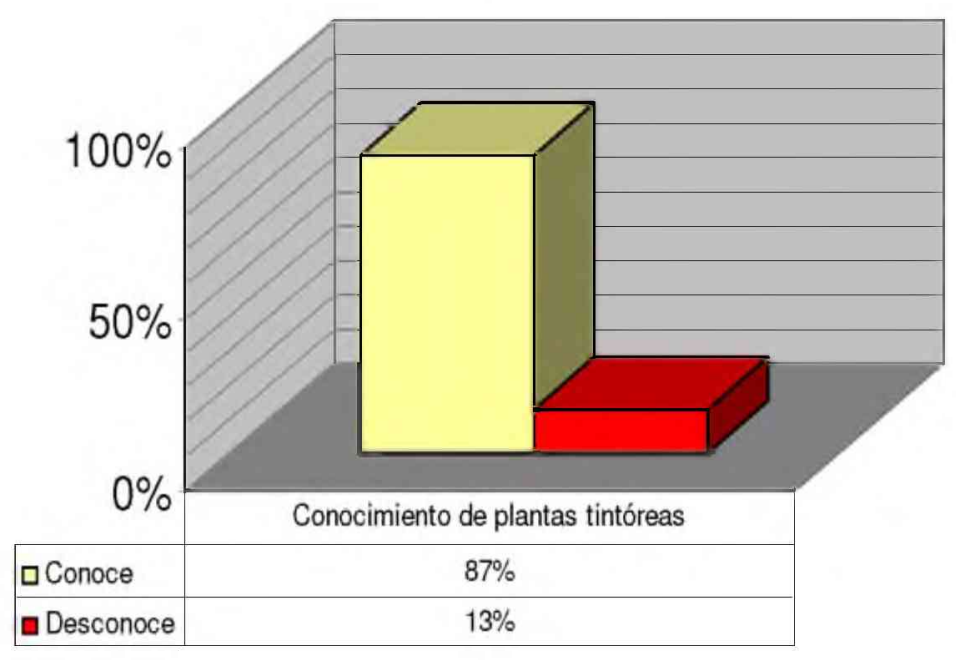

Gráfico 16: Conocimiento de las especies tintóreas

\subsubsection{Tejeduría en fibras vegetales}

Esta información solo se registró en un hogar de la zona rural de La Humada. Los artículos confeccionados son sombreros tejidos en técnica aduja, o en espiral, con cañas de coirón (Pappostipa vaginata) atadas con hilos de lana coloreados. Este tipo de artesanías no tiene mayor desarrollo en la zona, pero presenta un valor económico y estético potencial excelente debido a la alta calidad y terminación de estos productos. 


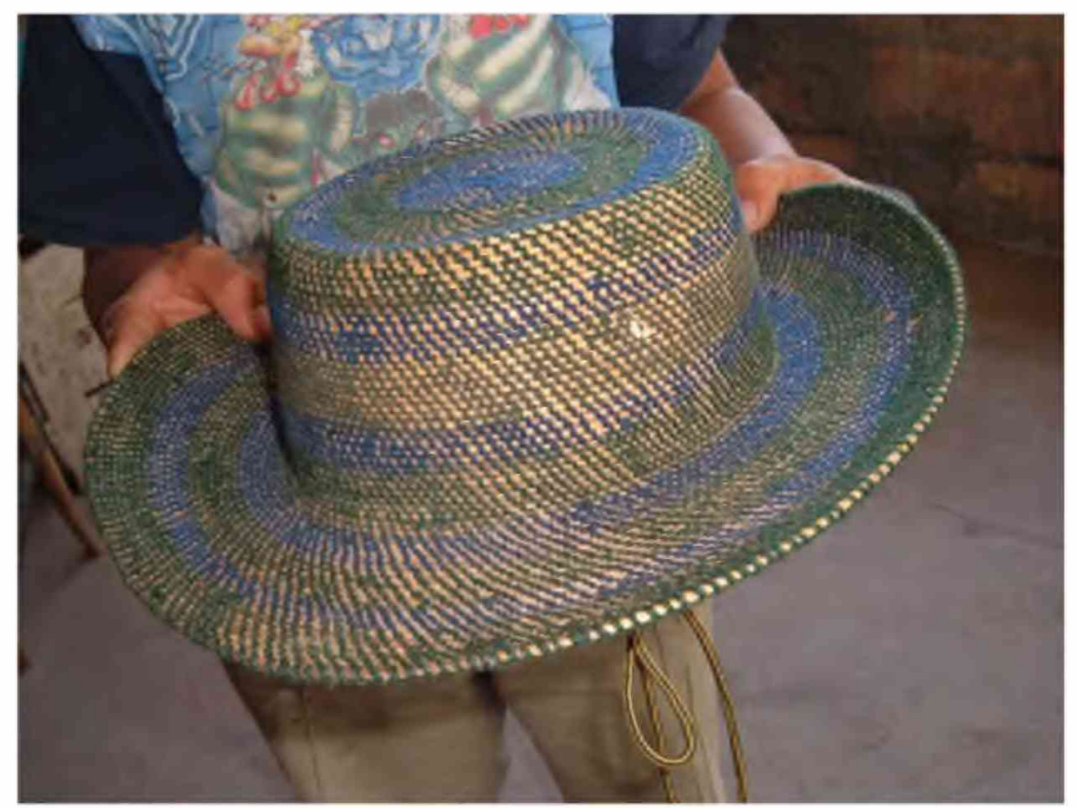

Fig. 9: Sombrero tejido con tallos de coirón (Pappostipa vaginata) e hilos de lana ovina coloreados.

\subsubsection{Artesanías en cuero}

La artesanía en cuero de potro o vacuno está ampliamente desarrollada en toda la zona, particularmente entre los varones adultos. Todo puestero tiene por lo menos nociones del trabajo en este material, ya que gran parte de su equipo de trabajo está constituido por útiles fabricados con este recurso. Los cueros de animales silvestres también se suelen emplear en confecciones típicas, como las tabaqueras. Estas se realizan con el cuero del "cogote" del avestruz moro (Rhea americana), y llevan ornamentaciones diversas con bordados en hilo o en lana coloreados.

No se registró el uso de especies vegetales como curtientes del cuero, empleándose para estos casos la sal común y el alumbre, no obstante las plantas cumplen otra función en este tipo de artesanías. En la confección de monturas, por ejemplo, el relleno de los bastos se realiza con blanquilla (Hyalis argentea), melosa (Grindelia chiloensis) o unco (Sporobolus rigens). En otros casos las plantas también se emplean como tintóreas. Para lograr coloraciones grises de distinta intensidad en el cuero destinado al trenzado de sogas se utiliza la yerba mate (Ilex paraguariensis). El tinte se logra 
recolectando los restos vegetales de las cebaduras del mate en un recipiente de lata, humedeciendo y mezclando su contenido con cierta frecuencia. La oxidación producida por la exposición al aire confiere a este depósito una coloración negra que al cabo de varios meses puede emplearse en el proceso de teñido de cuero.

\subsection{Recursos energéticos}

Sobre las leñas merecen hacerse dos distinciones: las destinadas a la calefacción y las destinadas a la preparación de alimentos. Dentro de la primera categoría entran todas las especies, aún las empleadas para cocinar, pero las propiedades más valoradas fueron el poder calórico y la duración de la combustión. En este sentido las más buscadas son el piquillín (Condalia microphylla), el algarrobo (Prosopis flexuosa f. flexuosa) y el molle (Schinus johnstonii). Entre las segundas se inscriben además otras leñas con menor capacidad calórica, características que las hacen aptas para la cocción de pan y otros alimentos en hornos donde se requiere un calor más moderado.

Las especies más buscadas para cocinar alimentos son el piquillín (Condalia microphylla), jarilla (Larrea divaricata), solupe (Neosparton aphyllum), ala (Monttea aphylla), molle (Schinus johnstonii) y alpataco (Prosopis flexuosa var. depressa). En menor medida son utilizadas la retamilla (Prosopidastrum striatum), monte negro (Bougainvillea spinosa), algarrobo (Prosopis flexuosa $f$. flexuosa), chañar brea (Cercidium praecox), y chilladora (Chuquiraga erinacea). En ambientes salinos cumplen esta función la vidriera (Suaeda divaricata), chañar (Geoffraea decorticans) y la zampa (Atriplex lampa) y hacia el norte, en áreas saxícolas, fue mencionado el altepe (Proustia cuneifolia) como fuente ocasional de leña. Estos recursos vegetales forman parte de los combustibles de uso cotidiano para preparar alimentos en cocinas a leña o en fogones dentro de la vivienda, los que a su vez cumplen con el rol de calefaccionar el ambiente. Para la extracción de leña las herramientas más empleadas son hachas y picos, ya que además de la parte aérea también se hace uso de las subterráneas.

De las especies mencionadas, las que mejores características poseen para usarlas en hornallas $y$ hornos de barro fueron la jarilla (Larrea 
divaricata), solupe (Neosparton aphyllum) y ala (Monttea aphylla). El piquilín (Condalia microphylla), en cambio, fue indicado como la mejor leña para asar carnes, calefaccionar ambientes, y calentar planchas para ropa.

Otras especies son evitadas en la recolección para estos fines porque su combustión produce humos tóxicos y olores desagradables. Estos humos causan dolores de cabeza, náuseas y las carnes asadas con estas leñas pueden provocar trastornos digestivos. Entre las especies mencionadas dentro de esta categoría están el atamisque (Capparis atamisquea) y la sombra de toro (Jodina rhombifolia). Al piquilín (Condalia microphylla) y a la retamilla (Prosopidastrum striatum) también se las indicó como productoras de humos fuertes en especial si su combustión ocurre en ambientes con poca ventilación. Todas las especies aquí citadas se indican en la Tabla 12.

El $72 \%$ de las personas entrevistadas considera que en la actualidad hay algunos tipos de leña difíciles de conseguir, dentro de las cuales se destaca el piquillín (Condalia microphylla), ala (Monttea aphylla) y molle (Schinus johnstonii).

El aprovisionamiento de leña se realiza preferentemente sobre plantas secas o quemadas en incendios anteriores. Con respecto a esto los entrevistados reconocieron una disminución en cantidad y tamaño de las mejores especies a lo largo del tiempo debido a tres factores principales: los incendios, que afectan indiscriminadamente a toda la vegetación, las sequías, tras las cuales mueren las plantas más añosas, y en las entrevistas del sector urbano también se destacó la extracción excesiva. No obstante, en el área rural se puso en evidencia una actitud conservacionista por parte de los pobladores. En otros casos puntuales manifestaron que algunas de las especies leñosas antes mencionadas no se cortan para permitir que sirva de alimento a los animales del rodeo y a los silvestres. "Acá no sacamos piquillín verde. Lo dejamos para el avestruz porque lo prefiere" (Daniel Morales, com. pers.).

Para terminar este capítulo merece hacerse un comentario sobre los métodos tradicionales de ignición del fuego y de iluminación. Si bien en la actualidad ya no se realizan estas prácticas, se registraron informaciones que 
ilustran modalidades del pasado. Una de las formas de producir fuego consistía en el frotamiento de ramas de chilca (Baccharis salicifolia) sobre una base de madera. El empleo de esta especie en taladros para ignición también fue referida por Arenas y Suárez (2007) para comunidades aborígenes del Gran Chaco. Otra se refiere a una suerte de yesquero constituido por una cola de piche (Zaedyus pichiy) que se vaciaba y en su interior se colocaba un trozo de tela que cuando era necesario se humedecía con bencina. La ignición se iniciaba al producirse chispas por fricción de piedras cuarcíferas que a los efectos se buscaban en los cerros de la zona. El uso de este instrumento, aparentemente de origen criollo (Arenas 2003), también ha sido descripto en otras comunidades de Argentina.

Las fuentes energéticas animales como las grasas y las heces de los herbivoros constituyeron en el pasado una materia prima indispensable para la iluminación. Un buen ejemplo de esto eran las velas de grasa y los candiles que utilizaban grasa animal como combustible $y$ excremento seco de caballo como mecha. 


\section{DISCUSIÓN}

Si se compara la región occidental de la provincia de La Pampa con otras áreas de la región pampeana, se evidencia para aquella una situación de aislamiento relativo debido a la distancia que la separa de los grandes centros urbanos y a una red vial poco desarrollada en la zona. Estas condiciones han contribuido a que los adelantos tecnológicos hayan llegado al área casi siempre en forma tardía, situación que favoreció la persistencia de un conjunto de conocimientos y valores tradicionales. En la actualidad, la velocidad con que operan los cambios tecnológicos y su nivel de alcance aún en el seno de las comunidades más alejadas constituyen una buena razón para deducir que los trabajos etnográficos como los propuestos en este estudio adquieran una vigencia inusual y sean de carácter prioritario con el fin de evitar una pérdida inexorable de conocimientos.

\subsection{Materiales y Metodología}

Aunque las características culturales de los residentes de La Humada son compartidas por otros pobladores establecidos en una región mucho más amplia, el criterio que se optó para la elección de este ejido municipal como área de estudio se fundamenta en los elementos de identidad y pertenencia que les confiere a sus habitantes el hecho de poseer una historia común relacionada con las instituciones, esto es: escolarización, asistencia sanitaria y otras actividades cívicas.

Luego de una exhaustiva búsqueda, la escasa documentación bibliográfica disponible para la zona fue un motivo para considerar pertinente la información relacionada con las áreas aledañas del oeste de La Pampa donde estuvieran presentes ecosistemas y comunidades humanas con formas de vida similares. Por esta razón se tuvieron en cuenta los trabajos desarrollados en el distrito de Malargüe, el más austral de la provincia de Mendoza, en las otras provincias cuyanas de San Juan y San Luis, así como la información que por influencia migratoria estuviera vinculada a distintos aspectos culturales e históricos de la sociedad chilena y de la región. 
Tal como se expresa en el capítulo correspondiente (ver 3.2. Trabajos de campo), existe un amplio consenso en la información suministrada por los pobladores, hecho que se pone de manifiesto a través de la reiteración de datos sobre algunas especies. No obstante también se registraron discrepancias en los nombres comunes y aún en el uso de algunas de ellas, así como datos aportados por única vez a lo largo de las entrevistas. Estos aspectos, ya observados en otros trabajos etnocientíficos (Arenas 2003, Arenas \& Porini 2009), no invalidan la información sino que ponen de manifiesto la complejidad y multiplicidad del conocimiento al interior de esta comunidad, razón por la cual se consideró como valida y se registró la totalidad de los datos. Solo se tomó como no válida la información que no pudo cotejarse con un ejemplar de herbario o no se obtuvieron otras referencias sobre la especie.

Algunos ejemplares herborizados debieron colectarse en estado vegetativo. Esta situación fue particularmente más acentuada entre las especies cultivadas, muchas de las cuales ya sea por las condiciones de rigurosidad del clima que no les permite completar su ciclo biológico, o por razones de aprovechamiento hortícola que condicionan a los pobladores a cosechar antes de la floración, hicieron imposible su colecta en estado reproductivo. En otros casos no pudo disponerse de material herborizado y así se indica en el Catálogo (Anexo III). En su gran mayoría se trata de frutas, hortalizas y especias ampliamente utilizadas en la alimentación diaria, algunas de ellas muy cultivadas en el pasado en las huertas, pero que actualmente se adquieren en los comercios de La Humada. Otras como Cucurbita maxima ssp. maxima, Cucumis melo, o Solanum lycopersicum no pudieron colectarse por no estar disponibles en las huertas visitadas, ya que si bien su cultivo persiste aún en la actualidad, este se realiza escasamente y hay una mayor predisposición a su compra en los comercios.

En el Catálogo Botánico de Nombres y Usos (ver Anexo III) se presentan algunas especies de las que solo se hace referencia a su nombre común. En estos casos no pudo incluirse información adicional alguna por medio de las entrevistas realizadas, pero pese a ello se decidió sumarlas al listado. Aquí, y al igual que en otros trabajos etnobiológicos (Arenas \& Porini 
2009), las razones que justifican esta inclusión están dadas por el valor que representan para una comunidad los nombres vernáculos aún sin otros datos de carácter utilitario. La sola existencia de estos nombres puede ser indicadora de conocimientos ocultos o perdidos por desuso y posterior olvido sobre estas entidades biológicas. Si bien esta investigación no trató sus causas, el solo hecho de que una especie presente un nombre común se considera aquí razón suficiente para agregarlas al catálogo en función del valor etnobotánico que representa su denominación local.

Lo expresado anteriormente contrasta a su vez con algunas especies vegetales que, siendo relativamente frecuentes en el ambiente, no se les asigna valor de uso alguno ni tampoco un nombre común. Esta situación, que también forma parte de los interrogantes de la etnobiología, también fue señalada por Arenas \& Porini (2009) pero excede los propósitos de este estudio.

\subsection{Flora del área de estudio}

De las 1327 especies vegetales que presenta la flora pampeana (Rúgolo de Agrasar \& al. 2005), en el área de estudio se estima un total de 294 taxones específicos (22\%) a partir de la base de datos del herbario SRFA y de los censos de vegetación registrados en la zona (INTA, Gob. de La Pampa, UNLPam 1980, Troiani \& al. 1994). Pese a la limitada diversidad florística que presenta esta región, la importancia que han tenido las plantas para la supervivencia queda aquí expresada a través del empleo del que han sido objeto en una amplia gama de actividades. Basta para ello considerar que las 145 especies silvestres registradas en este estudio con sus conocimientos y usos corresponden a un $49 \%$ de la flora total del área.

Este porcentaje de uso adquiere un significado relevante si se considera además la menor abundancia específica relativa propia de los ecosistemas áridos. Esta condición limitante ha favorecido una utilización diversificada de aquellas especies que se encuentran en mayor disponibilidad. Para ofrecer una idea más clara sobre la composición taxonómica de estos ambientes se puede tomar como referencia el índice de biodiversidad florística expresado como una relación entre el número de taxa presentes y el logaritmo natural del área 
geográfica de muestreo (Squeo \& al. 1998). Si se considera que la superficie del departamento Chicalcó es de $9.117 \mathrm{~km} 2$, el índice de diversidad florística obtenido a nivel específico e infraespecífico $(32,24)$ expresa un valor algo inferior al de la región aledaña de la Payunia $(40,70)$ (Prina \& al. 2003). Si bien las dos áreas poseen niveles de precipitación similares, la razón de esta diferencia se da por algunos factores en el oeste de Chicalcó entre los cuales se destacan la ausencia de especies endémicas y una mayor uniformidad del paisaje en relación a la geomorfología y a los suelos.

\subsection{Actividad Económica}

Los estudios sobre comunidades campesinas de zonas áridas ayudan a esclarecer las estrategias de supervivencia humana en ambientes cuyas condiciones para el establecimiento y posibilidades de desarrollo representan dificultades importantes que deben superarse permanentemente por sus habitantes. Para las poblaciones del oeste de La Pampa una de las dificultades más difíciles de sortear, además de las condiciones ambientales rigurosas, fue el aislamiento de los centros urbanos al que estuvieron sujetos desde la fundación de los pueblos hasta hace poco menos de tres décadas. Esta condición limitó durante mucho tiempo su abastecimiento eficiente en insumos y manufacturas para resolver sus necesidades vitales y llevar a cabo su actividad económica debiendo hacer uso en su reemplazo de los recursos naturales del entorno. La implementación de estas estrategias conformó a lo largo del tiempo un nutrido conjunto de prácticas y de creencias que dieron como resultado la fisonomía que aún persiste en la actualidad en este pueblo.

Al igual que otras comunidades humanas del Monte, la economía de los pobladores del oeste pampeano está basada en la explotación ganadera. No obstante, las comunidades pampeanas no realizan trashumancia como lo hacen otras sociedades establecidas en la región (Ladio \& Lozada 2008). Uno de los elementos que influyen sobre la práctica ganadera sedentaria probablemente esté relacionado con el proceso que dio origen a los primeros pueblos pampeanos. Los campesinos a los que hace referencia este estudio descienden de los antiguos colonos que se asentaron en pequeños poblados y en fortines militares a fines del siglo XIX. Estos asentamientos se ubicaban cerca de los cursos o espejos de agua naturales, sitios donde la práctica 
pastoril se realizaba en forma sedentaria sobre campos abiertos. Quienes adoptaron y aún hoy mantienen prácticas de uso vertical del ambiente fueron los colonos de las áreas cercanas a la cordillera de los Andes, utilizando los sitios de pastoreo de montaña y trasladándose a las tierras bajas en el invierno (Hilgert 1998, Krause Yornet 2000, Göbel 2002, Ladio \& Lozada 2004, Quiroga Mendiola 2004, Pérez Centeno \& al. 2007). Sobre este punto, es de destacar que el paisaje pampeano no favorece este tipo de práctica por su relieve Ilano sin contrastes marcados en la oferta forrajera. Este factor sumado a la escasez de fuentes de agua en superficie pueden haber sido elementos suficientes para condicionar la actividad ganadera sedentaria en detrimento de la trashumancia.

Dentro del total de especies silvestres consignadas se destacan las plantas forrajeras para todas las categorías de ganado de la zona. Si a este conjunto se le suman las que presentan efectos adversos y de toxicidad en el ganado, las empleadas en veterinaria y las que intervienen en la construcción de instalaciones rurales, el resultado denota la importancia que tienen los recursos vegetales en la actividad económica de los lugareños.

Aunque la familia con mayor representación en especies forrajeras corresponde a las Poaceae, cabe destacar que el $75 \%$ de los recursos citados dentro de esta categoría de uso está comprendido por dicotiledóneas. Estos resultados son consistentes con los dos tipos de ganado predominantes en el lugar, ya que por un lado, los vacunos explotan más el estrato herbáceo representado mayormente por gramíneas, y los caprinos lo hacen sobre el arbustivo, constituido principalmente por dicotiledóneas leñosas.

Tal como ocurre en otras comunidades pastoriles, la que concierne a este estudio posee un detallado conocimiento de las especies forrajeras presentes en el lugar (Burkart 1943, Boelcke 1957, Scarpa 2007). Esta experiencia es dinámica y acumulativa como se pudo comprobar en algunos testimonios relacionados con la aparición de algunas especies luego de ciertos eventos ambientales. Un testimonio referido a la verbenácea Glandularia flava se expresó del siguiente modo: "Acá le decimos Yerba de la vaca porque la busca mucho el vacuno. Antes no había pero vino mucho en los campos después de los incendios" (G. Corvalán, com pers.). Esto también se 
comprueba en las apreciaciones sobre la mayor abundancia de las especies de carácter invasor no preferidas por la hacienda sobre las de mejor calidad forrajera de comportamiento decreciente. Estas informaciones evidencian que los puesteros son conscientes de los cambios que ocurren en estos ecosistemas como resultado de las presiones ambientales.

La valoración de los recursos forrajeros también pudo registrarse en apreciaciones realizadas sobre el efecto del pisoteo según el tipo de ganado que se trate. "El ganado yeguarizo hace más daño al campo que el vacuno y por cada yeguarizo pueden entrar en el campo tres vacunos" (Abraham Romero, com. pers.). En este sentido, la disminución de la cantidad de cabezas de ganado equino que se acentuó en la segunda mitad del siglo XX en La Pampa pudo estar relacionada con la búsqueda de una mayor rentabilidad de la actividad. Sin embargo, otra de las razones que operan a favor de este cambio puede vincularse a una menor demanda de animales de trabajo debido a la mecanización de algunas tareas rurales.

La capacidad de observación de los lugareños abarca todos los elementos naturales del entorno. Como consecuencia de ello ponen en práctica formas de manejo empíricas con resultados efectivos. Un ejemplo de ello es la elección de las jornadas en las que se deben realizar determinadas actividades, como las castraciones de terneros en tiempo de luna menguante, época a la que se atribuye una menor probabilidad de riesgos por complicaciones en las heridas. La relación entre la elección de la fase lunar y la efectividad de determinados tratamientos veterinarios ya ha sido observado en otros trabajos etnobotánicos $y$ antropológicos de pueblos rurales de Argentina (Jiménez de Pupareli 1984a, Scarpa 2000).

La mayoría de los entrevistados reconoce la existencia de pocas especies tóxicas e identifican claramente los síntomas que producen este tipo de plantas en los animales. No obstante los casos de intoxicación referidos a Nicotiana noctiflora, Cucumis anguria y Euphorbia collina fueron muy poco frecuentes y no se registraron para Astragalus, género que está representado en la zona por dos especies: $A$. pehuenches y $A$. distinens. La actividad biológica y la toxicidad para el ganado de varias especies pertenecientes al género Astragalus ya han sido documentadas en otros trabajos donde se 
describen cuadros de pérdida de apetito, debilidad general, ataxia, ceguera, decúbito y muerte (Coburn Williams \& Barneby 1977, Lupo \& Echenique 1997, Steibel 2000, Robles \& al. 2000, Roig 2001). También se han descripto los efectos tóxicos de especies pertenecientes al género Euphorbia donde se registraron muertes súbitas sin síntomas previos pero con severas lesiones gastrointestinales debido a la notable actividad proteolítica de estas plantas (Bedotti \& al. 2002, Sequeiros \& al. 2003).

Con respecto a Sporobolus rigens es para destacar la referencia hecha sobre su toxicidad solo en el periodo de rebrote intenso en primavera. Esta información además de poner en relevancia la capacidad de observación e interpretación de los lugareños, coincide con los efectos ya observados en otras gramíneas causados por la acumulación metabólica de compuestos cianogenéticos cuando ocurren estas condiciones ambientales (Gallo 1979).

En cuanto a la herbolaria empleada en veterinaria se observa una composición equitativa entre las especies nativas y las exóticas (Tabla 4). Sin embargo, las dos plantas más utilizadas en terapéutica veterinaria son especies nativas y de fácil disponibilidad en el medio por su abundancia. Ellas son Larrea divaricata y Eupatorium patens. Los tratamientos tradicionales se aplican mayormente a casos de primeros auxilios y en afecciones agudas que revisten menor gravedad. En cambio, cuando se trata de afecciones de mayor riesgo se observa una preferencia por la aplicación de productos veterinarios de origen comercial. La facilidad de obtención de estos productos debido a la cercanía de núcleos urbanos y su consiguiente impacto sobre la pérdida de conocimiento y uso de los recursos naturales es un fenómeno que se ha observado en otras comunidades humanas (Carretero 2005, Reyes García \& al. 2005).

La mayor frecuencia de uso veterinario de las plantas se registró en desinfecciones, con un $46 \%$ sobre el total de las citas, seguido por los tratamientos antiparasitarios, de pariciones dificultosas ( $22 \%$ cada uno) y de trastornos digestivos (9\%). Simultáneamente con estos tratamientos existe en la zona un conjunto de prácticas de carácter mágico y religioso muy rico. Estas incluyen curas de palabra, por el rastro, es decir a partir de la huella que deja el ganado, y otras comunes en todo el campo argentino, así como terapias que 
requieren elementos de origen animal y mineral (Bartolomé 1968, Jiménez de Pupareli 1984 a, Scarpa 2000b). La importancia que tienen estas creencias en la terapéutica veterinaria queda ejemplificada en la práctica preventiva de las irritaciones cutáneas de los caballos cuya invocación de la cruz contiene evidentes connotaciones religiosas.

Asimismo, es para destacar el concepto generalizado en toda la región pampeana de la enfermedad como sustancia intrusa al organismo que debe ser extraída (Bartolomé 1968, Jiménez de Pupareli 1984 a). Este concepto también subsiste en el área de este estudio y se manifiesta a través de las prácticas de fomentos para madurar y hacer que "afloren" las infecciones, las prácticas de expulsión de parásitos internos y externos y los emplastos y lavajes con el fin de eliminar los "pasmos".

En las instalaciones ganaderas predomina el diseño y tipo de materiales que se disponen en el mercado, que en general están confeccionadas con materia prima ajena a la flora regional. Éstas sin embargo coexisten con otras que son tradicionales y comunes en las áreas ganaderas del país, ejemplo de ello son los cercos para el encierre de las cabras. La mayor diversificación de usos de las plantas en la confección de herramientas e instalaciones rurales está relacionada con la abundancia de las especies en el lugar. En base a esto se explica el mayor uso de Larrea divaricata. Para el caso de los árboles no existe una diferencia notable en la diversificación de usos entre la especie nativa Prosopis flexuosa y otras exóticas cultivadas en el ámbito peridoméstico de los puestos como Robinia pseudoacacia y Prosopis nigra. Dentro de esta categoría es para destacar el escaso uso que se hace de Condalia microphylla, si se considera la gran resistencia de su madera. La razón fundamental de este hecho radica en la dramática disminución actual del número de plantas de alto porte de esta especie de acuerdo a lo manifestado por los informantes de mayor edad.

\subsection{Alimentación}

Una de las razones que justifican que esta comunidad posea una dieta más rica en carnes se debe a que en estos ecosistemas las actividades de cacería de animales silvestres y la cría de domésticos es más eficiente que la 
recolección y el cultivo de plantas. Por esta misma razón, la proporción en la dieta correspondiente a los vegetales está condicionada a la obtención de estos productos a través de cultivos intermitentes o a la compra de los mismos.

La recolección de productos vegetales para la alimentación es una actividad muy limitada. Se puede tener una idea clara de esto si se considera que del total de las especies relacionadas con la alimentación, un 78 \% está constituido por las que son cultivadas y adquiridas en los comercios. La recolección de plantas alimenticias orientada tanto a la subsistencia cotidiana como a la obtención de reservas alimentarias en tiempos de escasez fue de importancia fundamental para los pueblos nativos, y estuvo ampliamente desarrollada en la región por Pehuenches y Puelches (Prieto \& Abraham 199394, Prieto 1997-98 a). Los colonos criollos y europeos, en cambio, centraron su subsistencia en la actividad pastoril y la recolección de plantas quedó restringida al consumo inmediato o como un complemento de otras fuentes de alimentación básicas de su dieta.

Los resultados señalan influencias de la cultura trasandina que llega hasta el oeste pampeano a través de Cuyo, región que aparece como componente principal del aporte migracional de la población. Buen ejemplo de ello son las elaboraciones con bebidas alcohólicas aquí registradas con los nombres de "curillena" y "chupilca". Según Agüero Blanch (1967), un alimento muy difundido en el sur de Mendoza consistente en una mezcla de ñaco con agua hirviendo y azúcar recibe el nombre de "chipilca". Como se puede observar, es llamativa la similitud entre los nombres de ambos, y la que existe en la composición de este último y la "curillena". Si además de ello se considera que en Chile se denomina "cupilca" a una mezcla de harina remojada en chicha (http://etimologias.dechile.net), todas estas similitudes entre denominaciones y formas de preparación establecen vínculos indudables entre la cultura local y las de Cuyo y Chile.

Otra relación con estos pueblos estaría representada a través de la presencia del arrope en la culinaria del oeste pampeano. El arrope, alimento de origen árabe, fue introducido en América por los españoles y su práctica como conserva alimentaria coincide con el área de difusión de los cultivos de 
vides, de cuyos frutos se elaboraban los arropes más apreciados en tiempos de la conquista y colonización española (Scarpa 1999). Siguiendo las observaciones de este autor, es llamativa la gran variedad de frutos empleados en la elaboración de arrope en el NOA y debido probablemente a una mayor disponibilidad de otras especies, el de piquillín no esté allí tan difundido como otros. Sin embargo, en La Pampa el arrope de piquillín es actualmente el único que continúa vigente ya que constituye la única planta abundante en el medio con frutos aptos para la preparación de este alimento.

Estas conservas, practicadas en el pasado con otras frutas silvestres como el solupe frutero (Ephedra ochreata), chañar (Geoffraea decorticans) o chaquil (Arjona tuberosa), actualmente han perdido vigencia en el oeste pampeano y han sido reemplazadas por los dulces y mermeladas con frutos de origen comercial. Si la elaboración del arrope está vinculada con el grado de persistencia de la economía tradicional (Scarpa 1999) y su discontinuidad de empleo como técnica de conservación se relaciona con procesos de erosión cultural, se puede señalar aquí que la desaparición de las distintas variantes de arrope en el oeste pampeano es una señal de este proceso.

En cuanto a las especias empleadas se corrobora aquí el uso de aquellas que se utilizan en toda la región pampeana, tanto en platos dulces como salados. La mayoría de estas especias son adquiridas comercialmente, y solo unas pocas son cultivadas en las huertas. El total de especias utilizadas denota una diversificación mucho menor si se compara con las comunidades del NOA, como por ejemplo la puneña, en las que se usa un conjunto de condimentos muy variados (Scarpa \& Arenas 1996). Esto expresaría una diferencia cultural marcada, ya que en el oeste pampeano no se observan estas y otras características típicas de la cocina del altiplano destacadas por estos autores, como son los sabores, aromas y colores intensos, sino más bien que aquí su rasgo es la austeridad y simplicidad, aspectos que no actúan en detrimento de su excelencia. Asimismo existe un marcado contraste con lo señalado para otras culturas, por ejemplo los tobas y wichís, entre quienes se destaca la escasez y frugalidad en el uso de condimentos en sus platos aún tras un prolongado contacto con la población criolla del NEA, en la que éstos se encuentran bien representados (Arenas 2003). 


\subsection{Salud y Medicina}

Para comprender la medicina y la farmacopea de un pueblo se debe conocer previamente qué significado tienen los conceptos de salud y enfermedad dentro de su cultura. En este sentido, conocer cómo se relaciona un pueblo con su ambiente y su cosmovisión para interpretar la etiología de las enfermedades nos permite una aproximación a estos términos.

En el área que compete a este trabajo el concepto de enfermedad no presenta límites bien definidos, y si bien se entiende como un desequilibrio, las diferencias entre síntoma y enfermedad son difusas llegándose a constituirse en una misma unidad de clasificación, una característica que ya fue señalada por Idoyaga Molina (2001).

La medicina tradicional sintetiza prácticas que persisten a lo largo de la historia y que nos remiten a los fundamentos de una ciencia médica vigente en el pasado, muchos de los cuales son actualmente rechazados por la medicina moderna. La medicina tradicional actual se ha construido con aquellos principios médicos, los conocimientos empíricos que persistieron a través del contacto entre criollos y aborígenes y la doctrina religiosa ejercida por la Iglesia Católica desde su llegada a estas tierras. En la región pampeana, algunos componentes como la interpretación y curación mágica provenientes de la cultura aborigen, no persistieron por entrar en conflicto con los lineamientos de la medicina oficial y con los preceptos religiosos de los vencedores, pero sí lo hicieron los conocimientos prácticos que no implicaban una trasgresión a esas normas.

Como todo proceso cultural, esta construcción posee una dinámica propia conforme a las transformaciones sociales que ocurren continuamente. En este sentido, la presencia del sistema médico oficial ha mejorado la situación atencional de la población, pero a su vez generó un marcado impacto en la comunidad local cuyo efecto es la pérdida de conocimientos y prácticas de la medicina tradicional, especialmente en los sectores de la población más joven y de mediana edad. En cuanto a las prácticas, contrariamente a lo que se esperaba, se ha registrado una persistencia levemente mayor de estas en los hogares del área urbana en relación con los puestos del área rural. Las causas 
de esta diferencia probablemente estén fundamentadas en cuestiones perceptuales sobre las figuras de los agentes oficiales de la salud o en otras variables de tipo social. Sean cuales fueren los motivos, escapan a los objetivos de este estudio.

No obstante, en algunos sectores más alejados de la influencia de la posta sanitaria subsisten pautas culturales tradicionales en lo que respecta a los conceptos de salud-enfermedad, y a los procedimientos de diagnóstico y terapéuticos. Esta situación se ve favorecida por otros aspectos sociales que entran en confrontación. Como ya ha sido observado por Idoyaga Molina (2001), el aumento de los diagnósticos presuntivos, la complejidad y la carencia explicativa de los diagnósticos de la medicina oficial suelen ser interpretadas por los pacientes como falta de conocimiento de los médicos. Junto con esto, la limitada eficacia y la falta de respuestas de la medicina oficial hacia algunos trastornos de carácter psicosomático y emocional son elementos que promueven el rechazo social del sistema oficial de salud y a la persistencia de conocimientos y prácticas tradicionales. La realidad nos muestra entonces que sería conveniente encontrar nuevas estrategias para hacer efectiva una integración entre ambas culturas sin que ello implique incurrir en contradicciones con la medicina oficial. Lamentablemente las dificultades en la comunicación entre los agentes de la salud y la población, y las actitudes descalificadoras de los médicos hacia la medicina tradicional hacen difícil vislumbrar tales perspectivas. Actitudes hostiles y de confrontación entre ambos sistemas médicos han sido señaladas en otras áreas del país (Jiménez de Pupareli 1984 b, Filipov 1997, Martínez 2001).

Al mismo tiempo, otras instituciones como las Iglesias Pentecostales, que tienen una presencia importante en el sector urbano, también han influido en el descrédito por parte de la población hacia los sanadores, ya sean curanderos o legos, particularmente en aquellas enfermedades naturales de origen emocional y en las impuestas. Estas iglesias, ofrecen sus propias explicaciones teóricas y sus prácticas como respuesta para curar dolencias mediante la directa participación de Dios, personificado en el Espíritu Santo, así como la praxis del culto y el ritual. 
Como ya se ha mencionado, en la medicina tradicional persisten principios de la vieja medicina oficial. Algunas dolencias como la ojeadura, presentan abundantes coincidencias vinculadas a su etiología, diagnóstico y tratamiento en escritos que nos remiten a la España del Medioevo (Ciapparelli 2005). Un claro ejemplo de la vigencia de antiguos conceptos etiológico-terapéuticos lo constituye el síndrome cálido-fresco vinculado a la teoría médica humoral, común en la medicina tradicional de toda Hispanoamérica, (Foster 1953, Currier 1966). Tomando como base estos principios se explica entonces las intervenciones a través de las cuales se induce la curación del dolor de cabeza, como ejemplo, por medio de la aplicación de un cuchillo en la nuca del paciente (elemento frío que contrarresta una dolencia generada por exceso de calor) o el empleo de un sapo (cuerpo frío) aplicado en masajes sobre la región inflamada de la cara.

En el proceso de curación con esta clase de terapias puede a veces intervenir el principio activo empleado pero en su efectividad participa en gran medida el proceso mecánico que contribuye al alivio del dolor. Esta clase de prácticas curativas empleadas nos remiten a un modelo terapéutico sustractivo (Laplantine 1997). Una evidencia de ello se puede observar en la norma terapéutica que indica realizar drenajes sobre los procesos infecciosos, que tiene alcance también en las prácticas veterinarias (Véase tratamiento del "mal seco").

Sin embargo, a lo largo de las entrevistas y tal como se manifiesta en los resultados expuestos, fue notable la ausencia de explicaciones del uso de la farmacopea encuadrada dentro de un corpus teórico que sustentara la práctica curativa. Aunque la vinculación con la teoría humoral en muchas de las terapias es indudable, el empleo de determinadas plantas, animales o minerales encuentra su razón más en la tradición empírica que en un marco etnocientífico. En relación con esto es notable la diferencia con otras sociedades de nuestro país donde este paradigma está profundamente arraigado en la cultura médica popular (Scarpa 2004).

Algunos principios de la medicina antigua como la "signatura" aún persisten entre los valores de la medicina tradicional. Esta teoria, enunciada por Paracelso, tenía como premisa que lo similar cura a lo similar ("simila similibus 
curantur"). A partir de ella, la morfología de la planta estaría indicando características de las dolencias que por su semejanza justificaría su uso terapéutico. Con respecto a esto, y entre los testimonios registrados, el aspecto de pequeñas lanzas de los frutos del alfilerillo (Erodium cicutarium) y la recomendación de uso de infusiones de esta planta para los dolores internos punzantes que se identificaron bajo el nombre de "puntadas" pareciera estar justificando la relación con esta teoría.

Otro gran paradigma médico en tiempos de la colonia estaba constituido por las teorías de Hipócrates dentro de las cuales se presenta el "principio de los opuestos". De ella derivan los preceptos de administración de remedios cálidos en enfermedades frías y viceversa. Estas terapias hallaban un sustento racional en el marco de la teoría humoral, que explicaba que las enfermedades se producian por desequilibrios entre los cuatro humores del cuerpo: sangre, flema, bilis negra y bilis amarilla (Foster 1953, Currier 1966, Queiroz 1984). Es probable entonces que la aplicación de algunas terapias registradas como la administración de ruda macho sobre una paciente mujer y viceversa, o la curación del asma por medio de una tortuga de sexo contrario al del paciente esté vinculada con el principio de los opuestos. No obstante, hay que señalar que en la medicina local los conceptos teóricos se expresan en la actualidad como desarticulados y muy pobres de datos.

Como ya se mencionó anteriormente, la labor evangelizadora de la Iglesia Católica en el oeste de la provincia de La Pampa fue llevada a cabo principalmente por sacerdotes salesianos. De este modo, la cultura criolla local quedó impregnada de símbolos y prácticas del dogma cristiano formando parte de las actividades cotidianas, dentro de las cuales las terapias curativas no fueron la excepción. Si bien la efectividad esperada de algunos tratamientos está relacionada indudablemente con el síndrome cálido-fresco, también presentan connotaciones de carácter religioso, que se evidencian por la indicación de efectuar masajes en forma de cruz o por la consigna de efectuar los tratamientos tres veces consecutivas, número clave en la religión católica.

Sin embargo la presencia de estos símbolos y prácticas no es tan rica como en otras partes del pais, especialmente en el NOA donde aparecen en muchas de las diferentes actividades cotidianas de la gente (Pérez de Nucci 
1988, Idoyaga Molina 2001) Es probable que las razones de este fenómeno sean diversas. Una de ellas podría estar fundada en que desde los tiempos del Virreinato la presencia de las instituciones gubernamentales y de la Iglesia Católica era más importante en las áreas centrales, mientras que en las zonas periféricas se presentaba más debilitada. Si se considera la prolongada condición de frontera austral con el territorio aborigen que caracterizó al sur mendocino y el oeste pampeano hasta fines del siglo XIX en comparación con la región central de Chile y las provincias del NOA (Prieto 1997-98 b, Gascón 2001), este hecho podría explicar la menor representación relativa que tienen aquí las prácticas del catolicismo en el acervo cultural de la región. A esto debería sumarse una entrada en escena más tardía de la Iglesia Católica a través de los curas salesianos y a un avance en la actualidad de las Iglesias Pentecostales.

Los habitantes del oeste de La Pampa, disponen de una farmacopea vegetal reducida en contraste con la herbolaria de las sociedades de ecosistemas tropicales. Esta condición podría estar influenciando la diversificación de usos que se registran sobre una misma especie, y en particular con aquellas de mayor abundancia. Esto también hace suponer que en regiones con una biodiversidad mayor, tales necesidades pueden ser cubiertas por una mayor oferta de la naturaleza. De este modo existe la posibilidad para sus habitantes de experimentar con un mayor número de materias primas seleccionando las que mejor cumplen con los propósitos buscados.

El conocimiento profundo que poseen los lugareños sobre el medio natural también se advierte en el reconocimiento del "tomillo" y la "yerba del lagarto" como entidades botánicas diferentes de uso medicinal y culinario, pese al aspecto idéntico de ambas. Desde el punto de vista taxonómico se trata de la misma especie (Acantholippia seriphioides) pero poseen diferencias en la composición de sus aceites esenciales (Ruiz Leal 1972) y esto se pone de manifiesto a través de sus fragancias, presentando respectivamente aromas alcanforados y cítricos.

Si se considera la totalidad de de los recursos vegetales empleados dentro de las diferentes categorías de uso, las plantas silvestres que 
intervienen en el control de la salud ocupan el segundo lugar luego de las relacionadas con la ganadería. Esa cifra se hace aún más importante si se consideran las especies cultivadas y adquiridas comercialmente ya que el conjunto de las especies vegetales que forman parte de la medicina tradicional están constituidas por un $61 \%$ de silvestres, repartiéndose el resto en forma similar entre las cultivadas y las adquiridas por intercambio.

En la terapéutica vegetal existen puntos en común entre la veterinaria y la medicina. De este modo, plantas que se aplican sobre el ganado también se emplean en el tratamiento de dolencias en humanos. El mejor ejemplo de ello es el uso de la jarilla (Larrea divaricata) de la que se aprovechan sus propiedades desinflamatorias y desinfectantes. Algunos ingredientes de la farmacopea local son compartidos por otros pueblos de Argentina, lo que estaría evidenciando, más allá de los matices propios de cada región, su origen común o procesos de incorporación en un pasado reciente. Algunos ejemplos de esto pueden evidenciarse con los baños corporales realizados con túmulos de los hormigueros (Martínez \& Planchuelo 2003), el empleo de nidos de picaflor en el tratamiento de dolencias diversas, o el cultivo de ruda (Ruta chalepensis) para alejar los males (Arenas \& Galafassi 1994).

Al hablar de la salud no se puede dejar de hacer referencia al papel que cumple la mujer en la transmisión de estos conceptos en el seno del hogar. Muchos conocimientos de los puesteros varones sobre los recursos locales y su empleo en la curación de enfermedades fueron aprendidos a partir de las prácticas que hacían sus madres o abuelas cuando eran niños. Así como este saber es generalmente compartido entre personas de ambos sexos, las cuestiones vinculadas al cuidado de la salud reproductiva de la mujer y los del niño recién nacido tienen mayor representatividad entre las mujeres, algunas de las cuales prestaron servicios de asistencia como parteras a otras vecinas de la zona. Las técnicas de asistencia en el parto y puerperio registradas en este estudio son similares a las documentadas por Agüero Blanch (1968) para el sur de Mendoza y en otros trabajos del país vinculados al tema (Jiménez de Pupareli 1984 b, Bianchetti 1989).

La farmacopea relacionada con la salud reproductiva de la mujer se destaca por una mayor presencia de plantas exóticas, como la manzanilla 
(Matricaria recutita), la borraja (Borago officinalis) y la canela (Cinnamomum zeylanicum). Otros métodos, en cambio, apelan al empleo de plantas nativas o a elementos de uso cotidiano para lograr los propósitos buscados. En este sentido, el efecto del tratamiento por el cual se inducían las contracciones del parto por ingesta de carbón de las sartenes mezclado con aceite o manteniendo en la boca de la madre los extremos de las riendas de los caballos probablemente se fundamenten en la provocación de náuseas, vómitos y contracciones internas violentas que pudiera ocasionar esta práctica en la paciente, o tal vez sean acciones de contenido metafórico que no fue posible develar.

Aunque no fue explícitamente manifestado, también existe una indudable vinculación con el síndrome cálido-fresco en las terapias del parto y postparto. Todo el cuidado que se brinda a la madre consiste en la administración de alimentos y bebidas calientes o con ingredientes a los que se les atribuye tal característica, así como en evitar todo tipo de desgaste físico y de exposición al frio. Estas prácticas, así como los cuidados en la atención del niño recién nacido constituyen una prueba más de la estrecha relación existente con los preceptos médicos vigentes en la época colonial.

En cuanto a los aspectos relacionados con la limpieza y la cosmética, los resultados expresan una importante dependencia en el pasado de los recursos vegetales del ambiente utilizados con este fin. La mayor parte de las plantas utilizadas en la elaboración de lejías pertenecen a la familia Chenopodiaceae debido al requerimiento de altas cantidades de carbonatos para actuar como agentes tensioactivos. Todas ellas son de amplia distribución en los bajos salobres de la región. No obstante, el recurso vegetal más empleado como jabón era el tupe (Panicum urvilleanum), una gramínea abundante, que por su crecimiento rizomatoso cubre amplias superficies en las planicies arenosas. La amplia difusión de su uso en la región hizo de esta planta un insumo aún más representativo que el jabón sólido hecho a partir de grasas animales. Su popularidad es significativa y así lo demuestran muchos de los testimonios que se refieren a él como "jabón de tupe", diferenciándolo con esta denominación de otros jabones. 
Sin embargo, en la actualidad los resultados de las entrevistas ponen en evidencia un fuerte proceso de erosión cultural en la utilización de estos productos tradicionales debido a su reemplazo por los modernos insumos para la limpieza que ofrece el mercado. El hecho de que actualmente se empleen exclusivamente estos productos es la razón por la cual la mayoría de quienes conocen los recursos empleados $y$, en especial, los métodos de preparación del jabón de tupe y las lejías sean adultos de más de 40 años. La mayoría de la población joven desconoce estos saberes que forman parte de su propia cultura.

\subsection{Vivienda}

Los métodos de construcción de las viviendas son similares a los descriptos en otras localidades cercanas de las provincias de La Pampa (Ambrosetti 1893) y de Mendoza (Böhm de Saurina 1961). El plan espacial de organización de las dependencias, con habitaciones separadas o contiguas pero sin comunicación interna es similar al observado en muchas otras partes del campo argentino, aún en regiones que no se corresponden culturalmente con el área en cuestión (Martínez Crovetto 1968 a). Además de estos aspectos, las aptitudes y uso para la construcción de paredes y techos de algunas de las especies vegetales aquí consignadas también se han señalado en otros trabajos etnobotánicos de Cuyo (Hernández 2002). Lo mismo ocurre con el embarrado de paredes, técnica ampliamente compartida con grupos humanos de diferentes regiones fitogeográficas (Martínez Crovetto 1968 a, Keller 2008).

Se destaca, sin embargo, la ausencia de especies vegetales empleadas para atar y sostener las estructuras de la construcción a diferencia de lo observado por Keller (2008) en comunidades del norte de Argentina. Debido a la escasa disponibilidad de estos materiales en el entorno, su función aquí la cumplen los alambres o los tientos de cuero, muy difundidos para estos usos en toda la región pampeana.

Es de singular interés el registro del uso en el pasado de un tipo de construcción con diseño cónico denominado localmente "torito". En la obra de Villalobos (1992) se puede observar un grabado de Famin de 1839 en el que 
aparece una toldería de cueros cónica perteneciente a los aborígenes pehuenches del lado oriental de la cordillera y actualmente, en las comunidades australes chilenas donde existe una importante presencia de la población mapuche, es muy común el tipo de construcción de viviendas con techo de diseño cónico. Sin embargo, tal como atestiguan documentos históricos, los Pehuenches, población con una importante influencia de los grupos mapuches trasandinos, abandonaron la vivienda cónica y adoptaron rápidamente el toldo de cuero, cuyo origen es típicamente pampeano (Durán 1993-94). Esto permite inferir que la reintroducción de aquel diseño es actual, lo cual fortalece la hipótesis de la existencia de vínculos con la cultura chilena por aporte migracional, probablemente a través de Mendoza. Esta hipótesis se fortalece aún más si se tiene en cuenta que el término "torito" se trata de un chilenismo pues en el país trasandino se denomina así a los toldos de lona de forma cónica (Morinigo 1966).

\subsection{Artesanías y enseres domésticos}

Los resultados expresados en torno a este tópico dentro de la cultura material pone de manifiesto la importancia que tiene aquí también la materia prima vegetal. Las plantas todavía siguen siendo recurso obligado en la confección de muchas artesanías, herramientas y utensilios de uso doméstico. Sin embargo, se destaca, al igual que en toda la región pampeana el predominio del cuero en la elaboración de una amplia variedad de instrumentos, $y$ en este sentido la importancia regional de este insumo trasciende en tal medida que bien puede hablarse de una cultura del cuero.

Existe una amplia diversidad de plantas leñosas silvestres que junto con los árboles cultivados proveen abundante material de buena calidad en cuanto a la resistencia mecánica, condición que permite confeccionar múltiples herramientas o partes de ellas destinadas a cubrir las exigencias de los trabajos más duros relacionados con la producción. Uno de los aspectos limitantes de las especies silvestres para este uso es la escasa disponibilidad de ramas y troncos de diámetro grande, condición que en parte se explica por las características inherentes a la vegetación del Monte y que en la actualidad se acentúa por la pérdida de las plantas de mayor porte debido al aumento de la frecuencia de los incendios (Medina $\&$ al. 2000). 
Muchas de las confecciones artesanales se están perdiendo en la actualidad debido a mejores posibilidades de acceso a los adelantos tecnológicos, esta situación pone un llamado de alerta sobre la necesidad de realizar registros de las tecnologías locales con el fin de evitar las consecuencias negativas que significan la pérdida de esos saberes. No obstante, otras actividades como el tejido están plenamente vigentes, a punto tal que el paraje de Chos Malal es el área de La Pampa donde más desarrollo tiene este arte (Ladaga de San Cristóbal 1980). Pese a que en algunos trabajos artesanales se manifiesta un proceso de erosión cultural como ocurre en otras partes del país (Martínez 2002), todavía pueden observarse o escuchar los detalles de un arte que se resiste a desaparecer a partir de las narraciones de los pobladores.

Como en otras categorías de uso aquí desarrolladas, gran parte de los enseres confeccionados con recursos naturales del entorno -que en el pasado formaban parte de la vida cotidiana de los pobladores- hoy se ven reemplazados por artículos comerciales de más fácil adquisición. En algunos de los hogares rurales de La Humada todavía pueden verse herramientas que han caído en un total desuso como por ejemplo las piedras de moler o los morteros de troncos ahuecados. En estos casos particulares, su extinción no responde tanto al reemplazo de estos instrumentos sino a la pérdida de algunas recetas culinarias, como el patay, el mote, el ñaco o la mazamorra, que requerían del empleo de ellos para la molienda de productos vegetales. Otros, como las escobas o los zarzos para usos diversos siguen en uso y su vigencia se debe a la facilidad de obtención de los materiales con que están construidos y a la eficiencia de su empleo. La amplia disponibilidad local de la jarilla (Larrea spp.) es un ejemplo de ello, razón por la cual es la especie más mencionada para estos fines.

En la tejeduría también se destaca un proceso de reemplazo parcial de los tintes naturales por anilinas sintéticas, y muchas de las tejedoras combinan las tonalidades provistas por ambos insumos en una misma prenda de acuerdo a sus preferencias personales o a la demanda de los clientes. La obtención de colores más intensos hace que los tintes artificiales se prefieran más que los naturales y su reemplazo se facilita por la fácil disponibilidad de 
las anilinas sintéticas. A ello se agrega la dificultad de obtención de ciertas partes de plantas para lograr los tintes deseados, como por ejemplo las raíces, dificultad representada no solo en el esfuerzo de la labor de obtención sino también en el hallazgo de plantas de tamaño adecuado para estos fines.

No obstante, se observa la persistencia del uso de varias especies vegetales y mordientes documentados en otras áreas de La Pampa al igual que la utilización del hollín de las cocinas a leña como tinte natural (Steibel 1982). El empleo de los recursos vegetales trasciende el espacio regional y se pueden observar usos y procesos con las mismas especies en otras partes del país (Trillo \& Demaio 2007). Asimismo se destaca el uso del telar vertical aborigen y de los mismos diseños y nombres de sus partes que los registrados en la provincia limítrofe de Mendoza (Ladaga de San Cristóbal 1980, Balbuena 1993).

En cuanto a la tejeduría con fibras vegetales se puede afirmar que está prácticamente ausente en el área ya que este tipo de artesanías se registró en un solo hogar en la confección de sombreros. Sin embargo, la supervivencia de este arte constituye un vínculo con la cestería aborigen cuyana, que actualmente se continúa practicando en la región de la laguna de Guanacache, en el norte de la provincia de Mendoza (Sosa \& Vallvé 1999).

\subsection{Recursos energéticos}

Tanto para la calefacción como para la preparación de alimentos la gente sigue empleando leña como un complemento importante de otras fuentes de energía. Este es un recurso abundante ya que el componente arbustivo es predominante en este ecosistema, a excepción de los sitios en los que el paisaje se modifica en pastizales psamófilos o halófilos.

Muchas de las especies consignadas como buenas leñas ya han sido registradas en estudios arqueológicos y etnobotánicos en otras regiones del país (Capparelli \& Raffino 1997) y en áreas aledañas como el sur mendocino (Hernández 2002) por lo que se puede afirmar que el uso y preferencia de las leñas están ampliamente compartidos en la región. 
La facilidad de obtención de leña permite a los pobladores adoptar actitudes conservacionistas que favorecen el crecimiento de ciertos árboles o arbustos para la satisfacción de otras necesidades y gustos. Por ejemplo, la decisión de no cortar o extraer plantas de piquilín (Condalia microphylla), está asociada a la preferencia por el consumo directo de sus frutos o para la elaboración de arrope y también con el propósito de atraer a los avestruces cerca del puesto, ya que la cacería de estos animales está muy arraigada entre algunos pobladores. Se señaló para el caso que estos animales son muy ávidos por el consumo de aquellos frutos.

Actualmente la mayor parte de la recolección de leña se efectúa a partir de individuos muertos en pie a causa del fuego. En ocasiones estos incendios son de alta intensidad ${ }^{1}$ y las plantas más afectadas son aquellas que mueren por no poder emitir rebrotes. Si bien el fuego es un componente importante en la dinámica de estos ecosistemas, la frecuencia y extensión de los mismos han aumentado en el área a partir de la colonización hispano criolla (Medina \& al. 2000). Si a esto se le suma su crecimiento lento, se comprende que si esta dinámica persiste conducirá a un empobrecimiento del paisaje aún mayor en especies con estas características y poco resistentes a fuegos de alta temperatura como son piquillines (Condalia microphylla), molles (Schinus johnstonii) y alas (Monttea aphylla).

En este tipo de ambientes, la extracción de leña conjuntamente con el ramoneo del ganado, (principalmente el caprino) suelen generar importantes procesos de deforestación en torno a las proximidades de los puestos rurales y de los poblados. Estas alteraciones del ecosistema remarcan la necesidad de ampliar la información sobre la ecología de los arbustales para implementar métodos de manejo adecuados a estos ambientes (Ruthsatz 1974).

\footnotetext{
${ }^{1}$ El incendio ocurrido entre noviembre de 2000 y enero de 2001 afectó más de 2.600.000 has. y anualmente se incendian en promedio aproximadamente 300.000 has. http://www.inta.gov.ar/pro/radar/info/documentos/Teledeteccion/96.pdf
} 


\section{CONCLUSIÓN}

Las condiciones de aislamiento del oeste pampeano han sido la causa principal para que los adelantos tecnológicos llegaran a la zona de manera tardía. Esta situación contribuyó con la persistencia de costumbres y formas de vida tradicionales que se mantuvieron con pocos cambios hasta hace solo unas pocas décadas. A partir del decenio de 1990, el fenómeno de globalización de los mercados permitió en la zona la llegada y el acceso de la población a nuevas tecnologías e insumos, hechos que generaron cambios en sus formas de vida y en las modas de consumo, con el consecuente impacto en sus tradiciones.

En la población estudiada, la actividad económica más importante es la ganadería de cría extensiva. Las estrategias implementadas para llevar a cabo esta actividad y las condiciones rigurosas del medio no solamente han definido un tipo particular de trabajador de la producción, el campesino criancero, sino que también jugaron un rol condicionante en la construcción de la identidad cultural de los habitantes.

Los primeros contingentes humanos de mestizos y extranjeros que llegaron a esta región desarrollaron un alto grado de dependencia sobre los recursos naturales pudiendo así sobrevivir en un medio que, dadas las condiciones de rigurosidad ambiental, no ofrece por sí mismo alicientes para el establecimiento permanente. Estas estrategias se pusieron en evidencia en las historias de vida que sirvieron de base al desarrollo de esta investigación.

El total de especies vegetales silvestres registradas asciende a 145, pertenecientes a 42 familias, cifra que corresponde a un $49 \%$ de la flora total estimada para el área. Las familias más representadas en orden decrecientes son Asteraceae, Poaceae, Verbenaceae, Solanaceae y Chenopodiaceae. No obstante, la limitada diversidad florística favoreció una utilización más variada sobre aquellas especies que se encuentran en mayor disponibilidad, siendo Larrea divaricata la que presentó mayor cantidad de registros de usos. 
La importancia de la ganadería para la economía de los pobladores queda demostrada por el detallado conocimiento de la flora silvestre local vinculada con este tema. Este conocimiento no se refiere solamente a su utilización directa, sino que también abarca su dinámica ecológica vinculada a los cambios climáticos y las presiones de manejo sobre el agroecosistema.

Existe una falta de correlación entre el conocimiento de las plantas y su uso con fines alimentarios. Concretamente se destaca un conocimiento del uso de especies vegetales mayor que las que realmente se utilizan y esta diferencia se relaciona con cambios en la forma de vida de los pobladores y con procesos de substitución de alimentos recolectados por productos manufacturados del mercado (Hilgert 1999, Ladio \& Lozada 2004, ReyesGarcía \& al. 2005, Arenas \& Scarpa 2007). Una señal indicadora de este fenómeno queda aquí demostrada con la pérdida del empleo de distintas variantes de arrope como técnica de conservación de los alimentos.

Junto con ello se pone de relieve una importante participación de las especies vegetales adquiridas comercialmente mientras que las cultivadas ocupan el segundo lugar. La recolección de plantas silvestres con fines alimentarios está escasamente representada.

La medicina tradicional se ha construido a partir de la fusión de fundamentos de la medicina oficial del pasado con los conocimientos empíricos que quedaron del largo contacto entre blancos y aborígenes. Sin embargo los principios de la teoría humoral y el síndrome cálido-fresco no tienen aquí la representatividad que se pone de manifiesto en otros sistemas médicos tradicionales de Argentina y de América Latina. No existe en este sentido un corpus teórico explícito que justifique diagnósticos y terapias sino que este subyace y persiste a la luz de los resultados empíricos de la práctica médica.

La medicina tradicional sufre actualmente un marcado desplazamiento por parte de la medicina oficial $y$ al mismo tiempo ha sido objeto de substituciones e incorporaciones de terapias por parte de las llamadas medicinas alternativas que llegan al lugar a través de los modernos medios de comunicación. 
Las plantas que forman parte de la farmacopea están relacionadas con la atención primaria de la salud. En este ámbito tiene mayor representatividad la recolección de especies silvestres sobre las cultivadas y adquiridas por otros medios. Al igual que en las prácticas veterinarias, las plantas se encuentran presentes en múltiples formas de diagnóstico y terapias ejercidos en contextos religiosos. En ellos cobran forma los símbolos e imágenes del catolicismo. En cambio, en los hogares que adhieren al culto protestante no se registraron datos que indiquen relaciones de ritual-farmacopea.

Los conocimientos y usos de las plantas son en general compartidos por varones y mujeres; sin embargo existen algunos temas en los que aportaron con mayores detalles los informantes de algunos de los dos sexos. Las áreas donde se puede establecer una clara dominancia del conocimiento de los varones son la actividad ganadera y en particular las especies forrajeras y tóxicas para el ganado, las de uso en veterinaria y las que forman parte de las construcciones de las instalaciones rurales mientras que las mujeres se destacaron en el conocimiento de todo aquello que estuviera relacionado con la medicina tradicional y la tejeduría en lana.

Existe un marcado proceso de erosión cultural en la porción más joven de la población que se evidencia por el desconocimiento de prácticas que ya no están vigentes. Un ejemplo de ello ocurre con las plantas utilizadas en la limpieza e higiene personal. Asimismo se observa una pérdida paulatina del conocimiento sobre las terapias tradicionales o los insumos vegetales que en ellas intervienen.

En las expresiones de la identidad de este pueblo se pueden advertir rasgos que señalan la persistencia de elementos de la cultura aborigen. Esta observación se puede comprobar en los registros que se refieren a la actividad artesanal actual, particularmente la tejeduría en lana y sus diseños.

En el área se verifica una importante influencia de las tradiciones cuyanas y elementos procedentes del país trasandino, siendo de origen mendocino el principal del aporte migracional de la población. Esta influencia se observa claramente en el arte culinario tradicional y en los nombres comunes de plantas que en otras áreas de La Pampa reciben diferente 
denominación. Asimismo, se pudieron observar algunos aspectos culturales de origen chileno como por ejemplo diseño y nombre común de las viviendas con techos cónicos.

Las especies vegetales de fácil disponibilidad en el entorno y que ofrecen comprobadas aptitudes de uso continúan utilizándose aún cuando estas compiten con insumos que pueden adquirirse comercialmente. Así es como todavía persisten los conocimientos y usos de plantas vinculados con la ganadería, con la farmacopea tradicional, con la confección de algunos enseres domésticos y con la recolección de una amplia gama de combustibles vegetales para cocinar y calefaccionar.

La recolección de leña es una actividad cotidiana que tiene plena vigencia. No obstante el acceso a otras fuentes de energía como el gas envasado, la energía eléctrica y los hidrocarburos, representan una alternativa en los hogares urbanos. Estas opciones no actúan en desmedro de una sobreexplotación de las plantas leñosas de los alrededores de La Humada por lo cual es recomendable desarrollar una legislación municipal adecuada sobre el tema.

La distancia a los centros de abastecimiento más próximos no actúa como un condicionante diferencial sobre el conocimiento y uso de las plantas. El alcance actual de los medios de comunicación y las mercaderías de consumo hasta poblados tan pequeños como los que se describen en este trabajo da como resultado un proceso de homogeneización de la cultura en el que no se observan diferencias en la persistencia o extinción de las prácticas tradicionales en función del distanciamiento de los centros urbanos, sino que cuando se advierten procesos de pérdidas de conocimientos tradicionales, estos ocurren por igual independientemente de él.

Las evidencias de erosión cultural expuestas no hacen más que enfatizar el carácter de urgencia que tienen las investigaciones etnobiológicas para documentar aspectos culturales que debido a los rápidos cambios que operan en la sociedad globalizada actual corren serios riesgos de desaparecer en forma indefectible. 
Los resultados de este estudio ponen de relieve la importancia que representan las plantas en la cultura de este pueblo. Ellas intervienen no solamente en la satisfacción de necesidades inmediatas como la alimentación, la vestimenta y el restablecimiento de la salud, sino también en otras que están subordinadas a las de mayor prioridad, pero que en suma contribuyen al mejoramiento del bienestar de las personas.

En este trabajo se presentaron resultados de una investigación que consistió básicamente en registrar los conocimientos vernáculos sobre un campo sapiencial en una sociedad determinada. Más allá del indudable valor que tiene la documentación del patrimonio cultural y natural, esta investigación pretende además constituirse en una herramienta de utilidad en la implementación de políticas destinadas a los campesinos de la región. En efecto, las acciones desarrolladas en los ecosistemas áridos deben considerar los resultados de las investigaciones sobre el funcionamiento de estos ambientes, pero también el conocimiento tradicional de los grupos humanos que habitan en ellos. De esta manera, se lograrán mejores resultados en los esfuerzos dirigidos hacia la conservación de la diversidad biológica y cultural.

Para concluir, las especies aquí registradas no constituyen un simple compendio exhaustivo de usos; a lo largo de estas páginas se han podido constatar en los testimonios de los pobladores el valor simbólico, el significado religioso y el rol ecológico que cumplen desde una perspectiva emic muchas de las especies vegetales que forman parte de la cultura de este pueblo. 


\section{BIBLIOGRAFÍA}

Agüero Blanch, V. O. 1963. Prácticas mortuorias en el departamento de Malargüe. Revista del Museo de Historia Natural 15: 23-34.

Agüero Blanch, V. O. 1965. La "charquiada" en Malargüe (provincia de Mendoza). Anales de Arqueología y Etnología. Universidad Nacional de Cuyo 20: 121-126.

Agüero Blanch, V. O. 1967. Supervivencia aborigen en la alimentación, en el departamento Malargüe (Mendoza). Anales de Arqueología y Etnología. Universidad Nacional de Cuyo 22: 93-100.

Agüero Blanch, V. O. 1968. Las remedieras de Malargüe. Instituto de Antropología. Universidad Nacional de Córdoba. Córdoba. 34 pp.

Agüero Blanch, V. O. 1970. La caza ritual del guanaco y del avestruz. Boletín de Antropología. Universidad de Antioquía 3 (12): 103-120.

Agüero Blanch, V. O. 1971. La última ollera de Malargüe (Prov. de Mendoza). Anales de Arqueología y Etnología. Universidad Nacional de Cuyo 26: 117-123.

Albuquerque, U. P., R. F. P. Lucena, J. M. Monteiro, A. T. N. Florentino \& C. C. B. R. Almeida. 2006. Evaluating two quantitative ethnobotanical techniques. Ethnobotany Research \& Applications 4: 51-60.

Alcorn, J. B. 1995. The scope and aims of ethnobotany in a developing world. In: Schultes R. E. \& S. Von Reis (eds.) Ethnobotany: Evolution of a Discipline. Dioscorides Press. Portland. U.S.A. Pp. 23-39.

Alexiades, M. N. 2003. Ethnobotany in the Third Millenium: expectations and unresolved issues. Delpinoa 45: 15-28. 
Álvarez, J. I. 1999. Los pueblos de La Pampa. Apuntes sobre su nacimiento, su historia. Dirección de Prensa. Subsecretaría de Información Pública. Gobierno de La Pampa. Ed. Extra. Santa Rosa. 157 pp.

Ambrosetti, J. B. 1976. Supersticiones y leyendas. Ed. Siglo Veinte. Buenos Aires. $140 \mathrm{pp}$.

Ambrosetti, J. B. 1893. Viaje a la Pampa Central. Boletín del Instituto Geográfico Argentino. Tomo XIV. Buenos Aires. 126 pp.

Anderson, D. L., J. A. Del Águila y A. E. Bernardon. 1970. Las formaciones vegetales en la provincia de San Luis. Revista de Investigaciones Agropecuarias 7 (3): 153-183.

Arenas, P. 1997. Las fuentes actuales y del pasado para la etnobotánica del Gran Chaco. Monografías del Jardín Botánico de Córdoba 5: 17-25.

Arenas, P. 2000. Farmacopea y curación de enfermedades entre algunas etnias del Gran Chaco. En: Amat, A. G. (ed.), Farmacobotánica y Farmacognosia en Argentina (1980-1998). Ediciones Científicas Americanas. La Plata. Pp. 87-118.

Arenas, P. 2003. Etnografía y alimentación entre los Toba - Nachilamole\#ek y Wichi - Lhuku'tas del Chaco Central (Argentina). P. Arenas (ed.). Buenos Aires. 562 pp.

Arenas, P. \& G. P. Galafassi. 1994. La ruda (Ruta chalepensis L. - Rutaceae -) en la medicina folklórica del Norte argentino. Dominguezia 11 (1): 7-32.

Arenas, P. \& G. Porini. 2009. Las aves en la vida de los tobas del Oeste de la provincia de Formosa (Argentina). Ed. Tiempo de Historia, Asunción. $300 \mathrm{pp}$.

Arenas, P. \& G. F. Scarpa. 2007. Edible wild plants of the Chorote indians, Gran Chaco, Argentina. Botanical Journal of the Linnean Society 153: 73-85. 
Arenas, P. \& M. E. Suárez. 2007. Woods employed by Gran Chaco Indians to make fire drills. Candollea 62 (1): 27-40.

Balbuena, M. L. 1993. Tejedoras de Malargüe. Artesanía textil de Cuyo. Ed. Universitaria. Universidad Nacional de Misiones. 23 pp.

Barrau J. 1981. La Etnobiología. En: Creswell, R. y M. Godelier (eds.), Útiles de encuesta y análisis antropológicos. Ed. Fundamentos, Madrid. Pp. 8192.

Barroso, H. D. 2000. Las técnicas de recolección de datos. En: Perez Lalanne, R. Investigación Social. Facultad de Ciencias Sociales. Universidad Nacional de Lomas de Zamora. Provincia de Buenos Aires. Pp. 237-267.

Bartolomé, L. J. 1968. El pensamiento mítico en la veterinaria folklórica. Runa $11(1-2): 71-92$.

Bedotti, D., A. Miranda, H. Allende y H. Troiani. 2002. Primera comunicación sobre la intoxicación por Euphorbia dentata en bovinos de la provincia de La Pampa. INTA. Boletín de Divulgación Técnica 73: 117-118.

Bedotti, D., A. G. Gómez Castro, M. Sánchez Rodríguez, A. García Martínez \& J. Martos Peinado. 2005. Aspectos sociológicos de los sistemas de producción caprina en el oeste pampeano (Argentina). Archivos de Zootecnia 54:599-608.

Bianchetti, M. C. 1995. Daño, ojeo y brujería en el valle Calchaquí. Actas de las Terceras Jornadas Nacionales de Folklore. Instituto Nacional Superior del Profesorado de Folklore. Buenos Aires. Pp.5-12.

Bianchetti, M. C. 1989. Embarazo, parto y puerperio en la Puna y Prepuna de Argentina. Cuadernos del Grupo de Estudios Socio-demográficos. Universidad Nacional de Salta. 43 pp.

Bocco, M. E., N. Vischi, y N. Montani. 1997. Relevamiento de las plantas medicinales espontáneas del Departamento Río Cuarto (Córdoba, Argentina). Parodiana 10: 11-18. 
Boelcke, O. 1957. Comunidades herbáceas del Norte de Patagonia y sus relaciones con la ganadería. Revista de Investigaciones Agrícolas 11 (1): 5-98.

Böhm de Saurina, K. 1961. Punta del Agua (provincia de Mendoza). Estudio antropológico-social preliminar. Anales de Arqueología y Etnología. Universidad Nacional de Cuyo 16: 181-199.

Bollig, M. \& A. Schulte. 1999. Environmental Change and Pastoral Perceptions: Degradation and Indigenous Knowledge in Two African Pastoral Communities. Human Ecology 27 (3): 493-514.

Bonasewicz, A. 2004. Las causas y los efectos de la globalización. Actas Latinoamericanas de Varsovia 27: 39-44.

Borrelli, P. y G. Oliva (eds.). 2001. Ganadería ovina sustentable en la Patagonia austral. Tecnología de manejo extensivo. INTA, E. E. A. Santa Cruz. Convenio INTA - UNPA - CAP. Río Gallegos. Argentina. 269 pp.

Burkart, A. 1943. Acantáceas indígenas como forrajeras de emergencia. Darwiniana 6 (2): 192-202.

Cabrera, A. L. 1968. Flora de la provincia de Buenos Aires. Tomo IV. INTA, Buenos Aires.

Cabrera, A. L. 1971. Fitogeografía de la República Argentina. Boletín de la Sociedad Argentina de Botánica 14 (1-2).

Cano, E. 1988. Pastizales naturales de La Pampa. Descripción de las especies más importantes. Tomo I. Convenio AACREA - Provincia de La Pampa. $425 \mathrm{pp}$.

Cantero, J. J. \& L. Ariza Espinar. 2006. Breve reseña histórica sobre el uso de las plantas medicinales en la provincia de Córdoba. En: Barboza, G. E., J. J. Cantero, C. O. Núñez y L. Ariza Espinar (eds.). Flora medicinal de la provincia de Córdoba (Argentina). Pteridófitas y Antofitas silvestres o 
naturalizadas. Universidad Nacional de Córdoba. Córdoba. Argentina. Pp. 2-12.

Capparelli, A. \& R. Raffino. 1997. La etnobotánica de "El Shincal" (Catamarca) y su importancia para la arqueología I: Recursos combustibles y madereros. Parodiana 10 (1-2): 181-188.

Carretero, A. L. 2005. Useful plants and tradicional knowledge in the Tucumano - Boliviano forest. MSc. Thesis. Institute of Biological Sciences. Faculty of Science. Aarhus University, Denmark. 57 pp.

Casagrande, G. A., G. T. Vergara \& Y. Bellini. 2006. Cartas agroclimáticas actuales de temperaturas, heladas y lluvia de la provincia de La Pampa (Argentina). Revista de la Facultad de Agronomía-UNLPam 17(1-2): 1522.

Ciapparelli, L. B. 2005. Medicina y literatura en el "Tratado de Fascinación" de Enrique de Villena. Cuadernos de Historia de España 79 (1): 31-56.

Coburn Williams, M. \& R. C. Barneby. 1977. The occurrence of nitro-toxins in old world and South American Astragalus (Fabaceae). Brittonia 29: 327331.

Comerci, M. E. 2005. La estructuración del espacio en Chos Malal. De los territorios reales y pensados a los territorios posibles. Tesis para optar al grado académico de Licenciado en Geografía. En: Anuario 2005. Facultad de Ciencias Humanas. Universidad Nacional de La Pampa. 107 pp.

Comerci, M. E. 2008. Construcción social del extremo oeste pampeano: tiempos, espacios y sujetos. En: Trabajo, propiedad y tecnología en la Argentina rural del siglo $X X$. $V$ Jornadas de Investigación y Debate. Universidad Nacional de Quilmes. 22 pp.

Correa, M. N. (ed.). 1998. Flora Patagónica. Tomo VIII. INTA, Buenos Aires. 
Cotton, C. M. 1996. Etnobotany. Principles and applications. Wiley \& Sons, New York. 399 pp.

Covas, M. R. 1998. Los espacios socioeconómicos de la provincia de La Pampa. Huellas 3: 11-27.

Cronquist, A. 1988. The Evolution and Classification of Flowering Plants. $2^{\text {nd }}$ edition. The New York Botanical Garden, New York, U.S.A. 555 pp.

Cuello, P. 1968. Bases para la ecología del Departamento Chical Co en el extremo oeste pampeano. Ministerio de Economía y Asuntos Agrarios. Gobierno de La Pampa. 57 pp.

Currier, R. L. 1966. The hot-cold syndrome and symbolic balance in Mexican and Spanish-American folk medicine. Ethnology 5: 251-263.

De la Cruz, L. 1910. Viaje a su costa, del Alcalde provincial del muy ilustre Cabildo de la Concepción de Chile, don Luis de la Cruz. En: De Angelis, P.: Colección de obras y documentos relativos a la historia antigua y moderna de las provincias del Río de la Plata. 2. Plus Ultra. Buenos Aires. Pp. 7-492.

Del Vitto, L. A., E. M. Petenatti \& M. E. Petenatti. 1997. Recursos herbolarios de San Luis (República Argentina). Primera parte: plantas nativas. Multequina 6: 49-66.

Del Vitto, L. A., E. M. Petenatti \& M. E. Petenatti. 1998. Recursos herbolarios de San Luis (Argentina). Segunda parte: plantas exóticas cultivadas, adventicias y/o naturalizadas. Multequina 7: 29-48.

Di Liscia, M. S. 2002. Cuerpos para experimentar. Objetivación médica, positivismo y eliminación étnica en Argentina (1860 - 1890). Asclepio 54 (1): $183-200$.

Di Liscia, M. S. \& A. O. Prina. 2002. Los saberes indígenas y la ciencia de la Ilustración. Revista Española de Antropología Americana 32: 295-319. 
Durán, V. 1993-1994. La araucanización de las poblaciones indígenas del Sur mendocino (siglos XVIII y XIX). Anales de arqueología y etnologíaUniversidad Nacional de Cuyo 48/49: 31-55.

Estrella, E. 1996. Función social de los trastornos culturales en la medicina tradicional de la región andina ecuatoriana. Scripta Ethnologica 18: 6574.

Feito, M. C. 2004. Antropología y políticas sociales rurales: una relación fructífera pero poco reconocida. Revista Interdisciplinaria de Estudios Agrícolas 21: 55-76.

Fernández Garay, A. V. 1988. Relevamiento lingüístico de hablantes mapuches en la provincia de La Pampa. Departamento de Investigaciones Culturales. Gobierno de la provincia de La Pampa. 61 pp.

Fester, G. A. 1963. Variedades fitoquímicas en plantas aromáticas argentinas. Boletín de la Sociedad Argentina para la Investigación de Productos Aromáticos 5: 1-5.

Filipov, A. 1997. La farmacopea natural en los sistemas terapéuticos de los indígenas Pilagá. Parodiana 10 (1-2): 35-74.

Ford, R. I. 1978. Ethnobotany: historical diversity and synthesis. In: Ford R. I. (ed.) The nature and status of ethnobotany. Anthropological Papers 67. University of Michigan, Ann Arbor, Michigan, USA. Pp. 33-49.

Foster, G. 1953. Relationships between Spanish folk medicine and SpanishAmerican folk medicine. Journal of American Folklore 66: 201-217.

Gallo, G. G. 1979. Plantas tóxicas para el ganado en el Cono Sur de América. Editorial Universitaria de Buenos Aires. Buenos Aires. 255 pp.

García, S. 1984. Conocimiento empírico, magia y religión en la medicina popular de los departamentos de Esquina y Goya (Corrientes). En: Fundación F. G. Bracht (ed.). Cultura tradicional del área del Paraná Medio. Instituto Nacional de Antropología. Buenos Aires. Pp. 256-267. 
García, S. P. \& D. I. Jiménez. 1986. Natural y postizo: Frío y caliente. Sistemas clasificatorios vigentes entre criollos del litoral argentino. Suplemento Antropológico, Universidad Católica de Asunción 21 (1): 131-146.

Gascón, M. 2001. La transición de periferia a frontera. Mendoza en el siglo XVII. Andes 12: 1-23.

Göbel, B. 2002. La arquitectura del pastoreo: Uso del espacio y sistema de asentamientos en la Puna de Atacama (Susques). Estudios Atacameños 23: 53-76.

Golluscio, R. A., V. A. Deregibus \& J. M. Paruelo. 1998. Sustainability and range management in the Patagonian steppes. Ecología Austral 8: 265284.

Graham, R. T. 1994. Quantitative ethnoecology. A metodology for the valuation and conservation of tropical forests in Beni, Bolivia. Report based on a dissertation presented for the degree of Master of Science. University of Edinburgh. 55 pp.

Gras, C. \& P. Barbetta. 2004. Trabajo y organización laboral en las pequeñas y medianas explotaciones de la región pampeana. Revista Interdisciplinaria de Estudios Agrarios 21: 33-53.

Grebe, M. E., J. Fernández \& C. Fiedler. 1971. Mitos, creencias y concepto de enfermedad en la cultura Mapuche. Acta psiquiátrica y psicológica para América Latina 17 (3): 180-193.

Grünwaldt, E., A. Vich \& A. Pedrani. 1992. Manejo de cuencas. Interrelación de la ganadería con la vegetación y el suelo. Multequina 1: 47-51.

Guber, R. 2001. La etnografía. Método, campo y reflexividad. Ed. Norma. Bogotá. 146 pp. 
Guevara, J. C., O. R. Estévez \& E. R. Torres. 1996. Utilization of the rain - use efficiency factor for determining potential cattle production in the Mendoza plain, Argentina. Journal of Arid Environments 33: 347-353.

Gusinde, M. 1936. Plantas medicinales que los indios araucanos recomiendan. Anthropos 31: 555-571, 850-873.

Hanazaki, N. 2004. Etnobotánica. En: Begossi, A. (ed.) Ecología de pescadores da Mata Atlântica e da Amazônia. Ed. Hucitec, Nepam/Unicamp, Nupaub/USP. Sâo Paulo. 37-57.

Hernández, A. M. 2002. Paleoetnobotánica en el sur de Mendoza. En: Gil A. F. \& G. A. Neme (eds.). Entre montañas y desiertos. Arqueología del sur de Mendoza. Sociedad Argentina de Antropología. Buenos Aires. 157180.

Hilgert, N. 1998. Las plantas vinculadas con el ámbito doméstico y la subsistencia de los campesinos de la cuenca del río Zenta, departamento Orán, provincia de Salta. Tesis presentada para optar al título de Doctora en Ciencias Biológicas. Universidad Nacional de Córdoba, Córdoba, Argentina. 343 pp.

Hilgert, N. I. 1999. Las plantas comestibles en un sector de las Yungas meridionales (Argentina). Anales Jardín Botánico de Madrid 57 (1): 117138.

Hilgert, N. I. 2001. Plants used in home medicine in the Zenta River basin, Northwest Argentina. Journal of Ethnopharmacology 76: 11-34.

Hoffman, B. \& T. Gallaher. 2007. Importance indices in ethnobotany. Ethnobotany Research \& Applications 201-218.

Holmgren, P. K.; Keuken, W. \& Schofield, E. K. 1981. Index Herbariorum. Part I. The Herbaria of the world. $7^{\text {th }}$ edition. Library of Congress Cataloguing in publication data. Netherlands. 452 pp. 
Ibarra Grasso, D. E. 1981. Argentina Indígena y Prehistoria Americana. Tipográfica Editora Argentina. Buenos Aires. 685 pp.

Idoyaga Molina, A. 2001. Etiologías, síntomas y eficacia terapéutica, el proceso diagnóstico de la enfermedad en el Noroeste argentino y Cuyo. Mitológicas 16: 9-43.

Idoyaga Molina, A. \& F. Sacristán Romero. 2008. En torno al uso de ensalmos terapéuticos en el Noroeste Argentino $y$ sus fundamentos míticoreligiosos. Revista de Antropología Iberoamericana 3 (2): 185-217.

INTA, Gobierno de La Pampa, UNLPam, 1980. Inventario integrado de los recursos naturales de la provincia de La Pampa. Clima, geomorfología, suelo y vegetación. Buenos Aires. 493 pp.

Jiménez de Pupareli, D. 1984 a. Aspectos tradicionales de la ganadería. En: Fundación F. G. Bracht (ed.). Cultura tradicional del área del Paraná Medio. Instituto Nacional de Antropología, Buenos Aires. 77-89.

Jiménez de Pupareli, D. 1984 b. Función de la medicina popular en la comunidad entrerriana y su relación con la medicina oficial. En: Fundación F. G. Bracht (ed.). Cultura tradicional del área del Paraná Medio. Instituto Nacional de Antropología, Buenos Aires. 237-254.

Jones, V. H. 1941. The nature and scope of ethnobotany. Chronica Botanica 6 (10): 219-221.

Keller H. A. 2008. Las plantas usadas en la construcción y el acondicionamiento de las viviendas y templos guaraníes en Misiones, Argentina. Bonplandia 17 (1): 65-81.

Kiesling, R. 1994. Flora de San Juan. Vol. 1. Vazquez Mazzini Editores, Buenos Aires. $348 \mathrm{pp}$.

Kiesling, R. 2003. Flora de San Juan. Vol. 2. Estudio Sigma, Buenos Aires. 256 pp. 
Kilongozi, N., Z. Kengera \& S. Leshongo. 2005. The utilization of indigenous knowledge in range management and forage plants for improving livestock productivity and food security in the Maasai and Barbaig communities. LinKS Project: Gender, biodiversity and local knowledge systems for food security, FAO. Report No 41, 45 pp.

Krause Yornet, M. C. 2000. Símbolo y procedimiento ritual en dos ceremonias vigentes entre los campesinos de San Juan. Scripta Ethnologica 22: 8797.

Ladaga de San Cristóbal, M. 1980. Artesanías folklóricas de La Pampa. Serie Folklore No 3. Dirección General de Cultura. Ministerio de Gobierno, Educación y Justicia. Gobierno de La Pampa. 21 pp.

Ladio, A. H. \& M. Lozada. 2004 a. Summer cattle trashumance and wild edible plant gathering in a Mapuche community of Northwestern Patagonia. Human Ecology 32 (2): 225-240.

Ladio, A. \& M. Lozada 2004 b. Patterns of use and knowledge of wild edible plants in distinct ecological environments: a case of study of a Mapuche community from northwestern Patagonia. Biodiversity and Conservation 13: $1153-1173$.

Ladio, A. H. \& M. Lozada. 2009. Human ecology, ethnobotany and traditional practices in rural populations inhabiting the Monte region: Resilience and ecological knowledge. Journal of Arid Environments 73 (2): 222227.

Lagiglia, H. A. 2002. Arqueología prehistórica en el Sur mendocino y sus relaciones con el centro Oeste argentino. En: Gil A. F. \& G. A. Neme (eds.). Entre montañas y desiertos. Arqueología del Sur de Mendoza. Sociedad Argentina de Antropología. Buenos Aires. Pp. 43-64.

León, J. 1992. Los recursos fitogenéticos del Nuevo Mundo. En: Hernández Bermejo, J. E. y J. León (eds.) Cultivos Marginados. Otra perspectiva de 1492. Organización de las Naciones Unidas para la Agricultura y la Alimentación. Roma, Italia. Pp. 3-22. 
Lupo, L. C. \& M. R. Echenique. 1997. Etnobotánica en la comunidad puneña de Yavi, Jujuy, Argentina. Parte I. Parodiana 10 (1-2): 19-34.

Martin, G. J. 2000. Etnobotánica. Manual de Métodos. Nordan - Comunidad. Montevideo. Uruguay. 240 pp.

Martinelli, M. (coord.) 2008. Sabores de nuestros pueblos: usos de los recursos naturales en la alimentación y comidas tradicionales en las comunidades de Valle Fértil, San Juan. Universidad Nacional de San Juan. 74 pp.

Martínez, G. J. 2002. Conocimiento de la flora de interés etnobotánico entre estudiantes del valle de Paravachasca, Córdoba (Argentina). Parodiana $12(1-2): 35-62$.

Martínez, G. J. 2003. Estudio etnobotánico de las plantas vinculadas con la medicina tradicional de los campesinos de Paravachasca y Calamuchita, provincia de Córdoba - aportes para su conservación. Tesis para optar al grado académico de Magister en Ciencias Agropecuarias. Mención: Recursos Naturales. Facultad de Ciencias Agropecuarias. Universidad Nacional de Córdoba.

Martínez, G. J. \& A. M. Planchuelo. 2003. La medicina tradicional de los criollos campesinos de Paravachasca y Calamuchita, Córdoba (Argentina). Scripta Ethnologica 25: 83-116.

Martínez, M. R., M. L. Pochettino \& A. R. Cortella. 2004. Environment and illness in the Calchaquí Valley (Salta, Argentina): Phytoterapy for osteoarticular and cardio-circulatory diseases. Journal of Ethnopharmacology 95: 317-327.

Martínez Carretero, E. 2004. La Provincia fitogeográfica de la Payunia. Boletín de la Sociedad Argentina de Botánica 39 (3-4):195-226.

Martínez Crovetto, R. 1963. Las noticias etnobotánicas de Augusto Guinnard. Primer Congreso del Área Araucana II: 29-41. 
Martínez Crovetto, R. 1968 a. Estado actual de las tribus mocovíes del Chaco (República Argentina). Etnobiológica 7: 1-23.

Martínez Crovetto, R. 1968 b. Estudios etnobotánicos III. Nombres de plantas y su utilidad, según los indios araucano - pampas del oeste de Buenos Aires (República Argentina). Etnobiológica 12: 1-24.

Martínez Sarasola, C. 1992. Nuestros Paisanos los Indios. Vida, Historia y Destino de las Comunidades Indígenas en la Argentina. EMECÉ. Buenos Aires. $659 \mathrm{pp}$.

Mateu, A. M. 1989. San Rafael, zona de frontera, antes y después de la Campaña al Desierto. Xama 2: 149-171.

Mateus, J. R. \& D. W. Brasset. 2002. La globalización: sus efectos y bondades. Economía y Desarrollo 1 (1): 65-77.

Medina, A. A., E. G. Dussart, H. D. Estelrich \& E. A. Morici. 2000. Reconstrucción de la historia del fuego en un bosque de Prosopis caldenia (Burk.) de Arizona, Sur de la provincia de San Luis. Multequina 9: 91-98.

Medus, N. M. \& M. I. Poduje. 1997. Las manos de la memoria. Artesanos tradicionales de La Pampa. Gobierno de La Pampa - Presidencia de la Nación. 65 pp.

Millán de Palavecino, M. D. 1964. Tejido. En: Arte popular y artesanías tradicionales de la Argentina. EUDEBA. Buenos Aires. Pp. 9-16.

Montes L. y G. E. Oliva (eds.). 1995. Patagonia. Actas del Taller Internacional sobre Recursos Fitogenéticos, Desertificación y Uso Sustentable. INTA Centro Regional Patagonia Sur - E. E. A. Santa Cruz, Río Gallegos. Argentina. 238 pp.

Morinigo, M. A. 1966. Diccionario de americanismos. Muchnik Editores, Buenos Aires. 738 pp. 
Muiño, W. 2010. Ethnobotanical study of the rural population of the west of the Pampa plain (Argentina). Ethnobotany Research \& Applications (in press)

Muiño, W. A., G. L. Alfonso \& A. O. Prina. 2006. Origen de los nombres vernáculos y usos de las plantas por parte de los pobladores del Sur mendocino. Encuentro de Lenguas Indígenas Americanas. Instituto de Lingüística. Universidad Nacional de La Pampa. 9 pp.

Newbery, S. J. 1978. Vigencia de las antiguas formas de curar en tres partidos de la provincia de Buenos Aires: Ayacucho, Madariaga y Rauch. Informes del Instituto Nacional de Antropología. Formas culturales tradicionales en el área pampeana 1. 23-39.

Núñez, C. \& J. J. Cantero. 2000. Las plantas medicinales del Sur de la Provincia de Córdoba. Ed. Fundación de la Universidad Nacional de Río Cuarto. Río Cuarto. Argentina. 144 pp.

Ojeda, R. A., C. M. Campos, J. M. Gonnet, C. E. Borghi \& V. G. Roig. 1998. The MaB Reserve of Ñacuñán, Argentina: its role in understanding the Monte Desert biome. Journal of Arid Environments 39: 299-313.

Pérez Centeno, M., M. R. Lanari, P. Romero, L. Monacci, M. Zimerman, M. Barrionuevo, A. Vázquez, M. Champredonde, J. Rocca, F. López Raggi y E. Domingo. 2007. Puesta en valor de un sistema tradicional y de sus recursos genéticos mediante una indicación geográfica: el proceso de la carne caprina del Norte neuquino en la Patagonia argentina. Boletín de Información sobre Recursos Genéticos Animales. FAO-AGRI 41: 17-24

Pérez de Nucci, A. 1988. La medicina tradicional del Noroeste argentino. Ediciones del Sol. 160 pp.

Phillips, O. \& A. H. Gentry. 1993 a. The useful plants of Tambopata, Peru: I. Statistical hypotheses tests with a new quantitative technique. Economic Botany 47 (1): 15-32. 
Phillips, O. \& A. H. Gentry. 1993 b. The useful plants of Tambopata, Peru: II. Additional hypotheses testing in quantitative ethnobotany. Economic Botany 47 (1): 33-43.

Pochettino, M. L. 2007. Conocimiento botánico tradicional. Boletín Latinoamericano y del Caribe de Plantas Medicinales y Aromáticas 6 (1): 3-4.

Poduje, M. I. 2000. Viviendas tradicionales en la provincia de La Pampa. Departamento de Investigaciones Culturales, Gobierno de La Pampa. Santa Rosa, Argentina. 49 pp.

Portères, R. 1966. Aspects de I'ethnobotanique comme discipline scientifique affirmée. Journal d'Agriculture Tropicale et Botanique Appliquée 13 (12): 701-704.

Prance, G. T., W. Balée, B. M. Boom \& R. L. Carneiro. 1987. Quantitative ethnobotany and the case for conservation in Amazonia. Conservation Biology 1 (4): 296-310.

Prelorán, J. 1975. Cochengo Miranda. 16 mm. Duración: 90 min. Auspiciada por Academia Nacional de Bellas Artes, Buenos Aires y School of Theater, Film and Television. University of California, Los Ángeles.

Prieto, M. R. 1997-1998 a. La población indígena, establecimiento de la línea base. En: La provincia de Cuyo en el siglo XVII. Tesis Doctoral. Anales de Arqueología y Etnología. Universidad Nacional de Cuyo 52/53: 55-79.

Prieto, M. R. 1997-1998 b. Formación y consolidación de una sociedad en un área marginal del Reino de Chile. En: La provincia de Cuyo en el siglo XVII. Tesis Doctoral. Anales de Arqueología y Etnología. Universidad Nacional de Cuyo 52/53: 313-327.

Prieto, M. R. y E. M. Abraham. 1993-1994. Indios, chilenos y estancieros en el sur de Mendoza. Historia de un proceso de desertificación. Anales de Arqueología y Etnología. Universidad Nacional de Cuyo 48/49: 11-29. 
Prina A. O. 1995. Las cruciferas de la provincia de La Pampa. Revista de la Facultad de Agronomía, UNLPam. 8 (2): 29-67.

Prina, A. O., G. L. Alfonso \& W. A. Muiño. 2003. Contribuciones al conocimiento de la flora de Malargüe. Nuevas citas para la provincia de Mendoza (Argentina). Parte I. Revista de la Facultad de Agronomía, UNLPam. 14 (1/2): 23-38.

Prina, A. O., G. L. Alfonso \& W. A. Muiño. 2008. Contribuciones al conocimiento de la flora de Malargüe. Nuevas citas para la provincia de Mendoza (Argentina). Parte II. Revista de la Facultad de Agronomía, UNLPam. 19: 81-90.

Queiroz, M. S. 1984. Hot and cold classification in traditional Iguape medicine. Ethnology 23: 63-72.

Quiroga Mendiola, M. 2004. Highland grassland vegetation in the Northwestern Andes of Argentina. Vegetation structure and species composition in relation to grazing. Mountain Research and Development. 24 (3): 243250.

Radovich, J. C. 1983. El pentecostalismo entre los Mapuche del Neuquén. Relaciones de la Sociedad Argentina de Antropología. Nueva Serie. 15: 121-132.

Rapoport E. H., A. H. Ladio \& E. H. Sanz. 2001. Plantas nativas comestibles de la Patagonia andina. I. Ed. Imaginaria. S. C. de Bariloche 81 pp.

Reyes-García, V., V. Vadez, T. Huanca, W. Leonard \& D. Wilkie. 2005. Knowledge and consumption of wild plants: a comparative study in two Tsimane' villages in the Bolivian Amazon. Ethnobotany Research \& Applications 3: 201-207.

Robles, C. A., C. Saber \& M. Jefrey. 2000. Intoxicación por Astragalus pehuenches (locoismo) en ovinos Merino de la Patagonia Argentina. Revista de Medicina. Veterinaria 81 (5): 380-384. 
Roig, F. A. 2001. Flora Medicinal Mendocina. Las Plantas Medicinales y Aromáticas de la Provincia de Mendoza (Argentina). EDIUNC. Mendoza. $305 \mathrm{pp}$.

Rúgolo de Agrasar, Z. E., P. E. Steibel \& H. O. Troiani. 2005. Manual Ilustrado de las gramíneas de la provincia de La Pampa. Editorial de la UNLPam, Santa Rosa, La Pampa y Editorial de la UNRC, Río Cuarto, Córdoba. 374 pp.

Ruiz Leal, A. 1972. Flora Popular Mendocina. Deserta 3: 3-296.

Ruthsatz B. 1974. Los arbustos de las estepas andinas del Noroeste argentino y su uso actual. Boletín de la Sociedad Argentina de Botánica 16 (1-2): 27-45.

Salomone, F \& N. Gouts. (eds.) 2006. Los vertebrados de las áreas protegidas de la provincia de La Pampa. Santa Rosa. 164 pp.

Scarpa, G. F. 1999. El arrope en el noroeste argentino. Ayer una fiesta, hoy un capital. En: Garrido Aranda, A. (ed.), Los sabores de España y América. Cultura y alimentación. La Val de Onsera. Huesca. España. 93-139.

Scarpa, G. F. 2000a. Estudio etnobotánico de la subsistencia de los "criollos" del Chaco Noroccidental argentino. Manuscrito presentado ante la Facultad de Ciencias Exactas y Naturales de la Universidad de Buenos Aires para optar por el título de Doctor en Ciencias Biológicas.

Scarpa, G. F. 2000b. Plants employed in traditional veterinary medicine by the criollos of northwestern argentine Chaco. Darwiniana 38 (3-4): 253265.

Scarpa, G. F. 2002. Plantas empleadas contra trastornos digestivos en la medicina tradicional criolla del Chaco Noroccidental. Dominguezia 18: 36-50. 
Scarpa, G. F. 2004. El síndrome cálido-fresco en la medicina popular criolla del Chaco argentino. Revista de Dialectología y Tradiciones Populares 59 (2): 5-29.

Scarpa, G. F. 2007. Etnobotánica de los criollos del oeste de Formosa: Conocimiento tradicional, valoración y manejo de las plantas forrajeras. Kurtziana 33 (1): 153-174.

Scarpa, G. F. \& P. Arenas. 1996. Especias y colorantes en la cocina tradicional de la Puna jujeña (Argentina). Candollea 51 (2): 483-514.

Scarpa, G. F. \& P. Arenas. 2004. Vegetation units of the Argentine semi - arid Chaco: The Toba - Pilagá perception. Phytocoenologia 34 (1): 133-161.

Sequeiros, C., L. M. I. López, N. O. Caffini \& C. L. Natalucci. 2003. Proteolytic activity in some Patagonian plants from Argentina. Fitoterapia 74: 570577.

Sosa, H. \& S. Vallvé. 1999. Lagunas de Guanacache (centro-oeste de Argentina). Procedimiento de inclusión a la convención sobre los humedales (Ramsar, 71). Multequina 8: 71-85.

Sosa Verón, H. \& A. Vivante. 1950-1951. Algunas recetas supersticiosas de Río Hondo (Santiago del Estero). Revista del Instituto de Antropología 5-6: 89-102. Universidad Nacional de Tucumán.

Squeo, F. A., L. A. Cavieres, G. Arancio, J. E. Novoa, O. Matthei, C. Marticorena, R. Rodríguez, M. T. Arroyo \& M. Muñoz. 1998. Biodiversidad de la flora vascular en la región de Antofagasta, Chile. Revista Chilena de Historia Natural 71: 571-591.

Steibel, P. E. 1982. Las plantas tintóreas y el antiguo arte de teñir. Boletín de la Cooperativa Popular de Electricidad de Santa Rosa Limitada 2 (16): 89.

Steibel, P. E. 1995. Las Euforbiáceas (Euphorbiaceae Juss.) nativas, naturalizadas y adventicias de la provincia de La Pampa, República Argentina. Revista de la Facultad de Agronomía, UNLPam 8 (2): 69-99. 
Steibel, P. E. 1997. Nombres y usos de las plantas aplicados por los indios Ranqueles de La Pampa (Argentina). Revista de la Facultad de Agronomía, UNLPam 9 (2): 1-40.

Steibel, P. E. 2000. Sinopsis de las Leguminosas (Leguminosae) de la provincia de La Pampa (República Argentina). Revista de la Facultad de Agronomía, UNLPam 11 (1): 1- 46.

Steibel, P. E. \& H. O. Troiani. 1999. El género Prosopis (Leguminosae) en la provincia de La Pampa (República Argentina). Revista de la Facultad de Agronomía, UNLPam 10 (2): 25-48.

Steibel, P., R. Toso \& H. Troiani. 2008. Plantas medicinales de la región pampeana. Laboratorios Lafitar S. R. L. Santa Fé. 264 pp.

Steibel, P. E.; Z. E. Rúgolo de Agrasar, H. O. Troiani \& O. Martínez. 1997. Sinopsis de las gramíneas (Gramineae Juss.) de la provincia de La Pampa, República Argentina. Revista de la Facultad de Agronomía, UNLPam 9 (1): 1-122.

Trillo, C. \& P. Demaio. 2007. Tintes Naturales: guía para el reconocimiento y uso de plantas tintóreas del centro de Argentina. Ed. Sezo. Córdoba. 80 pp.

Troiani, H. O. \& P. E. Steibel. 1999. Sinopsis de las Compuestas (Compositae Giseke) de la provincia de La Pampa, República Argentina. Revista de la Facultad de Agronomía, UNLPam 10 (1): 1-86.

Troiani, H., P. Steibel, G. Alfonso \& A. Prina. 1994. Catálogo de la Flora de la Provincia de La Pampa (Argentina), Actas VI Congreso Latinoamericano de Botánica. Mar del Plata, Argentina.

Valencia, L. A. 2006. Rankulche lawen (medicina rankel): persistencia actual de antiguas curaciones. En: Dupey, A. M. y M. I. Poduje, (comp.); La Narrativa folklórica como proceso social y cultural. Mundos representados y mundos interpretados. Gobierno de La Pampa, Instituto Nacional de Antropología y Pensamiento Latinoamericano, Secretaría de Cultura, Presidencia de la Nación. Santa Rosa. Pp. 271-278. 
Villalobos, S. 1992. La vida fronteriza en Chile. Ed. MAPFRE, Madrid. 435pp.

Villagrán, C., M. Romo y V. Castro. 2003. Etnobotánica del Sur de los Andes de la Primera Región de Chile: un enlace entre las culturas altiplánicas y las de quebradas altas del Loa superior. Chungará 35 (1): 73-124.

Zamorano, M. 1950. Acerca de la vivienda natural en la República Argentina y especialmente en Mendoza. Anales de Arqueología y Etnología. Universidad Nacional de Cuyo 9: 89-100.

\section{Fuentes de información en sitios web}

URL: http//antropomédica.com.ar/Kalla 10.htm

Torres, G. F. y M. E. Santoni. 2003/2004. Algunos aspectos de la veterinaria folklórica del departamento La Caldera (Salta, Argentina). Kallawaya Nueva Serie 10/11.

URL:http//equine-stranqles.co.uk

URL:http//chlorischile.cl

Prina, A. O.; G. L. Alfonso y W. A. Muiño. 2003 b. Diversidad de la flora vascular del distrito de La Payenia, Argentina. Chloris Chilensis 6 (1).

URL:http//darwin.edu.ar/Provectos/FloraArgentina/especies.asp (consulta 04I-10).

URL:http://etimologias.dechile.net

URL:http://indec.mecon.gov.ar

INDEC 2001. Censo nacional de población, hogares y vivienda 2001.

Serie 2. Resultados generales. No 11 Provincia de La Pampa.

URL:http://inta.gov.ar/pro/radar/info/documentos/Teledeteccion/96.pdf Red

Agroeconómica de Administración de Recursos. Los incendios en La Pampa.

URL:http://plants.usda.gov

The United States Department of Agriculture, NRCS. 2010. The PLANTS Database. (consulta 04-I-10). 


\section{ANEXO I}

\section{MODELOS DE ENTREVISTA ABIERTA Y ENCUESTA \\ ETNOBOTÁNICA. Aplicadas para la obtención de datos en La Humada y área de influencia.}

\section{MODELO DE ENTREVISTA ABIERTA}

\section{DATOS DEL INFORMANTE}

Nombre y apellido:

Lugar donde nació y vivió los primeros años de su vida:

Oficio, trabajos anteriores o destrezas adquiridas:

\section{CICLO ANUAL}

Ciclo de actividades en el año:

Conceptos sobre el clima y el tiempo:

Diferentes actividades económicas en las distintas épocas del año.

Conceptos sobre el tiempo de labor y los tiempos festivos. Diferencias entre el presente y el pasado:

\section{GANADERÍA}

Actividades actuales y del pasado (motivos de pérdida de la actividad).

Especies de cría. Ganado. Mascotas.

Corrales. Potreros. Viviendas.

Pasturas y forrajes. Plantas tóxicas para el ganado. Conservación de las pasturas y manejo del rodeo.

Instrumentos útiles para realizar estas actividades. Elementos de transporte.

Enfermedades de los animales domésticos. Tratamientos naturales y sobrenaturales. Santos tutelares de los animales.

Manejo del agua. Formas de aprovechamiento de ese recurso. Sistemas de extracción actual y en el pasado. Estrategias en épocas de escasez.

\section{ALIMENTACIÓN}

Plantas alimenticias: 1. Recolección. 2. Agricultura y jardinería. 3. Adquisición comercial. 
Fauna alimenticia: 4. Actividad cinegética.

\section{Plantas alimenticias}

1. Recolección.

Actividades actuales y del pasado (motivos de pérdida de la actividad).

Especie. Órganos consumidos. Formas de preparación y de consumo de la planta.

Útiles empleados en la recolección.

Métodos utilizados para la conservación.

Frutos ocasionales del campo.

Rol según el sexo y la edad en el trabajo de recolección o preparación de alimentos.

\subsection{Agricultura.}

Tipos de agricultura (Huertos hogareños o de explotación, sembradíos comerciales, pasturas).

Terrenos elegidos. Cualidades del terreno y del suelo. Regadíos. Preparación del terreno. Abonos. Siembra. Cuidados. Cosecha. Rol del hombre y de la mujer en las actividades agrícolas. Nómina de los productos hortícolas obtenidos.

\subsection{Jardinería y parquizado.}

Actividades actuales y del pasado (motivos de pérdida de la actividad). Árboles de parquizado (vivienda y arbolado urbano) Función (ornamental, especias, medicinal). Ideas sobre el jardín. Especies ornamentales. Formas de obtención de ellas e intercambio.

\section{Adquisición comercial.}

Productos adquiridos. Formas de intercambio. Frecuencia de los intercambios. Lugares de procedencia de los productos. Medios de transporte de los productos (En todos los puntos verificar diferencias entre el presente $y$ el pasado) 


\section{Fauna alimenticia}

4. Actividad cinegética.

Especies buscadas actualmente y en el pasado (motivos de pérdida de la actividad).

Métodos de caza.

Instrumentos utilizados para la caza. Armas y trampas. Instrumentos de trasporte de los ejemplares capturados.

\section{COMBUSTIBLES VEGETALES E ILUMINACIÓN}

Leñas e iluminación. Especies buscadas actualmente y en el pasado (motivos de pérdida de la actividad). Clasificación de las leñas: durables, para encender, inútiles, fétidas. Leñas para cocinar, para calentar agua, para calefaccionar. Métodos de iluminación. Candiles. Elaboración de velas.

\section{MANUFACTURAS CASERAS.}

\section{Vivienda}

Métodos de construcción de las viviendas. Adobes. Usos de maderas en la construcción. Maderamen: horcones y vigas. Especies buscadas actualmente y en el pasado (motivos de pérdida de la actividad). Techos y pisos.

Mobiliario: arcones, fiambreras, queseras.

Cocina, fogón y horno.

\section{Herramientas e instrumentos de uso en el hogar.}

Prácticas actuales y del pasado (motivos de pérdida de la actividad). Enseres domésticos. Morteros. Pisones. Escobas. Rastrillos. Cabos y mangos. Fuentes. Cucharones. Platos. Costureros y cajas para distintos usos, pantallas y abanicos. Representaciones e instrumentos religiosos: Altares y nichos. Pesebres. Esculturas.

\section{Cesteria v recipientes de transporte.}

Especies empleadas en cestería actualmente y en el pasado (motivos de pérdida de la actividad). Tipos de tramas. Diseños gráficos. Decoración. Instrumentos y materias primas empleados en la decoración.

Recipientes de transporte. Calabazas y troncos ahuecados. Usos. 
4. Tejido v tinción.

Especies buscadas actualmente $y$ en el pasado (motivos de pérdida de la actividad). Parte de la planta empleada. Época de recolección. Mordientes. Metodología completa del proceso de tinción.

\section{Artesanías en cuero.}

Curtientes. Tipos de cueros curtidos. Tratamientos del cuero. Uso de cenizas. Bateas para curtir.

\section{SALUD E HIGIENE}

Funcionamiento del cuerpo. Enfermedades de la zona. Tratamientos y dosis. Prácticas actuales y del pasado (motivos de pérdida de la actividad).

Especies empleadas. Mezclas y recetas.

Usos de grasas, plumas, tierras. Elementos humanos empleados para los tratamientos: saliva, sangre, leche, orina, excrementos.

Agentes curativos. Especialistas. Papel de la medicina oficial. Medicación sobrenatural. Maleficios curables o no. Curanderos: cualidades y poderes. Iniciación y aprendizaje. Herencia de su saber. Papel de las oraciones de santos o divinidades. Tratamientos complementarios con la medicina natural. Casos de intoxicaciones o peligros en el uso de la farmacopea. Vigencia de los distintos usos.

Magia de amor. Amuletos para el amor, para la casa, para los deportes, para los juegos de azar, para la simpatía personal.

Las plantas y la mujer. Menstruación. Embarazo, parto y puerperio. Especies empleadas.

Elaboración del jabón. Tipos de grasas empleadas. Lejías.

Aseo personal. Elementos para el tratamiento de la piel y el cabello. Desodorantes.

Tratamiento de la ropa: planchado, preservación del deterioro, perfumes.

Adornos personales: collares, cuentas, pendientes, pulseras.

\section{ACTIVIDADES SOCIALES Y RELIGIOSAS}

Reuniones religiosas: Navidad, Pascua. Celebraciones de santos patronos y otros referentes populares (Difunta Correa, Ceferino Namuncurá, Gaucho Gil, otros). 
Fiestas populares: Año Nuevo, día de la independencia, aniversario de la fundación del pueblo, señaladas, cosechas, cuadreras, domadas, peñas, cumpleaños.

Prácticas actuales $y$ del pasado (motivos de pérdida de la actividad).Clasificación de los juegos según edades y sexo. Instrumentos empleados en cada caso. Material con el que están construidos.

Reglamentos de juegos. 


\section{MODELO DE ENCUESTA ETNOBOTÁNICA}

Nombre y apellido:

Edad:

GANADERÍA

¿Con qué tipo de hacienda trabaja?

Bovina - Ovina - Caprina - Equina

¿Que otros animales cría?

Gallinas - Pavos - Otros (especificar)

¿Quién de los integrantes de la familia se dedica a cada tipo de animales?

Entrevistado - Cónyuge - Hijos (edad) - Otros (aclarar)

\section{ALIMENTACIÓN}

¿Conoce plantas del monte que sean comestibles?

Si - No

¿Recolecta alguna de ellas para comer?

Si - No

(Sí) ¿Quién es el integrante de la familia que se dedica a juntar frutos del monte?

Entrevistado - Cónyuge - Hijos (edad) - Otros (aclarar)

¿Quién de la familia se dedica a prepararlos?

Entrevistado - Cónyuge - Hijos (edad) - Otros (aclarar)

(No) ¿Por qué no las junta para consumir?

¿Algún integrante de la familia se dedica a cultivar la huerta? Si - No

(Sí) ¿Quién?

Entrevistado - Cónyuge - Hijos (edad) - Otros (aclarar)

(No) ¿Cuál es la razón de que no hacen huerta?

¿Algún integrante de la familia se dedica a cultivar jardín?

(Sí) ¿Quién? 
Entrevistado - Cónyuge - Hijos (edad) - Otros (aclarar)

(No) ¿Cuál es la razón de que no hacen jardín?

\section{COMBUSTIBLES VEGETALES E ILUMINACIÓN}

¿Cuál es la leña que más usa?

Piquillín - Jarilla - Ala - Otras (aclarar)

¿Para qué sirven cada una de ellas?

Calefaccionar - Cocinar - Otras (aclarar)

¿Existen leñas que cuesten conseguir? Si - No

¿Por qué piensa que no hay ese tipo de leña?

\section{MANUFACTURAS CASERAS}

¿Cuál era el método más usado en la construcción de viviendas?

Chorizo sobre alambres - Chorizo horizontal

Coirón sobre alambres y embarrado - Cerco de arbustos embarrado

¿Construye instrumentos caseros con maderas o plantas del lugar? Si - No

(sí) ¿Cuáles?

(no) ¿Por qué no emplea plantas del lugar en la construcción de objetos?

¿Conoce instrumentos del hogar que antes se construían en forma casera y ahora se dejaron de construir? Si - No

¿Por qué cree que se dio ese cambio?

¿Construye elementos entretejidos con plantas? Si - No

¿Algún integrante del hogar tiñe lana con plantas del lugar? Si - No

(sí) ¿Quién?

Entrevistado - Cónyuge - Hijos (edad) - Otros (aclarar)

¿De quién aprendió a teñir lana?

(no) ¿Conoce plantas que se usen para teñir? Si - No 
¿Algún integrante del hogar teje con lana?

(si) ¿Quién?

Entrevistado - Cónyuge - Hijos (edad) - Otros (aclarar)

¿Qué clase de telar emplea?

\section{SALUD E HIGIENE PERSONAL}

¿Cuáles eran las enfermedades más comunes en la zona?

¿Qué tratamientos recibían esas enfermedades?

Medicina oficial - Tratamientos naturales - Tratamientos sobrenaturales

¿Se siguen empleando esos tratamientos en la actualidad? Si - No

(no) ¿Por qué supone que dejaron de usarse?

¿Utiliza la posta sanitaria para atenderse? Si - No

¿Conoce plantas que se usaban o usan para atender problemas durante las menstruaciones, embarazos o partos? $\mathrm{Si}$ - No

¿Conoce enfermedades que se traten con curas mágicas? Si - No

(sí) ¿A quién acuden cuando tienen que hacer estos tratamientos?

Curandero local - Curandero foráneo - Vecino especialista

¿Conoce algún método de cura mágica? Si - No

(sí) ¿Cómo aprendió estos conocimientos?

\section{LIMPIEZA}

¿Conoce el proceso de elaboración que se usaba para hacer jabón? Si - No ¿Conoce el método que se usaba para la elaboración de lejía? Si - No Usa o usaba alguna planta como perfume personal o para la ropa? Si - No (sí) ¿Cuál? 
ACTIVIDAD SOCIAL Y RELIGIOSA

¿Se reúne con vecinos para celebrar alguna ocasión? Si - No

(sí) ¿Cuáles?

Fiestas familiares - Fiestas religiosas

Fiestas patrias - Marcadas o similares

(no) ¿Por qué cree que se han perdido las reuniones entre vecinos?

¿Se reúne para celebrar eventos religiosos? Si - No

¿Practica alguna religión? Si - No

¿Cuál?

Católica - Potestante (registrar Iglesia) - Otra 


\section{ANEXO II}

TABLAS

Tabla 1: Especies forrajeras para todas las clases de ganado.

\begin{tabular}{|c|c|c|c|c|}
\hline Especie (s) & $\begin{array}{l}\text { Nombre } \\
\text { común }\end{array}$ & Familia & $\begin{array}{l}\text { Cantidad de citas } \\
\text { (I) }\end{array}$ & $\begin{array}{c}\mathbf{I F =} \mathbf{I s} / \mathbf{N} \\
*\end{array}$ \\
\hline Panicum urvilleanum Kunth. & Tupe & Poaceae & 41 & 0.60 \\
\hline Poa lanuginosa Poir. & Unquillo & Poaceae & 39 & 0.57 \\
\hline Schinus johnstonii. F.A.Barkley & Molle & Anacardiaceae & 29 & 0.43 \\
\hline Lycium chilense Miers ex Bertero & Llaullín & Solanaceae & 27 & 0.40 \\
\hline Prosopis flexuosa DC var. depressa F.A.Roig & Alpataco & Fabaceae & 21 & 0.38 \\
\hline Condalia microphylla Cav. & Piquillín & Rhamnaceae & 20 & 0.29 \\
\hline Pappostipa vaginata (Phil.) Romaschenko & Coirón & Poaceae & 17 & 0.25 \\
\hline Acantholippia seriphioides (A.Gray) Moldenke & Tomillo & Verbenaceae & 14 & 0.21 \\
\hline Aristida mendocina Phil. & Flechilla & Poaceae & 14 & 0.21 \\
\hline Nassella tenuis (Phil.) Barkworth & Flechilla fina & Poaceae & 13 & 0.19 \\
\hline $\begin{array}{l}\text { Bromus catharticus Vahl var. rupestris (Speg.) Planchuelo \& } \\
\text { P.M.Peterson }\end{array}$ & Cebadilla & Poaceae & 13 & 0.19 \\
\hline
\end{tabular}




\section{Tabla 1: Continuación}

\begin{tabular}{|c|c|c|c|c|}
\hline Especie (s) & Nombre común & Familia & Cantidad de citas (I) & $\begin{array}{c}\mathbf{I F}=\mathbf{I s} / \mathbf{N} \\
*\end{array}$ \\
\hline Ephedra ochreata Miers & Solupe frutero & Ephedraceae & 10 & 0.15 \\
\hline Larrea divaricata Cav. & Jarilla & Zygophyllaceae & 10 & 0.15 \\
\hline Atriplex lampa (Moq.) D.Dietr. & Zampa & Chenopodiaceae & 8 & 0.12 \\
\hline Monttea aphylla (Miers) Benth. \& Hook. & Ala & Plantaginaceae & 8 & 0.12 \\
\hline Thelesperma megapotamicum (Spreng.) Kuntze & Té pampa & Asteraceae & 7 & 0.10 \\
\hline Schismus barbatus (L.) Thell. & Pasto de invierno & Poaceae & 7 & 0.10 \\
\hline Hyalis argentea D. Don ex Hook. \& Arn. & Blanquilla & Asteraceae & 6 & 0.09 \\
\hline Grindelia chiloensis (Cornel.) Cabrera & Melosa & Asteraceae & 5 & 0.07 \\
\hline Prosopidastrum striatum (Benth.) R. A. Palacios \& Hoc & Retamilla & Fabaceae & 5 & 0.07 \\
\hline Baccharis darwinii Hook. \& Arn. & Yerba de oveja & Asteraceae & 4 & 0.06 \\
\hline Bothriochloa springfieldii (Gould) Parodi & Pasto de hoja & Poaceae & 4 & 0.06 \\
\hline Gomphrena mendocina (Phil.) R.E.Fr. & Yerba del pollo & Amaranthaceae & 4 & 0.06 \\
\hline Jarava ichu Ruíz \& Pav. & Coirón fino & Poaceae & 4 & 0.06 \\
\hline Chuquiraga erinacea D.Don & Chirriadora & Asteraceae & 3 & 0.04 \\
\hline Junellia seriphioides (Gillies \& Hook. ex Hook.) Moldenke & Tomillo macho & Verbenaceae & 3 & 0.04 \\
\hline Parthenium hysterophorus L. & Altamisa & Asteraceae & 3 & 0.04 \\
\hline Senna aphylla (Cav.) H.S. Irwin \& Barneby & Cacho de cabra & Fabaceae & 3 & 0.04 \\
\hline Setaria mendocina Phil. & Pasto de hoja & Poaceae & 3 & 0.04 \\
\hline
\end{tabular}




\section{Tabla 1: Continuación}

\begin{tabular}{|c|c|c|c|c|}
\hline Especie (s) & $\begin{array}{l}\text { Nombre } \\
\text { común }\end{array}$ & Familia & $\begin{array}{l}\text { Cantidad de citas } \\
\text { (I) }\end{array}$ & $\begin{array}{c}\mathbf{I F}=\mathbf{I s} / \mathbf{N} \\
*\end{array}$ \\
\hline $\begin{array}{l}\text { Eragrostis mexicana (Hornem.) Link ssp. virescens (J. Presl) S.D. } \\
\text { Koch \& Sanchéz Veja }\end{array}$ & Gramilla & Poaceae & 2 & 0.03 \\
\hline Bougainvillea spinosa (Cav.) Heimerl & Monte negro & Nictaginaceae & 2 & 0.03 \\
\hline Eupatorium patens D.Don ex Hook. \& Arn. var. patens & Bejuco & Asteraceae & 2 & 0.03 \\
\hline Fabiana peckii Niederl. & Pichanilla & Solanaceae & 2 & 0.03 \\
\hline Glandularia flava (Gillies ex Hook.) Schnack \& Covas & $\begin{array}{r}\text { Yerba de la } \\
\text { vaca }\end{array}$ & Verbenaceae & 2 & 0.03 \\
\hline Gochnatia glutinosa (D.Don) Hook. \& Arn. & Jarillilla & Asteraceae & 2 & 0.03 \\
\hline Neosparton aphy/lum (Gillies \&Hook.) Kuntze & Solupe & Verbenaceae & 2 & 0.03 \\
\hline Pappophorum caespitossum R.E.Fr. & Pasto de hoja & Poaceae & 2 & 0.03 \\
\hline Plantago patagonica Jacq. & Cola de piche & Plantaginaceae & 2 & 0.03 \\
\hline Ximenia americana $\mathrm{L}$. & Albaricoque & Olacaceae & 2 & 0.03 \\
\hline Baccharis salicifolia (Ruiz \& Pav.) Pers. & Chilca & Asteraceae & 1 & 0.01 \\
\hline Caesalpinia gilliessii (Wall ex Hook.) D.Dietr. & Mal de ojo & Fabaceae & 1 & 0.01 \\
\hline Erodium cicutarium (L.) L’Hér. ex Aiton & Alfilerillo & Geraniaceae & 1 & 0.01 \\
\hline Habranthus jamesonii (Baker) Ravenna & $\begin{array}{r}\text { Cebolla del } \\
\text { zorro }\end{array}$ & Amarillydaceae & 1 & 0.01 \\
\hline Larrea cuneifolia Cav. & Jarilla crespa & Zygophyllaceae & 1 & 0.01 \\
\hline Lycium gilliessianum Miers & Llaullín crespo & Solanaceae & 1 & 0.01 \\
\hline
\end{tabular}




\section{Tabla 1: Continuación}

\begin{tabular}{|c|c|c|c|c|}
\hline Especie (s) & Nombre común & Familia & Cantidad de citas ( $\mathrm{I}$ ) & $\mathbf{I F}=\mathbf{I s} / \mathbf{N} *$ \\
\hline Margyricarpus pinnatus (Lam.) Kuntze & Yerba de la perdiz & Rosaceae & 1 & 0.01 \\
\hline Philibertia gilliessii Hook. \& Arn. & Enredadera del avestruz & Asclepiadaceae & 1 & 0.01 \\
\hline Prosopis flexuosa DC var. flexuosa & Algarrobo & Fabaceae & 1 & 0.01 \\
\hline Solanum elaeagnifolium Cav. & Quillo & Solanaceae & 1 & 0.01 \\
\hline Jarava neaei (Nees ex Steud.) Peñailillo & Flechilla & Poaceae & 1 & 0.01 \\
\hline Suaeda divaricata Moq. & Vidriera & Chenopodiaceae & 1 & 0.01 \\
\hline Bredemeyera microphylla (Griseb.) Hieron. & Yerba mora & Polygalaceae & 1 & 0.01 \\
\hline Total: 52 taxones, (P. flexuosa con dos variedades) & & & & \\
\hline
\end{tabular}

*: $\mathbf{I F}=$ Índice forrajero, $\mathbf{N}=$ Número total de entrevistas 
Tabla 2: Composición porcentual de las familias con valor forrajero.

\begin{tabular}{|l|r|}
\hline Familias & \% Forrajeras \\
\hline Poaceae & 29 \\
\hline Asteraceae & 17 \\
\hline Verbenaceae & 8 \\
\hline Solanaceae & 7 \\
\hline Fabaceae & 5 \\
\hline Fabaceae & 3 \\
\hline Chenopodiaceae & 3 \\
\hline Zygophyllaceae & 3 \\
\hline Amaranthaceae & 2 \\
\hline Amaryllidaceae & 2 \\
\hline Anacardiaceae & 2 \\
\hline Asclepiadaceae & 2 \\
\hline Ephedraceae & 2 \\
\hline Geraniaceae & 2 \\
\hline Nyctaginaceae & 2 \\
\hline Olacaceae & 2 \\
\hline Plantaginaceae & 2 \\
\hline Polygalaceae & 2 \\
\hline Rhamnaceae & 2 \\
\hline Rosaceae & 2 \\
\hline Santalaceae & 2 \\
\hline Scrophulariaceae & 2 \\
\hline
\end{tabular}


Tabla 3: Especies tóxicas o con efectos adversos en la ganadería.

\begin{tabular}{|l|r|r|r|}
\hline \multicolumn{1}{|c|}{ Especie } & Nombre común & Familia & Cantidad de citas \\
\hline Nicotiana noctiflora Hook. & Tabaco cimarrón & Solanaceae & 6 \\
\hline Cucumis anguria L. & Sandilleja & Cucurbitaceae & 4 \\
\hline Astragalus pehuenches Niederl. & Yerba loca & Fabaceae & 3 \\
\hline Sporobolus rigens (Trin.) E. Desv. & Unco & Poaceae & 2 \\
\hline Euphorbia collina Phil. & Pechuguilla & Euphorbiaceae & 1 \\
\hline Jarava neaei (Nees ex Steud.) Peñailillo & Flechilla & Poaceae & 1 \\
\hline Nassella tenuis (Phil.) Barkworth & Flechilla fina & Poaceae & 1 \\
\hline Total: 7 especies & & & $\mathbf{1 8}$ \\
\hline
\end{tabular}


Tabla 4: Especies empleadas en veterinaria.

\begin{tabular}{|c|c|c|c|c|}
\hline Especie & Nombre común & Familia & Categoría & $N^{\circ}$ de citas \\
\hline Larrea divaricata Cav. & Jarilla & Zigophyllaceae & Nativa & 24 \\
\hline Eupatorium patens D.Don ex Hook. \& Arn. var. patens & Bejuco & Asteraceae & Nativa & 12 \\
\hline Alium sativum $\mathrm{L}$. & Ajo & Liliaceae & Exótica $^{3}$ & 2 \\
\hline Nicotiana tabacum L. & Tabaco & Solanaceae & Exótica $^{3}$ & 2 \\
\hline Acantholippia seriphioides (A.Gray) Moldenke & Tomillo & Verbenaceae & Nativa & 1 \\
\hline Artemisia absinthium L. & Ajenjo & Asteraceae & Exótica $^{2}$ & 1 \\
\hline Baccharis spartioides (Hook. \& Arn. ex DC) J.Rémy. & Pichana & Asteraceae & Nativa & 1 \\
\hline Gochnatia glutinosa (D.Don) Hook. \& Arn. & Jarillilla & Asteraceae & Nativa & 1 \\
\hline Tamarix ramosissima Ledeb. & Tamarindo & Tamaricaceae & Exótica $^{1}$ & 1 \\
\hline Triticum aestivum $\mathrm{L}$. & Trigo & Poaceae & Exótica $^{3}$ & 1 \\
\hline Total: 10 especies & & & & 46 \\
\hline
\end{tabular}

1: Naturalizada. 2: Cultivada en los predios. 3: Adquirida comercialmente. 


\section{Tabla 5: Aplicaciones veterinarias}

\begin{tabular}{|c|c|c|c|c|c|c|c|c|c|c|}
\hline Especie & Nombre común & $1 *$ & 2* & 3* & $4^{*}$ & 5* & 6* & 7* & 8* & 9* \\
\hline Larrea divaricata Cav. & Jarilla & 19 & 13 & & 1 & & & & & 5 \\
\hline Eupatorium patens D.Don ex Hook. \& Arn. var. patens & Bejuco & & & 4 & 6 & & 3 & & 2 & \\
\hline Alium sativum $\mathrm{L}$. & Ajo & & & 1 & & 1 & & & & \\
\hline Nicotiana tabacum L. & Tabaco & & & & & 2 & & & & \\
\hline Acantholippia seriphioides (A.Gray) Moldenke & Tomillo & 1 & & & & & & & & \\
\hline Artemisia absinthium L. & Ajenjo & & & & & & & 1 & & \\
\hline Baccharis spartioides (Hook. \& Arn. ex DC) J.Rémy. & Pichana & 1 & & & & & & & & \\
\hline Gochnatia glutinosa (D.Don) Hook. \& Arn. & Jarillilla & & 1 & & & & & & & \\
\hline Tamarix ramosissima Ledeb. & Tamarindo & & & & & & & 1 & & \\
\hline Triticum aestivum $\mathrm{L}$. & Trigo & & & & & & & 1 & & \\
\hline Total: 11 especies & & & & & & & & & & \\
\hline
\end{tabular}

* Número de citas.

1: pasmos e infecciones; 2: retención de placenta; 3: gusano del cuajo (equinos); 4: miasis externas; 5: mordeduras de víboras; 6: indigestiones (equinos); 7: diarreas; 8: gusano del cuerno (caprinos); 9: mal seco (equinos). 
Tabla 6: Especies silvestres empleadas en la alimentación humana.

\begin{tabular}{|c|c|c|c|c|}
\hline Especie & Nombre común & Familia & $\begin{array}{l}\text { Forma de } \\
\text { obtención }\end{array}$ & $\begin{array}{l}\text { Número de } \\
\text { citas }\end{array}$ \\
\hline Condalia microphylla Cav. & Piquillín & Rhamnaceae & Recolectada & 38 \\
\hline $\begin{array}{l}\text { Prosopis flexuosa DC. var. depressa } \\
\text { F.A. Roig }\end{array}$ & Alpataco & Fabaceae & Recolectada & 26 \\
\hline $\begin{array}{l}\text { Arjona tuberosa Cav. var. tandilensis } \\
\text { (Kuntze) G. Dawson }\end{array}$ & Chaquil, Macachín & Santalaceae & Recolectada & 20 \\
\hline Ephedra ochreata Miers. & Solupe frutero & Ephedraceae & Recolectada & 7 \\
\hline Prosopis flexuosa f. flexuosa & Algarrobo & Fabaceae & Recolectada & 5 \\
\hline $\begin{array}{l}\text { Acantholippia seriphioides (A. Gray) } \\
\text { Moldenke }\end{array}$ & $\begin{array}{l}\text { Tomillo, Tomillo de olor, Tomillo } \\
\text { hembra, Yerba del lagarto }\end{array}$ & Verbenaceae & Recolectada & 5 \\
\hline $\begin{array}{l}\text { Geoffraea decorticans (Gillies ex Hook. } \\
\text { \& Arn.) Burkart }\end{array}$ & Chañar & Fabaceae & Recolectada & 3 \\
\hline Prosopanche bonacine Speg. & Papa indiana & Hidnoraceae & Recolectada & 2 \\
\hline Opuntia sulphurea Gillies ex Salm-Dick & Penca, Quiscalora & Cactaceae & Recolectada & 2 \\
\hline Ximenia americana $\mathrm{L}$. & Albaricoque, Bricoque & Olacaceae & Recolectada & 1 \\
\hline $\begin{array}{l}\text { Baccharis spartioides (Hook. \& Arn. ex } \\
\text { DC.) J. Rémy }\end{array}$ & Pichana & Asteraceae & Recolectada & 1 \\
\hline Cucurbita pepo L. & Zapallo anco & Cucurbitaceae & Cultivada & 19 \\
\hline Zea mays L. & Maíz & Poaceae & Cultivada & 17 \\
\hline
\end{tabular}


Tabla 6: Continuación

\begin{tabular}{|c|c|c|c|c|}
\hline Especie & $\begin{array}{l}\text { Nombre } \\
\text { común }\end{array}$ & Familia & $\begin{array}{l}\text { Forma de } \\
\text { obtención }\end{array}$ & $\begin{array}{l}\text { Número de } \\
\text { citas }\end{array}$ \\
\hline Lactuca sativa $L$. & Lechuga & Asteraceae & Cultivada & 10 \\
\hline Solanum licopersicum L. & Tomate & Solanaceae & Cultivada & 9 \\
\hline Beta vulgaris L. ssp. vulgaris & Acelga & Chenopodiaceae & Cultivada & 8 \\
\hline Prunus armeniaca L. & Damasco & Rosaceae & Cultivada & 6 \\
\hline Prunus persica (L.) Batsch & Duraznero & Rosaceae & Cultivada & 5 \\
\hline Raphanus sativus L. & Rabanito & Brassicaceae & Cultivada & 3 \\
\hline Pyrus communis $\mathrm{L}$. & Peral & Rosaceae & Cultivada & 3 \\
\hline Origanum vulgare $\mathrm{L}$. & Orégano & Lamiaceae & Cultivada & 3 \\
\hline Malus sylvestris (L.) Mill. & Manzano & Rosaceae & Cultivada & 2 \\
\hline Ocimun basilicum $\mathrm{L}$. & Albahaca & Lamiaceae & Cultivada & 2 \\
\hline Petroselinum crispum (Miller) A.W. Hill. & Perejil & Apiaceae & Cultivada & 2 \\
\hline $\begin{array}{l}\text { Cucurbita maxima Duchesne ssp. andreana (Naudin) } \\
\text { Filov }\end{array}$ & Zapallito verde & Cucurbitaceae & Cultivada & 2 \\
\hline Brassica oleracea L. & Repollo & Brassicaceae & Cultivada & 2 \\
\hline Vitis vinifera $\mathrm{L}$. & Parra & Vitaceae & Cultivada & 2 \\
\hline Ipomoea batatas (L.) Poir & Camote & Convolvulaceae & Cultivada & 2 \\
\hline Cydonia oblonga Mill. & Membrillo & Rosaceae & Cultivada & 2 \\
\hline Foeniculum vulgare Mill. & Hinojo & Apiaceae & Cultivada & 1 \\
\hline Laurus nobilis L. & Laurel & Lauraceae & Cultivada & 1 \\
\hline
\end{tabular}




\section{Tabla 6: Continuación}

\begin{tabular}{|c|c|c|c|c|}
\hline Especie & Nombre común & Familia & Forma de obtención & Número de citas \\
\hline Beta vulgaris L. ssp. macrocarpa (Guss.) Thell. & Remolacha & Chenopodiaceae & Cultivada & 1 \\
\hline Prunus domestica L. & Ciruelo & Rosaceae & Cultivada & 1 \\
\hline Punica granatum L. & Granada & Punicaceae & Cultivada & 1 \\
\hline Cucurbita máxima Duch. ssp. maxima & Zapallo criollo & Cucurbitaceae & Comercial & 19 \\
\hline Solanum tuberosum $\mathrm{L}$. & Papa & Solanaceae & Comercial & 10 \\
\hline Allium cepa L. & Cebolla & Alliaceae & Comercial & 10 \\
\hline Triticum aestivum $\mathrm{L}$. & Trigo & Poaceae & Comercial & 7 \\
\hline Citrullus lanatus ssp. vulgaris Schrad. & Sandía & Cucurbitaceae & Comercial & 7 \\
\hline Alium sativum $\mathrm{L}$. & Ajo & Liliaceae & Comercial & 6 \\
\hline Capsicum annuum L. & Pimiento & Solanaceae & Comercial & 4 \\
\hline Phaseolus vulgaris L. & Poroto & Fabaceae & Comercial & 2 \\
\hline Citrus $x$ sinensis (L.) Osbeck & Naranjo & Rutaceae & Comercial & 1 \\
\hline Cucumis melo L. & Melón & Cucurbitaceae & Comercial & 1 \\
\hline Citrus $x$ limon (L.) Burm. f. & Limonero & Rutaceae & Comercial & 1 \\
\hline Syzygium aromaticum (L.) Merr. \& L.M. Perry & Clavo de olor & Mirtaceae & Comercial & 1 \\
\hline Musa paradisiaca L. & Banana & Musaceae & Comercial & 1 \\
\hline Oryza sativa L. & Arroz & Poaceae & Comercial & 1 \\
\hline Cinnamomum zeylanicum Garcin ex Blume & Canela & Lauraceae & Comercial & 1 \\
\hline Piper nigrum $\mathrm{L}$. & Pimienta & Piperaceae & Comercial & 1 \\
\hline Total: 50 taxones & & & & 111 \\
\hline
\end{tabular}


Tabla 7: Especies utilizadas en la medicina tradicional

\begin{tabular}{|c|c|c|c|}
\hline Especie & Nombre común & Familia & $\begin{array}{l}\text { Número de } \\
\text { citas }\end{array}$ \\
\hline Larrea divaricata Cav. & Jarilla, Jarilla lisa & Zigophyllaceae & 12 \\
\hline Acantholippia seriphioides (A. Gray) Moldenke & $\begin{array}{l}\text { Tomillo, Tomillo de olor, Tomillo hembra, Yerba } \\
\text { del lagarto }\end{array}$ & Verbenaceae & 11 \\
\hline Marrubium vulgare L. & Yerba del sapo & Lamiaceae & 7 \\
\hline Gomphrena mendocina (Phil.) R.E.Fr. & Yerba del pollo & Asteraceae & 6 \\
\hline $\begin{array}{l}\text { Geoffraea decorticans (Gillies ex Hook. \& Arn.) } \\
\text { Burkart }\end{array}$ & Chañar & Fabaceae & 5 \\
\hline Schinus johnstonii F.A. Barkley & Molle & Anacardiaceae & 5 \\
\hline Artemisia abrotanum L. & Acanfor & Asteraceae & 5 \\
\hline Dysphania ambrosioides $\mathrm{L}$. & Paico & Chenopodiaceae & 4 \\
\hline Artemisia absinthium L. & Ajenjo & Asteraceae & 3 \\
\hline Artemisia douglasiana Bess. & Matico & Asteraceae & 3 \\
\hline Baccharis trimera (Less.) DC & Carqueja & Asteraceae & 3 \\
\hline Cyclolepis genistoides D. Don & Matorro & Asteraceae & 3 \\
\hline $\begin{array}{l}\text { Eupatorium patens D.Don ex Hook. \& Arn. } \\
\text { var. patens }\end{array}$ & Bejuco & Asteraceae & 3 \\
\hline Hyalis argentea D. Don ex Hook. \& Arn. & Blanquilla & Asteraceae & 3 \\
\hline Matricaria recutita L. & Manzanilla & Asteraceae & 3 \\
\hline Nicotiana tabacum L. & Tabaco & Solanaceae & 3 \\
\hline
\end{tabular}




\section{Tabla 7: Continuación}

\begin{tabular}{|c|c|c|c|}
\hline Especie & Nombre común & Familia & Número de citas \\
\hline Parthenium hysterophorus L. & Altamisa & Asteraceae & 3 \\
\hline Ruta chalepensis L. & Ruda & Rutaceae & 3 \\
\hline Salvia cuspidata ssp. gilliesii Benth. & Salvia morada & Lamiaceae & 3 \\
\hline Solanum tuberosum L. & Papa & Solanaceae & 3 \\
\hline Tamarix ramosissima Ledeb. & Tamarindo & Tamaricaceae & 3 \\
\hline Thymophylla pentachaeta (DC.) Small var. belenidium (DC.) Strother & Perlilla, Manzanilla & Asteraceae & 3 \\
\hline Trichocline reptans (Wedd.) Rob. & Contrayerba & Asteraceae & 3 \\
\hline Xanthium spinosum L. & Cadillo, Cepacaballo & Asteraceae & 3 \\
\hline Zea mays L. & Maíz & Poaceae & 3 \\
\hline Allium cepa L. & Cebolla & Alliaceae & 2 \\
\hline Aloysia polystachya (Griseb.) Moldenke & Burro, Té de burro & Verbenaceae & 2 \\
\hline Aloe saponaria (Ait.) Haw & Aloe, Aloe vera & Aloeaceae & 2 \\
\hline Baccharis salicifolia (Ruiz \& Pav.) Pers. & Chilca & Asteraceae & 2 \\
\hline Erodium cicutarium (L.) L'Hér. ex Aiton & Alfilerillo & Geraniaceae & 2 \\
\hline Grindelia chiloensis (Cornel.) Cabrera & Melosa & Asteraceae & 2 \\
\hline Malva sylvestris L. & Malva & Malvaceae & 2 \\
\hline Monttea aphylla (Miers) Benth. \& Hook. & Ala & Plantaginaceae & 2 \\
\hline Origanum vulgare $\mathrm{L}$. & Orégano & Lamiaceae & 2 \\
\hline Populus nigra $\mathrm{L}$. & Álamo & Salicaceae & 2 \\
\hline Prosopis flexuosa DC. var. depressa F.A. Roig & Alpataco & Fabaceae & 2 \\
\hline
\end{tabular}




\section{Tabla 7: Continuación}

\begin{tabular}{|c|c|c|c|}
\hline Especie & Nombre común & Familia & Número de citas \\
\hline Rosa canina L. & Rosa de remedio & Rosaceae & 2 \\
\hline Tagetes mendocina Phil. & Chilchil del cerro & Asteraceae & 2 \\
\hline Thelesperma megapotamicum (Spreng.) Kuntze & Té pampa & Asteraceae & 2 \\
\hline Tilia sp. & Tilo & Tiliaceae & 2 \\
\hline Triticum aestivum $\mathrm{L}$. & Trigo & Poaceae & 2 \\
\hline Verbesina encelioides (Cav.) Benth. \& Hook. f. ex A. Gray & Girasol, Mirasol del campo & Asteraceae & 2 \\
\hline Tanacetum balsamita L. & San Pedro & Asteraceae & 1 \\
\hline Aloysia citriodora Palau & Cedrón & Verbenaceae & 1 \\
\hline Borago officinalis $L$. & Borraja & Boraginaceae & 1 \\
\hline Brassica nigra (L.) W.D.J. Koch & Mostaza & Brassicaceae & 1 \\
\hline Buddleja araucana Phil. & Pañil & Buddlejaceae & 1 \\
\hline Capparis atamisquea Kuntze & Atamisque & Capparidaceae & 1 \\
\hline Cereus aethiops Haw. & Penca & Cactaceae & 1 \\
\hline Cestrum parqui L'Hér. & Palqui & Solanaceae & 1 \\
\hline Cheilanthes myriophylla Desv. & Doradilla & Pteridaceae & 1 \\
\hline Dysphania multifida L & Paico rastrero & Chenopodiaceae & 1 \\
\hline Cinnamomum zeylanicum Garcin ex Blume & Canela & Lauraceae & 1 \\
\hline Citrus $x$ limon (L.) Burm. f. & Limón & Rutaceae & 1 \\
\hline Condalia microphylla Cav. & Piquillín & Rhamnaceae & 1 \\
\hline
\end{tabular}




\section{Tabla 7: Continuación}

\begin{tabular}{|c|c|c|c|}
\hline Especie & Nombre común & Familia & Número de citas \\
\hline Cortaderia selloana (Schult. \& Schult. f.) Asch. \& Graebn. & Cortadera & Poaceae & 1 \\
\hline Eleagnus angustifolia $\mathrm{L}$. & Arabia & Eleagnaceae & 1 \\
\hline Ephedra ochreata Miers. & Solupe frutero & Ephedraceae & 1 \\
\hline Equisetum giganteum $\mathrm{L}$. & Yerba de la plata & Equisetaceae & 1 \\
\hline Eucalyptus cinerea F. Muell ex Benth. & Eucalipto & Mirtaceae & 1 \\
\hline Eupatorium buniifolium Hook \& Arn. var. buniifolium & Romerillo colorado & Asteraceae & 1 \\
\hline Euphorbia collina Phil. & Pechuguilla & Euphorbiaceae & 1 \\
\hline Fabiana patagonica Speg. & Pichanilla & Solanaceae & 1 \\
\hline Gaillardia megapotamica (Spreng.) Baker & Topazaire & Asteraceae & 1 \\
\hline Gochnatia glutinosa (D. Don) Hook. \& Arn. & Jarillilla & Asteraceae & 1 \\
\hline Lagenaria siceraria (Molina) Standl. & Mate & Cucurbitaceae & 1 \\
\hline Larrea nitida Cav. & Jarilla, Jarilla crespa & Zigophyllaceae & 1 \\
\hline Ligaria cuneifolia (Ruiz \& Pav.) Tiegh. & Liga & Loranthaceae & 1 \\
\hline Lippia turbinata Griseb. & Poleo & Verbenaceae & 1 \\
\hline Monnina dictyocarpa Griseb. & Quelén & Polygalaceae & 1 \\
\hline Musa paradisiaca $\mathrm{L}$. & Banana & Musaceae & 1 \\
\hline Petroselinum crispum (Miller) A.W. Hill. & Perejil & Apiaceae & 1 \\
\hline Piper nigrum $\mathrm{L}$. & Pimienta & Piperaceae & 1 \\
\hline Plantago lanceolata L. & Llantén & Plantaginaceae & 1 \\
\hline
\end{tabular}


Tabla 7: Continuación

\begin{tabular}{|l|l|l|l|}
\hline \multicolumn{1}{|c|}{ Especie } & Nombre común & \multicolumn{1}{|c|}{ Familia } & Número de citas \\
\hline Plantago patagonica Jacq. & Peludilla & Plantaginaceae & 1 \\
\hline Punica granatum L. & Granada & Punicaceae & 1 \\
\hline Rhodophiala mendocina (Phil.) Ravenna & Cebolla del zorro & Amarillidaceae & 1 \\
\hline Senecio filaginoides DC. & Romerillo blanco & Asteraceae & 1 \\
\hline Senecio subulatus D.Don ex Hook. \& Arn. & Romerillo & Asteraceae & 1 \\
\hline Sphaeralcea mendocina Phil. & Malvisco & Malvaceae & 1 \\
\hline Tessaria absinthioides (Hook. \& Arn.) DC. & Pájaro bobo & Asteraceae & 1 \\
\hline Tillandsia bryoides Griseb. & Clavel del aire & Bromeliaceae & 1 \\
\hline Verbascum thapsus L. & Paño & Scrophulariaceae & 1 \\
\hline Vitis vinifera L. & Vid & Vitaceae & 1 \\
\hline Ilex paraguariensis A.St.-Hil. var. paraguariensis & Yerba & Aquifoliaceae & 1 \\
\hline Total: 85 especies & & & 183 \\
\hline
\end{tabular}


Tabla 8: Especies empleadas como agentes tensioactivos

\begin{tabular}{|l|l|l|r|}
\hline \multicolumn{1}{|c|}{ Especie } & Nombre común & \multicolumn{1}{c|}{ Familia } & Número de citas \\
\hline Panicum urvilleanum Kunth. & Tupe & Poaceae & 15 \\
\hline Atriplex lampa (Moq.) D. Dietr. & Zampa & Chenopodiaceae & 10 \\
\hline Neosparton aphyllum (Gillies \& Hook.) Kuntze & Solupe & Verbenaceae & 4 \\
\hline Baccharis spartioides (Hook. \& Arn. ex DC.) J. Rémy & Pichana & Asteraceae & 2 \\
\hline Salsola kali L. & Cardo ruso & Chenopodiaceae & 2 \\
\hline Solanum elaeagnifolium Cav. & Quillo & Solanaceae & 2 \\
\hline Suaeda divaricata Moq. & Vidriera & Chenopodiaceae & 2 \\
\hline Allenrolfea vaginata (Griseb.) Kuntze & Jume & Chenopodiaceae & 1 \\
\hline Dysphania ambrosioides L. & Paico & Chenopodiaceae & 1 \\
\hline Junellia seriphioides (Gillies \& Hook. ex Hook.) Moldenke & Tomillo macho & Verbenaceae & 1 \\
\hline Xanthium ambrosioides Hook. \& Arn. & Yerba de vizcacha & Asteraceae & 1 \\
\hline Xanthium spinosum L. & Cadillo, Cepacaballo & Asteraceae & 1 \\
\hline Total: 12 especies & & & 39 \\
\hline
\end{tabular}




\section{Tabla 9: Especies tintóreas}

\begin{tabular}{|c|c|c|c|}
\hline Especie & Nombre común & Familia & Número de citas \\
\hline Schinus johnstonii F.A. Barkley & Molle & Anacardiaceae & 12 \\
\hline Gochnatia glutinosa (D. Don) Hook. \& Arn. & Jarillilla & Asteraceae & 11 \\
\hline Condalia microphylla Cav. & Piquillín & Rhamnaceae & 9 \\
\hline Thelesperma megapotamicum (Spreng.) Kuntze & Té pampa & Asteraceae & 7 \\
\hline Allium cepa $\mathrm{L}$. & Cebolla & Alliaceae & 4 \\
\hline Senna aphylla (Cav.) H.S. Irwin \& Barneby & Cacho de cabra, Algarrobillo, Pichanilla & Fabaceae & 4 \\
\hline Baccharis spartioides (Hook. \& Arn. ex DC.) J. Rémy & Pichana & Asteraceae & 2 \\
\hline Ilex paraguarienses A.St.-Hil. var. paraguariensis & Yerba & Aquifoliaceae & 2 \\
\hline Larrea divaricata Cav. & Jarilla, Jarilla lisa & Zigophyllaceae & 2 \\
\hline Baccharis crispa Spreng. & Carqueja & Asteraceae & 1 \\
\hline Beta vulgaris L. ssp. macrocarpa (Guss.) Thell. & Remolacha & Chenopodiaceae & 1 \\
\hline Cucurbita máxima Duch. & Zapallo & Cucurbitaceae & 1 \\
\hline Cyclolepis genistoides D. Don & Matorro & Asteraceae & 1 \\
\hline Larrea nitida Cav. & Jarilla, Jarilla crespa & Zigophyllaceae & 1 \\
\hline Prosopis caldenia Burkart & Caldén & Fabaceae & 1 \\
\hline Total: 15 especies & & & 59 \\
\hline
\end{tabular}




\section{Tabla 10: Especies empleadas en la cultura material}

\begin{tabular}{|c|c|c|c|}
\hline Especie & Nombre común & Familia & Número de citas \\
\hline Larrea divaricata Cav. & Jarilla, Jarilla lisa & Zigophyllaceae & 29 \\
\hline Prosopis flexuosa DC. var. flexuosa & Algarrobo & Fabaceae & 18 \\
\hline Baccharis spartioides (Hook. \& Arn. ex DC.) J. Rémy & Pichana & Asteraceae & 15 \\
\hline Populus nigra L. & Álamo & Fabaceae & 15 \\
\hline Condalia microphylla Cav. & Piquillín & Rhamnaceae & 3 \\
\hline Prosopis flexuosa DC. var. depressa F.A. Roig & Alpataco & Fabaceae & 11 \\
\hline Geoffraea decorticans (Gillies ex Hook. \& Arn.) Burkart & Chañar & Fabaceae & 9 \\
\hline Prosopis caldenia Burkart & Caldén & Fabaceae & 8 \\
\hline Pappostipa vaginata (Phil.) Romaschenko & Coirón & Poaceae & 8 \\
\hline Robinia pseudoacacia L. & Acacia & Fabaceae & 4 \\
\hline Neosparton aphy/lum (Gillies \& Hook.) Kuntze & Solupe & Verbenaceae & 3 \\
\hline Eucalyptus sp. & Eucalipto & Mirtaceae & 2 \\
\hline Hyalis argentea D. Don ex Hook. \& Arn. & Blanquilla & Asteraceae & 2 \\
\hline Sporobolus rigens (Trin.) Desv. & Unco & Poaceae & 2 \\
\hline Tamarix ramosissima Ledeb. & Tamarindo & Tamaricaceae & 2 \\
\hline Uimus sp. & Olmo & Ulmaceae & 2 \\
\hline Arundo donax L. & Caña & Poaceae & 1 \\
\hline Baccharis salicifolia (Ruiz \& Pav.) Pers. & Chilca & Asteraceae & 1 \\
\hline Cucumis anguria $\mathrm{L}$. & Sandilleja & Cucurbitaceae & 1 \\
\hline
\end{tabular}




\section{Tabla 10: Continuación}

\begin{tabular}{|l|l|l|r|}
\hline \multicolumn{1}{|c|}{ Especie } & Nombre Común & Familia & Número de citas \\
\hline Elionurus muticus (Spreng.) Kuntze & Paja amarga & Poaceae & 1 \\
\hline Pinus $s p$. & Pino & Pinaceae & 1 \\
\hline Total: 21 taxones & & & \\
\hline
\end{tabular}


Tabla 11: Especies nativas y cultivadas utilizadas para arbolado

\begin{tabular}{|c|c|c|c|}
\hline Especie & Nombre común & Familia & Número de citas \\
\hline Ulmus procera Salisb. & Olmo & Ulmaceae & 20 \\
\hline Tamarix ramosissima Ledeb. & Tamarindo & Tamaricaceae & 17 \\
\hline Eleagnus angustifolia L. & Arabia & Eleagnaceae & 12 \\
\hline Populus nigra L. & Álamo & Fabaceae & 12 \\
\hline Robinia pseudoacacia L. & Acacia & Fabaceae & 11 \\
\hline Cupressus arizonica Greene & Pino, Ciprés & Cupressaceae & 6 \\
\hline Ailanthus altíssima (Mill.) Swingle & Árbol del cielo & Simaroubaceae & 3 \\
\hline Eucalyptus cinerea F. Muell ex Benth. & Eucalipto & Mirtaceae & 3 \\
\hline Morus alba L. & Mora, Mora silvestre & Moraceae & 3 \\
\hline Parthenocissus quinquefolia (L.) Planch. & Enredadera & Vitaceae & 3 \\
\hline Pinus sp. & Pino & Pinaceae & 3 \\
\hline Prosopis flexuosa DC var. flexuosa & Algarrobo & Fabaceae & 3 \\
\hline Schinus areira L. & Pimiento, Gualeguay & Anacardiaceae & 3 \\
\hline Melia azedarach L. & Paraíso & Meliaceae & 2 \\
\hline Platycladus orientalis (L.) Franco & Ciprés, Tuya & Cupressaceae & 2 \\
\hline Vitis vinifera $\mathrm{L}$. & Parra & Vitaceae & 2 \\
\hline Cupressus sempervirens L. f. stricta (Ait) & Ciprés & Cupressaceae & 1 \\
\hline Ficus carica $\mathrm{L}$. & Higuera & Moraceae & 1 \\
\hline Pyrus communis $\mathrm{L}$. & Peral & Rosaceae & 1 \\
\hline Prunus armeniaca L. & Damasco & Rosaceae & 1 \\
\hline
\end{tabular}




\begin{tabular}{|l|l|l|r|}
\hline \multicolumn{1}{|c|}{ Especie } & Nombre común & \multicolumn{1}{|c|}{ Familia } & Número de citas \\
\hline Prunus persica L. & Duraznero & Rosaceae & 1 \\
\hline Prunus cerasifera Ehrh. & Ciruelo de jardín & Rosaceae & 1 \\
\hline Schinus johnstonii F.A. Barkley & Molle & Anacardiaceae & 1 \\
\hline Total: 23 especies & & & 112 \\
\hline
\end{tabular}




\section{Tabla 12: Especies utilizadas como leña}

\begin{tabular}{|c|c|c|c|}
\hline Especie & Nombre común & Familia & Número de citas \\
\hline Condalia microphylla Cav. & Piquillín & Rhamnaceae & 42 \\
\hline Larrea divaricata Cav. & Jarilla, Jarilla lisa & Zigophyllaceae & 39 \\
\hline Monttea aphylla (Miers) Benth. \& Hook. & Ala & Plantaginaceae & 13 \\
\hline Schinus johnstonii F.A. Barkley & Molle & Anacardiaceae & 8 \\
\hline Prosopidastrum striatum (Benth.) R. A. Palacios \& Hoc & Retamilla, Monte amarillo & Fabaceae & 3 \\
\hline Suaeda divaricata Moq. & Vidriera & Chenopodiaceae & 3 \\
\hline Atriplex lampa (Moq.) D. Dietr. & Zampa & Chenopodiaceae & 2 \\
\hline Chuquiraga erinacea D. Don ssp. erinacea & Cola de zorro, Chilladora & Asteraceae & 2 \\
\hline Prosopis flexuosa DC var. flexuosa & Algarrobo & Fabaceae & 1 \\
\hline Proustia cuneifolia D. Don & Altepe & Asteraceaea & 1 \\
\hline Total: 15 taxones & & & 138 \\
\hline
\end{tabular}




\section{ANEXO III \\ CATÁLOGO BOTÁNICO DE NOMBRES Y USOS}

En el catálogo se hace referencia tanto al nombre científico, como al nombre común de la planta cuando éste fue mencionado por los informantes. El conocimiento tradicional de las plantas fue ordenado en función de los ámbitos de subsistencia, y en los casos en que se aportó información adicional de interés, ésta fue incorporada dentro de las observaciones. Se deja constancia también de la información del material de referencia que se encuentra depositado en el herbario SRFA.

En el catálogo se excluye la información referida a la descripción e iconografía de las especies porque exceden el carácter etnobotánico de este estudio. La información al respecto está ampliamente documentada en la cuantiosa bibliografía florística y taxonómica referida a Argentina. (Cabrera 1968, Correa 1998, Kiesling 1994, Kiesling 2003).

\section{PTERIDOPHYTA}

\section{EQUISETACEAE}

\section{Equisetum giganteum $\mathrm{L}$.}

Yerba de la plata

Medicina e higiene: La infusión de la parte aérea se emplea para mitigar dolencias de los riñones.

Observaciones: Las plantas para consumo son adquiridas comercialmente o traídas por vecinos o familiares de las zonas donde éstas crecen.

Material estudiado: ARGENTINA, Prov. Mendoza: Dpto. San Rafael, Villa Atuel, acequia de riego sobre Ruta Prov. 143, 20/12/06, Prina, Muiño \& Morici 3202 (SRFA) 


\section{PTERIDACEAE}

\section{Cheilanthes myriophylla Desv.}

Doradilla

Medicina e higiene: La parte aérea de la planta se emplea en infusiones como depurativo de la sangre.

Material estudiado: ARGENTINA, Prov. La Pampa: Dpto. Chicalcó, Ruta Prov. 190, 5 $\mathrm{km}$ al N de Agua Escondida, 14/01/07, Muiño 159 (SRFA), S 36 09'46,2”' W 68 18' 27,1", 09/02/09, Muiño 164 (SRFA)

\section{PINOPHYTA (GIMNOSPERMAS)}

\section{CUPRESSACEAE \\ Cupressus sempervirens Sudworth}

\section{Ciprés}

Ornamental: Suele cultivarse en el patio de las casas del pueblo y en los puestos como árbol de adorno.

Material estudiado: ARGENTINA, Prov. La Pampa, Dpto. Chicalcó, La Humada, S $36^{\circ}$ 21'02.3", W 68 00' 87.2”, 06/02/09, Muiño 274 (SRFA)

\section{Cupressus arizonica Greene}

Ciprés

Ornamental: Suele cultivarse como árbol ornamental en el patio de las casas del pueblo y en los puestos.

Material estudiado: ARGENTINA, Prov. La Pampa, Dpto. Chicalcó, La Humada, S $36^{\circ}$ 24'06,4', W 67"16'28,3', 26/11/08, Muiño 187 (SRFA) 


\section{Platycladus orientalis (L.) Franco}

Ornamental: Suele cultivarse como árbol ornamental y como cerco vivo en el patio de las casas y en las veredas de las calles de La Humada.

Material estudiado: ARgentinA, Prov. La Pampa, Dpto. Chicalcó, La Humada, S $36^{\circ} 24^{\prime} 06,4^{\prime \prime}$, W $67^{\circ} 16^{\prime} 28,3$ ', 26/11/08, Muiño 186 (SRFA)

\section{EPHEDRACEAE}

\section{Ephedra ochreata Miers}

\section{Solupe frutero}

Ganadería: Especie de importancia forrajera, muy apetecida por caprinos, ovinos y bovinos.

Medicina e higiene: Se emplea en fomentos y cataplasmas junto con tintura de árnica en contusiones y torceduras.

Alimentación: La fruta se consume directamente recolectada en el campo y con ella también se hacía arrope, pero en la actualidad ya no se elabora.

Material estudiado: ARGENTINA, Prov. La Pampa, Dpto. Chicalcó, Algarrobo del Águila, Ruta Prov. 14, 4 km al W de Ruta Nac. 151, 26/11/07, Muiño 90 (SRFA)

\section{PINACEAE}

\section{Pinus halepensis Mill.}

\section{Pino}

Cultura material: La madera es muy utilizada en la construcción de bastidores, palas y otros componentes de los telares.

Ornamental: Se cultiva como árbol de sombra en patios de casas.

Material estudiado: ARGENTINA, Prov. La Pampa, Dpto. Chicalcó, La Humada, S $36^{\circ}$ 21'06.0', W 68 00' 77.6', 05/02/09, Muiño 265 (SRFA) 


\title{
MAGNOLIOPHYTA (ANGIOSPERMAE)
}

\section{MAGNOLIOPSIDA (DICOTYLEDONEAE)}

\author{
ACERACEAE \\ Acer negundo L.
}

Ornamental: Se cultiva escasamente en las veredas de las calles de La Humada.

Material estudiado: ARGENTINA, Prov. La Pampa: Dpto. Chicalcó, La Humada, S $36^{\circ}$

20'94.8', W 68 00'90.5', 05/02/09, Muiño 260 (SRFA)

\section{AIZOACEAE}

\section{Aptenia cordifolia (L. f.) Scwantes}

Madre de familia

Ornamental: Se cultiva con frecuencia como planta de adorno en jardines.

Material estudiado: ARGENTINA, Prov. La Pampa, Dpto. Chicalcó, La Humada, S $36^{\circ}$ 20'70.2”, W 68 01'55.1', 06/02/09, Muiño \& Mansilla 307 (SRFA)

\section{Lampranthus roseus (Willd.) Schwantes}

Deditos

Ornamental: Cultivada en jardines hogareños con fines ornamentales por la belleza de sus flores.

Material Estudiado: ARGENTINA, Prov. La Pampa: Dpto. Chicalcó, La Humada. S $36^{\circ}$

20'91.6”, W 68 00' 78.0”'. 05/02/09, Muiño \& Vázquez 311 (SRFA) 


\section{AMARANTHACEAE \\ Amaranthus blitoides S. Watson}

Verdolaga

Ganadería: Indicada como planta consumida por todo tipo de ganado.

Material estudiado: ARGENTINA, Prov. La Pampa: Dpto. Chicalcó, La Humada. Puesto La Vasconia. Tranquera de entrada, 13/02/07, Muiño 82 (SRFA)

\section{Amaranthus caudatus L.}

Bledo verde, Bledo rojo

Ornamental: Suele formar parte de las plantas cultivadas en los jardines hogareños, por su rusticidad y el color rojizo de la planta.

Observaciones: Se han observado ejemplares que presentan coloraciones variables entre el verde y el rojo a las que los pobladores identifican como variedades diferentes.

Material estudiado: ARGENTINA, Prov. La Pampa: Dpto. Chicalcó, La Humada, S $36^{\circ}$ 21' 13,8', W 68 00' 87,8', 06/02/09, Muiño \& Rojas 240 (SRFA), La Humada, S $36^{\circ}$ $21^{\prime} 13,8^{\prime \prime}$, W $68^{\circ} 00^{\prime} 87,8^{\prime}$, , 06/02/09, Muiño \& Rojas 241 (SRFA)

\section{Amaranthus crispus (Lesp. \& Thévenau) A. Terrac.}

Yerba de la chiva, Yerba meona

Ganadería: Especie considerada con buenas cualidades forrajeras y consumida por todo tipo de ganado.

Material estudiado: ARGENTINA, Prov. La Pampa: Dpto. Chicalcó, Chos Malal, Puesto Las Tosquitas, 24/02/05, Muiño 12 (SRFA); Chos Malal, Puesto Chos Malal, 24/02/05, Muiño 27 (SRFA); La Humada, S 36 20'91,6”, W 68 00' 78,0’, 05/02/09, Muiño \& Vázquez 207 (SRFA) 


\section{Gomphrena mendocina (Phil.) R.E.Fr.}

Yerba del pollo

Ganadería: Considerada como buena forrajera para todo tipo de ganado pero en especial para vacunos y ovinos.

Medicina e higiene: La infusión de la parte aérea se bebe con azúcar tostada cuando hay dolores de estómago debido a malas digestiones, especialmente en los niños. También para combatir resfríos y como febrífugo. Para los resfríos se puede emplear la infusión de la planta sola o mezclada con raspaduras del tallo de jarilla (Larrea divaricata). Este preparado se elabora colocando azúcar en un recipiente, que en contacto con un hierro incandescente se carameliza. Se agregan entonces las partes vegetales, tras lo cual se vierte agua en ebullición y se deja reposar unos minutos antes de beber.

Observaciones: Para su uso medicinal, la gente suele recolectarla en el verano y usarla seca durante el resto del año.

Material Estudiado: ARGENTINA, Prov. La Pampa: Dpto. Chicalcó, La Humada, Ruta Prov. 10, entrada al pueblo, 25/01/06, Muiño \& Arenas 24 (SRFA); Chos Malal, Puesto Chos Malal, 24/02/05, Muiño 17 (SRFA)

\section{ANACARDIACEAE}

\section{Schinus areira $\mathrm{L}$.}

\section{Gualeguay, Pimiento}

Ornamental: Cultivado en el área rural y en La Humada como árbol de sombra.

Material Estudiado: ARGENTINA, Prov. La Pampa: Dpto. Chicalcó, La Humada, S $36^{\circ}$ 21'02.3', W 68000' 87.2', 06/02/09, Muiño 276 (SRFA)

\section{Schinus johnstonii F.A. Barkley}

Molle

Ganaderia: Considerada un valioso recurso forrajero para cabras y ovejas, en menor medida para el ganado vacuno y equino. 
Medicina e higiene: La infusión de las hojas o de las raspaduras de las ramas se emplea para curar resfríos, catarros y dolores de estómago. Para los dos primeros fines puede ser empleado con tomillo (Acantholippia seriphioides), jarilla (Larrea divaricata), chañar (Geoffraea decorticans), tamarisco (Tamarix ramosissima), arabia (Eleagnus angustifolia) y raíz de blanquilla (Hyalis argentea). La flor se puede aplicar sobre las muelas para mitigar el dolor. La infusión de las hojas se emplea para el corazón y con aspirina está indicada para el tratamiento del sarampión.

Cultura material: La raíz se emplea en decocciones para teñir lana, obteniéndose tintes variables según la concentración que van del rosado claro a los marrones suaves.

Combustible: Se emplea como leña de buen contenido calórico. Se registraron algunos testimonios sobre los efectos nocivos de su humo por lo que se evita cocinar alimentos con ella.

Material Estudiado: ARGENTINA, Prov. La Pampa, Dpto. Chicalcó, Chos Malal. Borde de camino, $4 \mathrm{~km}$ al $\mathrm{N}$ del salón comunitario, 27/11/07, Muiño 88 (SRFA)

\section{APIACEAE \\ Apium graveolens L.}

Apio

Alimentación: Se sembraba en las huertas con fines alimentarios, pero no se han registrado cultivos actuales y solo se encontró espontánea en sitios donde anteriormente existieron huertos. En la actualidad se la adquiere en el comercio.

Material Estudiado: ARGENTINA, Prov. La Pampa, Dpto. Chicalcó, La Humada, S $36^{\circ}$ 21'00,0', W 68 00'46,9', 26/11/08, Muiño 192 (SRFA)

\section{Daucus carota L ssp. sativus (Hoffm.) Arcang.}

\section{Zanahoria}

Alimentación: Es una de las hortalizas que más se sembraba en las huertas, pero en la actualidad se está perdiendo su cultivo por la facilidad de adquisición en comercios de La Humada. 
Material Estudiado: ARGENTINA, Prov. La Pampa, Dpto. Chicalcó, La Humada, S $36^{\circ}$ 21' 13.8', W 68000' 87.8', 06/02/09, Muiño \& Rojas 289 (SRFA)

\section{Foeniculum vulgare Mill.}

Hinojo

Observaciones: Poco frecuente en huertas y jardines. Se cultiva con doble propósito: como planta ornamental y para utilizar los frutos como aderezo de platos dulces, como tortas fritas, buñuelos y torrejas.

Material Estudiado: ARGENTINA, Prov. La Pampa, Dpto. Chicalcó, La Humada, S $36^{\circ}$ 20'70.2', W 68 01'55.1', 06/02/09, Muiño y Mansilla 304 (SRFA)

\section{Hydrocotyle bonariensis Lam.}

Ornamental: Poco cultivada en jardines en macizos vegetales junto con otras plantas de bajo porte.

Material Estudiado: ARGENTINA, Prov. La Pampa, Dpto. Chicalcó, La Humada, S $36^{\circ}$ 21'03.2', W 68 00' 75.4”, 06/02/09, Muiño \& Maya 271 (SRFA)

\section{Mulinum spinosum (Cav.) Pers.}

Yerba negra

Medicina e higiene: La infusión de la raíz se emplea para el tratamiento de la gastritis.

Observaciones: La escasa presencia de esta especie en el área es motivo de que su consumo se realice a partir de plantas traídas por vecinos o familiares desde la provincia de Mendoza, donde es más abundante.

Material Estudiado: ARGENTINA, Prov. La Pampa, Dpto. Chicalcó, Salitral de La Amarga, 20/12/89, Troiani \& Prina 10023 (SRFA) 
Petroselinum crispum (Mill.) A.W. Hill.

\section{Perejil}

Alimentación: Es una de las especies que aún se cultivan en las huertas para emplearla como aderezo en diferentes platos.

Medicina e higiene: Se indicó la posibilidad del uso del tallo en infusión como abortivo.

Material Estudiado: ARGENTINA, Prov. La Pampa, Dpto. Chicalcó, S 36 20’94.8”, W $68^{\circ} 00^{\prime} 90.5^{\prime},, 05 / 02 / 09$, Muiño 263 (SRFA)

\section{APOCYNACEAE}

\section{Nerium oleander L.}

Laurel de jardín

Oramental: Se cultiva en jardines del pueblo por la belleza de sus flores.

Material Estudiado: ARgENTINA, Prov. La Pampa, Dpto. Chicalcó, La Humada, S $36^{\circ}$ 21'03.2', W 68 00' 75.4', Muiño \& Maya 256 (SRFA)

\section{Vinca major L.}

Ornamental: Se cultiva en los jardines pero con poca frecuencia.

Material Estudiado: ARGENTINA, Prov. La Pampa, Dpto. Chicalcó, La Humada, S $36^{\circ}$ 21'06.0", W 68000'77.6", 05/02/09, Muiño 267 (SRFA)

\section{AQUIFOLIACEAE}

\section{Ilex paraguariensis A.St.-Hil.}

\section{Yerba mate}

Medicina e higiene: La infusión de yerba tostada se emplea para interrumpir las hemorragias menstruales intensas.

Cultura material: Se emplea en decocciones para teñir lana obteniéndose una coloración verde claro. También se emplea para teñir el cuero que sirve para la confección de sogas. 
En tales casos se deposita la yerba usada en recipientes de lata y se mantiene húmeda. Con el tiempo se va ennegreciendo por oxidación y en el momento oportuno se realiza con ella una decocción con la que se tiñe el cuero obteniéndose coloraciones gris oscuro.

Observaciones: Se carece de material de referencia. Se trata de un producto de adquisición comercial ya que la especie no se distribuye naturalmente en el área.

\section{ARALIACEAE}

\section{Hedera helix $L$.}

Hiedra

Ornamental: Se cultiva esporádicamente en patios y jardines.

Material Estudiado: ARGENTINA, Prov. La Pampa, Dpto. Chicalcó, La Humada, S $36^{\circ}$ 21' 13,8', W $68^{\circ} 00^{\prime} 87,8$ ', 06/02/09, Muiño \& Rojas 232 (SRFA)

\section{ASCLEPIADACEAE}

\section{Philibertia gilliesii Hook. \& Arn.}

Enredadera del campo, Enredadera del avestruz, Yuyo de víbora

Ganadero: Las hojas son consumidas por los vacunos, y los frutos por cabras y avestruces. Material Estudiado: ARGENTINA, Prov. La Pampa, Dpto. Chicalcó, Agua de Torres. Puesto La Envidia, 30/11/07, Muiño 84 (SRFA); La Humada, Ruta Prov. 10, entrada al pueblo, 25/01/06, Muiño \& Arenas 41 (SRFA)

Tweedia brunonis Hook. \& Arn.

Yerba del choique

Ganadero: Indicada como una especie preferida para el consumo por el ganado y por los avestruces.

Material Estudiado: ARGENTINA, Prov. La Pampa, Dpto. Chicalcó, La Humada, S $36^{\circ}$ 21' 13,1', W $67^{\circ} 45^{\prime} 41.3$ ', 27/11/08, Muiño 169 (SRFA) 
ASTERACEAE

\section{Achillea filipendulina Lam.}

Arbusto

Ornamental: Se cultiva escasamente como adorno en jardines del pueblo.

Material Estudiado: ARGENTINA, Prov. La Pampa, Dpto. Chicalcó, La Humada, S $36^{\circ}$ 21' 13,8', W 68000' 87,8', 06/02/09, Muiño \& Rojas 239 (SRFA)

\section{Achillea millefolium L.}

Ornamental: Se cultiva como adorno en jardines del pueblo.

Material Estudiado: ARGENTINA, Prov. La Pampa, Dpto. Chicalcó, La Humada, S $36^{\circ}$ 21'03.2', W 68 00' 75.4', 05/02/09, Muiño \& Maya 250 (SRFA)

\section{Artemisia abrotanum L.}

\section{Alcanfor}

Medicinal: La infusión de sus partes aéreas se utiliza para facilitar el sueño. Hervida en aceite se emplea con fines diversos, en fricciones corporales cuando hay dolores musculares, sobre el pecho cuando hay resfríos y en la cara en congestiones nasales. Las gotas de este aceite se aplican al interior de los oídos para mitigar el dolor. Cuando existen procesos de parálisis faciales, se indicó realizar masajes con grasa de gallina en la cual debe haberse cocido previamente esta planta. Los masajes deben realizarse sobre la región afectada con la ayuda de ciertas partes de animales como la cabeza de un piche o un hueso de puma.

Material Estudiado: ARGENTINA, Prov. La Pampa, Dpto. Chicalcó, La Humada, S $36^{\circ}$ 21'03,2', W 680 00' 75,4', 14/08/09, Muiño \& Maya 317 (SRFA)

\section{Artemisia absinthium L.}

\section{Ajenjo}

Ganadería: Se emplea la infusión de la parte aérea para curar diarreas en el ganado. 
Medicina e higiene: En infusión como digestivo o para afecciones del hígado, sola o mezclada con matico (Artemisia douglasiana) y carqueja (Baccharis trimera). Se usa con mucha frecuencia para saborizar el mate.

Observaciones: Se cultiva profusamente en los jardines y huertas. Se indicó que las mujeres no deben cosecharla durante el período menstrual.

Material Estudiado: ARGENTINA, Prov. La Pampa, Dpto. Chicalcó, La Humada, S $36^{\circ}$ 21' 13.8', W 68 00' 87.8', 06/02/09, Muiño \& Rojas 271 (SRFA)

\section{Artemisia douglasiana Bess.}

Matico

Medicina e higiene: Se emplea en infusión de la parte aérea como digestiva y para las gastritis. Junto con carqueja (Baccharis trimera) y ajenjo (Artemisia absinthium) para el hígado. Utilizada con mucha frecuencia para saborizar el mate.

Observaciones: Se cultiva profusamente en los jardines y huertas hogareñas.

Material Estudiado: ARGENTINA, Prov. La Pampa, Dpto. Chicalcó, La Humada, Puesto La Humada, 03/12/07, Muiño 95 (SRFA)

\section{Baccharis darwinii Hook \& Arn.}

Yerba de oveja, Manzanilla de las lomas

Ganadería: Es considerada una especie muy buscada por el ganado vacuno y ovino. Cuando está seca por los equinos.

Observaciones: Se la mencionó como especie indicadora de la presencia y abundancia de tubérculos de chaquil (Arjona tuberosa) bajo su dosel.

Material estudiado: ARGENTINA, Prov. La Pampa: Dpto. Chicalcó, La Humada, Puesto La Humada, 25/01/06, Muiño 37 (SRFA); Ruta prov 14, 4 km al W de Ruta Nac. 151, 26/11/07, Muiño 101 (SRFA), La Humada, S 36 20'82,4’, W 68 01'20,0’, 06/02/09, Muiño 220 (SRFA) 


\section{Baccharis gilliesii A. Gray}

Yerba de oveja

Ganadería: Se la señaló como especie forrajera consumida por ovejas y vacunos.

Material Estudiado: ARGENTINA, Prov. La Pampa: Dpto. Loventué, El Durazno, S $36^{\circ}$ 42'09,4”', W 65'17'52,9’', 27/11/08, Muiño 171 (SRFA)

\section{Baccharis rufescens Spreng.}

Jarillilla

Medicina e higiene: La infusión de la parte aérea se emplea para mitigar inflamaciones del hígado.

Material estudiado: ARGENTINA, Prov. La Pampa: Dpto. Chicalcó, Ruta Prov. 190, 5 $\mathrm{km}$ al NE de Agua Escondida, 14/01/07, Muiño 158 (SRFA)

\section{Baccharis salicifolia (Ruiz \& Pav.) Pers.}

\section{Chilca}

Ganadería: Especie forrajera consumida por el ganado caprino.

Medicia e higiene: La infusión se emplea como estomacal para curar empachos y para afecciones del hígado y la vesícula, para mejorar la circulación de la sangre y para controlar la presión arterial.

Observaciones: Frecuente en cauces secos de escorrentía y con frecuencia cultivada en el sector peridoméstico en torno a los tanques de agua u otros sitios húmedos para su uso medicinal. En el pasado se empleaban los tallos para producir fuego por fricción.

Material Estudiado: ARGENTINA, Prov. La Pampa: Dpto. Chicalcó, Puesto La Humada, 25/01/06, Muiño 30 (SRFA); Puente Ruta Nac. 143 y Arroyo de la Barda, 26/11/07, Muiño 103 (SRFA) 


\section{Baccharis spartioides (Hook. \& Arn. ex DC.) J. Rémy}

\section{Pichana}

Ganadería: Se emplea en decocciones para desinfectar las heridas producidas por la castración del ganado.

Alimentación: La ceniza de la planta se emplea en el primer hervor con agua para acelerar la cocción de granos de trigo y maíz en la preparación de mote. Luego se aplica un segundo hervor para separar los pericarpos.

Cultura material: En la construcción de viviendas era una de las especies utilizadas para la elaboración de ladrillos y de chorizos de adobe; también para armar paredes con la técnica de cerco embarrado y para cubrir techos de viviendas sobre la tirantería. En el teñido de lana se emplea su decocción para obtener un color verde amarillento. Muy frecuente en la elaboración de escobas. En el pasado servía para preparar lejías con la ceniza, la cual se usaba en la limpieza de la ropa.

Material Estudiado: ARGENTINA, Prov. La Pampa: Dpto. Chicalcó, Chos Malal, Puesto Chos Malal, 24/02/05, Muiño 11 (SRFA); Algarrobo del Águila, S 36 21' 13,1'”, W $67^{\circ}$ 45' 41,3', 27/11/08, Muiño 172 (SRFA)

\section{Baccharis tenella Hook. \& Arn.}

\section{Romerillo blanco}

Observaciones: No se indicaron usos ni aptitudes de esta planta.

Material Estudiado: ARGentinA, Prov. La Pampa: Dpto. Chicalcó, Chos Malal. Salitral de la Perra, 28/11/07, Muiño 116 (SRFA)

\section{Baccharis trimera (Less.) DC.}

\section{Carqueja}

Medicina e higene: La infusión de toda la planta se emplea para problemas digestivos, aparentemente vinculados con el hígado, pudiendo ser aplicada junto con matico (Artemisia douglasiana) y ajenjo (Artemisia absinthium). La infusión también es reputada para el estómago y para purificar la sangre. 
Cultura material: La parte aérea en decocción se emplea para teñir lana obteniéndose tonalidades amarillas.

Material Estudiado: ARGENTINA, Prov. Mendoza: Dpto. Malargüe, Agua Escondida, S $36^{\circ} 08^{\prime} 23,7^{\prime}$, W $68^{\circ} 18^{\prime} 87,8^{\prime}$ ', 09/02/09, Muiño 242 (SRFA)

\section{Brachyclados lycioides D. Don}

Yerba mora

Ganadería: Es una especie considerada con buenas aptitudes forrajeras.

Material Estudiado: ARGENTINA, Prov. La Pampa: Dpto. Chicalcó, La Humada. Ruta Prov. 10 salida del pueblo hacia el N, 01/12/07, Muiño 122 (SRFA)

\section{Calendula officinalis $\mathrm{L}$.}

\section{Caléndula, Panchita}

Ornamental: Se cultiva con frecuencia en los jardines hogareños como ornamental por la belleza de sus flores.

Material Estudiado: ARGENTINA, Prov. La Pampa: Dpto. Chicalcó, La Humada, S $36^{\circ}$ $21^{\prime} 13,8^{\prime \prime}$, W $68^{\circ} 00^{\prime} 87,8^{\prime \prime}, 06 / 02 / 09$, Muiño \& Rojas 230 (SRFA)

\section{Cosmos bipinnatus Cav.}

Alegría

Ornamental: Se cultiva frecuentemente en jardines por la belleza de sus flores.

Material Estudiado: ARGENTINA, Prov. La Pampa: Dpto. Chicalcó, La Humada, S $36^{\circ}$ 20'70,2", W 68 01' 55,1', 06/02/09, Muiño \& Mansilla 301 (SRFA); S 36 21'03.2", W 68 00' 75.4', 05/02/09, Muiño y Maya 306 (SRFA)

\section{Chuquiraga erinacea D. Don ssp. erinacea}

Chirriadora, Chilladora, Cola de zorro

Ganadería: La flor es consumida por caprinos y equinos. 
Combustible: Se emplea como leña de menor calidad, con frecuencia para iniciar el fuego.

Observaciones: $\mathrm{Su}$ abundancia fue señalada como indicadora de agua cercana a la superficie del suelo.

Material Estudiado: ARGENTINA, Prov. La Pampa: Dpto. Chicalcó, Puesto La Humada, 25/01/06, Muiño 39 (SRFA); Chos Malal, Puesto Chos Malal, 24/02/05, Muiño 6 (SRFA)

\section{Chuquiraga rosulata Gaspar}

Cola de zorro

Ganadería: Como la especie anterior, la flor es consumida por caprinos y equinos.

Material Estudiado: ARGENTINA, Prov. La Pampa: Dpto. Chicalcó, La Humada, Ruta Prov. 10, $20 \mathrm{~km}$ al N del pueblo, 29/11/07, Muiño 63 (SRFA)

\section{Cyclolepis genistoides D. Don}

Matorro, Palo azul

Cultura material: La decocción de las partes aéreas de la planta se emplea para teñir lana obteniéndose tintes verde azulados.

Medicina e higiene: La infusión de las raspaduras de los tallos se utiliza para calmar dolores de riñones. Para este fin puede emplearse simultáneamente con chañar (Geoffraea decorticans).También es utilizada para calmar dolores de estómago y en aplicaciones locales de paños como desinflamatorio de contusiones.

Material Estudiado: ARgENTINA, Prov. La Pampa, Dpto. Chicalcó, Algarrobo del Águila, S $36^{\circ} 21^{\prime} 13,1$ ', W $67^{\circ} 45^{\prime}$ 41,3”, 27/11/08, Muiño 173 (SRFA)

\section{Doniophyton anomalum (D. Don) Kurtz}

Clavel del campo

Observaciones: No se indicaron usos ni aptitudes sobre esta especie.

Material Estudiado: ARgENTINA, Prov. La Pampa: Dpto. Chicalcó, Ruta Prov 14, 50 km al W de Ruta Nac. 151, 27/11/07, Muiño 124 (SRFA) 


\section{Eupatorium buniifolium Hook. \& Arn. var. buniifolium}

\section{Romerillo colorado}

Medicinal: Las cenizas se aplican directamente sobre la piel para tratar quemaduras.

Material Estudiado: ARGENTINA, Prov. Mendoza: Dpto. Malargüe, Agua Escondida, S $36^{\circ} 09^{\prime} 46.2$ ', W 68 18' 27.1'”, 09/02/09, Muiño 244 (SRFA)

\section{Eupatorium patens D. Don ex Hook. \& Arn.var patens}

Bejuco, Mejuco

Ganadería: Es una especie con buenas cualidades forrajeras para el ganado caprino. En veterinaria se pica la planta y se aplica como emplasto sobre heridas, en especial en las afectadas por gusaneras (miasis). Para este fin también se emplea la decocción de la planta entera sola o mezclada con fluído "Manchester". Esta decocción se emplea por vía oral para problemas digestivos y para combatir el gusano del cuerno en los caprinos y el gusano del cuajo en los equinos.

Medicina e higiene: La infusión del raspado de los tallos se emplea como digestivo para dolores de estómago, contra diarreas y también para inflamaciones del hígado.

Material Estudiado: ARGENTINA, Prov. La Pampa, Dpto. Chicalcó, La Humada, Ruta Prov. 10, entrada al pueblo, 30/01/06, Muiño 44 (SRFA), S $36^{\circ} 20^{\prime} 86,7^{\prime \prime} \mathrm{W} 68^{\circ} 01^{\prime}$ 01,8", 06/02/09, Muiño 226 (SRFA)

\section{Gaillardia megapotamica (Spreng.) Baker}

\section{Topazaire}

Medicina e higiene: En el pasado la infusión de toda la planta se empleaba para mitigar dolores de cabeza en forma de lavajes y paños.

Observaciones: Se señaló que en la actualidad ha disminuido su abundancia debido a los incendios.

Material Estudiado: ARGENTINA, Prov. La Pampa, Dpto. Chicalcó, La Humada, S $36^{\circ} 24^{\prime} 06,4^{\prime \prime}$, W $67^{\circ} 16^{\prime} 28,3$ ', 24/11/08, Muiño 176 (SRFA) 


\section{Gaillardia pulchella Foug.}

Enamorada del sol

Observaciones: Cultivada en los jardines hogareños por la belleza de sus flores.

Material Estudiado: ARGENTINA, Prov. La Pampa, Dpto. Chicalcó, La Humada, S $36^{\circ}$ 21' 13,8', W 68 00'87,8', 06/02/09, Muiño \& Rojas 314 (SRFA), S 36 20' 70,2'”, W $68^{\circ} 01$ ' 55,1'”, 06/02/09, Muiño \& Mansilla 315 (SRFA)

\section{Gochnatia glutinosa (D. Don) Hook. \& Arn.}

Jarillilla

Ganadería: El ganado caprino la consume con normalidad pero es poco apetecida por las otras clases de ganado. La decocción se emplea como oxitócico.

Cultura material: Todas las partes de la planta se emplean para teñir lana. Los tintes obtenidos son de color amarillo verdoso, similares a los obtenidos con jarilla (Larrea divaricata), pero más intensos.

Medicina e higiene: La planta en infusión se emplea para las inflamaciones del hígado y como expectorante en bronquitis.

Material Estudiado: ARGENTINA, Prov. La Pampa: Dpto. Chicalcó, Chos Malal. Puesto Las Tosquitas, 24/02/05, Muiño 10 (SRFA)

\section{Grindelia chiloensis (Cornel.) Cabrera}

\section{Melosa}

Ganadería: Los ganados bovino, ovino y caprino solo consumen la flor.

Medicina e higiene: La infusión de tres hojas de la planta se emplea para interrumpir diarreas. La planta entera en infusión sirve para dolores generalizados; se mezcla con cadillo (Xanthium spinosum) y raspaduras de tallos de ala (Monttea aphylla). La planta se aplica en forma de cataplasmas para los tratamientos de fracturas de huesos. Para ello debe picarse pudiendo mezclarse con jarilla (Larrea divaricata) y esta mezcla se hierve en 
aceite verde. Se añaden cenizas y la mezcla se aplica vendada sobre la fractura. La cataplasma debe renovarse cada semana hasta la curación del hueso.

Cultura material: En el pasado se empleaba para cubrir los techos en forma imbricada para impermeabilizarlos y en el relleno de los bastos de las monturas.

Ornamental: En algunos hogares forma parte del jardín por la belleza de sus flores.

Observaciones: Se indicó que su abundancia en el campo actúa en detrimento de la existencia de buenos pastos forrajeros.

Material estudiado: ARGENTINA, Prov. La Pampa, Dpto. Chicalcó, Chos Malal, Ruta Prov. 14, 51 km al W de Ruta Nac. 151, 27/11/07, Muiño 73 (SRFA)

\section{Helianthus annuus L.}

\section{Girasol}

Ornamental: Las diferentes variedades se cultivan en los jardines por la belleza de los capítulos.

Material estudiado: ARGENTINA, Prov. La Pampa, Dpto. Chicalcó, La Humada, Puesto La Humada, S $36^{\circ} 20^{\prime} 70,2^{\prime \prime}$, W $68^{\circ} 01^{\prime} 55,1^{\prime \prime}, 06 / 02 / 09$, Muiño \& Mansilla 313 (SRFA)

\section{Helianthus petiolaris Nutt.}

Mirasol de campo, Girasol de jardín

Observaciones: Espontánea y a veces cultivada en los jardines como planta ornamental.

Material estudiado: ARgENTINA, Prov. La Pampa, Dpto. Chicalcó, La Humada, S $36^{\circ}$ 21' 14,5", W 68०00'94,3", 05/02/09, Muiño 300 (SRFA)

\section{Hyalis argentea D. Don ex Hook. \& Arn.}

Blanquilla

Ganadería: Forraje de mantenimiento consumido a veces por los vacunos y equinos cuando la planta es joven. 
Medicina e higiene: Indicada para los resfríos e irritaciones de garganta y en los tratamientos de la tos convulsa. Se emplea la infusión de las raspaduras de los rizomas pudiendo mezclarse con hojas o tallos de molle (Schinus johnstonii) y tomillo (Acantholippia seriphioides).

Cultura material: Iguales usos que la melosa. Se empleaba en el pasado para cubrir techos y rellenar bastos de monturas.

Material estudiado: ARGEnTINA, Prov. La Pampa, Dpto. Chicalcó, Algarrobo del Águila, Ruta Prov. 14, 12 km al W de Ruta Nac. 151, 26/11/07, Muiño 79 (SRFA)

\section{Hysterionica jasionoides Willd.}

Pelusilla

Observaciones: No se indicó más información que su nombre común.

Material estudiado: ARGENTINA, Prov. La Pampa: Dpto. Chicalcó, Ruta Prov. 10, 15 km al N de La Humada, 29/11/07, Muiño 139 (SRFA)

\section{Lactuca sativa $\mathrm{L}$.}

\section{Lechuga}

Alimentación: Cultivada con cierta frecuencia en las huertas familiares para autoconsumo.

Observaciones: Existe actualmente una tendencia mayor a adquirirla en los comercios de La Humada.

Material estudiado: ARGENTINA, Prov. La Pampa: Dpto. Chicalcó, La Humada, S $36^{\circ}$ 21'03,2', W 68 00' 75,4", 05/02/09, Muiño \& Luna 196 (SRFA)

\section{Leucanthemum maximum (Ramond) DC.}

Margarita

Ornamental: Cultivada en jardines del pueblo por la belleza de sus flores.

Material estudiado: ARGENTINA, Prov. La Pampa: Dpto. Chicalcó, La Humada, S $36^{\circ}$ 21'13.8', W 68 00' 87.8', 06/02/09, Muiño \& Rojas 309 (SRFA) 


\section{Matricaria recutita L.}

\section{Manzanilla}

Medicina e higiene: Se utiliza sola o mezclada con perlilla (Thymophylla pentachaeta) hervidas en grasa de gallina o en aceite. Este preparado se aplica en friegas para dar calor al cuerpo. En el pasado se le solía añadir una pastilla de alcanfor. En infusión para controlar diarreas, para aliviar dolores menstruales y para ayudar a la expulsión de la placenta durante los partos. Durante el postparto se acostumbraba a dar de beber a las madres una infusión de esta planta con canela (Cinnamomum zeylanicum), y hasta tanto la madre no produjera leche se daba de beber a los niños recién nacidos una infusión liviana de manzanilla.

Material Estudiado: ARGENTINA, Prov. Mendoza: Dpto. Malargüe, Agua Botada, S $35^{\circ}$ 50' 13', W 69 44' 23', 28/02/03, Prina, Alfonso \& Muiño 2125 (SRFA)

\section{Parthenium hysterophorus L.}

\section{Altamisa}

Ganadería: Cuando es consumida intensamente por las cabras, confiere sabor amargo a su carne.

Medicina e higiene: La infusión de la parte aérea de la planta se emplea para el tratamiento de los resfríos, como febrífugo, para desinflamar el hígado y mitigar dolores de estómago.

Material estudiado: ARGENTINA, Prov. La Pampa, Dpto. Chicalcó, Chos Malal, Ruta Prov 14, $50 \mathrm{~km}$ al W de Ruta Nac. 151, 26/11/07, Muiño 99 (SRFA)

\section{Proustia cuneifolia D. Don}

\section{Altepe}

Combustible: El único uso registrado fue como leña pero de menor calidad. Generalmente para encender el fuego.

Material estudiado: ARGENTINA, Prov. La Pampa, Dpto. Chicalcó, Ruta Prov. 190, 5 $\mathrm{km}$ al N de Agua Escondida, 14/01/07, Muiño 156 (SRFA) 


\section{Senecio filaginoides DC.}

Romerillo blanco, Ajenjo de perro, Té pampa crespo

Medicinal: Las partes aéreas en infusión para los dolores de estómago.

Material estudiado: ARGENTINA, Prov. La Pampa, Dpto. Chicalcó, Agua de Torres, Ruta Prov. 10, 3 km antes de Agua Escondida, 29/11/07, Muiño 77 (SRFA); La Humada. Puesto Rivadavia. En borde de contrafuego, 29/11/07, Muiño 137 (SRFA)

\section{Senecio melanopotamicus Cabrera}

Clavelillo

Observaciones: No se informaron más datos que su nombre común.

Material estudiado: ARGENTINA, Prov. La Pampa, Dpto. Chicalcó, Ruta Prov. 10, 20 km al N de La Humada. Sobre cerro de basalto, 29/11/07, Muiño 136 (SRFA)

\section{Senecio pampeanus Cabrera}

Manzanilla, Manzanilla de los cerros, Pinito de jardín

Ornamental: Se cultiva en los jardines y huertas del pueblo por la belleza de su porte y el color verde intenso en estado vegetativo.

Material estudiado: ARGENTINA, Prov. La Pampa, Dpto. Chicalcó, Ruta Prov. 14, 50 km al W de Ruta Nac. 151, 26/11/07, Muiño 123 (SRFA), La Humada, S 36²1' 13,8', W $68^{\circ} 00^{\prime} 87,8^{\prime}$, , 06/02/09, Muiño \& Rojas 227 (SRFA)

\section{Senecio subulatus D.Don ex Hook.\& Arn. var. erectus Hook.\& Arn.}

\section{Romerillo}

Ganadería: Fue señalada como una planta que es consumida por el ganado caprino.

Medicina: El humo de las partes aéreas de la planta se aplica en el interior del oído para mitigar dolores. Se arman cigarrillos, se fuman y el humo se sopla en el oído del paciente. 
Material estudiado: ARGENTINA, Prov. La Pampa, Dpto. Chicalcó, Chos Malal. Puesto Las Rosillas, 28/11/07, Muiño 86

\section{Tagetes mendocina Phil.}

\section{Chilchil del cerro}

Medicina e higiene: La infusión se emplea para el dolor de riñones y para controlar diarreas. Se emplea también para saborizar el mate.

Material estudiado: ARgENTINA, Prov. La Pampa, Dpto. Chicalcó, Agua de Torres. Ladera S de cerro sobre ribera izquierda del río Huayco, 30/11/07, Muiño 120 (SRFA)

\section{Tagetes patula L.}

\section{Copete enano, Clavelina}

Ornamental: Cultivada en jardines del pueblo por la belleza de sus flores. Se indicó su utilidad como control biológico de plagas en las huertas, información que se difunde ampliamente en las cartillas informativas del Programa INTA-Pro Huerta, de donde provendría el conocimiento local.

Material estudiado: ARGENTINA, Prov. La Pampa, Dpto. Chicalcó, La Humada, S $36^{\circ}$ 20'70,2", W 68 01' 55,1', 06/02/09, Muiño \& Mansilla 219 (SRFA), S 36 21'03.2',, W 68 00' 75.4', 05/02/09, Muiño \& Maya 251 (SRFA)

\section{Tanacetum balsamita L.}

\section{San Pedro}

Medicinal: Se emplea la infusión de la parte aérea y en el mate en indigestiones y en inflamaciones del hígado. Especie exótica que se cultiva en huertas y jardines.

Material estudiado: ARGENTINA, Prov. La Pampa, Dpto. Chicalcó, La Humada, S $36^{\circ}$ 21'03.2", W 68 0' 75.4", 05/02/09, Muiño \& Luna 153 (SRFA) 
Tessaria absinthioides (Hook. \& Arn.) DC.

\section{Pájaro bobo}

Medicina e higiene: Se informó que la infusión puede emplearse para el control del colesterol.

Material estudiado: ARgENTINA, Prov. La Pampa, Dpto. Chicalcó, La Humada. En área inundable de la entrada al pueblo, 29/01/06, Muiño 50 (SRFA)

\section{Thelesperma megapotamicum (Spreng.) Kuntze}

Té pampa, Manzanilla del campo

Ganadería: Forraje de buena calidad para todo el ganado de la zona.

Medicina e higiene: La infusión se usa como digestiva, para el hígado, para controlar la presión sanguínea y con aceite en friegas. Suele usarse para saborizar el mate. Se considera una planta cálida.

Cultura material: La decocción se emplea para teñir lana obteniéndose matices de color castaño claro.

Observaciones: Cuando no es abundante a veces se prefiere dejar para su consumo por la hacienda. Se registró la preparación de un licor dulce con la infusión, agregándole alcohol y azúcar quemado.

Material estudiado: ARGENTINA, Prov. La Pampa: Dpto. Chicalcó, La Humada. Puesto La Humada, 26/01/07, Muiño 22 (SRFA); Chos Malal, Ruta Prov 14, $50 \mathrm{~km}$ al W de Ruta Nac. 151, 26/11/07, Muiño 109 (SRFA), La Humada, S 36 24’06,4”, W 67 16’28,3’', 24/11/08, Muiño 177 (SRFA)

\section{Thymophylla pentachaeta (DC.) Small var. belenidium (DC.) Strother}

\section{Perlilla}

Medicina e higiene: La infusión de la parte aérea se emplea para desinflamar las vías urinarias. Junto con manzanilla (Matricaria recutita) puede emplearse en friegas con aceite o grasa de gallina para dar calor al cuerpo. 
Material estudiado: ARGENTINA, Prov. La Pampa, Dpto. Chicalcó, La Humada, Ruta Prov. 10, $20 \mathrm{~km}$ al N del pueblo, 29/11/07, Muiño 62 (SRFA)

\section{Trichocline reptans (Wedd.) Hieron.}

\section{Contrahierba}

Medicina e higiene: La infusión de la parte aérea con azúcar quemado se emplea para curar los resfríos. Para mitigar dolores de cabeza se emplea el humo de la combustión de la planta mediante sahumados.

Observaciones: La raíz seca se muele y se puede mezclar con el tabaco (Nicotiana tabacum) para saborizarlo.

Material estudiado: ARgentinA, Prov. La Pampa, Dpto. Chicalcó, Algarrobo del Águila, Ruta Prov. 14, 4 km al W de Ruta Nac. 151, 26/11/07, Muiño 100 (SRFA); La Humada, S $36^{\circ} 24^{\prime}$ 06,4', W 67 16' 28,3', 24/11/08, Muiño 179 (SRFA)

\section{Verbesina encelioides (Cav.) Benth. \& Hook. f. ex A. Gray}

Mirasol de campo, Girasol

Medicina e higiene: La infusión de la parte aérea se emplea contra las almorranas y como desinflamatorio en procesos de apendicitis.

Material estudiado: ARGENTINA, Prov. La Pampa: Dpto. Chicalcó, Chos Malal, Puesto Rincón de Chos Malal, 27/02/05, Muiño 7 (SRFA)

\section{Xanthium ambrosioides Hook. \& Arn.}

Yerba de la vizcacha

Cultura material: La ceniza se empleaba para preparar lejía.

Material estudiado: ARGENTINA, Prov. La Pampa: Dpto. Chicalcó, La Humada, S $36^{\circ}$ 21'05.7', W 68 01'11.5', 05/02/09, Muiño 249 (SRFA) 


\section{Xanthium spinosum L.}

Cadillo, Cadillo de la sierra, Abrojo, Cepa de caballo

Medicina e higiene: La infusión de la raíz se emplea para inflamaciones del hígado y dolores de estómago y de riñones. Para esto último también se puede mezclar con raíz de cortadera (Cortaderia selloana). Estas infusiones también pueden beberse a temperatura ambiente, es decir como aguapasto. Fue indicada también para dolencias generales en infusión con raspaduras de ala (Monttea aphylla) y melosa (Grindelia chiloensis).

Cultura material: La ceniza se empleaba para preparar lejía. Se usaba para lavar la vajilla y otros enseres domésticos.

Material estudiado: ARGENTINA, Prov. La Pampa, Dpto. Chicalcó, La Humada. Acceso al pueblo desde el E, 25/01/06, Muiño 75 (SRFA)

\section{Zinnia peruviana (L.) L.}

Flor de papel

Ornamental: Cultivada con frecuencia en los jardines por sus flores.

Material estudiado: ARGENTINA, Prov. La Pampa, Dpto. Chicalcó, La Humada, S $36^{\circ}$ 20'70,2", W 68 01' 55,1', 06/02/09, Muiño \& Mansilla 302 (SRFA)

\section{BERBERIDACEAE}

\section{Berberis thumbergii DC.}

Ornamental: Cultivada en calles del pueblo por el color de su follaje y sus flores.

Material estudiado: ARGENTINA, Prov. La Pampa, Dpto. Chicalcó, La Humada, S $36^{\circ}$

21'03,4', W 68 00' 89,6', 07/02/09, Muiño 218 (SRFA) 


\section{BORAGINACEAE}

\section{Borago officinalis L.}

\section{Borraja}

Medicina e higiene: La infusión caliente o en aguapasto se utilizaban durante el parto y postparto de las mujeres para dar calor al cuerpo y evitar los "pasmos".

Material estudiado: No se dispone de material de referencia. Actualmente ya no se emplea. La planta se adquiría comercialmente a los vendedores ambulantes de la zona.

\section{Heliotropium chrysanthum Phil.}

Romerillo blanco, Vira vira

Observaciones: No se informaron datos adicionales sobre la especie.

Material estudiado: ARGENTINA, Prov. La Pampa, Dpto. Chicalcó, Ruta Prov. 10, 10 km al S de Agua Escondida, 29/11/07, Muiño 146 (SRFA); La Humada, Puesto Pozo de la Víbora, 18/01/07, Muiño155 (SRFA)

\section{BRASSICACEAE}

\section{Brassica oleracea L.}

\section{Repollo}

Alimentación: Adquirida comercialmente para consumo a los vendedores ambulantes o en La Humada. En la actualidad se la cultiva ocasionalmente en las huertas.

Material estudiado: ARGENTINA, Prov. La Pampa, Dpto. Chicalcó, La Humada, S $36^{\circ}$ 20' 91,9', W 68 00' 87,9', 05/02/09, Muiño \& Luna 193 (SRFA)

\section{Lobularia maritima (L.) Desv.}

\section{Canastilla}

Ornamental: Cultivada en macizos vegetales en los jardines de las casas del pueblo. 
Material estudiado: ARGENTINA, Prov. La Pampa, Dpto. Chicalcó, La Humada, S $36^{\circ}$ 21 ' 13,8', W $68^{\circ} 00$ ' 87,8', 06/02/09, Muiño \& Rojas 234 (SRFA)

\section{Malcolmia maritima (L.) R. Br.}

Alhelí de Mahón

Ornamental: Cultivada en los jardines de las casas del pueblo.

Material estudiado: ARGENTINA, Prov. La Pampa, Dpto. Chicalcó, La Humada, S $36^{\circ}$ 20'70,2', W 68 01' 55,1'”, 06/02/09, Muiño \& Mansilla 221 (SRFA)

\section{Matthiola incana (L.) R. Br.}

Alelí

Ornamental: Cultivada en los jardines por sus flores. Las variedades observadas son de flores de color amarillo y violeta.

Material estudiado: ARGENTINA, Prov. La Pampa, Dpto. Chicalcó, La Humada, S $36^{\circ}$ 20' 91,6”, W 68 00'78,0”, 05/02/09, Muiño \& Vázquez 200 (SRFA); S 36 21'06,0”, W 68 00' 77,6”, 05/02/09, Muiño \& Vázquez 201 (SRFA)

\section{Raphanus sativus L.}

Rabanito

Alimentación: Cultivada en las huertas para autoconsumo en forma de ensaladas.

Material estudiado: ARGENTINA, Prov. La Pampa, Dpto. Chicalcó, La Humada, S $36^{\circ}$ 20' 94.8', W 680 00' 90.5', 05/02/09, Muiño 259 (SRFA)

\section{$B U D D L E J A C E A E$}

\section{Buddleja araucana Phil.}

Pañil

Medicina e higiene: La infusión es empleada para dolencias del estómago e hígado. 
Observaciones: Las plantas son traídas de Mendoza por familiares o vecinos, quienes las recolectan en las áreas serranas o las cultivan ocasionalmente en los jardines. En viajes realizados al área cordillerana de Malargüe se registró el mismo uso con Buddleja globosa (Muiño \& al. 2006).

Material estudiado: ARGENTINA, Prov. Mendoza: Dpto. Malargüe, Agua Escondida, S $36^{\circ} 09^{\prime} 30.1^{\prime \prime}$, W $68^{\circ} 18^{\prime} 18.3$ ', 09/02/09, Muiño 245 (SRFA)

\section{CACTACEAE}

\section{Cereus aethiops Haw.}

Penca. Tuna de cerro

Medicina e higiene: El mucílago interno se usa en friegas con alcohol alcanforado para aliviar las congestiones pulmonares y la infusión del tallo se empleaba para el tratamiento de la tos convulsa.

Material estudiado: ARGENTINA, Prov. La Pampa, Dpto. Chicalcó, La Humada, S $36^{\circ}$ 20' 98.6”, W 6800' 44.0”, 06/02/09, Muiño 310 (SRFA)

\section{Opuntia sulphurea Gillies ex Salm-Dick}

Penca, Quiscalora

Alimentación: Los frutos se recolectan para consumir como fruta fresca.

Material estudiado: ARGENTINA, Prov. La Pampa, Dpto. Chicalcó, La Humada. Ruta Prov. 10, $15 \mathrm{~km}$ al N del pueblo, 29/11/07, Muiño 94 (SRFA)

\section{CALYCERACEAE}

\section{Boopis anthemoides Juss.}

Manzanilla de campo

Observaciones: A excepción de su nombre común no se indicó otra información adicional. 
Material estudiado: ARGENTINA, Prov. La Pampa: Dpto. Chicalcó, Agua de Torres, Ruta Prov. 10, $20 \mathrm{~km}$ al N de La Humada, en cerro, 29/11/07, Muiño 144 (SRFA)

\section{CAPPARACEAE}

\section{Capparis atamisquea Kuntze}

\section{Atamisque}

Medicina e higiene: Con las hojas y ramas freídas en grasa de puma se lograba una pomada que se utilizaba en friegas para mitigar dolores corporales.

Observaciones: Se señaló que el humo producido en su combustión produce efectos tóxicos en el organismo y por tal motivo no se emplea como leña.

Material estudiado: ARGENTINA, Prov. La Pampa, Dpto. Chicalcó, Algarrobo del Águila, S $36^{\circ} 21^{\prime} 36,3^{\prime \prime}$, W $67^{\circ} 14^{\prime} 43,9^{\prime \prime}, 24 / 11 / 08$, Muiño 184 (SRFA)

\section{CAPRIFOLIACEAE}

\section{Lonicera japonica Thunb.}

\section{Madreselva}

Ornamental: Se cultiva con cierta frecuencia en jardines del pueblo.

Material estudiado: ARGENTINA, Prov. La Pampa, Dpto. Chicalcó, La Humada, S $36^{\circ}$

21'02.3', W 68 00' 87.2”, 06/02/09, Muiño 275 (SRFA)

\section{CARYOPHYLLACEAE}

\section{Dianthus caryophyllus L.}

Clavel

Ornamental: Cultivada en los jardines hogareños por sus flores.

Material estudiado: ARGENTINA, Prov. La Pampa, Dpto. Chicalcó, La Humada, S 36 21' 13.8', W 68 00' 87.8', 06/02/09, Muiño \& Rojas 276 (SRFA) 


\section{Dianthus chinensis L.}

Clavelina

Ornamental: Se cultiva en jardines por la belleza de sus flores.

Material estudiado: ARGENTINA, Prov. La Pampa, Dpto. Chicalcó, La Humada, S $36^{\circ}$ 20'70.2', W 68 01'55.1', 06/02/09, Muiño \& Mansilla 303 (SRFA)

\section{Saponaria officinalis $\mathrm{L}$.}

Ramillete

Ornamental: Su cultivo está muy difundido en los jadines.

Material estudiado: ARGENTINA, Prov. La Pampa, Dpto. Chicalcó, La Humada,S $36^{\circ}$ 20'70.2', W 68 01'55.1', 06/02/09, Muiño y Mansilla 305 (SRFA)

\section{CHENOPODIACEAE}

\section{Allenrolfea vaginata (Griseb.) Kuntze}

Jume

Cultura material: La ceniza se empleaba para preparar una lejía para lavar el cabello.

Material estudiado: ARgENTINA, Prov. La Pampa, Dpto. Chicalcó, Algarrobo del Águila, S $36^{\circ} 21^{\prime} 13,1^{\prime \prime}$, W $67^{\circ} 45^{\prime}$ 41,3', 27/11/08, Muiño 166 (SRFA)

\section{Atriplex lampa (Moq.) D. Dietr.}

\section{Zampa}

Ganadería: Constituye un recurso forrajero muy buscado en áreas salobres por vacunos y caprinos.

Cultura material: Con las cenizas se preparaba una lejía que se empleaba en el lavado de ropa y enseres domésticos. También en la elaboración de jabón, hirviendo grasa en agua con las cenizas de esta planta.

Combustible: Se utiliza como leña de bajo poder calórico en la cocción de alimentos. 
Material estudiado: ARGenTINA, Prov. La Pampa, Dpto. Chicalcó, Chos Malal, Ruta Prov. 14, 34 km al W de Ruta Nac. 151, 26/11/07, Muiño 106 (SRFA)

\section{Beta vulgaris L. ssp. vulgaris}

\section{Acelga}

Alimentación: Se cultiva en las huertas hogareñas para el autoconsumo.

Material estudiado: ARGENTINA, Prov. La Pampa, Dpto. Chicalcó, La Humada, S $36^{\circ}$ 20'94.8', W 6800' 90.5', 05/02/09, Muiño 264 (SRFA)

\section{Beta vulgaris L. ssp. macrocarpa (Guss.) Thell.}

\section{Remolacha}

Cultura material: La raíz se utiliza para teñir lana y obtener tonos rosados de diferente intensidad.

Alimentación: Ocasionalmente cultivada en huertas para consumo. Por lo común se adquiere en los comercios de La Humada.

Material estudiado: ARGENTINA, Prov. La Pampa, Dpto. Chicalcó, La Humada, S $36^{\circ}$ 21' 13.8', W 680 00' 87.8', 06/02/09, Muiño \& Rojas 286 (SRFA)

\section{Dysphania ambrosioides (L.) Mosyakin \& Clemants}

Paico, Paico macho

Medicina e higiene: Se utiliza la infusión de la parte aérea en agua o en leche para curar empachos y para desinflamar el hígado.

Cultura material: La raíz se molía con el rizoma del tupe (Panicum urvilleanum), se hervían juntas y se utilizaba para lavar ropa. Se menciona su capacidad de ablandar el agua.

Observaciones: Ocasionalmente cultivada en los jardines.

Material estudiado: ARGENTINA, Prov. La Pampa: Dpto. Chicalcó, La Humada. Puesto La Humada, 26/01/07, Muiño 20 (SRFA) 


\section{Dysphania multifida L.}

Paico, Paico rastrero, Paico aparragado

Medicina e higiene: La infusión de las partes aéreas se utiliza para curar empachos y como hepática, pero no se considera tan efectivo como la especie anterior.

Material estudiado: ARGENTINA, Prov. La Pampa: Dpto. Chicalcó, Chos Malal, alrededores del salón comunitario, 27/11/07, Muiño 72 (SRFA); La Humada. Puesto La Humada, 26/01/07, Muiño 21 (SRFA); Chos Malal, Puesto Chos Malal, 24/02/05, Muiño 18 (SRFA)

\section{Salsola kali L.}

\section{Cardo ruso}

Cultura material: Las cenizas se empleaban para preparar lejías.

Material estudiado: ARGENTINA, Prov. La Pampa: Dpto. Chicalcó, Salitral de La Perra, 20/03/86, Steibel \& Troiani 9080 (SRFA)

\section{Suaeda divaricata Moq.}

Vidriera

Ganadería: Recurso forrajero de buena calidad para las cabras.

Cultura material: En el pasado se empleaban las cenizas para elaborar jabón y lejías.

Combustible: Se recolecta para calefaccionar el hogar.

Material estudiado: ARGENTINA, Prov. La Pampa, Dpto. Chicalcó, Chos Malal, Ruta Prov. 14, 34 km al W de Ruta Nac. 151, 26/11/07, Muiño 89 (SRFA) 


\section{CONVOLVULACEAE}

\section{Convolvulus arvensis L.}

Dama de noche, Suspiro, Enredadera

Ornamental: Se cultiva en los jardines y cuando es espontánea se deja crecer en alambrados perimetrales de las casas por la belleza de sus flores y por su carácter de planta trepadora.

Material estudiado: ARGENTINA, Prov. La Pampa, Dpto. Chicalcó, La Humada. En alambrado de la escuela del pueblo, 29/01/06, Muiño 49 (SRFA)

\section{Ipomoea batatas (L.) Lam.}

\section{Camote}

Alimentación: Utilizada con frecuencia como ingrediente en distintos platos en los hogares rurales. Se adquiere comercialmente.

Ornamental: Se cultiva también en macetas y en canteros a partir de las raíces como planta ornamental por su follaje.

Material estudiado: ARGENTINA, Prov. La Pampa, Dpto. Chicalcó, La Humada, S $36^{\circ}$ 20'91,6”, W 68 00'78,0”, 05/02/09, Muiño \& Vázquez 210 (SRFA)

\section{Ipomoea purpurea (L.) Roth}

\section{Suspiro, Enredadera}

Ornamental: Se cultiva en los jardines por la belleza de sus flores.

Material estudiado: ARGENTINA, Prov. La Pampa, Dpto. Chicalcó, La Humada, S $36^{\circ}$ 20'94,8', W 68 00' 90,5”, 05/02/09, Muiño \& Romero 195 (SRFA) 


\section{CRASSULACEAE}

\section{Aeonium sp.}

Rosa verde

Ornamental: Cultivada en macetas en los jardines del pueblo y con mayor frecuencia en la zona rural por su resistencia a la sequía.

Material estudiado: ARGENTINA, Prov. La Pampa, Dpto. Chicalcó, La Humada, S $36^{\circ}$ 21'03.2", W 68 00' 75.4", 05/02/09, Muiño \& Maya 308 (SRFA)

\section{Crassula multicava Lem.}

\section{Bálsamo}

Ornamental: Se cultiva en jardines, comunmente en macetas.

Material estudiado: ARGENTINA, Prov. La Pampa, Dpto. Chicalcó, La Humada, S $36^{\circ}$ 21'03,2", W 68 00' 75,4", 05/02/09, Muiño \& Maya 292 (SRFA)

\section{CUCURBITACEAE}

Citrullus lanatus (Thunb.) Matsum. \& Nakai ssp. vulgaris (Schrad. ex Eckl. \& Zeyh.) Fursa

Sandía

Alimentación: Cultivada en las huertas con mayor frecuencia en el pasado. Actualmente se adquiere preferentemente en los comercios de La Humada.

Material estudiado: ARGENTINA, Prov. La Pampa: Dpto. Chicalcó, La Humada, S $36^{\circ}$ 20' 91,9', W 6800' 87,9', 05/02/09, Muiño \& Luna 194 (SRFA)

\section{Cucumis anguria L.}

Sandilleja

Ganadería: Suele ser consumida por caprinos, pero en exceso produce intoxicaciones, a veces fatales. 
Observaciones: A veces los frutos suelen ser usados por los niños para jugar. Construyen pequeños muñecos de figura humanoide ensamblando diferentes objetos sobre ellos (el fruto hace las veces del tronco del cuerpo). También juegan arrojándose entre sí estos frutos, ya que cuando se rompen con el impacto despiden mal olor.

Material estudiado: ARGENTINA, Prov. La Pampa: Dpto. Chicalcó, La Humada, Ruta Prov. 10, entrada al pueblo, 25/01/06, Muiño \& Arenas 32 (SRFA)

\section{Cucurbita maxima Duchesne ssp. andreana (Naudin) Filov}

\section{Zapallito verde}

Alimentación: A veces cultivada en las huertas para el autoconsumo familiar. En el pasado se cultivó con mayor frecuencia.

Material estudiado: ARGENTINA, Prov. La Pampa: Dpto. Chicalcó, La Humada, S $36^{\circ}$ 21' 13,8', W 68 00' 87,8', 06/02/09, Muiño \& Rojas 213 (SRFA)

\section{Cucurbita máxima Duch. ssp. maxima}

\section{Zapallo criollo}

Alimentación: Es una de la hortalizas que forman parte de muchos platos tradicionales como carbonadas, pucheros y guisos. Se cultivaba con frecuencia en las huertas en el pasado. Actualmente se adquiere en los comercios de La Humada.

Material estudiado: Se carece de material de referencia. Actualmente en las huertas se prefiere el cultivo de zapallo anco (Cucurbita pepo L.).

\section{Cucurbita pepo L.}

\section{Zapallo anco}

Alimentación: Es una de la hortalizas que forman parte de muchos platos tradicionales como carbonadas, pucheros y guisos. A veces se cultiva en las huertas pero lo fue con mayor frecuencia en el pasado. Actualmente se adquiere en los comercios de La Humada.

Cultura material: La infusión de las hojas se emplea a veces para teñir lana obteniéndose colores verde claros. 
Material estudiado: ARGENTINA, Prov. La Pampa: Dpto. Chicalcó, La Humada, S $36^{\circ}$ 20'70,2', W 68 01' 55,1', 06/02/09, Muiño \& Rojas 214 (SRFA)

\section{Cucumis melo L.}

Melón

Alimentación: Se cultivaba con mayor frecuencia en el pasado para autoconsumo, pero en la actualidad disminuyó notoriamente su cultivo.

Observaciones: La oferta de esta y otras hortalizas en los comercios de La Humada, sumado a las dificultades de disponibilidad de agua abundante para riego puede ser la razón de la casi desaparición de su producción actual.

Material estudiado: No se dispone de material de referencia.

\section{Lagenaria siceraria (Molina) Standl.}

Mate

Alimentación: Los frutos vaciados de su contenido constituyen los recipientes más comunes para preparar la infusión homónima.

Medicina e higiene: Los frutos con los cuales se elaboran mates se empleaban para el tratamiento de las paperas haciendo con ellos masajes en forma de cruz sobre la zona inflamada de las parótidas. Para esto, el mate debía estar precalentado en el fogón. Posteriormente se debía imprimir fuertes movimientos de torsión a la cabeza del enfermo tomándola por el mentón y la parte posterior de la misma.

Material estudiado: No se dispone de material de referencia. Los mates se adquieren en el comercio. 


\section{DIPSACACEAE}

\section{Scabiosa atropurpurea L.}

Viudita

Ornamental: Se cultiva profusamente en jardines del pueblo y en el área rural por su belleza y rusticidad.

Material estudiado: ARGENTINA, Prov. La Pampa: Dpto. Chicalcó, La Humada, S $36^{\circ}$ 21'03.2", W 68"00' 75.4', 05/02/09, Muiño \& Maya 252 (SRFA); S 36 21'06.0”, W $68^{\circ} 00^{\prime} 77.6^{\prime}$, 05/02/09, Muiño 269 (SRFA)

\section{ELEAGNACEAE}

\section{Eleagnus angustifolia L.}

Arabia

Medicina e higiene: La infusión de las raspaduras del tallo junto con las de jarilla (Larrea divaricata) y molle (Schinus johnstonii) se usa para curar resfríos.

Ornamental: Cultivada con mucha frecuencia como árbol de sombra en los patios de las casas y en veredas del pueblo.

Material estudiado: ARGENTINA, Prov. La Pampa: Dpto. Chicalcó, La Humada, S $36^{\circ}$ 20' 91,9', W 6800' 87,9', 05/02/08, Muiño 204 (SRFA)

\section{EUPHORBIACEAE}

\section{Euphorbia collina Phil.}

Lechuguilla, Pichoga, Pechuguilla

Ganadería: Produce diarreas en los animales que la consumen. Suele ser abundante en años húmedos.

Medicina e higiene: El látex se aplica sobre la piel para eliminar ojos de gallo.

Material estudiado: ARGENTINA, Prov. La Pampa: Dpto. Chicalcó, Chos Malal, Ruta Prov. 14, 50 km al W de Ruta Nac. 151, 27/11/07, Muiño 92 (SRFA) 


\section{Euphorbia klotzschii Oudejans}

Yerba meona, Pechuguilla

Observaciones: No se informó ningún uso para esta especie.

Material estudiado: ARGENTINA, Prov. La Pampa: Dpto. Chicalcó, Chos Malal, Puesto Valle Chico, 25/02/05, Muiño 9 (SRFA); La Humada, Puesto La Humada, 26/01/06, Muiño 55 (SRFA)

\section{Euphorbia serpens Kunth}

Yerba meona, Yerba de la perdiz

Observaciones: Para la especie no se informaron más datos que su nombre común.

Material estudiado: ARGENTINA, Prov. La Pampa: Dpto. Chicalcó, Chos Malal. Salitral de la Perra, 28/11/07, Muiño 118 (SRFA)

\section{FABACEAE}

\section{Adesmia retrofracta Hook. \& Arn.}

\section{Porotillo}

Observaciones: No se informaron más datos que su nombre común. Las plantas observadas no presentaban signos de estar comidas.

Material estudiado: ARGENTINA, Prov. La Pampa: Dpto. Chicalcó, Ruta Prov. 10, 20 km al N de La Humada. Sobre cerro de basalto, 29/11/07, Muiño 135 (SRFA)

\section{Astragalus pehuenches Niederl.}

Yerba loca

Ganadería: Es reconocida como planta tóxica (Coburn Williams \& Barneby 1977, Lupo \& Echenique 1997, Steibel 2000, Robles \& al. 2000, Roig 2001), pero no se han registrado casos de toxicidad en el área de este estudio. La información de los lugareños sobre estas intoxicaciones hace referencia a ganado ubicado en áreas serranas de la Payunia y de Sierras de Borbarán en la provincia de Mendoza. 
Material estudiado: ARGENTINA, Prov. Mendoza: Dpto. Malargüe, Sierras de Borbarán, Cerro de la India Muerta, S 35 55'08', W 68 33'31', 21/03/02, Prina, Morici \& Mazzola 1656 (SRFA)

\section{Caesalpinia gilliesii (Wall. ex Hook.) D. Dietr.}

Mal de ojo

Ganadería: Especie consumida por las cabras.

Ornamental: Cultivada en jardines y patios por sus flores.

Material estudiado: ARGENTINA, Prov. La Pampa, Dpto. Chicalcó, La Humada, S $36^{\circ}$ 21'00,0', W 68'00'46,9', 26/11/08, Muiño 190 (SRFA)

\section{Cercidium praecox (Ruiz \& Pav. ex Hook.) Harms}

\section{Chañar brea}

Combustible: Se emplea escasamente como leña. No es abundante en el área.

Material estudiado: ARGENTINA, Prov. La Pampa: Dpto. Chicalcó, Algarrobo del Águila, S $36^{\circ} 21^{\prime} 36,3^{\prime \prime}$, W $67^{\circ} 15^{\prime}$ 11,0', 24/11/08, Muiño 180 (SRFA); Ruta Prov. 14, 31 km al W de Ruta Nac. 151, 26/11/07, Muiño 110 (SRFA)

\section{Geoffraea decorticans (Gillies ex Hook. \& Arn.) Burkart}

\section{Chañar}

Alimentación: El fruto se recolecta como alimento de ocasión. En el pasado se elaboraba arrope a partir de los mismos.

Medicina e higiene: La infusión de la raspadura de los tallos se utiliza para curar resfríos, dolores de estómago y en el pasado en el tratamiento del postparto. En este caso no se pudo consignar el propósito del uso, pero es de suponer que se obtenían beneficios de sus propiedades astringentes. Para el tratamiento de resfríos se usa con "entrecáscara" de molle (Schinus johnstonii), es decir la raspadura de los tallos descortezados. También se usa en infusión con matorro (Cyclolepis genistoides) para dolencias de riñones. 
Cultura material: La madera es muy utilizada para confeccionar cabos de herramientas, puntales, horcones y tirantería de las casas.

Combustible: La madera se usa para calefacción.

Material estudiado: ARGENTINA, Prov. La Pampa, Dpto. Chalileo, Santa Isabel, S $67^{\circ}$ 45' 41,3', W 360 21' 13,1'”, 27/11/08, Muiño 167 (SRFA)

\section{Hoffmannseggia erecta Phil.}

Yerba del potrillo, Retortuño, Porotillo del campo

Observaciones: No se registró información sobre sus usos, pero su nombre común sugiere que puede tratarse de una especie con buenas cualidades forrajeras.

Material estudiado: ARGENTINA, Prov. La Pampa: Dpto. Chicalcó, Chos Malal, Ruta Prov. 14, $50 \mathrm{~km}$ al W de Ruta Nac. 151, 27/11/07, Muiño 115 (SRFA)

\section{Medicago sativa L.}

Alfa

Observaciones: Cultivada en huertas con fines forrajeros para las aves de corral.

Material estudiado: ARGENTINA, Prov. La Pampa, Dpto. Chicalcó, La Humada, S $36^{\circ}$ 20' 94.8', W 68000' 90.5', 05/02/09, Muiño 261 (SRFA)

\section{Phaseolus vulgaris $\mathrm{L}$.}

\section{Poroto}

Alimentación: Las semillas forman parte de muchos platos tradicionales tales como el locro y el printincao.

Material estudiado: No se dispone de material de referencia. Las semillas se obtienen en los comercios de la zona. 


\section{Prosopidastrum striatum (Benth.) R. A. Palacios \& Hoc}

\section{Retamilla, Monte amarillo}

Ganadería: Recurso forrajero de buena calidad para bovinos, equinos y caprinos.

Combustible: Es un buen recurso combustible para calefaccionar ambientes. Sin embargo se indicó que produce un humo muy denso.

Material estudiado: ARGENTINA, Prov. La Pampa: Dpto. Chicalcó, La Humada, Ruta Prov. 10, entrada al pueblo, 25/01/06, Muiño \& Arenas 26 (SRFA); Algarrobo del Águila, Ruta Prov. 14, 34 km al W de Ruta Nac. 151, 26/11/07, Muiño 111 (SRFA)

\section{Prosopis caldenia Burkart}

\section{Caldén}

Cultura material: La corteza del tallo se usa para teñir lana obteniéndose colores marrones.

Observaciones: Muy empleado junto con el algarrobo (Prosopis flexuosa f. flexuosa) para obtener postes destinados al alambrado perimetral de los campos.

Material estudiado: ARGENTINA, Prov. La Pampa: Dpto. Chicalcó, Algarrobo del Águila, Ruta Prov. 10, $20 \mathrm{~km}$ al W de Algarrobo del Águila, 03/12/07, Muiño 134 (SRFA)

\section{Prosopis flexuosa DC. f. flexuosa}

\section{Algarrobo}

Ganadería: El follaje y los frutos constituyen un recurso forrajero de alta calidad para todas las clases de ganado que se producen en la zona.

Alimentación: Los mismos usos que el alpataco (Prosopis flexuosa var. depressa) pero la harina de los frutos es de mejor calidad.

Cultura material: También empleada para encabar herramientas, en puntales para sostener las roldanas en los jagüeles y en el pasado para obtener horcones esquineros para las viviendas. Ampliamente usada para confeccionar postes para los alambrados perimetrales al igual que el caldén (Prosopis caldenia), pero considerada más durable que esta última.

Combustible: Se utiliza como recurso combustible para calefaccionar ambientes. 
Observaciones: Las plantas que crecen en el campo reciben cuidados por parte de los pobladores y a veces se dejan prosperar en los patios como árbol de sombra.

Material estudiado: ARGENTINA, Prov. La Pampa: Dpto. Chalileo, Santa Isabel, S $36^{\circ}$ 14'35.5', W 660 55' 89.8', 11/02/09, Muiño 247 (SRFA)

\section{Prosopis flexuosa DC. var. depressa F.A. Roig}

\section{Alpataco}

Ganadería: Recurso forrajero de alta calidad para todas las clases de ganado que se producen en la zona.

Alimentación: Las legumbres se consumen directamente o se puede preparar con ellas alimentos y bebidas típicas como el patay, arrope o aloja. En el pasado era más frecuente la preparación de estos alimentos.

Medicina e higiene: La infusión de la raspadura de los tallos se usa para combatir resfríos y la infusión de la hoja como colirio.

Cultura material: La madera se utiliza por su resistencia para confeccionar cabos de rebenques y otras herramientas, pero se considera de menor calidad que la de chañar (Geoffraea decorticans). Se suele tostar previamente al fuego para evitar la fractura durante su uso posterior. Se emplea también en husos para el hilado de lana y en el armado de corrales de cabras. En el pasado se utilizaba para confeccionar postes esquineros en la construcción de viviendas.

Combustible: La leña se emplea profusamente por ser uno de los recursos madereros más abundantes.

Material estudiado: ARgEnTINA, Prov. La Pampa, Dpto. Chicalcó, Algarrobo del Águila, Puente Ruta Nac. 143 y Arroyo de la Barda, 26/11/07, Muiño 102 (SRFA)

\section{Prosopis strombulifera (Lam.) Benth.}

\section{Mastuerzo}

Ganadería: Se informó como especie causal de intoxicaciones en los caprinos que la consumen. 
Material estudiado: ARGENTINA, Prov. La Pampa, Dpto. Chicalcó, Algarrobo del Águila, S $36^{\circ} 21^{\prime} 13,1$, W $67^{\circ} 45^{\prime}$ 41,3”, 27/11/08, Muiño 168 (SRFA)

\section{Robinia pseudoacacia L.}

Acacia

Cultura material: Por la resistencia de su madera se emplea para postes destinados a la construcción de corrales y potreros. Asimismo, para cabos de herramientas y en el pasado para horcones y postes de la vivienda.

Ornamental: Muy cultivada en los patios de las casas como árbol de sombra.

Material estudiado: ARGENTINA, Prov. La Pampa, Dpto. Chicalcó, La Humada, S $36^{\circ}$ 21'00,0”, W 68000'46,9', 26/11/08, Muiño 189 (SRFA)

\section{Senna aphylla (Cav.) H.S. Irwin \& Barneby}

Cacho de cabra, Algarrobillo, Algarrobilla

Ganadería: La flor es consumida por cabras y caballos.

Cultura material: La raíz hervida se utiliza para teñir lana obteniéndose colores intermedios entre amarillos y marrones.

Material estudiado: ARGENTINA, Prov. La Pampa: Dpto. Chicalcó, La Humada, Ruta Prov. 10, entrada al pueblo, 25/01/06, Muiño \& Arenas 36 (SRFA); Algarrobo del Águila, Ruta Prov. 14, 4 km al W de Ruta Nac. 151, 26/11/07, Muiño 96 (SRFA); Dpto. Puelén, Chos Malal. Puesto Los Carrizales, 26/02/05, Muiño 8 (SRFA)

\section{GERANIACEAE}

\section{Erodium cicutarium (L.) L'Hér. ex Aiton}

\section{Alfilerillo}

Ganadería: Constituye un buen recurso forrajero que es preferido por el ganado bovino.

Medicina e higiene: La infusión de la planta entera se emplea para dolencias ("puntadas") del estómago y el corazón, y para lavar heridas. 
Material estudiado: ARGentinA, Prov. La Pampa, Dpto. Chicalcó, Chos Malal. Alrededores de salón comunitario, 27/11/07, Muiño 71 (SRFA)

\section{Pelargonium hortorum L. H. Bailey}

Malvón

Ornamental: Se cultiva en jardines hogareños.

Observaciones: En la localidad se han observado las variedades de flores rojas y blancas.

Material estudiado: ARGENTINA, Prov. La Pampa, Dpto. Chicalcó, La Humada, S $36^{\circ}$ 20'70,2" W 68 01' 55,1", 06/02/09, Muiño \& Mansilla 161 (SRFA), S 36 20'91,6”, W $68^{\circ} 00^{\prime} 78,0^{\prime}$, , 05/02/09, Muiño \& Vázquez 211 (SRFA)

\section{GROSSULARIACEAE}

\section{Ribes cfr. aureum Pursh var. villosum DC}

Clavito, Clavito de jardín

Ornamental: Se cultiva en los jardines y huertos.

Material estudiado: ARGENTINA, Prov. La Pampa, Dpto. Chicalcó, La Humada, S $36^{\circ}$ 21'06,0"' W 6800'77,6”, 05/02/09, Muiño \& Vázquez 163 (SRFA)

\section{HYDNORACEAE}

\section{Prosopanche bonacine Speg.}

Papa indiana

Alimentación: En el pasado se consumían los frutos. Para ello se recolectaban debajo del suelo y se asaban en las brasas.

Material estudiado: ARgENTINA, Prov. La Pampa, Dpto. Chalileo, Colonia Emilio Mitre, 27/02/86, Steibel \& Troiani 9005 (SRFA) 


\section{LAMIACEAE}

\section{Lavandula angustifolia Mill.}

Lavanda

Ornamental: Cultivada en jardines del pueblo.

Observaciones: Se mencionó el empleo de las inflorescencias como aromatizante para la ropa.

Material estudiado: ARGENTINA, Prov. La Pampa, Dpto. Chicalcó, La Humada, S $36^{\circ}$ 20'70,2', W 68 01' 55,1'”, 06/02/09, Muiño 224 (SRFA); S 36 21'06.0”, W 68 00' 77.6”, 05/02/09, Muiño 270 (SRFA)

\section{Marrubium vulgare $\mathrm{L}$.}

Yerba del sapo

Medicina e higiene: La infusión de la parte aérea se utiliza con diferentes propósitos. En forma oral para aliviar la tos, para mitigar dolores de estómago, empachos, y para desinflamar el hígado. Para ello se debe tomar durante tres mañanas en ayunas. Exteriormente se aplica para desinflamar hemorroides, para evitar la formación de caspa y la caída de cabello, para aliviar las molestias de las erupciones producidas por la varicela.

Material estudiado: ARGENTINA, Prov. La Pampa, Dpto. Chicalcó, Algarrobo del Águila, S $36^{\circ} 21^{\prime}$ 36,3', W 67 14' 43,9', 24/11/08, Muiño 183 (SRFA)

\section{Mentha x piperita L.}

Menta

Medicina e higiene: Con frecuencia se emplea junto con el mate como digestiva.

Ornamental: Cultivada en los jardines y huertas.

Material estudiado: ARGENTINA, Prov. La Pampa, Dpto. Chicalcó, La Humada, S $36^{\circ}$ 20'91,6”, W 68 00’78,0”, 05/02/09, Muiño \& Vázquez 212 (SRFA) 


\section{Mentha $\mathrm{x}$ villosa Huds.}

Menta

Medicina e higiene: $\mathrm{Al}$ igual que la especie anterior se agrega al mate como digestiva.

Ornamental: Cultivada en los jardines y huertas.

Material estudiado: ARGENTINA, Prov. La Pampa, Dpto. Chicalcó, La Humada, S $36^{\circ}$ 21'03.2", W 68 00' 75.4', 05/02/09, Muiño \& Luna 258 (SRFA)

\section{Ocimum basilicum L.}

Albahaca

Alimentación: Forma parte de diversos platos de la cocina tradicional.

Observaciones: Cultivada en los jardines y huertas.

Material estudiado: ARGENTINA, Prov. La Pampa, Dpto. Chicalcó, La Humada, S $36^{\circ}$ 20'91,9', W 680 00' 87,9', 05/02/09, Muiño \& Luna 198 (SRFA)

\section{Origanum vulgare L.}

\section{Orégano}

Alimentación: Escasamente cultivada en las huertas, se emplea con poca frecuencia para condimentar comidas. Se adquiere además en los comercios.

Medicina e higiene: La parte aérea de la planta se usa en infusión para curar empachos y resfríos.

Material estudiado: ARGENTINA, Prov. La Pampa, Dpto. Chicalcó, La Humada. Puesto La Humada, 26/01/06, Muiño 57 (SRFA)

\section{Salvia coccinea Etl.}

Ornamental: Cultivada en jardines aunque escasamente.

Material estudiado: ARGENTINA, Prov. La Pampa, Dpto. Chicalcó, La Humada, S $36^{\circ}$ 21' 13,8', W 6800'87,8', 06/02/09, Muiño \& Rojas 237 (SRFA) 
Salvia cuspidata Ruiz \& Pav. ssp. gilliesii (Benth.) J.R.I. Wood

Salvia, Salvia morada, Malva del cerro

Medicina e higiene: La partea aérea de la planta en infusión se indicó como desinfectante, para los dolores de muelas, de estómago y para malestares del corazón.

Material estudiado: ARGENTINA, Prov. Mendoza, Dpto. Malargüe, Agua Escondida. Cerro aledaño al pueblo, 29/11/07, Muiño 125 (SRFA)

\section{Salvia cfr. pallida Benth.}

Toronjil macho

Ornamental: Escasamente cultivada en jardines.

Material estudiado: ARGENTINA, Prov. La Pampa, Dpto. Chicalcó, La Humada, S $36^{\circ}$

$20^{\prime} 70,2^{\prime \prime}, \mathrm{W} 68^{\circ} 01^{\prime} 55,1^{\prime \prime}$, Muiño \& Mansilla 224 (SRFA)

\section{LAURACEAE}

\section{Cinnamomum zeylanicum Garcin ex Blume}

\section{Canela}

Medicina e higiene: En el pasado fue empleada en infusiones junto con manzanilla (Matricaria recutita) en tratamientos postparto de las mujeres.

Alimentación: Utilizada como especia en platos dulces como torrejas y buñuelos.

Material estudiado: No se dispone de material de referencia. Se adquiría comercialmente como canela en rama a los vendedores ambulantes y actualmente en los comercios.

\section{Laurus nobilis L.}

Laurel

Alimentación: se usa como especia en platos diversos como guisos y estofados. 
Observaciones: En algunos puestos se ensayó su cultivo pero las plantas no prosperaron por el clima.

Material estudiado: No se dispone de material de referencia. Se adquiere envasada en forma de hojas enteras o trituradas en los comercios de La Humada.

\section{LORANTHACEAE}

\section{Ligaria cuneifolia (Ruiz \& Pav.) Tiegh.}

Injerto

Medicina e higiene: La infusión de una porción muy pequeña de la parte aérea se emplea para regular la presión arterial.

Observaciones: El ejemplar de referencia fue entregado por el Sr. Roberto Bravo quien lo recolectó para uso personal pocos $\mathrm{km}$ al $\mathrm{S}$ de Agua Escondida. Esta hemiparásita crecía sobre plantas de molle (Schins johnstonii)

Material estudiado: ARGENTINA, Prov. Mendoza: Dpto. Malargüe, Agua Escondida, recolectada pocos km al S de Agua Escondida, 09/02/09, Muiño \& Bravo 299 (SRFA)

\section{MALVACEAE}

\section{Hibiscus syriacus L.}

Ornamental: Se cultiva en jardines del pueblo.

Material estudiado: ARGENTINA, Prov. La Pampa: Dpto. Chicalcó, La Humada, S $36^{\circ}$ 21 ' 13,8', W 6800'87,8', 06/02/09, Muiño \& Rojas 231 (SRFA)

\section{Lecanophora heterophylla (Cav.) Krapov.}

Malvisco, Yerba de la vaca

Ganadería: Especie a la que se le atribuyen buenas cualidades forrajeras para el ganado vacuno. 
Material estudiado: ARGENTINA, Prov. La Pampa: Dpto. Chicalcó, La Humada, Ruta Prov. 10, $15 \mathrm{~km}$ al N del pueblo, 29/11/07, Muiño 59 (SRFA); Algarrobo del Águila, Puente Ruta Nac. 143 y Arroyo de la Barda, 26/11/07, Muiño 147 (SRFA)

\section{Malva sylvestris $\mathrm{L}$.}

Salvia de jardín

Medicina e higiene: La infusión se empleaba tiempo atrás para ablandar las flemas del pecho producidas por resfríos.

Ornamental: Es una planta que se siembra en los jardines, pero que luego es espontánea.

Material estudiado: ARGENTINA, Prov. La Pampa: Dpto. Chicalcó, La Humada, S $36^{\circ}$ 20' 91,6”, W 68 00' 78,0”, 05/02/08, Muiño \& Vázquez 206 (SRFA)

\section{Sphaeralcea mendocina Phil.}

Malvisco

Medicina e higiene: La infusión de la hoja con azúcar quemado se emplea para mitigar las fiebres.

Material estudiado: ARGEnTINA, Prov. La Pampa: Dpto. Chicalcó, Chos Malal, Ruta Prov 14, $50 \mathrm{~km}$ al W de Ruta Nac. 151, 26/11/07, Muiño 113 (SRFA); S 36² 24' 06,4”', W $67^{\circ} 16^{\prime} 28,3^{\prime \prime}, 24 / 11 / 08$, Muiño 178 (SRFA)

\section{$M E L I A C E A E$}

\section{Melia azedarach $\mathrm{L}$.}

\section{Paraíso}

Ornamental: Cultivada en los patios de las casas como árbol de sombra. Los cultivos son recientes. También escasamente en las veredas de las calles de La Humada.

Material estudiado: ARGENTINA, Prov. La Pampa: Dpto. Chicalcó, La Humada, S $36^{\circ}$ 20' 88.7', W 68 00' 74.2', 07/02/09, Muiño 248 (SRFA) 


\section{MIRTACEAE}

\section{Eucalyptus cinerea F. Muell ex Benth.}

\section{Eucalipto}

Medicina e higiene: La infusión de las hojas se usa como expectorante.

Cultura material: Las varillas y a veces los postes de los potreros están confeccionados con madera de esta y otras especies de eucaliptos.

Ornamental: En los puestos se ha intentado su cultivo como árbol de sombra pero con resultados dispares.

Material estudiado: ARGENTINA, Prov. La Pampa, Dpto. Chicalcó, La Humada, S $36^{\circ}$ 21'02,3', W 6800' 87,2', 07/02/09, Muiño 217 (SRFA)

\section{Syzygium aromaticum (L.) Merr. \& L.M.Perry}

Clavo de olor

Alimentación: Se informó su uso como especia en diversos platos dulces.

Material estudiado: Se carece de material de referencia. Los botones florales secos se adquieren en comercios de La Humada.

\section{NYCTAGINACEAE \\ Bougainvillea spinosa (Cav.) Heimerl}

Monte negro, Uña de gato

Ganadería: Recurso forrajero consumido por los caprinos.

Combustible: Se informó su uso como leña.

Material estudiado: ARGENTINA, Prov. La Pampa, Dpto. Chicalcó, Algarrobo del Águila, Ruta Prov. 14, 12 km al W de Ruta Nac. 151, 26/11/07, Muiño 98 (SRFA) 


\section{Mirabilis jalapa L.}

Buenas noches

Ornamental: Cultivada en los jardines por sus flores.

Material estudiado: ARGENTINA, Prov. La Pampa, Dpto. Chicalcó, La Humada, S $36^{\circ}$ 21'06,0', W 68 00' 77,6', 05/02/09, Muiño \& Vázquez 202 (SRFA)

\section{OENOTHERACEAE}

Oenothera odorata Jacq.

Flor de seda

Ornamental: Cultivada en jardines.

Material estudiado: ARGENTINA, Prov. La Pampa, Dpto. Chicalcó, La Humada, S $36^{\circ}$ 21'13,8', W 68 00' 87,8', 06/02/09, Muiño \& Rojas 228 (SRFA)

\section{OLACACEAE}

\section{Ximenia americana L.}

Albaricoque, Bricoque

Ganadería: Recurso forrajero consumido por caprinos.

Alimentación: Se consume como fruta fresca.

Material estudiado: ARGENTINA, Prov. La Pampa, Dpto. Chicalcó, Algarrobo del Águila, S 36 21' 36,3', W 67 14' 43,9'”, 24/11/08, Muiño 185 (SRFA)

\section{$O L E A C E A E$}

\section{Fraxinus americana $\mathrm{L}$.}

Fresno

Ornamental: Se cultiva en veredas de las calles del pueblo.

Material estudiado: ARGENTINA, Prov. La Pampa, Dpto. Chicalcó, La Humada, S $36^{\circ}$ 21'02.3', W 68 00' 87.2"', 06/02/09, Muiño 284 (SRFA) 


\section{Ligustrum vulgare $\mathrm{L}$.}

Siempreverde

Ornamental: Se cultiva en patios del pueblo como cerco vivo.

Material estudiado: ARGENTINA, Prov. La Pampa, Dpto. Chicalcó, La Humada, S $36^{\circ}$ 21'03.2', W 68 00' 75.4', 06/02/09, Muiño \& Maya 281 (SRFA)

\section{PAPAVERACEAE}

\section{Argemone subfusiformis G. B. Ownbey}

Cadillo, Cola de caballo

Observaciones: No se indicaron usos para esta especie.

Material estudiado: ARGENTINA, Prov. Mendoza, Dpto. Malargüe, Agua Escondida, Camino a Sierras de Borbarán, $5 \mathrm{~km}$ al N del pueblo, 14/01/07, Muiño 83 (SRFA)

\section{PASSIFLORACEAE}

\section{Passiflora caerulea L.}

\section{Pasionaria}

Ornamental: Se cultiva en los jardines.

Material estudiado: ARGENTINA, Prov. La Pampa: Dpto. Utracán, El Loro, 22/10/84, Troiani, Steibel \& Prina 8159 (SRFA)

\section{PIPERACEAE}

\section{Piper nigrum L.}

\section{Pimienta}

Alimentación: Se emplea como especia en diversos platos.

Medicina e higiene: En el pasado se usó en infusión durante los partos para provocar contracciones. 
Material estudiado: No se dispone de material de referencia. Los frutos se adquieren en comercios de La Humada.

\section{PLANTAGINACEAE}

Monttea aphylla (Miers) Benth. \& Hook.

Ala, Ala de loro, Matasebo

Ganadería: El fruto es un recurso forrajero muy buscado por cabras y ovejas.

Medicina e higiene: La infusión de las raspaduras del tallo descortezado ("entrecáscara") se utiliza para dolencias renales y con melosa (Grindelia chiloensis) y cadillo (Xanthium spinosum) para dolores generales del cuerpo.

Combustible: Después del piquillín (Condalia microphylla) es una de las especies preferidas para calefaccionar ambientes y para cocinar.

Material estudiado: ARGENTINA, Prov. La Pampa, Dpto. Chicalcó, La Humada, Ruta Prov. 10, sector de la entrada al pueblo, 30/01/06, Muiño 52 (SRFA); Ruta Prov. 14, 4 km al W de Ruta Nac. 151, 26/11/07, Muiño 97 (SRFA)

\section{Plantago lanceolata L.}

Llantén

Medicina e higiene: Se empleaba en infusión como desinflamatorio de las vías urinarias.

Material estudiado: ARGENTINA, Prov. Mendoza, Dpto. Malargüe, Bardas Blancas, 12/12/95, Troiani, Steibel \& Prina 11635 (SRFA)

\section{Plantago patagonica Jacq.}

\section{Cola de piche}

Ganadería: Recurso forrajero de buena calidad para todas las categorías de ganado pero con gran preferencia por los ovinos.

Medicina e higiene: Se indicaron los mismos usos medicinales que la especie anterior. 
Material estudiado: ARGentinA, Prov. La Pampa, Dpto. Chicalcó, Chos Malal, Ruta Prov 14, $50 \mathrm{~km}$ al W de Ruta Nac. 151, 26/11/07, Muiño 108 (SRFA)

\section{POLYGALACEAE \\ Bredemeyera microphylla (Griseb.) Hieron.}

Yerba mora

Ganadería: Constituye un forraje de buena calidad que es preferido por el ganado vacuno.

Material estudiado: ARGENTINA, Prov. La Pampa, Dpto. Chicalcó, La Humada, Puesto Pozo de la Víbora, 19/01/07, Muiño \& Vázquez 154 (SRFA)

\section{Monnina dictyocarpa Griseb.}

Quelén

Medicina e higiene: La infusión de la raíz se emplea para desinflamar las vías urinarias.

Material estudiado: ARgENTINA, Prov. La Pampa, Dpto. Chicalcó, La Humada, Ruta Prov. 10, $15 \mathrm{~km}$ al N del pueblo, 29/11/07, Muiño 61 (SRFA)

\section{Polygala stenophylla A. Gray}

Yerba del choique

Ganadería: Indicada como buena forrajera.

Material estudiado: ARGENTINA, Prov. La Pampa, Dpto. Chicalcó, La Humada, Ruta Prov. 10, $15 \mathrm{~km}$ al N del pueblo, 29/11/07, Muiño 60 (SRFA)

\section{POLYGONACEAE}

Muehlembeckia hastulata (Sm.) I. M. Johnst. var. hastulata

Enredadera, Espuma de leche.

Ornamental: Cultivada en los jardines como cerco vivo en divisiones internas del patio. 
Material estudiado: ARGENTINA, Prov. La Pampa, Dpto. Chicalcó, La Humada, Puesto El Centinela, 17/01/07, Muiño 157 (SRFA); S 36 20' 70,2”, W 68 01' 55,1”, 06/02/09, Muiño \& Mansilla 223 (SRFA); S 36 21'03.2”, W 68 00' 75.4'”, 05/02/09, Muiño \& Maya 253 (SRFA)

\section{PORTULACACEAE}

\section{Portulaca grandiflora Hook.}

Portulaca, Uñita de gato

Ornamental: Cultivada en los jardines de La Humada en macizos o en macetas.

Material estudiado: ARGENTINA, Prov. La Pampa: Dpto. Chicalcó, La Humada, S $36^{\circ}$ $20^{\prime} 70,2$ ', W $68^{\circ} 01^{\prime}$ 55,1'”, 06/02/09, Muiño \& Mansilla 293 (SRFA)

\section{Portulaca oleracea L.}

Verdolaga

Alimentación: Se informó que antes se consumía formando parte de los ingredientes de croquetas.

Ornamental: Espontánea en jardines y huertas.

Material estudiado: ARGENTINA, Prov. La Pampa: Dpto. Chicalcó, La Humada, S $36^{\circ}$ 20'91,6”, W 68 00' 78,0”, 05/02/09, Muiño \& Vázquez 295 (SRFA)

\section{PUNICACEAE}

\section{Punica granatum L.}

\section{Granada}

Medicina e higiene: La infusión de la cáscara de los frutos se utiliza como antidiarreico.

Ornamental: Cultivada en jardines hogareños del pueblo.

Material estudiado: ARGENTINA, Prov. La Pampa: Dpto. Chicalcó, La Humada, S $36^{\circ}$ 21'03.2', W 68 00'75.4”, 05/02/09, Muiño \& Maya 257 (SRFA) 


\section{$R H A M N A C A E$}

\section{Condalia microphylla Cav.}

Piquillín

Ganadería: Constituye un recurso forrajero valioso para el ganado caprino y ovino

Alimentación: Los frutos se recolectan para consumo como postre; se emplea solo o mezclado con azúcar o también para preparar dulces y arrope. La recolección se realiza colocando cueros o mantas debajo de la planta golpeándola con un palo. Algunos entrevistados informaron que este método daña a la planta lo cual promueve en años posteriores un bajo rendimiento de la producción.

Medicina e higiene: En el pasado las cenizas se aplicaban en las ampollas y llagas producidas por la varicela para mitigar el escozor.

Cultura material: La raíz en decocciones se emplea para la tinción de lana obteniéndose coloraciones marrones. En construcción de viviendas se utilizaba en los horcones que requerían mayor resistencia. Asimismo, suelen emplearse los troncos y ramas como postes en el armado de corrales de cabras.

Combustible: Está considerada como la leña de mayor poder calórico por lo cual suele ser muy buscada para calefaccionar ambientes y para asar. En muchos lugares es escasa debido a los incendios recientes.

Material estudiado: ARGENTINA, Prov. La Pampa: Dpto. Chicalcó, Chos Malal, Puesto Chos Malal, 24/02/05, Muiño 13 (SRFA)

\section{ROSACEAE}

\section{Cydonia oblonga Mill.}

Membrillo

Alimentación: Cultivada en huertas del pueblo para el consumo de los frutos.

Material estudiado: ARGENTINA, Prov. La Pampa: Dpto. Chicalcó, La Humada, S $36^{\circ}$ 21'02,3', W 68०00'87,2", 06/02/09, Muiño 236 (SRFA) 


\section{Malus sylvestris Mill.}

Manzano

Observaciones: Escasamente cultivada en patios de las casas del pueblo para el consumo de sus frutos.

Material estudiado: ARGENTINA, Prov. La Pampa: Dpto. Chicalcó, La Humada, S $36^{\circ}$ 21'06.0', W 68 00' 77.6', 05/02/09, Muiño 266 (SRFA)

\section{Margyricarpus pinnatus (Lam.) Kuntze}

Yerba de la perdiz

Ganadería: Recurso forrajero de buena calidad consumido por el ganado ovino.

Material estudiado: ARgENTINA, Prov. La Pampa: Dpto. Chicalcó, Escalón de la Barda, Ruta Prov. 10 al W de Algarrobo del Águila, 09/02/73, Steibel 2520 (SRFA)

\section{Prunus armeniaca L.}

\section{Damasco}

Alimentación: Cultivada en patios y huertas para autoconsumo. Con los excedentes de la producción doméstica se elaboran mermeladas.

Material estudiado: ARGENTINA, Prov. La Pampa: Dpto. Chicalcó, La Humada, S $36^{\circ}$ 21'03.2', W 68 0'75.4'”, 06/02/09, Muiño \& Luna 280 (SRFA)

\section{Prunus domestica $\mathrm{L}$.}

\section{Ciruelo}

Alimentación: Cultivada en patios del pueblo para el consumo de los frutos.

Material estudiado: ARGENTINA, Prov. La Pampa: Dpto. Chicalcó, La Humada, S $36^{\circ}$ 21' 13,8', W 68 00' 87,8', 06/02/09, Muiño \& Rojas 229 (SRFA) 


\section{Prunus persica (L.) Batsch.}

Duraznero, Pelón

Alimentación: Cultivado en las huertas para autoconsumo. Con los excedentes de la producción doméstica se elaboran mermeladas.

Material estudiado: ARGENTINA, Prov. La Pampa: Dpto. Chicalcó, La Humada, S $36^{\circ}$ 21'06,0', W 68 00'77,6", 05/02/09, Muiño \& Vázquez 203 (SRFA); S 36 21'03.2', W $68^{\circ} 00^{\prime} 75.4$ ', 06/02/09, Muiño \& Luna 282 (SRFA)

\section{Prunus cerasifera Ehrh.}

Observaciones: Cultivada en patios y con menor frecuencia en veredas de calles del pueblo. Su nombre común no pudo ser informado.

Material estudiado: ARGENTINA, Prov. La Pampa: Dpto. Chicalcó, La Humada, S $36^{\circ}$ 21'02.3', W 680 00' 87.2', 06/02/09, Muiño 277 (SRFA)

\section{Pyracantha angustifolia (Franch.) C. K. Schneid.}

Ornamental: Cultivada en bulevares de calles del pueblo.

Observación: No se informó el nombre común para esta especie. Las plantas fueron cultivadas por la Municipalidad y la gente del pueblo desconoce su nombre.

Material estudiado: ARGENTINA, Prov. La Pampa: Dpto. Chicalcó, La Humada, S $36^{\circ}$ $20^{\prime} 94,8^{\prime}$, , W $68^{\circ} 00^{\prime} 90,5^{\prime}$ ', 05/02/09, Muiño 298 (SRFA)

\section{Pyrus communis L.}

Peral

Alimentación: Escasamente cultivada en patios de las casas del pueblo para autoconsumo.

Material estudiado: ARGENTINA, Prov. La Pampa: Dpto. Chicalcó, La Humada, S $36^{\circ}$ 21'02,3', W 6800' 87,2', 06/02/09, Muiño 297 (SRFA) 


\section{Rosa canina L.}

\section{Rosa de remedio}

Medicina e higiene: La infusión de la flor se emplea para desinflamar el hígado y para mitigar las dolencias del estómago. Se indicó su uso apto para bebés.

Ornamental: Cultivada en jardines y huertas.

Material estudiado: ARGENTINA, Prov. La Pampa, Dpto. Chicalcó, La Humada, S $36^{\circ}$ 21'06.0", W 68 00' 77.6", 05/02/09, Muiño \& Vázquez 289 (SRFA)

\section{RUTACEAE}

\section{Citrus x limon (L.) Burm. f.}

\section{Limonero}

Alimentación: La cáscara de los frutos se emplea como saborizante de tortas y bizcochuelos y el jugo de los frutos para elaborar bebidas refrescantes como limonadas y sangrías.

Medicina e higiene: El jugo de los frutos se emplea como desodorante para las axilas. El jugo de medio limón en medio vaso con agua al que se añade una cucharada de aceite y una de azúcar se indicó para desintoxicar el hígado. Este tratamiento debe efectuarse durante tres días en ayunas.

Observación: No se cultiva en el área debido a los impedimentos climáticos.

Material estudiado: No se dispone de material de referencia. Los frutos se adquieren en comercios de La Humada.

\section{Citrus $\mathrm{x}$ sinensis (L.) Osbeck}

\section{Naranjo}

Alimentación: Los frutos se consumen crudos y su cáscara se emplea para saborizar tortas y bizcochuelos.

Observaciones: No se cultiva en el área debido a los impedimentos climáticos. 
Material estudiado: No se dispone de material de referencia. Los frutos se adquieren en comercios de La Humada.

\section{Ruta chalepensis L.}

\section{Ruda hembra, Ruda macho}

Medicina e higiene: La infusión liviana de las partes aéreas se emplea para los dolores de estómago y para control de la diabetes. En aplicaciones locales se utiliza para el dolor de huesos. Junto con jarilla (Larrea sp.) y sal se aplica en baños corporales en los casos de parálisis producidas por pasmos. La terapia se acompaña de oraciones recitadas por un lego. Es una especie a la que atribuyen propiedades mágicas y se cultiva en los hogares para contrarrestar los efectos de la envidia de otras personas y evitar las desgracias. Para este fin también suele recetarse en forma de infusiones de la planta. En estos casos rige la ley de los opuestos. En tal sentido las mujeres deben beber la infusión de ruda macho y los hombres deben hacerlo con la infusión de la ruda hembra. En realidad no se trata de especies diferentes sino de formas distintas de la misma.

Ornamental: Se cultiva en los jardines y huertas.

Material estudiado: ARGENTINA, Prov. La Pampa, Dpto. Chicalcó, La Humada, S $36^{\circ}$ 21'03.2', W 68 00' 75.4', 05/02/09, Muiño \& Maya 255 (SRFA)

\section{SALICACEAE}

\section{Populus alba L.}

Álamo

Ornamental: Cultivada en veredas de calles del pueblo.

Material estudiado: ARGENTINA, Prov. La Pampa, Dpto. Chicalcó, La Humada, S $36^{\circ}$ 20'94.8', W 68\%00'90.5', 05/02/09, Muiño 268 (SRFA) 


\section{Populus x canadensis Moench.}

Álamo

Observaciones: Cultivada en patios de casas y veredas del pueblo como árboles de sombra y con menor frecuencia en el patio de los puestos.

Material estudiado: ARGENTINA, Prov. La Pampa, Dpto. Chicalcó, La Humada, S $36^{\circ}$ $20^{\prime} 94,8^{\prime \prime}$, W $68^{\circ} 00^{\prime} 90,5{ }^{\prime}$ ', 05/02/09, Muiño 243 (SRFA)

\section{Populus nigra L.}

Álamo

Cultura material: En el pasado se sacaban postes de esta planta para usarlos como horcones en la construcción de viviendas. En la actualidad aún persiste el uso de la madera para la confección de muebles, maderos de los telares y otros enseres domésticos, así como el de los postes como puntales de los pozos de agua. La madera se utiliza en tirantería en el techo de las viviendas. Las tablas provenientes de cortes de la periferia de los rollizos, un subproducto de las carpinterías industriales, se emplean en el armado de corrales de cabras. Medicinal: La infusión de las hojas se emplea en irritaciones oculares como colirio, pudiendo usarse conjuntamente con hojas de jarilla (Larrea divaricata) y alpataco (Prosopis flexuosa var. depressa). La infusión de las raspaduras de las ramas se emplea en resfríos y gripes.

Ornamental: Cultivado en los patios de las casas del pueblo y en los puestos como cortinas rompevientos y para sombra.

Material estudiado: ARGENTINA, Prov. La Pampa, Dpto. Chicalcó, La Humada, S $36^{\circ}$ 21'02.3", W 68000' 87.2', 06/02/09, Muiño 272 (SRFA)

\section{Salix babylonica L.}

Sauce

Ornamental: Se cultiva con poca frecuencia en veredas de La Humada.

Material estudiado: ARGENTINA, Prov. La Pampa, Dpto. Chicalcó, La Humada, S $36^{\circ}$ 20' 94,8', W 6800' 90,5’, 05/02/09, Muiño 215 (SRFA) 


\section{SANTALACEAE}

\section{Arjona tuberosa Cav. var. tandilensis (Kuntze) G. Dawson}

Chaquil, Macachín, Macachil

Alimentación: En el pasado los tubérculos se consumían directamente. En la actualidad ha decaído su consumo. Además del consumo directo constituye en edulcorante usado con cierta frecuencia. Esto se logra macerando los tubérculos frescos o secos y agregando al agua de la preparación del mate.

Observaciones: Se indicó que los piches (Zaedyus pichiy) consumen estos tubérculos y los buscan con avidez.

Material estudiado: ARGENTINA, Prov. La Pampa, Dpto. Chicalcó, Agua de Torres, Ruta Prov. 10, 3 km antes de Agua Escondida, 29/11/07, Muiño 131 (SRFA)

\section{SCROPHULARIACEAE}

\section{Antirrhinum majus L.}

Conejito

Ornamental: Se cultiva en los jardines de La Humada.

Material estudiado: ARGENTINA, Prov. La Pampa, Dpto. Chicalcó, La Humada, S $36^{\circ}$ 21'02,3', W 68 00'87,2", 06/02/09, Muiño 208 (SRFA)

\section{Verbascum thapsus L.}

\section{Paño}

Medicina e higiene: La infusión de las partes aéreas se emplea para combatir resfríos.

Material estudiado: ARGENTINA, Prov. Mendoza: Dpto.Malargüe, Agua Escondida, S $36^{\circ} 09^{\prime} 12,6^{\prime}$, , W $68^{\circ} 18^{\prime} 45,4^{\prime \prime}, 10 / 02 / 09$, Muiño 296 (SRFA) 


\section{SIMAROUBACEAE}

\section{Ailanthus altissima (Mill.) Swingle}

Árbol del cielo

Ornamental: Poco cultivada en los patios del área rural y del pueblo.

Material estudiado: ARGENTINA, Prov. La Pampa: Dpto. Chicalcó, La Humada, S $36^{\circ}$ 21'06.0', W 68 00' 77.6”, 06/02/09, Muiño \& Vázquez 283 (SRFA)

\section{SOLANACEAE}

\section{Capsicum annuum L.}

Ají, Pimiento

Alimentación: Los frutos secos y molidos constituyen uno de los principales condimentos de la cocina local. Se emplea como especia en la elaboración artesanal de quesos. Los frutos al natural se consumen en ensaladas y cocidos.

Observaciones: Aunque en el pasado fue profusamente cultivado en las huertas, actualmente casi ha desaparecido su cultivo.

Material estudiado: No se dispone de material de referencia. En sus distintas formas de uso se adquiere en los comercios de La Humada.

\section{Cestrum parqui L'Hér.}

\section{Palqui}

Medicina e higiene: En el pasado se usaba para curar las ojeaduras de los niños golpeándolos ligeramente en el pecho con una pequeña rama de esta planta como terapia en un contexto religioso.

Material estudiado: ARGENTINA, Prov. La Pampa: Dpto. Chicalcó, La Humada, S $36^{\circ}$ 21'00,0', W 68 00'46,9', 26/11/08, Muiño \& Maya 191 (SRFA) 


\section{Fabiana patagonica Speg.}

Pichanilla

Ganadería: Constituye un recurso forrajero para caprinos y bovinos.

Medicina e higiene: La infusión de la parte aérea se emplea para combatir resfríos.

Cultura material: La parte aérea de la planta se emplea para teñir lana.

Material estudiado: ARGENTINA, Prov. La Pampa: Dpto. Chicalcó, Chos Malal, Puesto Chos Malal, 24/02/05, Muiño 15 (SRFA)

\section{Fabiana peckii Niederl.}

Pichanilla, Retamilla

Observaciones: Presenta los mismos usos de Fabiana patagonica.

Material estudiado: ARGENTINA, Prov. La Pampa, Dpto. Chicalcó, La Humada, Ruta Prov. 10, entrada al pueblo, 25/01/06, Muiño \& Arenas 31 (SRFA)

\section{Lycium chilense Miers ex Bertero}

Llaullín, Llaullín blando, Llaullín liso

Ganadería: Recurso forrajero de buena calidad para el ganado caprino, bovino y equino. Constituye uno de los principales arbustos forrajeros de la zona.

Material estudiado: ARGENTINA, Prov. La Pampa: Dpto. Chicalcó, La Humada, Ruta Prov. 10, entrada al pueblo, 29/01/06, Muiño 47 (SRFA); Dpto. Chicalcó, Chos Malal, Puesto Chos Malal, 24/02/05, Muiño 19 (SRFA)

\section{Lycium gilliesianum Miers}

Llaullín crespo, Llaullín duro, Llaullín espinudo

Ganadería: Constituye un recurso forrajero de buena calidad para caprinos.

Material estudiado: ARGENTINA, Prov. La Pampa: Dpto. Chicalcó, La Humada, Ruta Prov. 10, entrada al pueblo, 25/01/07, Muiño 23 (SRFA); Chos Malal. Alrededores del salón comunitario, 29/11/07, Muiño 85 (SRFA) 


\section{Lycium tenuispinosum Miers var. friesii (Dammer) C.L.Hitchc.}

\section{Llaullín espinudo}

Ganadería: Constituye un recurso forrajero de buena calidad para caprinos.

Material estudiado: ARGENTINA, Prov. La Pampa, Dpto. Chicalcó, La Humada. Ruta Prov. 10 camino a Agua Escondida, 29/11/07, Muiño 76 (SRFA)

\section{Nicotiana noctiflora Hook.}

\section{Tabaquillo, Tabaco cimarrón, Tabaco del campo}

Ganadería: Especie tóxica para el ganado cuyo consumo puede ocasionar la muerte de los animales. Las intoxicaciones suelen ocurrir en caprinos y equinos.

Material estudiado: ARGENTINA, Prov. La Pampa, Dpto. Chicalcó, Algarrobo del Águila. Arroyo de la Barda y Ruta Nac. 151, 26/11/07, Muiño 91 (SRFA); La Humada. Puesto La Vasconia. Tranquera de entrada, 03/12/07, Muiño 81 (SRFA)

\section{Nicotiana tabacum L.}

Tabaco

Ganadería: El tabaco frito en grasa de piche (Zaedyus pichiy) y posteriormente filtrado se aplica al ganado y otros animales domésticos en casos de mordeduras de víboras. También se emplea la decocción en agua junto con ajo (Allium sativum).

Medicina e higiene: El humo de tabaco soplado al interior de los oídos se aplica para mitigar dolores. El tabaco hervido con mostaza (Brassica nigra) en grasa de gallina se aplicaba en friegas para eliminar dolores corporales. Hervido en grasa de piche se emplea en masajes sobre las picaduras de insectos y de víboras.

Material estudiado: Se carece de material de referencia. El producto se adquiere envasado en los comercios de La Humada. 


\section{Solanum elaeagnifolium Cav.}

Quillo

Ganadería: Especie consumida por el ganado caprino.

Cultura material: Las cenizas de la planta se empleaban en decocción acuosa para preparar lejía y el jugo de los frutos como quitamanchas por aplicación directa sobre la prenda.

Material estudiado: ARGENTINA, Prov. La Pampa: Dpto. Chicalcó, La Humada, S $36^{\circ}$ 24' 06,4"', W 67 16' 28,3', 26/11/08, Muiño 165 (SRFA); S 36 20' 96,8', W 68 00' 83,0 ", 05/02/09, Muiño 294 (SRFA)

\section{Solanum lycopersicum L.}

\section{Tomate}

Alimentación: Se cultiva en las huertas para consumo diario en diversos platos. Debido al período corto entre heladas se suele cosechar verde y consumir los frutos inmaduros. La gente los adquiere preferentemente en los comercios de La Humada.

Material estudiado: No se dispone de material de referencia.

\section{Solanum tuberosum L.}

\section{Papa}

Medicina e higiene: La cáscara de los tubérculos o rodajas finas del mismo aplicadas en las sienes con paños de vinagre se emplean para disminuir el dolor de cabeza. La misma terapia se emplea como antifebril. La ingesta de papa rallada en ayunas se recomienda para corregir indigestiones ("asientos de estómago").

Alimentación: En el pasado se cultivaba en las huertas hogareñas. Constituye uno de los principales alimentos de origen vegetal de los hogares rurales.

Material estudiado: No se dispone de material de referencia. En el pasado el producto se compraba a vendedores ambulantes y en la actualidad en comercios de La Humada. 


\section{TAMARICACEAE}

\section{Tamarix ramosissima Ledeb.}

Tamarindo, Tamarisco, Tamarindo colorado

Ganadería: La decocción de las ramas se administra en forma oral para interrumpir las diarreas en los cabritos.

Medicina e higiene: La raspadura del tallo descortezado en infusión con molle (Schinus johnstonii), jarilla (Larrea divaricata) y tomillo (Acantholippia seriphioides) se usa para tratar congestiones nasales. Sola o empleando la hoja se utiliza para interrumpir las diarreas y para mitigar los dolores de estómago.

Cultura material: Las ramas se entrelazaban horizontalmente para conferir resistencia a las paredes de cerco de jarilla (Larrea divaricata) que luego se recubrían con barro. Observaciones: Fue la primera especie cultivada en forma generalizada como árbol de sombra antes de que se popularizara el olmo (Ulmus pumila, U. procera) para los mismos fines. Actualmente quedan árboles longevos en algunos puestos que datan de esa época.

Material estudiado: ARGentinA, Prov. La Pampa, Dpto. Chicalcó, La Humada, en plaza del pueblo, 01/02/06, Muiño 42 (SRFA), Algarrobo del Águila, Puente Ruta Nac. 143 y Arroyo de la Barda, 26/11/07, Muiño 104 (SRFA)

\section{TILIACEAE}

\section{Tilia sp.}

Tilo

Medicina e higiene: Las inflorescencias se empleaban en infusiones para atenuar los efectos del resfrío, el sarampión y la varicela.

Material estudiado: Se carece de material de referencia. Estas hierbas secas se compraban a vendedores ambulantes de la zona y en la actualidad en los comercios de La Humada. 


\section{ULMACEAE}

\section{Ulmus procera Salisb.}

Olmo

Cultura material: La madera se utiliza en la fabricación de varillas para potreros. Por tratarse de una madera resistente se emplea para confeccionar cabos de herramientas.

Observaciones: Constituye una de las especies más cultivadas como árboles de sombra en los patios.

Material estudiado: ARgentinA, Prov. La Pampa, Dpto. Chicalcó, La Humada, S $36^{\circ}$ $21^{\prime}$ 02,3'”, W 6800' 87,2', 06/02/09, Muiño 235 (SRFA)

\section{VERBENACEAE}

\section{Acantholippia seriphioides (A. Gray) Moldenke}

Tomillo, Tomillo de olor, Tomillo hembra

Ganadería: Recurso forrajero valioso para el ganado equino y bovino. También, las ramas se colocan bajo las cinchas de las monturas en forma de cruz para prevenir eventuales irritaciones de la piel.

Alimentación: Utilizada para condimentar chacinados y distintos platos guisados y carnes asadas.

Medicina e higiene: La infusión de la parte aérea con azúcar tostada se emplea para curar resfríos, puede mezclarse con hojas de molle (Schinus johnstonii), raspadura de tallos de jarilla (Larrea divaricata), tamarindo (Tamarix ramosissima) y rizoma de blanquilla (Hyalis argentea). La infusión también puede hacerse en vino. Además de las partes aéreas se puede usar la raíz pero el hervor debe ser más prolongado. La infusión de las partes aéreas también se bebe para mitigar dolores de estómago, interrumpir diarreas, desinflamar las vías urinarias y en forma de buches para disminuir el dolor de muelas. En concentraciones mayores como afrodisíaco masculino. Se considera una planta cálida.

Material estudiado: ARGENTINA, Prov. La Pampa, Dpto. Chicalcó, La Humada. Puesto La Humada, 25/01/06, Muiño 34 (SRFA); La Humada. Contrafuego, $4 \mathrm{~km}$ al N de cruce con Ruta Prov. 14, 29/11/07, Muiño 119 (SRFA); Chos Malal. Puesto Las Tosquitas, 24/02/05, Muiño 152 (SRFA) 


\section{Acantholippia seriphioides (A. Gray) Moldenke}

\section{Hierba del lagarto}

Medicina e higiene: La infusión se emplea como cordial y con los mismos fines que el tomillo de olor, pero no es tan efectivo como este. En el pasado se maceraba la planta en alcohol para lograr un perfume de uso personal.

Observaciones: Se trata de una variedad o un ecotipo de $A$. seriphioides cuyos vástagos presentan una intensa fragancia cítrica, a diferencia de la anterior que posee olor alcanforado. Los pobladores distinguen a ambas como etnoespecies diferentes a través de sus nombres vernáculos. Los estudios de Fester (1963) confirman la composición diferente en las esencias de ambas. Es el mismo taxón que describe Ruiz Leal (1972) con el nombre vernáculo de "alagarto".

Material estudiado: ARGENTINA, Prov. La Pampa: Dpto. Chicalcó, Chos Malal, Puesto Valle Chico, 25/02/05, Muiño 1 (SRFA)

\section{Aloysia citriodora Palau}

\section{Cedrón}

Medicina e higiene: Las hojas secas se agregan en el mate para darle sabor.

Material estudiado: Se carece de material de referencia. No se cultiva en la zona. Las partes secas se traen de otras localidades y se adquieren envasadas en comercios de La Humada.

\section{Aloysia polystachya (Griseb.) Moldenke}

Burro, Burrito, Té de burro

Medicina e higiene: La infusión de la parte aérea se emplea como digestivo y para saborizar el mate.

Observaciones: Se cultiva en los jardines de los puestos.

Material estudiado: ARGENTINA, Prov. La Pampa: Dpto. Chicalcó, La Humada, S $36^{\circ}$ 20'94,8', W 68 00' 90,5', 05/02/09, Muiño 216 (SRFA) 


\section{Glandularia crithmifolia (Gillies ex Hook.) Schnack \& Covas}

\section{Verbena}

Observaciones: No se informaron usos para esta especie. Solo se encontró en áreas serranas.

Material estudiado: ARGENTINA, Prov. La Pampa: Dpto. Chicalcó, Ruta Prov. 10, 3 km antes de Agua Escondida. Sobre cerro a la izquierda del camino, 29/11/07, Muiño 126 (SRFA)

\section{Glandularia flava (Gillies ex Hook.) Schnack \& Covas}

Yerba de la vaca

Ganadería: Especie consumida por el ganado bovino.

Material estudiado: ARGENTINA, Prov. La Pampa: Dpto. Chicalcó, Chos Malal, Puesto Chos Malal, 24/02/05, Muiño 14 (SRFA)

\section{Junellia seriphioides (Gillies \& Hook. ex Hook.) Moldenke}

Tomillo macho, Tomillón

Ganadería: Cuando la planta está tierna es apetecida por las cabras. Su abundancia actúa en detrimento de la existencia de buenos pastos forrajeros.

Medicina e higiene: En el pasado se maceraban las flores en alcohol junto con las de solupe (Neosparton aphyllum) para obtener un perfume de uso personal.

Material estudiado: ARGENTINA, Prov. La Pampa, Dpto. Chicalcó, Algarrobo del Águila, Ruta Prov. 14, $22 \mathrm{~km}$ al W de Ruta Nac. 151, 26/11/07, Muiño 80 (SRFA); La Humada. Puesto La Humada, 25/01/06, Muiño 33 (SRFA)

\section{Lippia turbinata Griseb.}

Poleo

Medicina e higiene: Se utiliza para conferirle sabor al mate y las partes aéreas en infusión como digestivo. 
Material estudiado: ARGENTINA, Prov. La Pampa, Dpto. Chicalcó, La Humada, S $36^{\circ}$ $21^{\prime} 13,8^{\prime \prime}$, W 68 00' 87,8', 06/02/09, Muiño \& Rojas 238 (SRFA)

\section{Neosparton aphyllum (Gillies \& Hook.) Kuntze}

\section{Solupe, Retamilla}

Ganadería: Constituye un recurso forrajero consumido por el ganado equino.

Medicina e higiene: En el pasado se maceraban las flores en alcohol junto con las de tomillo macho (Junellia seriphioides) para obtener un perfume de uso personal.

Cultura material: Las plantas enteras colocadas verticalmente se utilizan en la construcción de corrales para el encierro del ganado caprino. También forma parte de la cobertura de los techos de las viviendas antiguas. Actualmente se reemplaza por materiales de construcción modernos. Las cenizas de la planta se empleaban para preparar lejías y jabón.

Combustible: Constituye un recurso combustible de bajo poder calórico pero es muy usado para calentar cocinas y hornos de barro. En menor proporción para calefaccionar ambientes.

Material estudiado: ARGENTINA, Prov. La Pampa, Dpto. Chicalcó, Chos Malal. Loma de basalto. $4 \mathrm{~km}$ al N del salón comunitario, 27/11/07, Muiño 114 (SRFA)

\section{VITACEAE}

\section{Parthenocissus quinquefolia (L.) Planch.}

\section{Parra loca}

Ornamental: Cultivada en jardines y patios. También como planta de sombra en galerías y glorietas.

Material estudiado: ARGENTINA, Prov. La Pampa, Dpto. Chicalcó, La Humada, S $36^{\circ}$ 20'70,2', W 68 01' 55,1'”, 06/02/09, Muiño \& Mansilla 222 (SRFA) 


\section{Vitis vinifera $\mathrm{L}$.}

\section{Parra, Parra criolla}

Alimentación: Se cultiva en huertos y patios por sus frutos comestibles y para proporcionar sombra.

Medicina e higiene: Los frutos no tienen aplicaciones en medicina tradicional, pero sí su producto elaborado, el vino. Para el alivio de resfríos es costumbre tomar por la noche un vaso de vino que se somete previamente a un calentamiento a ebullición. Cuando esto ocurre, se provoca la ignición del alcohol y se bebe cuando cesa la combustión. Junto con este preparado, al que puede agregársele una cáscara de naranja, se aconseja tomar una aspirina.

Material estudiado: ARGENTINA, Prov. La Pampa, Dpto. Chicalcó, La Humada, S $36^{\circ}$ 21'03,2", W 68 00' 75,4"', 05/02/09, Muiño \& Luna 197 (SRFA); S 36 21'03.2', W 68 00' 75.4', 05/02/09, Muiño \& Luna 255 (SRFA); S 36 21'06.0', W 6800' 77.6", 05/02/09, Muiño \& Vázquez 288 (SRFA)

\section{ZYGOPHYLLACEAE}

\section{Larrea cuneifolia Cav.}

Jarilla crespa

Ganadería: Recurso forrajero que consumen los caprinos.

Observación: Se informaron los mismos usos que para Larrea divaricata.

Material estudiado: ARGENTINA, Prov. La Pampa, Dpto. Chicalcó, Algarrobo del Águila, Ruta Prov. 14, 4 km al W de cruce con Ruta Nac. 151, 26/11/07, Muiño 149 (SRFA)

\section{Larrea divaricata Cav.}

Jarilla, Jarilla lisa

Ganadería: Recurso forrajero que consumen los caprinos. La decocción acuosa de la parte aérea se emplea para el tratamiento de miasis, para desinfectar heridas del ganado y en la aplicación de fomentos en el tratamiento del "mal seco" de los caballos. En lavajes junto 
con jabón blanco se emplea como desinflamatorio; el jabón puede suplirse por ceniza y sal. El agua de jarilla se administra en forma oral a los animales como oxitócico.

Medicina e higiene: La infusión de las raspaduras del tallo descortezado con azúcar quemado se emplea para curar resfríos. Puede mezclarse con raíz de tomillo (Acantholippia seriphioides), con hojas de molle (Schinus johnstonii), ramas de tamarindo (Tamarix ramosissima) y de arabia (Eleagnus angustifolia). En forma de vapores para descongestionar las vías respiratorias. Las cataplasmas hechas con las partes aéreas de jarilla y melosa (Grindelia chiloensis) fritas en aceite verde, mezcladas con cenizas se emplean como desinflamatorio, en fracturas de huesos. Los paños hechos con la infusión acuosa se aplican en quemaduras, y junto con tomillo (Acantholippia seriphioides) para los dolores de las articulaciones. La infusión por vía oral se aplica en gastritis y úlceras gástricas y con algunos granos de sal se utiliza como hepático. En forma de buches y con jabón blanco para mitigar el dolor de muelas. Si esta infusión es concentrada se puede emplear como abortivo. En forma de lavajes se emplea para irritaciones de los ojos, desinfectante de heridas, para madurar forúnculos y como desodorante para los pies. En baños corporales se utiliza junto con ruda (Ruta chalepensis) y sal en las parálisis causadas por pasmos. Esta terapia se realiza en contexto religioso y en ella intervienen las oraciones efectuadas por un lego.

Cultura material: Con la planta se confeccionan escobas en los hogares rurales cuando en los alrededores no abunda la pichana (Baccharis spartioides). En la construcción de viviendas, las ramas colocadas en hileras formaban parte de las estructuras de las paredes, que luego se recubrían con estiércol vacuno a modo de revoque. También formaba parte estructural de la cobertura del techo, que se revestía con barro. Los guardapatios y los corrales de las cabras también se realizan con ramas entrelazadas de jarilla formando cercos de varios centímetros de espesor, pero estos no llevan cobertura. Cuando las plantas adquieren gran desarrollo de los tallos, estos suelen usarse como cabos de herramientas o rebenques. Para evitar posteriores fracturas de la madera, sus extremos deben quemarse superficialmente. Las hojas y ramas se emplean en decocciones acuosas para teñir lana obteniéndose tintes amarillo-verdosos. La madera se utilizaba para elaborar instrumentos de uso doméstico como ejes de roldanas, punzones para trabajar el cuero, ensartadores para asar la carne y emparrillados para secar quesos.

Combustible: Es una especie muy utilizada como leña, especialmente para calentar agua, cocinar en fogones y en hornillos practicados en el suelo, con usos similares al solupe 
(Neosparton aphyllum). Se usa también para calefaccionar ambientes cuando no existen maderas de mejor calidad para este fin. Su poder calórico es bajo y se consume más rápido que otros tipos de leña como el piquillín (Condalia microphylla) o el ala (Monttea aphylla).

Material estudiado: ARGENTINA, Prov. La Pampa: Dpto. Chicalcó: La Humada, Ruta Prov. 10, entrada al pueblo, 25/01/06, Muiño \& Arenas 38 (SRFA); Chos Malal, Puesto Chos Malal, 24/02/05, Muiño 16 (SRFA); Algarrobo del Águila, Ruta Prov. 14, 4 km al W de cruce con Ruta Nac. 151, 26/11/07, Muiño 148 (SRFA)

\section{Larrea nitida Cav.}

Jarilla, Jarilla crespa.

Medicina e higiene: La infusión de hojas y tallos tiernos se emplea para el tratamiento de úlceras gástricas y se aplica en fomentos locales como desinflamatorio y como desinfectante de heridas. Para el primer uso la infusión debe prepararse por la noche, dejarla "al sereno" y beberla por la mañana durante tres días seguidos, luego debe repetirse el tratamiento a los diez o quince días. Está reputada como más efectiva que Larrea divaricata.

Cultura material: Las partes aéreas en decocción acuosa se utiliza en la tinción de lana obteniéndose las mismas coloraciones que Larrea divaricata.

Material estudiado: ARGENTINA, Prov. La Pampa: Dpto. Chicalcó: Agua de Torres, S $36^{\circ} 11^{\prime} 62.8^{\prime \prime}$, W 68 $11^{\circ}$ '25.5', 08/02/09, Muiño 246 (SRFA)

\section{LILIOPSIDA (MONOCOTYLEDONEAE)}

\section{ALLIACEAE}

\section{Allium cepa L.}

\section{Cebolla}

Alimentación: Es una de las hortalizas más utilizadas en diversos platos. 
Medicina e higiene: La infusión de trozos del bulbo con azúcar quemado se emplea como expectorante. Las catáfilas internas más delgadas se aplican localmente con grasa de caballo para extraer espinas.

Cultura material: La decocción de las catáfilas exteriores se utiliza para teñir lana obteniéndose colores amarillos de intensidad variable.

Observaciones: En el pasado fue muy cultivada en las huertas familiares.

Material estudiado: No se dispone de material de referencia. Actualmente se adquiere en comercios de La Humada.

\section{Allium sativum $\mathrm{L}$.}

Ajo

Alimentación: Es uno de los ingredientes más usados en la elaboración de diversos platos.

Ganadería: Los bulbos en infusión con leche sirven para combatir el gusano del cuajo en los equinos. Mezclado con tabaco para atender los animales mordidos por víboras, aplicando paños sobre la lesión.

Observaciones: En el pasado fue cultivada en las huertas. Es una planta utilizada en adivinaciones. Para ello se deben colocar tres dientes de ajo en una cajita debajo de la cama de una mujer soltera en la noche de San Juan (24 de junio). Si a la mañana siguiente los ajos aparecen brotados, esta señal es indicadora de que ella se casará en el año próximo.

Material estudiado: No se dispone de material de referencia. Actualmente se abandonó su cultivo y se adquiere en los comercios de La Humada.

\section{ALOEACEAE}

\section{Aloe saponaria (Ait.) Haw}

\section{Aloe vera}

Medicina e higiene: Se utiliza en aplicación tópica para el alivio de irritaciones y quemaduras. Para calmar dolores de estómago y de muelas se consume el mucílago interno de las hojas.

Observaciones: Muy cultivada en los jardines. 
Material estudiado: ARGENTINA, Prov. La Pampa, Dpto. Chicalcó, La Humada, S $36^{\circ}$ 21'03,2', W 68 00' 75,4', 14/08/09, Muiño \& Cisterna 316 (SRFA)

\section{AMARYLLIDACEAE \\ Habranthus jamesonii (Baker) Ravenna}

Cebolla de la zorra

Medicinal: Los mismos usos que la especie anterior.

Material estudiado: ARGENTINA, Prov. La Pampa, Dpto. Chicalcó, La Humada, S $36^{\circ}$ 20'06,0', W 670 59' 47,0', 26/11/08, Muiño 174 (SRFA)

\section{Rhodophiala mendocina (Phil.) Ravenna}

Cebolla de la zorra

Ganadería: La flor es muy apetecida por las ovejas.

Medicina e higiene: El bulbo cortado en rodajas, frito y caliente se coloca sobre el vientre (compresas) o directamente sobre el ano para calmar diarreas muy fuertes.

Material Estudiado: ARGEnTINA, Prov. La Pampa, Dpto. Chicalcó, Chos Malal, borde de camino, $1 \mathrm{~km}$ al $\mathrm{N}$ de salón comunitario, 27/11/07, Muiño 74 (SRFA)

\section{ASPARAGACEAE}

\section{Asparagus officinalis $\mathrm{L}$.}

\section{Espárrago}

Alimentación: Escasamente cultivada en huertas de La Humada para autoconsumo.

Material estudiado: ARGENTINA, Prov. La Pampa, Dpto. Chicalcó, La Humada, S $36^{\circ}$ 21'03.2', W 68 00' 75.4', 06/02/09, Muiño \& Luna 279 (SRFA) 


\section{BROMELIACEAE}

\section{Tillandsia bryoides Griseb. ex Baker}

Clavel del aire

Medicina e higiene: La infusión de la flor es empleada para tonificar el corazón.

Material estudiado: ARGENTINA, Prov. La Pampa, Dpto. Chicalcó, Lomas de Jagüel del Moro, 20/12/89, Troiani \& Prina 10031 (SRFA)

\section{CYPERACEAE}

Schoenoplectus californicus (C.A.Mey.) Soják var. californicus

Totora del río

Observaciones: No se indicaron usos con esta especie.

Material Estudiado: ARGENTINA, Prov. La Pampa, Dpto. Chicalcó, Algarrobo del Águila. Arroyo de la Barda y Ruta Nac. 151, 26/11/07, Muiño 93 (SRFA)

\section{IRIDACEAE}

\section{Iris germanica L.}

Lirio, Gladiolo

Ornamental: Cultivada en jardines del pueblo y en el área rural.

Material estudiado: ARGENTINA, Prov. La Pampa, Dpto. Chicalcó, La Humada, S $36^{\circ}$ 20'91,6”, W 68 00'78,0”, 05/02/09, Muiño \& Vázquez 205 (SRFA)

\section{MUSACEAE}

\section{Musa paradisiaca $\mathrm{L}$.}

\section{Banana}

Medicina e higiene: La cáscara del fruto en infusión con azúcar quemado se emplea como expectorante. 
Material estudiado: No se dispone de material de referencia. No se cultiva en el área y los frutos se adquieren en comercios de La Humada.

\section{POACEAE}

\section{Aristida adscencionis L.}

\section{Coirón}

Ganadería: Indicada como buena forrajera, también se señaló que antes no existía en la zona.

Material estudiado: ARgentinA, Prov. La Pampa, Dpto. Puelén, Chos Malal. Puesto Los Carrizales, 26/02/05, Muiño 70 (SRFA)

\section{Aristida mendocina Phil.}

Coirón, Flechilla crespa

Ganadería: Es un recurso forrajero de buena calidad para equinos, bovinos y ovinos.

Material estudiado: ARGENTINA, Prov. La Pampa, Dpto. Puelén, Puesto Los Carrizales, 26/02/05, Muiño 4 (SRFA), Chos Malal, Ruta Prov. 14, 50 km al W de Ruta Nac. 151, 26/11/07, Muiño 107 (SRFA)

\section{Asistida spegazzinii Arechav.}

Coirón fino, Cebadilla, Flechilla

Ganadería: Especie considerada con buenas cualidades forrajeras.

Material estudiado: ARGENTINA, Prov. La Pampa, Dpto. Chicalcó, Chos Malal. Puesto Las Rosillas, 28/11/07, Muiño 130 (SRFA) 


\section{Arundo donax L.}

Caña, Caña de Castilla

Cultura material: Constituía otra de las especies utilizadas para techar viviendas. Esta cubierta era posteriormente revestida con barro. Actualmente continúa su uso para hacer techados de galerías y otras dependencias domésticas.

Observaciones: Cultivada con cierta frecuencia en huertas.

Material estudiado: ARGENTINA, Prov. La Pampa, Dpto. Chicalcó, La Humada, S $36^{\circ}$ 20'702'”, W 68 01'55.1'”, 06/02/09, Muiño \& Mansilla 285 (SRFA)

\section{Bothriochloa springfieldii (Gould) Parodi}

Cebadilla gruesa, Pasto de hoja, Pasto de coyuntura, Flechilla

Ganadería: Es un recurso forrajero de buena calidad para bovinos y equinos.

Material estudiado: ARgENTINA, Prov. La Pampa, Dpto. Chicalcó, Chos Malal. Puesto Las Rosillas, 28/11/07, Muiño 129 (SFA)

\section{Bromus catharticus Vahl var. rupestris (Speg.) Planchuelo \& P. M. Peterson}

Cebadilla fina, Unquillo, Gramilla, Cebadilla

Ganadería: Constituye un recurso forrajero de invierno de muy buena calidad para vacunos, ovinos y equinos, pero su abundancia está condicionada a los años húmedos.

Material estudiado: ARGENTINA, Prov. La Pampa, Dpto. Chicalcó, La Humada. Huella, $10 \mathrm{~km}$ al N de Ruta Prov. 10. Camino a Puesto La Vasconia, 01/12/07, Muiño 121 (SRFA); Prov. Mendoza, Dpto. Malargüe, Agua Escondida. Cerro aledaño al pueblo, 29/11/07, Muiño 132 (SRFA)

\section{Cortaderia selloana (Schult. \& Schult. f.) Asch. \& Graebn.}

\section{Cortadera}

Medicina e higiene: La raíz se emplea mezclada con cadillo (Xanthium spinosum) en infusión para desinflamar los riñones. 
Material estudiado: ARGENTINA, Prov. La Pampa, Dpto. Chicalcó, La Humada, S $36^{\circ}$ 20' 86,7', W 68 01'01.8', 06/02/09, Muiño 290 (SRFA)

\section{Digitaria californica (Benth.) Henrard}

Coirón, Pasto de hoja

Ganadería: Especie con buenas cualidades forrajeras.

Material estudiado: ARGENTINA, Prov. La Pampa, Dpto. Chicalcó, La Humada, Ruta Prov. 10, entrada al pueblo, 30/01/06, Muiño 45 (SRFA), Agua de Torres, Ruta Prov. 10, 3 km antes de Agua Escondida. Sobre cerro a la izquierda del camino, 29/11/07, Muiño 128 (SRFA)

\section{Distichlis spicata (L.) Greene}

\section{Pasto salado}

Cultura material: Constituye la materia prima del "adobe champa". Este material es un ladrillo muy liviano formado íntegramente por rizomas de esta planta con tierra compacta que se corta y extrae de las áreas bajas salitrosas, donde crece.

Material estudiado: ARGENTINA, Prov. La Pampa, Dpto. Chicalcó, La Humada, S $36^{\circ}$ 21'00,0', W 6800'46,9', 26/11/08, Muiño 188 (SRFA)

\section{Elionurus muticus (Spreng.) Kuntze}

Paja amarga

Cultura material: Se utiliza para la elaboración de la masa de barro que constituye los ladrillos de adobe.

Material estudiado: ARGENTINA, Prov. La Pampa, Dpto. Chalileo, Colonia Emilio Mitre, 27/02/86, Steibel \& Troiani 9015 (SRFA) 
Eragrostis mexicana (Hornem.) Link ssp. virescens (J. Presl) S.D. Koch \& Sanchéz Vega

Gramilla fina, Gramilla, Pasto de martineta, Cebadilla

Ganadería: Es uno de los pastos que prefiere para el consumo el ganado bovino, equino y caprino.

Material estudiado: ARGENTINA, Prov. La Pampa, Dpto. Chicalcó, La Humada. Puesto La Humada, 26/01/06, Muiño 54 (SRFA); La Humada, Ruta Prov. 10, 3 km antes de Agua Escondida. Sobre cerro a la izquierda del camino, 29/11/07, Muiño 127 (SRFA)

\section{Hordeum murinum L. ssp. glaucum (Steud.) Tsvelev}

Cebadilla

Ganadería: Recurso forrajero temporario cuya existencia está condicionada a los años húmedos.

Material estudiado: ARGENTINA, Prov. Mendoza, Dpto. Malargüe, Agua Botada, 12/12/95, Troiani, Steibel \& Prina 11788 (SRFA)

\section{Hordeum parodii Covas}

Observaciones: Prospera en áreas bajas e inundables de La Humada. No se informaron usos de esta especie.

Material estudiado: ARGENTINA, Prov. La Pampa, Dpto. Chicalcó, La Humada, S $36^{\circ}$ 20'96.8', W 68 00' 83.0”', 05/02/09, Muiño 262 (SRFA)

\section{Jarava hypsophylla (Speg.) Peñailillo}

\section{Coirón}

Observaciones: A excepción de su nombre común, no se informaron otros datos sobre esta especie.

Material estudiado: ARgENTINA, Prov. La Pampa, Dpto. Chicalcó, Agua de Torres. Ruta Prov. 10, $3 \mathrm{~km}$ al S de Agua Escondida, 29/11/07, Muiño 67 (SRFA); Algarrobo del Águila, S $36^{\circ} 21^{\prime} 36,3^{\prime \prime}$, W $67^{\circ} 14^{\prime}$ 43,9', 24/11/08, Muiño 182 (SRFA) 


\section{Jarava ichu Ruiz \& Pav.}

\section{Coirón, Coirón fino}

Ganadería: Constituye un recurso forrajero de emergencia cuando no existen pastos mejores.

Cultura material: En el pasado empleada con frecuencia en la elaboración de ladrillos de adobe.

Material estudiado: ARgentinA, Prov. La Pampa, Dpto. Chicalcó, La Humada, Ruta Prov. 10, $15 \mathrm{~km}$ al N del pueblo, 29/11/07, Muiño 66 (SRFA)

\section{Jarava neaei (Nees ex Steud.) Peñailillo}

\section{Flechilla}

Ganadería: En estado vegetativo constituye un forraje de buena calidad, pero al florecer, los antecios se clavan en el cuero de las ovejas y les producen heridas. Cuando estas se infectan o agusanan, pueden provocarles la muerte.

Material estudiado: ARGENTINA, Prov. La Pampa: Dpto. Chicalcó, Chos Malal, Puesto Chos Malal, 24/02/05, Muiño 2 (SRFA)

\section{Leymus erianthus (Phil.) Dubcovsky}

Gramilla, Algodón

Ganadería: Especie forrajera considerada como pasto duro al igual que los coirones.

Material estudiado: ARGENTINA, Prov. La Pampa: Dpto. Chicalcó, Ruta Prov. 14, 50 km al W de Ruta Nac. 151, 26/11/07, Muiño 142 (SRFA); La Humada, S 36 24'06,4”, W $67^{\circ} 16^{\prime} 28,3^{\prime \prime}, 25 / 11 / 08$, Muiño 175 (SRFA) 


\section{Nassella tenuis (Phil.) Barkworth}

Flechilla fina, Flechilla

Ganadería: Especie de invierno de muy buena calidad forrajera para bovinos, equinos y ovinos.

Material estudiado: ARGENTINA, Prov. La Pampa: Dpto. Chicalcó, La Humada. Puesto La Humada, 25/01/06, Muiño 29 (SRFA); Chos Malal, Ruta Prov. 14, $50 \mathrm{~km}$ al W de Ruta Nac. 151, 26/11/07, Muiño 151 (SRFA)

\section{Nassella tenuissima (Trin.) Barkworth}

Flechilla blanca, Flechilla

Ganadería: Constituye un forraje de regular calidad, las inflorescencias son muy consumidas por el ganado vacuno.

Material estudiado: ARGENTINA, Prov. La Pampa, Dpto. Chicalcó, La Humada, Ruta Prov. 10, $15 \mathrm{~km}$ al $\mathrm{N}$ del pueblo, 29/11/07, Muiño 65 (SRFA)

\section{Oryza sativa L.}

Arroz

Alimentación: Junto con el maíz y el trigo es uno de los cereales que más interviene en las preparaciones culinarias.

Material estudiado: No se dispone de material de referencia. El producto se adquiere envasado en los comercios de La Humada.

\section{Panicum urvilleanum Kunth.}

Tupe

Ganadería: Está considerado en la zona como el mejor pasto forrajero de verano, en especial para vacunos, equinos y caprinos, pudiendo utilizarse diferido en el invierno.

Medicina e higiene: Los rizomas macerados y hervidos en agua actúan como agentes saponificables. En el pasado esta propiedad se aprovechaba para el lavado del cabello y 
para la limpieza de la ropa y lana. Junto con el rizoma de tupe también podía usarse la raíz de paico (Dysphania ambrosioides).

Material estudiado: ARGENTINA, Prov. La Pampa, Dpto. Chicalcó: La Humada, Ruta Prov. 10, entrada al pueblo, 25/01/06, Muiño \& Arenas 35 (SRFA); Chos Malal, Ruta Prov 14, $50 \mathrm{~km}$ al W de Ruta Nac. 151, 26/11/07, Muiño 105 (SRFA)

\section{Pappophorum philippianum Parodi}

\section{Pasto de hoja, Unquillo grueso}

Ganadería: Forraje de verano que consumen todas las clases de ganado.

Material estudiado: ARgentinA, Prov. La Pampa, Dpto. Chicalcó, La Humada. Alrededores del pueblo, 25/01/06, Muiño \& Arenas 78 (SRFA); La Humada, Ruta Prov. 10, $15 \mathrm{~km}$ al N de La Humada, 29/11/07, Muiño 140 (SRFA)

\section{Pappostipa vaginata (Phil.) Romaschenko}

\section{Coirón, Flechilla}

Ganadería: Especie forrajera que prefiere el ganado equino y en ocasiones el bovino. Su disponibilidad suele manejarse con quemas periódicas para favorecer el rebrote, de mejor calidad que las partes maduras de la planta.

Cultura material: Utilizada en la confección de sombreros. Las partes empleadas son las cañas entretejidas que se disponen atadas entre sí con hilos de lana teñidos con colores vivos. También se emplea en la elaboración de ladrillos y chorizos de adobe y en la pasta de barro usada para cubrir techos de las viviendas.

Material estudiado: ARGENTINA, Prov. La Pampa: Dpto. Chicalcó, Chos Malal, Puesto Los Carrizales, 26/02/05, Muiño 3 (SRFA); Chos Malal, Ruta Prov. 14, $50 \mathrm{~km}$ al W de Ruta Nac. 151, 26/11/07, Muiño 112 (SRFA) 


\section{Poa lanuginosa Poir.}

Unquillo

Ganadería: Considerado como el mejor pasto forrajero de invierno y muy buscado por vacunos, ovinos y equinos.

Material estudiado: ARgENTINA, Prov. La Pampa, Dpto. Chicalcó, Algarrobo del Águila, S 36 21 ' 36,3' 'W 67 14' 43,9'”, 24/11/08, Muiño 160 (SRFA)

\section{Schismus barbatus (L.) Thell.}

Pasto de invierno, Pasto engordador, Flechilla engordadora, Pasto cuneta

Ganadería: Es un pasto de buenas características forrajeras aprovechado por bovinos, equinos y ovinos, con un corto período de uso por el ganado, pero este transcurre cuando escasean otras fuentes de alimento. Por esta razón es considerado muy valioso en el área.

Material estudiado: ARGENTINA, Prov. La Pampa, Dpto. Chicalcó, Chos Malal. Salitral de la Perra, 28/11/07, Muiño 117 (SRFA)

\section{Setaria leucopila (Scribn. \& Merr.) K. Schum.}

\section{Pasto de hoja}

Ganadería: Es un pasto de verano de buenas características forrajeras.

Material estudiado: ARGENTINA, Prov. La Pampa: Dpto. Chicalcó, La Humada, Ruta Prov. 10, entrada al pueblo, 25/01/06, Muiño \& Arenas 28 (SRFA)

\section{Setaria mendocina Phil.}

Pasto de hoja

Ganadería: Es un pasto estival de buenas características forrajeras.

Material estudiado: ARGENTINA, Prov. La Pampa: Dpto. Chicalcó, La Humada, Ruta Prov. 10, $15 \mathrm{~km}$ al N del pueblo, 29/11/07, Muiño 64 (SRFA), Chos Malal, Puesto Chos Malal, 24/02/05, Muiño 5 (SRFA) 


\section{Sporobolus crypthandrus (Torr.) A. Gray}

Gramilla

Ganadería: Es considerado un pasto de buenas características forrajeras.

Material estudiado: ARGENTINA, Prov. La Pampa, Dpto. Chicalcó, La Humada. Puesto La Humada, 25/01/06, Muiño 143 (SRFA); S 36² 21'02,3', W 68 00' 87,2'”, 06/02/09, Muiño 233 (SRFA)

\section{Sporobolus rigens (Trin.) E. Desv.}

Unco

Ganadería: El consumo del rebrote en invierno por el ganado puede ocasionarles efectos tóxicos.

Cultura material: En el pasado se utilizaban manojos de esta planta para techar viviendas en forma de quinchados sobre una capa de ramas de jarilla (Larrea divaricata). Al conjunto posteriormente se lo cubría con barro. También se empleaba para rellenar bastos de monturas.

Material estudiado: ARGENTINA, Prov. La Pampa, Dpto. Chicalcó, Chos Malal. Alrededores de salón comunitario, 27/11/07, Muiño 69 (SRFA)

\section{Trichloris crinita (Lag.) Parodi}

\section{Pasto de hoja}

Ganadería: Es considerada una especie con buenas cualidades forrajeras.

Material estudiado: ARGENTINA, Prov. La Pampa, Dpto. Chicalcó, Algarrobo del Águila, S $36^{\circ} 21^{\prime} 36,3^{\prime \prime}$, W $67^{\circ} 14^{\prime}$ 43,9', 24/11/08, Muiño 181 (SRFA)

\section{Triticum aestivum L.}

Trigo

Ganadería: La harina batida en agua tibia se les da de beber a los animales para interrumpir las diarreas. 
Alimentación: Constituye una de las bases de la alimentación. Además de los múltiples platos que se preparan con la harina, el grano entero forma parte de platos tradicionales tales como el mote, el ñaco y la mazamorra. También participa en guisos y locros, en especial cuando falta el maíz (Zea mays).

Medicina e higiene: La harina tostada e ingerida con agua se emplea para interrumpir las diarreas.

Material estudiado: No se dispone de material de referencia. No se cultiva y la harina se adquiere en los comercios de la Humada y a vendedores ambulantes.

\section{Zea mays L.}

Maíz

Alimentación: Forma parte de muchos platos tradicionales, entre ellos el ñaco, el mote, el locro, la mazamorra y el printincao. Además de estos también es un ingrediente en la preparación de guisos y pucheros. Los choclos, suelen consumirse asados sobre las brasas y los granos calentados sobre piedras calientes como "flores de maíz". Una variante de maíz molido y empleada para el consumo se denomina frangollo.

Medicina e higiene: Los estigmas y la parte aérea de la planta se emplean en infusión como diurético. Tres cucharaditas del almidón en un vaso de agua previamente hervida con azúcar se emplean para interrumpir las diarreas.

Observaciones: Cultivada en las huertas hogareñas.

Material estudiado: ARGENTINA, Prov. La Pampa, Dpto. Chicalcó, La Humada, S $36^{\circ}$ 20'91,9', W 68 00' 87,9', 05/02/09, Muiño \& Luna 199 (SRFA) 


\section{ÍNDICE DE NOMBRES CIENTÍFICOS Y COMUNES}

Abrojo 202

Acacia 220, 250

Acantholippia

245,246

Acelga 208

Acer negundo 180

Achillea filipendulina 187

Achillea millefolium 187

Adesmia retrofracta 215

Aeonium sp. 211

Ailanthus altísima 240

Ajenjo 187

Ajenjo de perro 198

Ají 240

Ajo 252

Ala 230

Ala de loro 230

Álamo 237, 238

Albahaca 223

Albaricoque 228

Alcanfor 187

Alegría 191

Alfa 217

Alfilerillo 220

Algarrobilla 220

Algarrobillo 220
Algarrobo 218

Algodón 259

Alelí 204

Alhelí de Mahón 204

Allenrolfea vaginata 207

Allium cepa 251

Allium sativum 252

Aloe saponaria 252

Aloe vera 252

Aloysia citriodora 246

Aloysia polystachya 246

Alpataco 219

Altamisa 197

Altepe 197

Amaranthus blitoides 181

Amaranthus caudatus 181

Amaranthus crispus 181

Antirrhinum majus 239

Apio 183

Apium graveolens 183

Aptenia cordifolia 180

Arabia 214

Árbol del cielo 240

Arbusto 187

Argemone subfusiformis 232 
Aristida adscencionis 255

Aristida mendocina 255

Aristida spegazzinii 255

Arjona tuberosa

tandilensis 239

Arroz 260

Artemisia abrotanum 187

Artemisia absinthium 187

Artemisia douglasiana 188

Arundo donax 256

Aristida adscencionis 255

Aristida spegazzinii 264

Asparagus officinalis 253

Astragalus pehuenches 215

Atamisque 206

Atriplex lampa 207

Baccharis darwinif 188

Baccharis gilliesii 189

Baccharis rufescens 189

Baccharis salicifolia 189

Baccharis spartioides 190

Baccharis tenella 190

Baccharis trimera 190

Bálsamo 211

Banana 254

Bejuco 193

Berberis thumbergii 202
Beta vulgaris ssp. vulgaris 208

Beta vulgaris ssp. macrocarpa 208

Blanquilla 195

Bledo rojo 181

Bledo verde 181

Boopis anthemoides 205

Borago officinalis 203

Borraja 203

Bothriochloa springfieldii 256

Bougainvillea spinosa 227

Brachyclados lycioides 191

Brassica oleracea 203

Bredemeyera microphylla 231

Bricoque 228

Bromus catharticus rupestres 256

Buddleja araucana 204

Buenas noches 228

Burrito 246

Burro 246

Cacho de cabra 220

Cadillo 202, 237

Cadillo de la sierra 202

Caesalpinia gilliesii 216

Caldén 218

Caléndula 191 
Calendula officinalis 191

Camote 210

Canastilla 203

Canela 224

Caña 256

Caña de Castilla 256

Capparis atamisquea 206

Capsicum annuum 240

Cardo ruso 209

Carqueja 190

Cebadilla 255, 256, 258

Cebadilla fina 256

Cebadilla gruesa 256

Cebolla 251

Cebolla de la zorra 253

Cedrón 246

Cepa de caballo 202

Cercidium praecox 216

Cereus aethiops 205

Cestrum parqui 240

Chañar 216

Chañar brea 216

Chaquil 239

Cheilanthes myriophylla 178

Chilca 189

Chilchil del cerro 199

Chilladora 191
Chirriadora 191

Chuquiraga erinacea 191

Chuquiraga rosulata 192

Cinnamomum zeylanicum 224

Ciprés 178

Ciruelo 234

Citrullus lanatus ssp. vulgaris 211

Citrus x limon 236

Citrus $x$ sinensis 236

Clavel 206

Clavel del aire 254

Clavel del campo 192

Clavelillo 198

Clavelina 199, 207

Clavito 221

Clavito de jardín 221

Clavo de olor 227

Coirón 255, 257, 258, 259, 261

Coirón fino 255, 259

Cola de caballo 237

Cola de piche 230

Cola de zorro 191, 192

Condalia microphylla 233

Conejito 239

Contrahierba 201

Convolvulus arvensis 210 
Copete enano 199

Cortadera 256

Cortaderia selloana 256

Cosmos bipinnatus 191

Crassula multicava 211

Cucumis anguria 211

Cucumis melo 213

Cucurbita maxima

andreana 212

Cucurbita máxima ssp.

maxima 212

Cucurbita pepo 212

Cupressus arizonica 178

Cupressus sempervirens 178

Cyclolepis genistoides 192

Cydonia oblonga 233

Dama de noche 210

Damasco 234

Daucus carota 183

Deditos 180

Dianthus caryophyllus 206

Dianthus chinensis 207

Digitaria californica 257

Distichlis spicata 257

Doniophyton anomalum 192

Doradilla 178

Duraznero 235
Dysphania ambrosioides 208

Dysphania multifida 209

Eleagnus angustifolia 214

Elionurus muticus 257

Enamorada del sol 194

Enredadera 210, 214, 231

Enredadera del avestruz 188

ssp. $\quad$ Enredadera del campo 188

Ephedra ochreata 179

Equisetum giganteum 177

Eragrostis mexicana ssp.

virescens 258

Erodium cicutarium 220

Espárrago 253

Espuma de leche 231

Eucalipto 227

Eucalyptus cinerea 227

Eupatorium buniifolium 193

Eupatorium patens 193

Euphorbia collina 214

Euphorbia klotzschii 215

Euphorbia serpens 215

Fabiana patagonica 241

Fabiana peckii 241

Flechilla 255, 256, 259, 260, 261

Flechilla blanca 260

Flechilla crespa 255 
Flechilla engordadora 262

Flechilla fina 260

Flor de papel 202

Flor de seda 228

Foeniculum vulgare 184

Fraxinus americana 228

Fresno 228

Gaillardia pulchella 194

Gaillardia megapotamica 193

Gazania sp. 196

Geoffraea decorticans 216

Girasol 195, 201

Girasol de jardín 195

Gladiolo 254

Glandularia crithmifolia 247

Glandularia flava 247

Gochnatia glutinosa 194

Gomphrena mendocina 182

Gramilla 256, 258, 259, 263

Gramilla fina 258

Granada 232

Grindelia chiloensis 194

Gualeguay 182

Habranthus jamesonii 253

Hedera helix 186

Helianthus annuus 195

Helianthus petiolaris 195
Heliotropium chrysanthum 203

Hibiscus syriacus 225

Hiedra 186

Hierba del lagarto 246

Hinojo 184

Hoffmannseggia erecta 217

Hordeum murinum ssp.

glaucum 258

Hordeum parodii 258

Hyalis argentea 195

Hydrocotyle bonariensis 184

Hysterionica jasionoides 196

Ilex paraguariensis 185

Injerto 225

Ipomoea batatas 210

Ipomoea purpurea 210

Iris germanica 254

Jarava hypsophylla 258

Jarava ichu 259

Jarava neaei 259

Jarilla 249, 251

Jarilla crespa 249,251

Jarilla lisa 249

Jarillilla 189, 194

Jume 207

Junellia seriphioides 247

Lactuca sativa 196 
Lagenaria siceraria 213

Lampranthus roseus 180

Larrea cuneifolia 249

Larrea divaricata 249

Larrea nitida 251

Laurel 224

Laurel de jardín 185

Laurus nobilis 224

Lavanda 222

Lavandula angustifolia 222

Lecanophora heterophylla 225

Lechuga 196

Lechuguilla 214

Leucanthemum maximum 196

Leymus erianthus 259

Ligaria cuneifolia 225

Ligustrum vulgare 229

Limonero 236

\section{Lippia turbinata 247}

Lirio 254

Llantén 230

Llaulín 241

Llaulín blando 241

Llaulín crespo 241

Llaulín duro 241

Llaulín espinudo 241, 242

Llaulín liso 241
Lobularia maritima 203

Lonicera japonica 206

Lycium chilense 241

Lycium gilliesianum 241

Lycium tenuispinosum var

friesii 242

Macachil 239

Macachín 239

Madre de familia 180

Madreselva 206

Maíz 264

Mal de ojo 216

Malcolmia maritima 204

Malus sylvestris 234

Malva del cerro 224

Malva sylvestris 226

Malvisco 225, 226

Malvón 221

Manzanilla 197, 198, 200

Manzanilla de campo 205

Manzanilla de las lomas 188

Manzanilla de los cerros 198

Manzanilla del campo 200

Manzano 234

Margarita 197

Margyricarpus pinnatus 234

Marrubium vulgare 222 
Mastuerzo 219

Matasebo 230

Mate 213

Matico 188

Matorro 192

Matricaria recutita 197

Matthiola incana 204

Medicago sativa 217

Mejuco 193

Melia azedarach 226

Melón 213

Melosa 194

Membrillo 233

Menta 222, 223

Mentha x piperita 222

Mentha x villosa 223

Mesembrianthemum sp. 187

Mirabilis jalapa 228

Mirasol de campo 195, 201

Molle 182

Monnina dictyocarpa 231

Monte amarillo 218

Monte negro 227

Monttea aphylla 230

Muehlembeckia hastulata var.

hastulata 231

Mulinum spinosum 184
Musa paradisiaca 254

Naranjo 236

Nassella tenuis 260

Nassella tenuissima 260

Neosparton aphyllum 248

Nerium oleander 185

Nicotiana noctiflora 242

Nicotiana tabacum 242

Ocimum basilicum 223

Oenothera odorata 228

Olmo 245

Opuntia sulphurea 207

Orégano 223

Origanum vulgare 223

Oryza sativa 260

Paico 208, 209

Paico aparragado 209

Paico macho 208

Paico rastrero 209

Paja amarga 257

Pájaro bobo 200

Palo azul 192

Palqui 240

Panchita 191

Panicum urvilleanum 260

Pañil 204

Paño 239 
Papa 243

Papa indiana 221

Pappophorum philippianum 261

Pappostipa vaginata 261

Paraíso 226

Parra 249

Parra criolla 249

Parra loca 248

Parthenium hysterophorus 197

Parthenocissus quinquefolia 248

Passiflora caerulea 229

Pasionaria 229

Pasto cuneta 262

Pasto de coyuntura 256

Pasto de hoja 256, 257, 261, 262, 263

Pasto de invierno 262

Pasto de martineta 258

Pasto engordador 262

Pasto salado 257

Pechuguilla 214, 215

Pelargonium hortorum 221

Pelón 235

Pelusilla 196

Penca 205

Peral 235
Perejil 185

Perlilla 200

Petroselinum crispum 185

Phaseolus vulgaris 217

Philibertia gilliesii 186

Pichana 190

Pichanilla 241, 245

Pichoga 214

Pimienta 229

Pimiento 182,240

Pinito de jardín 198

Pino 179

Pinus halepensis 179

Piper nigrum 229

Piquillín 233

Plantago lanceolata 230

Plantago patagonica 230

Platycladus orientalis 179

Poa lanuginosa 262

Poleo 247

Polygala stenophylla 231

Populus alba 237

Populus x canadensis 238

Populus nigra 238

Porotillo 215

Porotillo del campo 217

Poroto 217 
Portulaca 232

Portulaca grandiflora 232

Portulaca oleracea 232

Prosopanche bonacine 221

Prosopidastrum striatum 218

Prosopis caldenia 218

Prosopis flexuosa var.

depressa 219

Prosopis flexuosa f. flexousa 218

Prosopis strombulifera 219

Proustia cuneifolia 197

Prunus armeniaca 234

Prunus persica 235

Prunus cerasifera 235

Prunus domestica 234

Punica granatum 232

Pyracantha angustifolia 235

Pyrus communis 235

Quelén 231

Quillo 243

Quiscalora 205

Rabanito 204

Ramillete 207

Raphanus sativus 204

Remolacha 208

Repollo 203
Retamilla 218, 241, 248

Retortuño 217

Rhodophiala mendocina 253

Ribes aureum var. villosum 221

Robinia pseudoacacia 220

Romerillo 198

Romerillo blanco 190, 198, 203

Romerillo colorado 193

Rosa canina 236

Rosa de remedio 236

Rosa verde 211

Ruda hembra 237

Ruda macho 237

Ruta chalepensis 237

Salix babylonica 238

Salsola kali 209

Salvia 224

Salvia coccinea 223

Salvia de jardín 226

Salvia cuspidata ssp. gilliesii 224

Salvia morada 224

Salvia pallida 224

San Pedro 199

Sandía 211

Sandilleja 211 
Saponaria officinalis 207

Sauce 238

Scabiosa atropurpurea 214

Schinus areira 182

Schinus johnstonii 182

Schismus barbatus 262

Schoenoplectus californicus 254

Senecio filaginoides 198

Senecio melanopotamicus 198

Senecio pampeanus 198

Senecio subulatus 198

Senna aphylla 220

Setaria leucopila 262

Setaria mendocina 262

Siempreverde 229

Solanum elaeagnifolium 243

Solanum Iycopersicum 243

Solanum tuberosum 243

Solupe 248

Solupe frutero 179

Sphaeralcea mendocina 226

Sporobolus crypthandrus 263

Sporobolus rigens 263

Suaeda divaricata 209

Suspiro 210,214

Syzygium aromaticum 227
Tabaco 242

Tabaco cimarrón 242

Tabaco del campo 242

Tabaquillo 242

Tagetes mendocina 199

Tagetes patula 199

Tamarindo 244

Tamarindo colorado 244

Tamarisco 244

Tamarix ramosissima 244

Tanacetum balsamita 199

Té de burro 246

Té pampa 200

Té pampa crespo 198

Tessaria absinthioides 200

Thelesperma megapotamicum 200

Thymophylla pentachaeta 200

Tilia sp. 244

Tillandsia bryoides 254

Tilo 244

Tomate 243

Tomillo 245

Tomillo de olor 245

Tomillo hembra 245

Tomillo macho 247

Tomillón 247 
Topazaire 193

Toronjil macho 224

Totora del río 254

Trichloris crinita 263

Trichocline reptans 201

Trigo 263

Triticum aestivum 263

Tuna de cerro 205

Tupe 260

\section{Tweedia brunonis 186}

UImus procera 245

Unco 263

Unquillo 256, 262

Unquillo grueso 261

Uña de gato 227

Uñita de gato 232

Verbascum thapsus 239

Verbena 247

Verbesina encelioides 201

Verdolaga 182,232

Vidriera 209

Vinca major 185

Vira vira 203

Vitis vinifera 249

Viudita 214
Xanthium spinosum 202

Ximenia americana 228

Yerba de la chiva 181

Yerba de la perdiz 215, 234

Yerba de la plata 177

Yerba de la vaca 225, 247

Yerba de la vizcacha 201

Yerba de oveja 188, 189

Yerba del choique 186, 231

Yerba del pollo 182

Yerba del potrillo 217

Yerba del sapo 222

Yerba loca 215

Yerba mate 185

Yerba meona 181, 215

Yerba mora 191, 231

Yerba negra 184

Yuyo de víbora 188

Zampa 207

Zanahoria 183

Zapallito verde 212

Zapallo anco 212

Zapallo criollo 212

Zea mays 264

Zinnia peruviana 202

Xanthium ambrosioides 201 
Muiño, W. A. El uso de las plantas silvestres...
Índice de nombres científicos y comunes 